University of Tennessee Health Science Center

UTHSC Digital Commons

\title{
Discovery of Novel Tubulin Inhibitors and Selective Survivin Inhibitors for Advanced Melanoma and Total Synthesis of Bioactive 20S-hydroxyvitamin D3
}

Qinghui Wang

University of Tennessee Health Science Center

Follow this and additional works at: https://dc.uthsc.edu/dissertations

Part of the Medicinal and Pharmaceutical Chemistry Commons, Neoplasms Commons, and the Pharmaceutics and Drug Design Commons

\section{Recommended Citation}

Wang, Qinghui (http://orcid.org/0000-0002-9587-790X), "Discovery of Novel Tubulin Inhibitors and Selective Survivin Inhibitors for Advanced Melanoma and Total Synthesis of Bioactive 20S-hydroxyvitamin D3" (2017). Theses and Dissertations (ETD). Paper 452. http://dx.doi.org/10.21007/etd.cghs.2017.0446.

This Dissertation is brought to you for free and open access by the College of Graduate Health Sciences at UTHSC Digital Commons. It has been accepted for inclusion in Theses and Dissertations (ETD) by an authorized administrator of UTHSC Digital Commons. For more information, please contact jwelch30@uthsc.edu. 


\title{
Discovery of Novel Tubulin Inhibitors and Selective Survivin Inhibitors for Advanced Melanoma and Total Synthesis of Bioactive 20S-hydroxyvitamin D3
}

\author{
Abstract \\ According to the statistics from American Cancer Society, the 5-year survival rate for patients with \\ advanced melanoma is as low as $5 \%$. Treatment of advanced melanoma, therefore, represents an unmet \\ medical need. In this dissertation, I will show the effort to develop new generations of bioavailable tubulin \\ inhibitors targeting the colchicine binding site and selective small-molecule survivin inhibitors for treating \\ advanced melanoma. Extensive structure-activity relationship (SAR) studies of lead molecules ABI-231 \\ and UC-112 have been performed.
}

Chapter 1 will introduce the current situation of advanced or metastatic melanoma, its clinical drug treatments, as well as problems in current drug treatments. Microtubule dynamics and survivin will be discussed as promising therapeutic targets for developing anticancer drugs. 20S-hydroxyvitamin D3 (20S$\mathrm{OH}-\mathrm{D} 3$ ) will be introduced as a promising anti-inflammatory scaffold.

Chapter 2 will disclose the SAR study of ABI-231, a previously reported potent tubulin inhibitor from our lab. In this chapter, a new synthetic method was developed to enable the synthesis of ABI-231 analogues modifying the indole moiety. The novel synthetic method involved the synthesis of a key diamine intermediate and imidazoline formation. From the new synthetic method, thirty ABI-231 analogues were synthesized and tested for activities. Among all analogues, $10 \mathrm{ab}$ with a 4-methyl-3-indole moiety and $10 \mathrm{bb}$ with a 4-indole moiety showed the most potent antiproliferative activities against a panel of melanoma cell lines. $10 \mathrm{ab}$ and $10 \mathrm{bb}$ had IC50s of 2.2 and $3.0 \mathrm{nM}$, respectively. The SAR result revealed that modification of the indole moiety in $\mathrm{ABI}-231$ was beneficial to activity.

In Chapter 3, we will describe our effort to develop the SAR study of ABI-231 focusing on modification of the 3,4,5-TMP moiety. This is selected since it is one of the most common moieties in current tubulin inhibitors targeting the colchicine binding site. To circumvent the use of potentially explosive azide reported in Chapter 2, an alternative was established to efficiently generate ABI-231 analogues. This new synthetic method involved Suzuki coupling and Grignard reactions to modify the 3,4,5-TMP moiety and to produce target compounds in gram-scale. Among the eight analogues synthesized, the one containing an unique 3-methoxybenzo[4,5]-dioxene moiety had the strongest antiproliferative activity against a panel of melanoma cell lines with an average IC50 of $1.9 \mathrm{nM}$. To our best knowledge, it represents the most successful instance of isosterically modifying the 3,4,5-TMP moiety in CA-4 derivatives.

Chapter 4 will highlight our effort to synthesize reverse $A B I(R A B I)$ analogues for SAR study. In this chapter, a novel and concise synthetic route was established toaccess RABI scaffold. RABI scaffold was constructed through a Grignard reaction/Suzuki-Miyaura coupling reaction strategy. From this new synthetic method, twelve novel RABI analogues were synthesized. Compared to MX-RABI (the previously reported most potent $\mathrm{RABI}$ ), several new RABI analogues showed significantly improved cytotoxicities. In particular, analogue $15 \mathrm{i}$ with a 4-indazole moiety showed the most potent antiproliferative activity against a panel of melanoma cell lines and had an average IC50 of $0.8 \mathrm{nM}$. This is the first sub-nM anti-tubulin compound in the related scaffolds.

Chapter 5 will reveal our latest SAR study of UC-112, a previously reported selective survivin inhibitor. Fourteen UC-112 analogues modifying the benzyloxy moiety of UC- 112 were synthesized. Their corresponding SAR result demonstrated that indole moiety was the most favorable (analogue 12a). Subsequent structural optimization of $12 \mathrm{a}$ by introducing either mono-substituent or di-substituent to the indole moiety led to the synthesis of another twenty-four new UC-112 analogues. Several substituted indole analogues showed equipotency to that of UC-112 and MX-106. Importantly, new indole analogues 
exhibited significant abilities to overcome multidrug-resistance mediated by Pgp overexpression.

Chapter 6 is characterized by the establishment of a total synthetic method of 20SOH-D3 which showed comparable antiproliferative activity to 1,25 $\alpha$-dihydroxyvitamin D3 without hypercalcemic toxic effect upto a concentration of $60 \mu \mathrm{g} / \mathrm{kg}$ in vivo. The total synthesis of 20S-OH-D3 involved parallel generation of key intermediates from ergocalciferol. The vitamin D3 core structure was constructed through Wittig-Horner coupling reaction. Deprotection of SEM and TBS was achieved in one step. 20S-OH-D3 was furnished in sixteen steps with an overall yield of $0.4 \%$.

Document Type

Dissertation

Degree Name

Doctor of Philosophy (PhD)

\section{Program}

Pharmaceutical Sciences

\section{Research Advisor}

Wei Li, Ph.D.

\section{Keywords}

medicinal chemistry, microtubule inhibitor, survivin inhibitor, synthetic chemistry, total synthesis, vitamin D3

\section{Subject Categories}

Diseases | Medicinal and Pharmaceutical Chemistry | Medicine and Health Sciences | Neoplasms | Pharmaceutics and Drug Design | Pharmacy and Pharmaceutical Sciences 
Discovery of Novel Tubulin Inhibitors and Selective Survivin Inhibitors for Advanced Melanoma and Total Synthesis of Bioactive 20S-hydroxyvitamin D3

\author{
A Dissertation \\ Presented for \\ The Graduate Studies Council \\ The University of Tennessee \\ Health Science Center \\ In Partial Fulfillment \\ Of the Requirements for the Degree \\ Doctor of Philosophy \\ From The University of Tennessee
}

By

Qinghui Wang

August 2017 
Portions of Chapter 6 (C) 2015 by Elsevier. All other material (C) 2017 by Qinghui Wang. All rights reserved. 


\section{ACKNOWLEDGEMENTS}

First and foremost, I wish to express my special appreciation to my advisor, Dr. Wei $\mathrm{Li}$, who opened a door for me to join his group in the third year of my graduate study. This is an unforgettable favor in my whole life. Dr.Li has been supportive from all perspectives including course learning and research conducting. In the last more than three years, he kept navigating me toward the right direction wherever he thought was right; he also endowed me the freedom to pursue what I proposed. He has set an outstanding example of being a supervisor, researcher, and individual.

My gratitude is also extended to Dr. Subhash C. Chauhan, Dr. Duane D. Miller, Dr. Bob M. Moore, and Dr. Fatima Rivas (from St. Jude Children`s Research Hospital) for serving as my committee members. Their discussion and ideas are invaluable throughout my research. In addition, special thank is addressed to Dr. Duane D. Miller for his meaningful discussion during every group meeting.

I would especially thank my labmate Kinsie E. Arnst and Dr.Yi Xue for obtaining in vitro biological data for the synthesized tubulin inhibitors and survivin regulators. I am also grateful to the following persons for helping my research from different perspectives: Dr. Yuxi Wang and Dr.Jinliang Yang at Sichuan University for generating many co-crystal structures of tubulin inhibitors in complex with tubulin protein, Zining Lei and Dr.Zhe-sheng Chen at St.John`s University for acquiring biological data on P-gp overexpressed cell lines in survivin project, Dr. Andrzej T. Slominski and Mr. Tae-kang Kim at University of Alabama for helping on the vitamin D3 project. I am also indebted to the current and former members of Dr. Wei Li`s group.

Last, thanks to my parents for their unconditional support in my life. Special thanks to my wife Chenghong Meng. Without her encouragement, this thesis would never be finished. Thanks to my sweetheart Clair and Elvin for bringing joy to my life. 


\begin{abstract}
According to the statistics from American Cancer Society, the 5-year survival rate for patients with advanced melanoma is as low as 5\%. Treatment of advanced melanoma, therefore, represents an unmet medical need. In this dissertation, I will show the effort to develop new generations of bioavailable tubulin inhibitors targeting the colchicine binding site and selective small-molecule survivin inhibitors for treating advanced melanoma. Extensive structure-activity relationship (SAR) studies of lead molecules ABI-231 and UC-112 have been performed.
\end{abstract}

Chapter 1 will introduce the current situation of advanced or metastatic melanoma, its clinical drug treatments, as well as problems in current drug treatments. Microtubule dynamics and survivin will be discussed as promising therapeutic targets for developing anticancer drugs. 20S-hydroxyvitamin D3 (20S-OH-D3) will be introduced as a promising antiinflammatory scaffold.

Chapter 2 will disclose the SAR study of ABI-231, a previously reported potent tubulin inhibitor from our lab. In this chapter, a new synthetic method was developed to enable the synthesis of ABI-231 analogues modifying the indole moiety. The novel synthetic method involved the synthesis of a key diamine intermediate and imidazoline formation. From the new synthetic method, thirty ABI-231 analogues were synthesized and tested for activities. Among all analogues, 10ab with a 4-methyl-3-indole moiety and 10bb with a 4-indole moiety showed the most potent antiproliferative activities against a panel of melanoma cell lines. 10ab and 10bb had $\mathrm{IC}_{50} \mathrm{~S}$ of 2.2 and $3.0 \mathrm{nM}$, respectively. The SAR result revealed that modification of the indole moiety in ABI-231 was beneficial to activity.

In Chapter 3, we will describe our effort to develop the SAR study of ABI-231 focusing on modification of the 3,4,5-TMP moiety. This is selected since it is one of the most common moieties in current tubulin inhibitors targeting the colchicine binding site. To circumvent the use of potentially explosive azide reported in Chapter 2, an alternative was established to efficiently generate ABI-231 analogues. This new synthetic method involved Suzuki coupling and Grignard reactions to modify the 3,4,5-TMP moiety and to produce target compounds in gram-scale. Among the eight analogues synthesized, the one containing an unique 3-methoxybenzo[4,5]-dioxene moiety had the strongest antiproliferative activity against a panel of melanoma cell lines with an average $\mathrm{IC}_{50}$ of $1.9 \mathrm{nM}$. To our best knowledge, it represents the most successful instance of isosterically modifying the 3,4,5-TMP moiety in CA-4 derivatives.

Chapter 4 will highlight our effort to synthesize reverse ABI (RABI) analogues for SAR study. In this chapter, a novel and concise synthetic route was established to access RABI scaffold. RABI scaffold was constructed through a Grignard reaction/Suzuki-Miyaura coupling reaction strategy. From this new synthetic method, twelve novel RABI analogues were synthesized. Compared to MX-RABI(the previously reported most potent $\mathrm{RABI}$ ), several new RABI analogues showed significantly 
improved cytotoxicities. In particular, analogue $\mathbf{1 5 i}$ with a 4-indazole moiety showed the most potent antiproliferative activity against a panel of melanoma cell lines and had an average $\mathrm{IC}_{50}$ of $0.8 \mathrm{nM}$. This is the first sub-nM anti-tubulin compound in the related scaffolds.

Chapter 5 will reveal our latest SAR study of UC-112, a previously reported selective survivin inhibitor. Fourteen UC-112 analogues modifying the benzyloxy moiety of UC-112 were synthesized. Their corresponding SAR result demonstrated that indole moiety was the most favorable (analogue 12a). Subsequent structural optimization of 12a by introducing either mono-substituent or di-substituent to the indole moiety led to the synthesis of another twenty-four new UC-112 analogues. Several substituted indole analogues showed equipotency to that of UC-112 and MX-106. Importantly, new indole analogues exhibited significant abilities to overcome multidrug-resistance mediated by Pgp overexpression.

Chapter 6 is characterized by the establishment of a total synthetic method of $20 S$ OH-D3 which showed comparable antiproliferative activity to 1,25 $\alpha$-dihydroxyvitamin D3 without hypercalcemic toxic effect upto a concentration of $60 \mu \mathrm{g} / \mathrm{kg}$ in vivo. The total synthesis of 20S-OH-D3 involved parallel generation of key intermediates from ergocalciferol. The vitamin D3 core structure was constructed through Wittig-Horner coupling reaction. Deprotection of SEM and TBS was achieved in one step. 20S-OH-D3 was furnished in sixteen steps with an overall yield of $0.4 \%$. 


\section{TABLE OF CONTENTS}

CHAPTER 1. INTRODUCTION .................................................................................

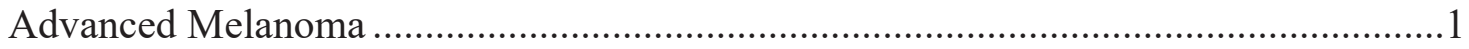

Drug Treatment for Advanced Melanoma ................................................................... 1

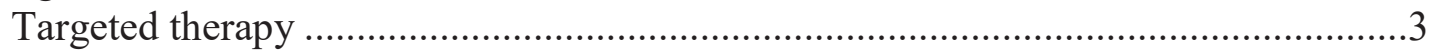

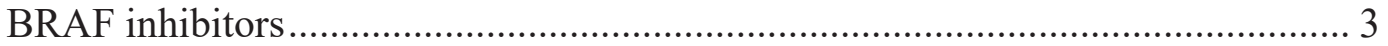

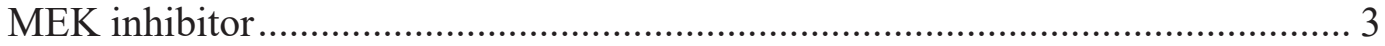

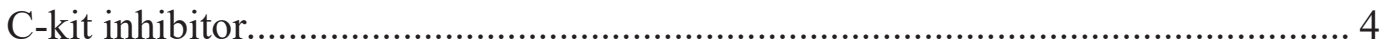

Immune checkpoint inhibitors ....................................................................

Anti CTLA4 antibodies.......................................................................... 5

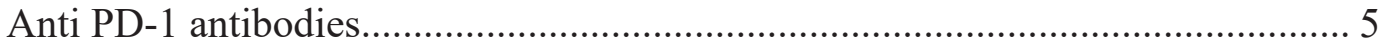

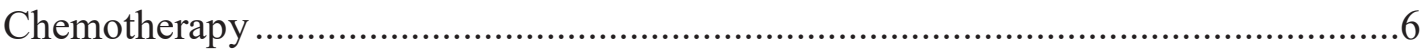

Challenges in targeted therapy and immunotherapy ...........................................6

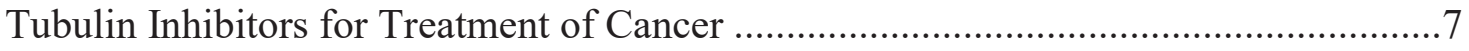

Microtubule dynamics as a therapeutic target.....................................................

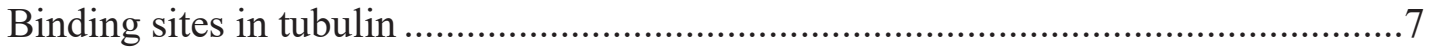

Tubulin inhibitors approved by FDA or in clinical development ............................ 9

Challenges in developing microtubule targeting agents as anticancer agents ............ 9

Targeting colchicine binding site in tubulin for development of anticancer agents .. 11

Survivin as a Therapeutic Target for Cancer Treatment..........................................11

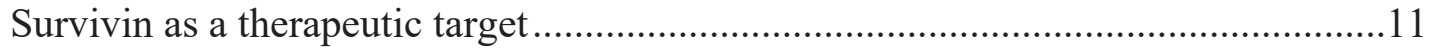

Major survivin inhibitors ......................................................................... 13

Challenges in developing survivin inhibitors as anticancer agents .........................13

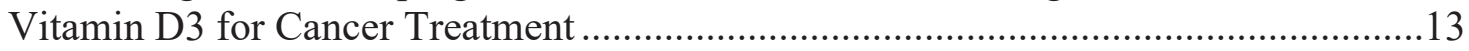

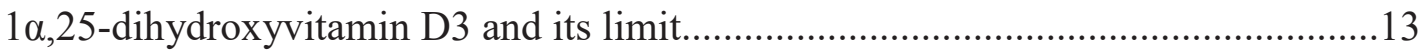

$20 S$-hydroxyvitamin D3 as a promising therapy for cancers ............................. 15

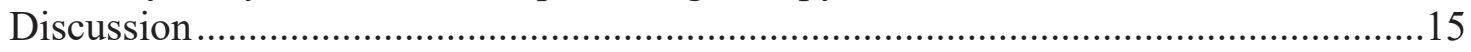

\section{CHAPTER 2. STRUCTURE-ACTIVITY RELATIONSHIP STUDY OF ABI- 231 LEADS TO IMPROVED ACTIVITIES AGAINST MICROTUBULE

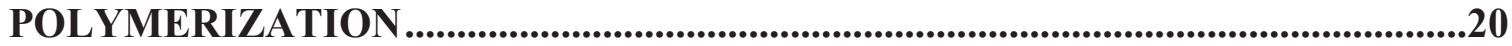

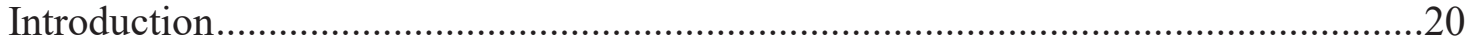

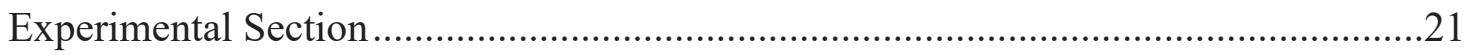

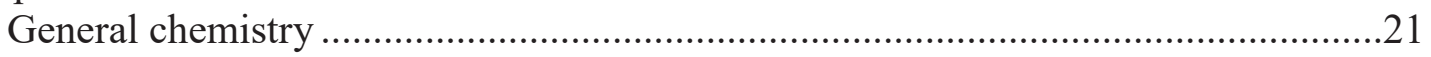

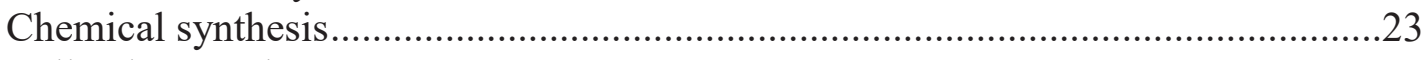

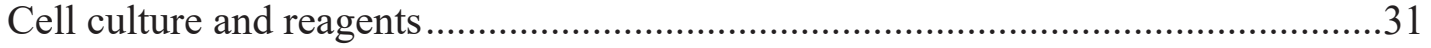

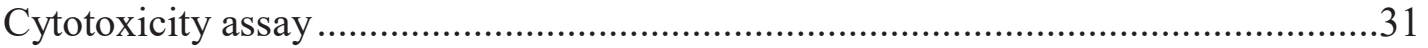

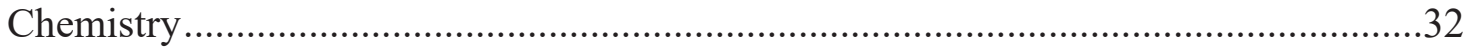

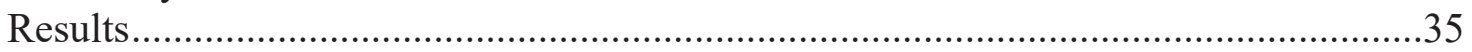

In vitro growth inhibitory effects of ABI-231 analogues with 3-indolyls .................35

In vitro growth inhibitory effects of $\mathrm{ABI}-231$ analogues with rotation of indolyls...40

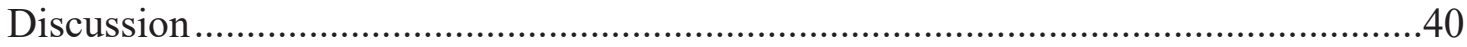




\section{CHAPTER 3. STRUCTURAL MODIFICATION OF THE 3,4,5-}

TRIMETHOXYPHENYL MOIETY IN ABI-231 LEADS TO IMPROVED ANTIPROLIFERATIVE ACTIVITIES...............................................................44

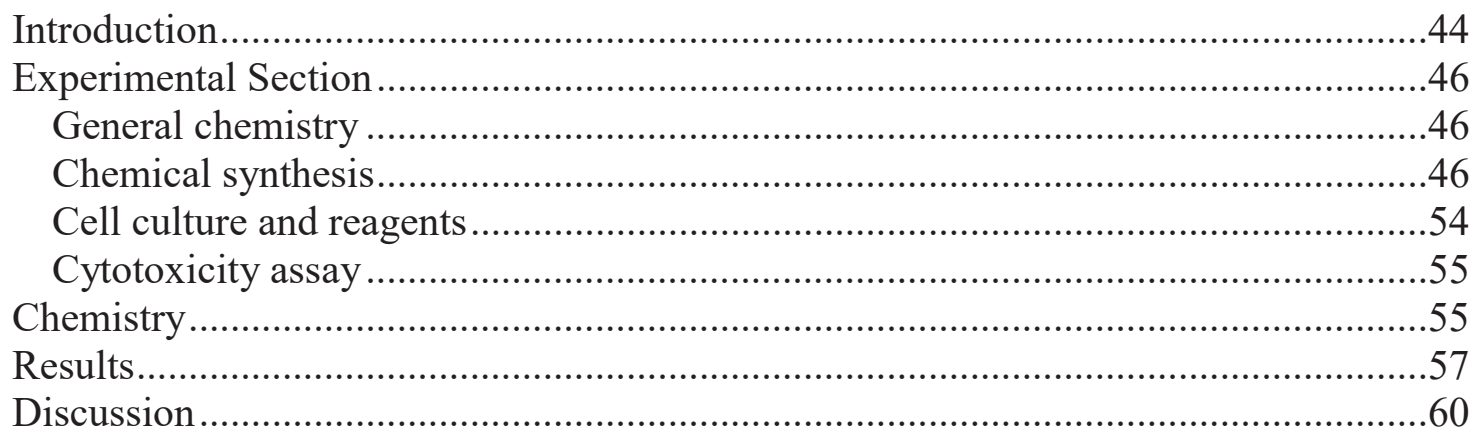

\section{CHAPTER 4. DESIGN AND SYNTHESIS OF NOVEL RABI ANALOGUES} AS POTENT ANTITUBULINS............................................................................

Introduction .

\section{CHAPTER 5. DESIGN, SYNTHESIS AND STRUCTURE-ACTIVITY}

RELATIONSHIP STUDY OF NOVEL UC-112 ANALOGUES ..................................80

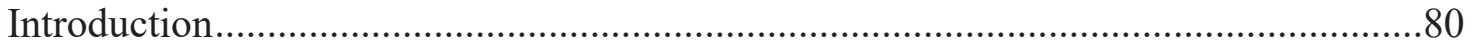

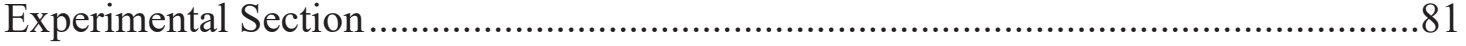

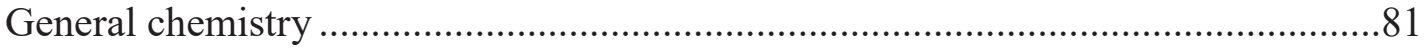

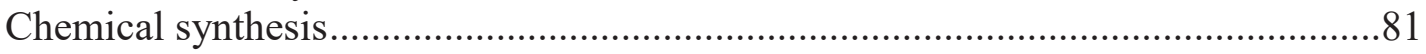

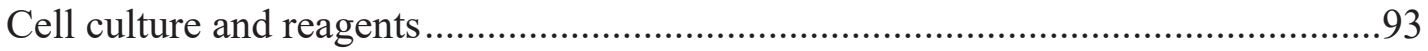

Cytotoxicity assay ........................................................................................99

Cytotoxicity against P-gp overexpressed cell lines by MTT assay ...........................94

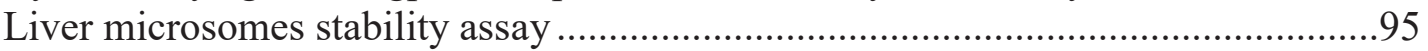

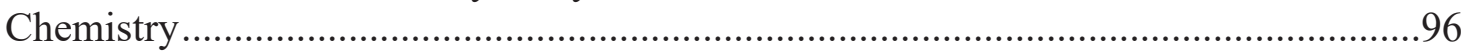

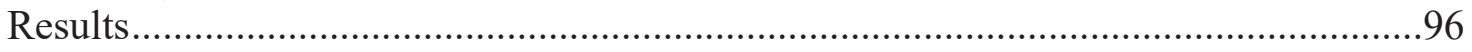

In vitro growth inhibitory effects of UC-112 analogues with modification of

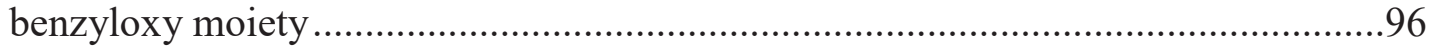
In vitro growth inhibitory effects of UC-112 analogues with mono-substitution

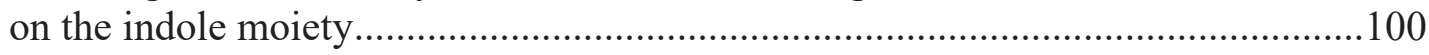
In vitro growth inhibitory effects of UC-112 analogues with di-substituents on the indole moiety ................................................................................................. 100 Inhibitory effect against P-gp overexpressed cell lines ..........................................103

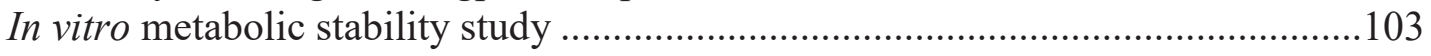


Discussion 106

CHAPTER 6. TOTAL SYNTHESIS OF BIOLOGICAL ACTIVE 20S-

HYDROXYVITAMIN D3 ...........................................................................................108

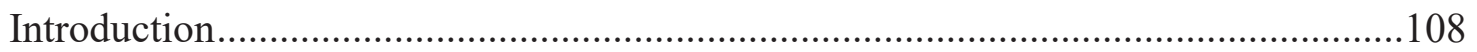

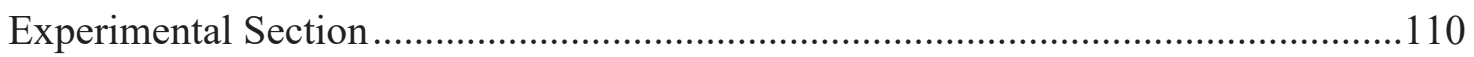

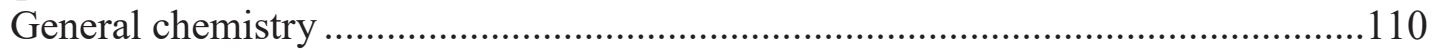

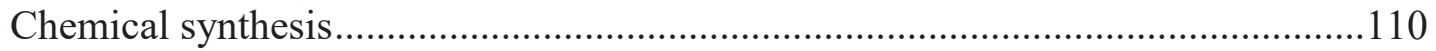

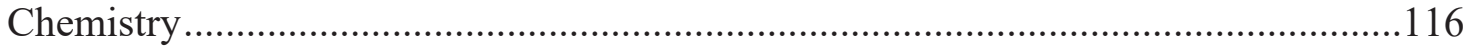

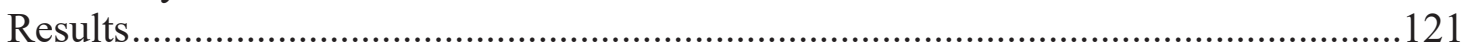

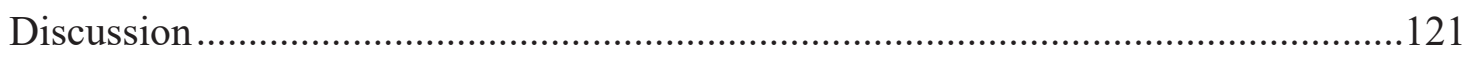

CHAPTER 7. SUMMARY AND FUTURE DIRECTION ...................................125

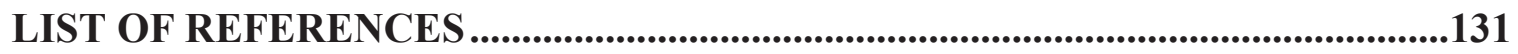

VITA 


\section{LIST OF TABLES}

Table 2-1. In vitro growth inhibitory effects $(\mathrm{nM})$ of ABI-231 analogues with 3indolyls $(\mathrm{n}=3)$

Table 2-2. In vitro growth inhibitory effects (nM) of ABI-231 analogues with rotation of indolyls $(\mathrm{n}=3)$

Table 2-3. Crystallographic data and structure refinement statistics for 10ab

Table 3-1. In vitro growth inhibitory effects (nM) of ABI-231 analogues modifying the $3,4,5$-TMP moiety $(\mathrm{n}=3)$

Table 4-1. In vitro growth inhibitory effects $(\mathrm{nM})$ of RABI analogues $(\mathrm{n}=3) \ldots \ldots \ldots \ldots . . .76$

Table 5-1. In vitro growth inhibitory effects $(\mu \mathrm{M})$ of UC-112 analogues with modification of benzyloxy moiety $(n=3)$

Table 5-2. In vitro growth inhibitory effects $(\mu \mathrm{M})$ of UC-112 analogues with monosubstituent on the indole moiety $(n=3)$

Table 5-3. In vitro growth inhibitory effects $(\mu \mathrm{M})$ of UC-112 analogues with disubstituents on the indole moiety $(n=3)$

Table 5-4. In vitro growth inhibitory effects of indole analogues in P-gp overexpressed cell line M14/MDR1 ( $n=3$ ).

Table 5-5. In vitro growth inhibitory effects of 10f, 10i, 101 and 10o in P-gp overexpressed cell lines $(n=3)$

Table 5-6. In vitro microsomal stabilities of compounds 10f, 10i, 101 and $10 \mathrm{o}$

Table 7-1. In vitro growth inhibitory effect of proposed analogue and its intermediates 


\section{LIST OF FIGURES}

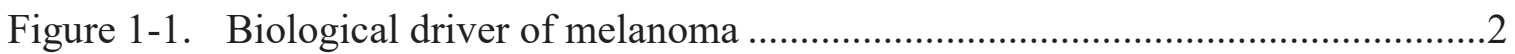

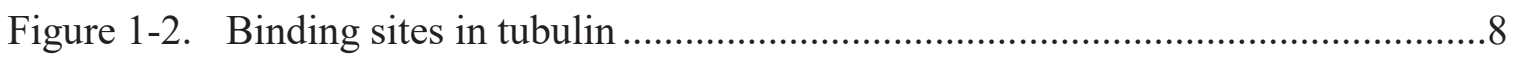

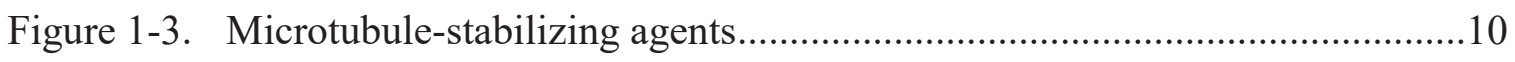

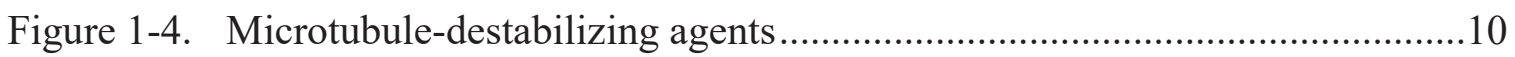

Figure 1-5. Colchicine binding site inhibitors in clinical trials ........................................12

Figure 1-6. Structures of the major survivin inhibitors .................................................14

Figure 1-7. Molecule modeling result of ABI-231 in tubulin (PDB: 3HKD) ……….....17

Figure 1-8. Proposed modification of UC-112 by reducing the flexibility of benzyloxy moiety ………………...............................................................19

Figure 2-1. Examples of microtubule inhibitors that target colchicine binding sites in

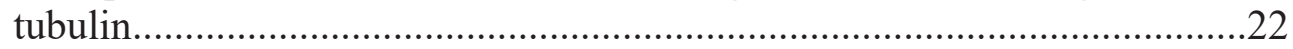

Figure 2-2. Synthesis of an intermediate for 2-methyl-3-indole ABI-231 analogue........38

Figure 2-3. Co-crystal structure of 10ab in complex with tubulin ..................................43

Figure 3-1. Examples of microtubule inhibitors with 3,4,5-TMP moieties targeting colchicine binding sites in tubulin.............................................................

Figure 4-1. Examples of microtubule inhibitors binding to the colchicine binding

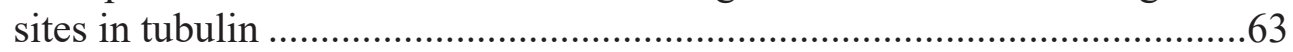

Figure 4-2. Hypothesis: modifying the benzene in RABI to indole can increase activity

Figure 4-3. Synthesis of RABI scaffolds and proposed mechanism toward the

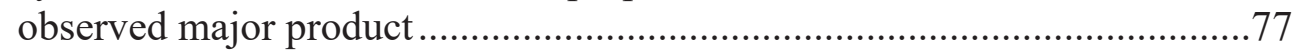

Figure 4-4. Synthesis of an intermediate for ABI-231 analogue ...................................79

Figure 4-5. Structure and IC50 comparisons between ABI-231 and 15a, 15b and 15i...79

Figure 5-1. Example of reported survivin inhibitors ...................................................82

Figure 5-2. Structures of UC-112 analogues with modification of benzyloxy moiety ...99

Figure 6-1. Marketed vitamin D analogs and noncalcemic 20S-(OH)D3 109 
Figure 6-2. Preferred conformation of the intermediate (compound 12) calculated with density function theory with $6-31 \mathrm{G}^{* *}$ baseset...................................122

Figure 6-3. ${ }^{1} \mathrm{H}-\mathrm{NMR}$ comparison of 20S-(OH)D3 obtained via UVB irradiation and

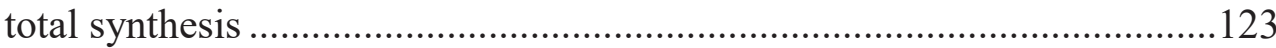

Figure 7-1. Docking study of proposed ABI-231 analogues in co-crystal structure of 4-methyl-3-indole analogue in complex with tubulin 


\section{LIST OF ABBREVIATIONS}

$\begin{array}{ll}\text { ABC } & \text { ATP binding cassette } \\ \text { ABI } & \text { 2-aryl-4-benzoyl-imidazoles } \\ \text { ADC } & \text { antibody-drug conjugate } \\ \text { ADP } & \text { adenosine triphosphate } \\ \text { ATCC } & \text { American type culture collection } \\ \text { ATP } & \text { adenosine triphosphate } \\ \text { CA-4 } & \text { combretastatin A-4 } \\ \text { CA-4P } & \text { combretastatin A-4 phosphate } \\ \text { CBSI } & \text { colchicine binding site inhibitor } \\ \text { CDK } & \text { cyclin-dependent kinase } \\ \text { CYP } & \text { cytochrome P450 } \\ \text { DCM } & \text { dichloromethane } \\ \text { DMEM } & \text { Dulbecco's modified eagle's medium } \\ \text { DMF } & \text { dimethylformamide } \\ \text { DMSO } & \text { dimethyl sulfoxide } \\ \text { DNA } & \text { deoxyribonucleic acid } \\ \text { EtOAc } & \text { ethyl acetate } \\ \text { FDA } & \text { food and drug administration } \\ \text { GDP } & \text { guanosine diphosphate } \\ \text { GTP } & \text { guanosine triphosphate } \\ \text { HPLC } & \text { high performance liquid chromatography } \\ \text { IAP } & \text { inhibitor of apoptosis protein } \\ \text { IC50 } & \text { concentration of 50\% growth inhibition } \\ \text { MAP } & \text { mitogen-activated protein kinase } \\ \text { MDR1 } & \text { multidrug resistance protein 1 } \\ \text { MRP } & \text { multidrug resistance associated protein } \\ \text { MTA } & \text { microtubule-targeting agent } \\ \text { mTOR } & \text { mammalian target of rapamycin } \\ \text { PAT } & \text { phenyl-aminothiazole } \\ \text { PBS } & \text { phosphate-buffered saline } \\ \text { PD-1 } & \text { programmed cell death-1 } \\ \text { P-gp } & \text { P-glycoprotein } \\ \text { PI3K } & \text { phosphatidylinositol 3-kinase } \\ \text { PFS } & \text { progression-free survival } \\ \text { RABI } & \text { reverse 2-aryl-4-benzoyl-imidazoles } \\ \text { RAF } & \text { rapidly accelerated fibrosarcoma } \\ \text { RTK } & \text { receptor tyrosine kinase } \\ \text { SAR } & \text { structure-activity relationships } \\ \text { Sma } & \text { second mitochondria-derived activator of caspases } \\ \text { SMART } & \text { 4-substituted methoxy benzoylaryl-thiazoles } \\ \text { THF } & \text { tetrahydrofuran } \\ \text { TLC } & \text { thin layer chromatography } \\ \text { TMS } & \\ & \end{array}$


VDR

XIAP

$1,25(\mathrm{OH})_{2} \mathrm{D} 3$

2-ME

20S- $(\mathrm{OH}) \mathrm{D} 3$

25-(OH)D3 vitamin D3 receptor

$\mathrm{X}$-linked inhibitor of apoptosis

$1 \alpha, 25$-dihydroxyvitamin D3

2-methoxyestradiol

20S-hydroxyvitamin D3

25-hydroxyvitamin D3 


\section{CHAPTER 1. INTRODUCTION}

\section{Advanced Melanoma}

Melanoma is the least common form of skin cancers and accounts for only about $5 \%$ in cases. It is, however, the deadliest form of all skin cancers and is responsible for approximately $80 \%$ deaths of patients with skin cancers. According to the statistics from the American Cancer Society, it is estimated that approximately 87,110 new cases of melanoma will be diagnosed and about 9,730 deaths will result from melanoma in 2017 [1]. There are five stages in melanoma progress: stages 0-IV. Melanoma begins within a single lesion but can spread to nearby lymph nodes and distant organs such as the lung, liver, or brain. Melanoma in stage IV is named advanced or metastatic melanoma. For patients who are at the very early stage of melanoma, the 5-year survival rate is over $98 \%$. Surgery is an effective treatment for patients having melanoma with a low thickness in the skin (Breslow depths of up to $1.0 \mathrm{~mm}$ ) [2]. For patients with advanced melanoma, the 5-year survival rate is $5-19 \%$ [3].

In nearly $90 \%$ cases of melanoma, mitogen-activated protein kinase (MAPK) pathway kinases were reported as activated [4]. MAPK pathway (Figure 1-1) is composed of a variety of kinases linking the extracellular signals to the DNA in the nucleus. MAPK pathway plays an important role in controlling diverse cellular functions including cell growth, differentiation, proliferation and apoptosis [5]. RAS is a G protein attached to the inner membrane. Upon receiving the activation signals from upstream kinases, GDP on the RAS can be detached. Free RAS can bind to GTP to form RAS-GTP complex and become activated. On one hand, the RAS-GTP complex can activate BRAF. Activated BRAF subsequently induces the phosphorylations of MEK and ERK in a sequential fashion. Phosphorylated ERK can then translocate into the nucleus to exert a series of cell-regulating functions [6-8]. On the other hand, the RAS-GTP complex can stimulate the phosphoinositide 3-kinase (PI3K) which phosphorylates phospholipid phosphatidylinositol 4,5-bisphophate (PIP2) to phospholipid phosphatidylinositol 3,4,5trisphophate (PIP3). The intracellular signaling propagator PIP3 can promote the phosphorylation of the well-known oncogene AKT. Elevated phosphorylation of AKT activates the downstream serine/threonine kinase mTOR, a protein that is of great importance in regulating cell growth, metabolism, and proliferation [9-11].

Phosphorylated AKT and activated mTOR are related to the death of melanoma patients. It is reported that nearly $70 \%$ of the malignant melanoma cases have elevated levels of phosphorylated AKT and activated mTOR $[12,13]$.

\section{Drug Treatment for Advanced Melanoma}

Currently, drug treatments for melanoma can be divided into three categories: targeted therapy, chemotherapy, and immunotherapy. 


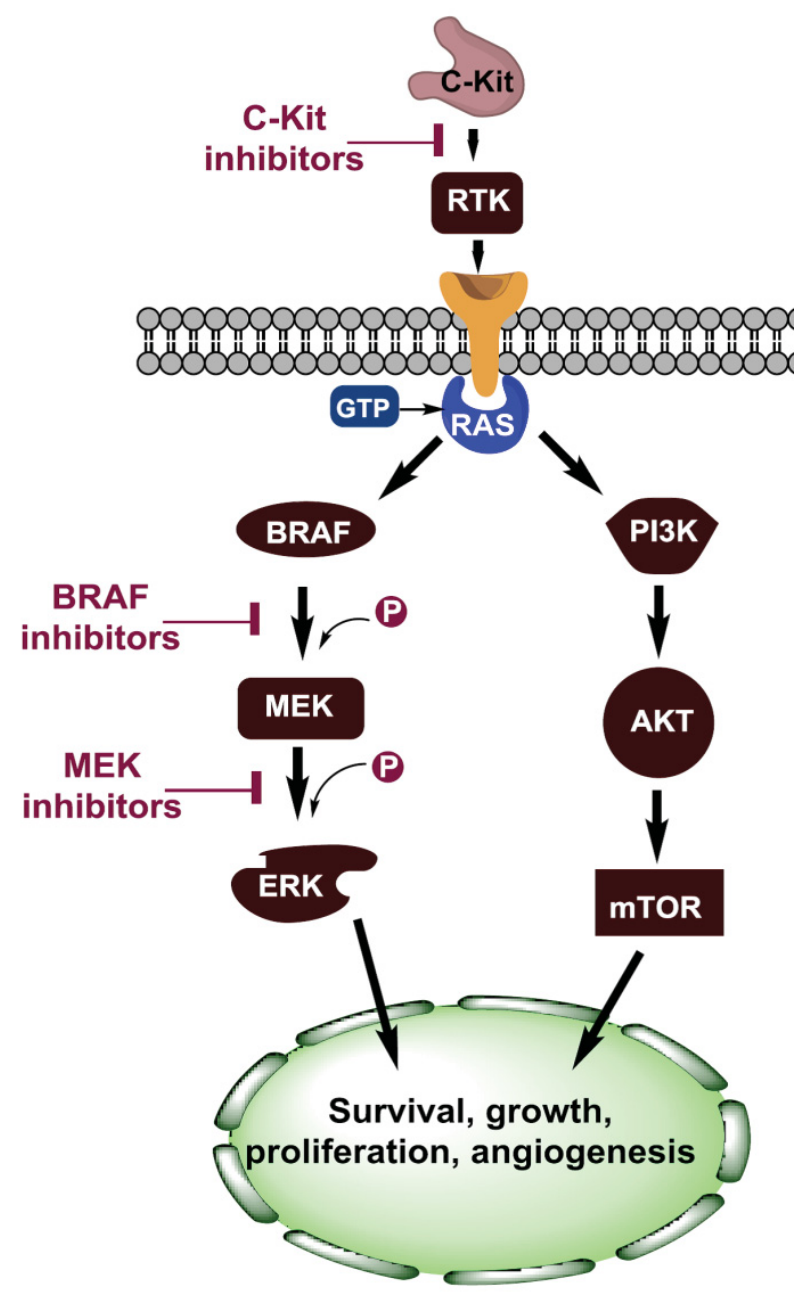

Figure 1-1. Biological driver of melanoma 


\section{Targeted therapy}

\section{BRAF inhibitors}

RAF is a serine/threonine-specific protein kinase. The RAF family consists of four family members: ARAF, BRAF, CRAF and RAF1 [14]. BRAF is an oncogenic driver, which has been demonstrated in both in vitro and in vivo models [15-17]. It was shown in 2002 that nearly $50 \%$ of melanomas harbored BRAF mutations. $90 \%$ of the mutations replaced valine at amino acid 600 with glutamate (V600E) while a small portion of mutations substituted the valine with lysine, arginine or aspartic acid (V600K,V600R/D) [15]. These mutations in the BRAF gene was demonstrated to be responsible for the activation of MAPK pathway [18].

Vemurafenib, the first BRAF inhibitor, was approved by the FDA in 2011. It is applied for the treatment of metastatic or unresectable melanoma harboring the BRAF V600E mutation. Unlike nonspecific kinase inhibitors such as sorafenib, in a preclinical study vemurafenib was revealed to selectively bind to the activated mutant kinase BRAF at the ATP-binding site of V600E to inactivate the ERK phosphorylation [19]. An in vivo BRAF V600E xenograft animal model study suggested that vemurafenib markedly impeded tumor growth in the absence of significant toxicity. In phase I and II clinical studies, vemurafenib treatment significantly reduced the tumor size, improved overall survival rate, and enhanced progression-free survival in melanoma patients harboring BRAF V600E mutation. It was also reported that the median overall survival reached 13.6 months on average [20, 21]. For patients harboring BRAF V600K or non-V600K mutation, no complete or partial response was observed after treated with vemurafenib. Most frequently observed side effects for vemurafenib treatment in Phase II and III studies included but were no limited to fatigue, rash, and arthralgia [22].

Another FDA approved selective BRAF inhibitor is dabrafenib (approved in 2013). Darafenib has a similar response rate and survival rate to that of vemurafenib. Darafenib differs from vemurafenib in adverse effect profile. Whilst drug-specific side effects for darafenib include fever, specific side effects for vemurafenib involve photosensitivity and aminotransferase elevations [22]. In addition, dabrafenib is less likely to induce arthralgia and squamous cell carcinoma than vemurafenib [23].

\section{MEK inhibitor}

MEK1/2 is a serine/tyrosine/threonine kinase. It is a downstream target of the MAPK pathway. This cascade is activated and phosphorylated by RAF kinase at serines 22 and 218 in the activation loop [24]. The abilities of RAF subtypes to activate MEK follow the sequence of BRAF $>$ RAF1 $>$ ARAF $>\operatorname{CRAF}[25,26]$. Activated MEK subsequently stimulates the phosphorylation of ERK. Inhibition of MEK can obstruct cell proliferation and promote apoptosis [27]. Trametinib and cobimetinib are FDA approved MEK inhibitors. Other MEK1/2 inhibitors such as selumetinib, sinimetinib (MEK162), PD-0325901, TAK733, pimasertib, and RO4987655 are currently under clinical development. 
Trametinib (GSK1120212) is the first MEK1/2 inhibitor approved by the FDA (approved in 2013). It is applied for treatment of metastatic melanoma with BRAF $\mathrm{V} 600 \mathrm{E} / \mathrm{K}$ mutation. Trametinib is a non-competitive MEK $1 / 2$ inhibitor and specifically binds to an allosteric binding site instead of the ATP site in MEK. Compared to BRAF inhibitors vemurafenib and dabrafenib, trametinib was less effective to improve median PFS and to trigger complete or partial response [28, 29] but was less likely to cause significant toxicities [30]. In particular, trametinib did not induce cutaneous squamous cell carcinoma. In a phase III trial that enrolled 322 patients, trametinib significantly prolonged the median PFS and overall survival of the patients with BRAF-mutated melanoma compared to chemotherapy treatments such as paclitaxel, or dacarbazine (DTIC) [31].

Cobimetinib is another MEK1/2 inhibitor approved by the FDA recently (2015). It is mainly used as a combinational therapy with vemurafenib to treat patients with BRAF-mutated metastatic melanoma. In phase III clinical trial that enrolled 495 patients with advanced melanoma, the combination of cobimetinib and vemurafenib significantly improved the median progression-free survival compared to vemurafenib alone [32].

Selumetinib is a MEK1/2 inhibitor that was in a phase II clinical trial. The in vitro assay displayed that selumetinib specifically bond to an adjacent allosteric binding site next to the ATP site in MEK1/2. Selumetinib showed potent antiproliferative activity in melanoma cell lines with BRAF V600E mutation and arrested the cell cycle in G1-phase [33-35]. In a phase I clinical study, selumetinib was found to markedly inactivate phosphorylation of ERK [33]. Nevertheless, in a phase II clinical study, selumetinib was unable to induce significant objective response. Current effort on selumetinib is, therefore, focusing on improving its clinical efficacy by combining with a BRAF inhibitor [36].

\section{C-kit inhibitor}

$\mathrm{C}-\mathrm{Kit}$, a receptor tyrosine kinase protein encoded by the Kit gene, is expressed in mature melanocytes. C-Kit binds to its ligand stem cell factor to trigger several signaling pathways including the MAPK pathway, the PI3K/AKT pathway, and the JAK-STAT pathway. In melanoma, 55\% of the c-Kit mutated cells contain the substitution of L576P and K642E [37]. Recent studies reveal that c-Kit can induce melanocyte proliferation and melanoma survival through activation of the MAPK pathway [38].

Imatinib mesylate is an ATP-competitive inhibitor of c-Kit. In a Phase II study, imatinib was demonstrated to show significant antitumor activity, particularly in patients with advanced melanoma harboring c-Kit abreactions [39]. It was pointed out that metastatic melanoma with c-Kit mutations responded more strikingly to imatinib than metastatic melanoma with c-Kit amplifications [40]. An in-depth investigation is currently undergoing to explore the effect of imatinib on c-Kit mutated advanced melanoma.

Nilotinib, a tyrosine kinase inhibitor, was reported to be effective in imatinibresistant gastrointestinal stromal tumors. Recently, in a phase II clinical trial, nilotinib 
showed a lasting response in patients with metastatic melanoma harboring c-Kit mutations [41]. In another phase II study that enrolled patients with metastatic melanoma harboring c-Kit mutations, nilotinib tremendously improved one-year survival rate of patients and triggered durable response without causing severe adverse effects [41, 42].

\section{Immune checkpoint inhibitors}

Cancer cells can develop various mechanisms to evade the surveillance of the immune system. The mechanisms include but are not limited to releasing of inhibitory cytokines, recruiting immunosuppressive immune cells and upregulating immune checkpoints [43]. Therefore, inhibition of the immune checkpoints should re-enable the immune system to detect and kill cancer cells. To date, reported targetable checkpoints for melanoma treatment include but are not limited to programmed cell death 1 (PD1) and cytotoxic T-lymphocyte antigen 4 (CTLA4). PD-1 and CTLA-4 are both negative regulators of $\mathrm{T}$ cell activation.

\section{Anti CTLA4 antibodies}

Ipilimumab is discovered as a CTLA-4 checkpoint inhibitor. It was approved by the FDA in 2011 for the treatment of unresectable or metastatic melanoma. In contrast to a treatment group receiving placebo, ipilimumab treatment significantly prolonged PFS in patients with stage III melanoma [44]. Improved overall survival and median PFS were also observed for ipilimumab treatment [45]. However, due to the excessive immune activity caused by ipilimumab, mild to severe adverse effects were present in patients treated with ipilimumab $[45,46]$.

Tremelimumab, another anti CTLA-4 antibody, is currently under clinical development. In a phase I/II clinical trial that recruited patients with metastatic melanoma, less significant toxicity was observed for patients receiving tremelimumab than patients treated with ipilimumab[47]. However, tremelimumab did not markedly improve the overall survival in a phase III study when compared to conventional chemotherapy [48].

\section{Anti PD-1 antibodies}

Nivolumab is a monoclonal antibody specific for human PD1. It was approved by the FDA in 2014 for the treatment of advanced melanoma. In a phase I study that nivolumab was applied to treat patients with advanced melanoma, significant clinical efficacy and manageable safety profile were observed. Nivolumab gave an overall survival rate of 32\%. 1-year, 2-year, 3-year and 4-year overall survival rates for nivolumab treatment were $63 \%, 48 \%, 42 \%$ and $32 \%$, respectively. Immune-related grade $3 / 4$ adverse effects were present in $14 \%$ of the patients. In a phase III trial, nivolumab was effective for metastatic melanoma that was previously treated with ipilimumab. Nivolumab accomplished significantly higher overall survival rate than chemotherapy treatment [49]. 
Pembrolizumab (lambrolizumab or MK-3475) is another anti PD-1 antibody approved by the FDA in 2014. Pembrolizumab has a high affinity to the IgG4 isotype. In a phase I trial that recruited 135 patients with advanced melanoma, the highest response rate $(\sim 52 \%)$ was observed in the highest dose arm. A median duration progression-free survival of $>7$ months was seen. $13 \%$ of the regimen showed grade $3 / 4$ adverse events. Manageable adverse effects were accompanied with pembrolizumab treatment [50]. A clinical trial enrolling 411 patients indicated that pembrolizumab had an overall response rate of 34\%, a median progression-free survival of 5.5 months, and an overall survival rate of $69 \%$ at one-year. For patients with metastatic melanoma who were refractory to ipilimumab treatment, pembrolizumab was more effective than chemotherapy to prolong progression-free survival [51].

\section{Chemotherapy}

Traditional chemotherapeutics used for treating melanoma mainly include dacarbazine, temozolomide. While these drugs are very effective for treating melanoma at the early stages, their clinical effect is not satisfactory when applied to treat advanced melanoma. The tumor is prone to acquire resistance over the course of cancer treatment when dacarbazine or temozolomide is used. Furthermore, chemotherapy can cause broad drug-related side effects such as fatigue, hair loss, appetite loss, diarrhea and peripheral neuropathy. Therefore, in modern cancer treatment, chemotherapy is a less preferred strategy to targeted therapy and immunotherapy.

\section{Challenges in targeted therapy and immunotherapy}

Discovery of the oncogenic mutation in BRAF at codon 600 in the MAPK signaling pathway has revolutionized the treatment of advanced or metastatic melanoma in the last ten years. Several inhibitors targeting the BRAF mutation V600E or its downstreams (ERK and MEK) have been approved by the FDA to treat advanced stage melanoma. The years 2011 and 2014 have witnessed the approvals of immune checkpoint inhibitors ipilimumab and pembrolizumab. Both targeted therapy and immunotherapy have brought more substantial clinical benefits than traditional chemotherapies in treating metastatic melanoma. However, there are profound problems within targeted therapy and immunotherapy.

Despite the fact that targeted therapies such as BRAF inhibitors (vemurafenib and dabrafenib) and MEK inhibitor (trametinib) bring substantial initial tumor regression, drug resistance can be acquired in nearly $50 \%$ patients after a period of $6-8$ months ' treatment $[52,53]$. The mechanism of resistance can be divided into three categories: intrinsic, acquired, and adaptive resistance [54]. While intrinsic resistance is characterized by no response to therapy, acquired resistance is typified by initially significant response followed by drug tolerance and progressive disease [54]. The major resistant mechanism is the reactivation of the MAPK pathway. The tumor can re-trigger the MAPK pathway by activating the downstream MEK1/2 kinase or upstream RAS 
kinase mutation, elevating the CRAF level, amplifying the BRAF, overexpressing the RAF1 or MAP3K8-(COT)-kinase, ERK1/2 mutation, upregulating the RTK, as well as mutating the PI3K pathway gene [55-61]. The mechanism of resistance was discussed in detail in recent reviews [62-65]. Although combinational therapies of BRAF inhibitors and MEK inhibitors, for instance, vemurafenib and trametinib or dabrafenib and trametinib, were demonstrated to be more effective for improving median PFS than dabrafenib or vemurafenib monotherapy [66], drug resistance remains a significant problem with combinational therapies $[67,68]$.

Unlike targeted therapy, immune checkpoint inhibitors do not have the problem of drug resistance, but they can cause immune-related adverse events (irAEs). IrAEs are distinct from adverse events brought by chemotherapy or targeted therapy. These unique adverse events result from unrestrained $\mathrm{T}$ cell activation and include dermatologic, gastrointestinal, hepatic and endocrine toxicities. These toxicities can be reversed, however, if not managed timely, they can upgrade to high-grade adverse events and even to life-threatening situations [69].

\section{Tubulin Inhibitors for Treatment of Cancer}

\section{Microtubule dynamics as a therapeutic target}

Microtubules are key elements in eukaryotic cells. They are involved in many critical cellular functions, such as cell division, cell shape maintenance, vesicles transportation, and motility regulation. Formed from polymerized $\alpha / \beta$-tubulin heterodimers, microtubules are responsible for the generation of mitotic spindle and induction of the movement of chromosomes during cellular mitosis [70-72]. Disruption of microtubule dynamics causes cell cycle arrest in the G2/M phase, leading to mitotic catastrophe and ultimately cellular apoptosis. Given the important role of microtubules in cell growth and division, tubulin dynamics has been a fertile target for developing anticancer drugs [73-75].

\section{Binding sites in tubulin}

At least four binding sites on tubulin have been reported to date: the taxane site, the laulimalide site, the vinca site, and the colchicine site (Figure 1-2). A number of approved tubulin inhibitors interact with the taxane site (e.g. paclitaxel, docetaxel, and epothilones) or the vinca site (e.g. vinblastine, vincristine) in tubulin. They have been highly successful in the clinical treatment for many cancer types including ovarian, lung, and breast cancers [76-79]. However, the clinical use of these drugs is often associated with several limitations. First, these drugs are usually good substrates for a number of ATP-binding cassette (ABC) transporters, including P-glycoprotein (P-gp or MDR1), breast cancer resistance protein (BCRP), and multidrug resistant proteins (MRP1, 


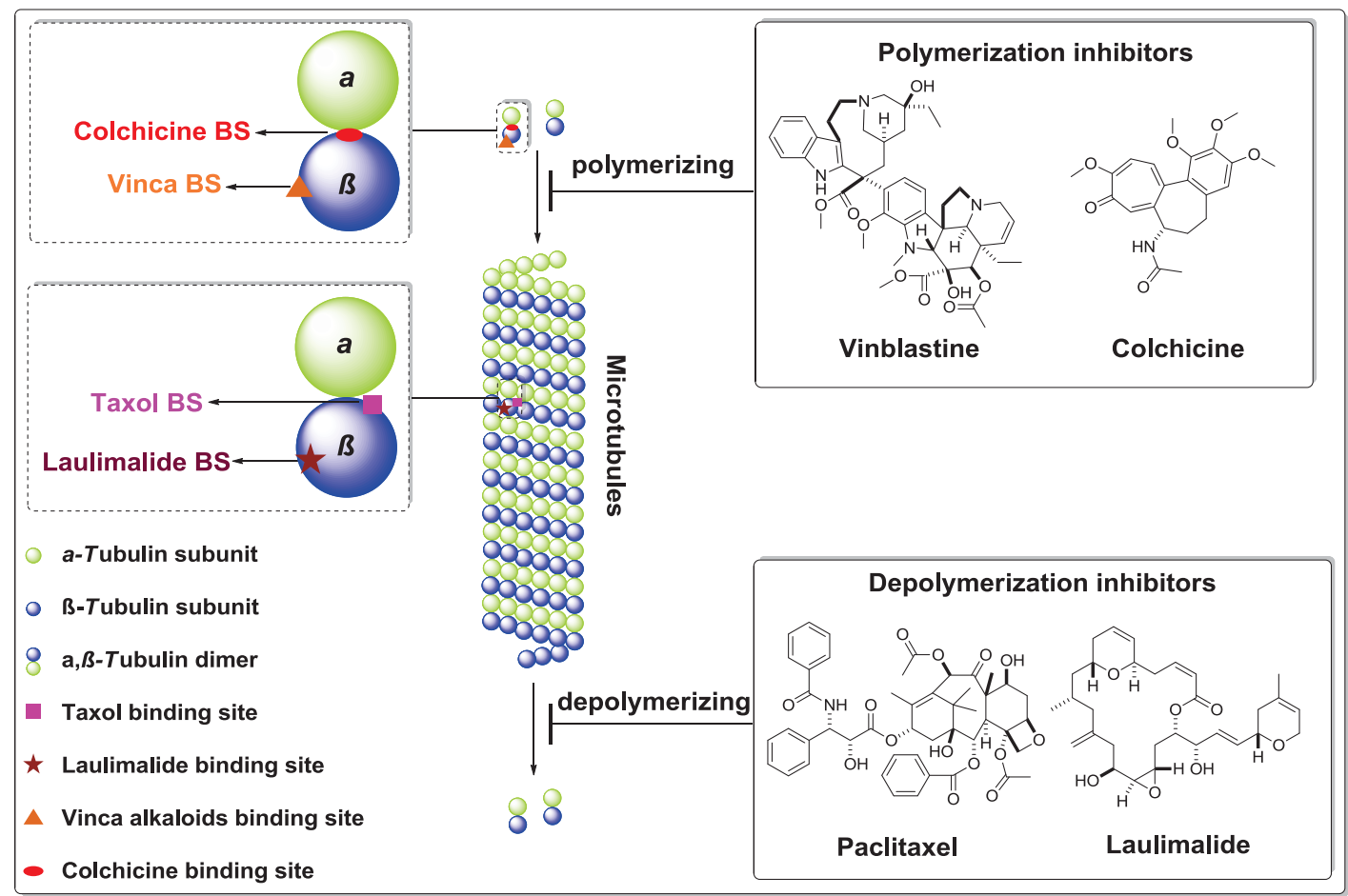

Figure 1-2. Binding sites in tubulin

Reprinted with permission from Bentham Science Publishers. Wu XX, Wang QH, Li W. Recent Advances in Heterocyclic Tubulin Inhibitors Targeting the Colchicine Binding Site. Anti-cancer agents in medicinal chemistry, 2016, 16:1325-1338. 
MRP2). Thus multidrug resistance often develops in patients upon an extended period of drug administration [80-82]. Second, these drugs have very poor aqueous solubility; harmful surfactants such as Cremophor EL are usually required in their formulations [83]. Finally, overexpression of $\beta$-tubulin isoforms (especially the $\beta$-III tubulin isoform) and certain mutations in tubulin are associated with the development of resistance for most of these agents [84-87].

\section{Tubulin inhibitors approved by FDA or in clinical development}

Based on their effects on the microtubule structures at high concentrations, microtubule-targeting agents (MTAs) can be divided into two categories: microtubule stabilizers and microtubule destabilizers. Figure 1-3 and Figure 1-4 list some notable examples of the microtubule-stabilizing agents and microtubule-destabilizing agents, respectively.

\section{Challenges in developing microtubule targeting agents as anticancer agents}

Taxanes and vinca alkaloids have achieved great success in clinical treatment for a variety of cancers in the last decades; however, acquired drug resistance develops over the course of clinical administration and represented a significant obstacle [88]. Mechanistically, cancer cells evade cytotoxic MTAs mainly through the following pathways: (1) Overexpression of tubulin $\beta$-III isotype. Strong clinical evidence supported that overexpression of tubulin $\beta$-III isotype was responsible for drug resistance to either microtubule stabilizer or microtubule destabilizer in patients with different tumor types [89]. Overexpression of tubulin $\beta$-III might also inherently promote microtubule dynamics and prevent cells from proceeding to anaphase [90]. (2) Upregulation of MRP1, MRP2 or MDR1 gene. MDR1 gene is responsible for the encoding of P-gp) [72]. P-gp mediated drug efflux has been reported as the major mechanism mediated drug-resistance to taxanes in many types of tumors [91]. (3) Overexpressed microtubule-regulating proteins. It was demonstrated that increased expression of microtubule-regulating proteins can stabilize microtubules and contribute to the occurrence of multidrug resistance [72]. (4) Changes in cytoskeletal proteins. Mutation in $\gamma$-actin was revealed to induce vinblastine-resistance [92]. In addition, downregulation of $\gamma$-actin was also related to drug resistance in childhood leukemia [93]. (5) Tubulin mutations. Certain mutations in tubulin are also known to confer resistance to CBSIs. For example, a K350N mutation in tubulin induces conformational change to the colchicine binding site and results in 2ME2 resistance [94]. Besides these mechanisms, there were other factors that might mediate drug resistance to tubulin inhibitors $[72,95]$. However, it does not mean that these mechanisms induce resistance exclusively, in fact, these mechanisms often work collectively. 


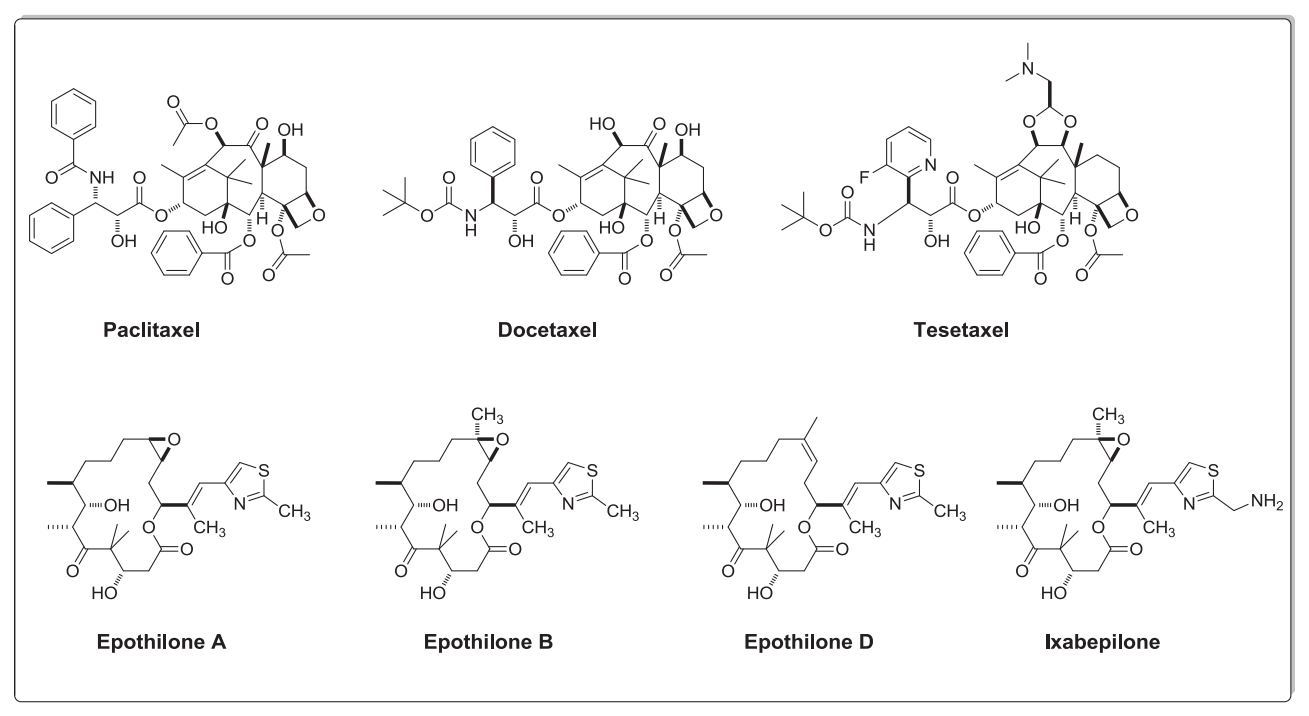

Figure 1-3. Microtubule-stabilizing agents

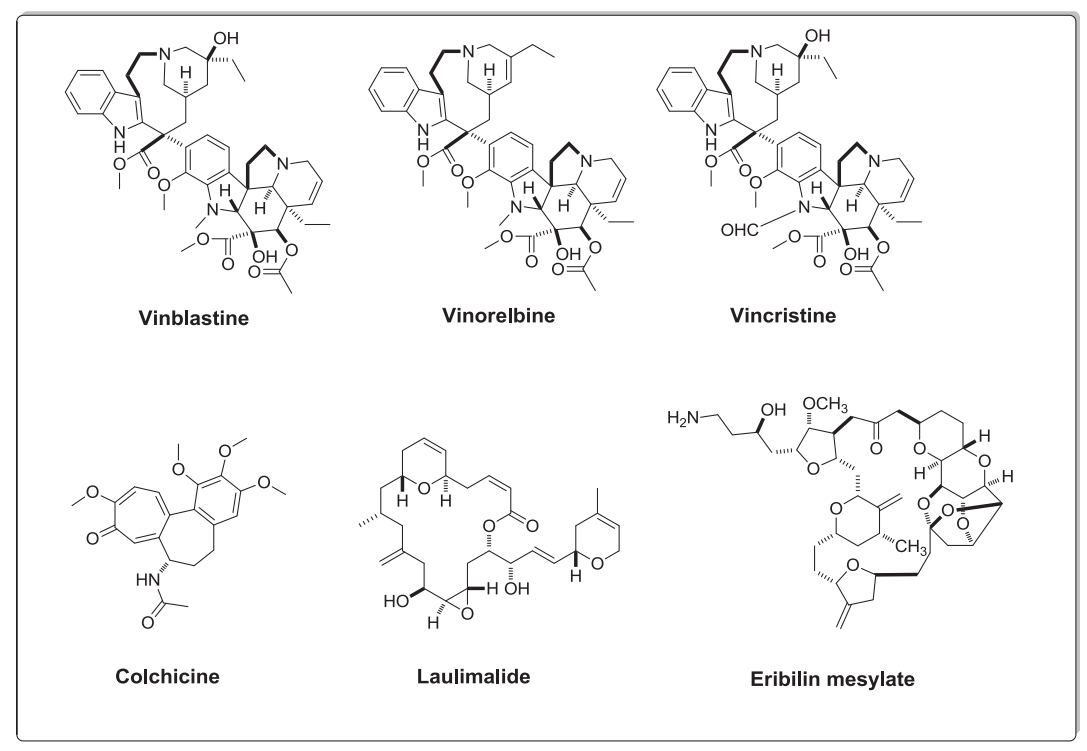

Figure 1-4. Microtubule-destabilizing agents 


\section{Targeting colchicine binding site in tubulin for development of anticancer agents}

The colchicine binding site, one of the many well-documented binding sites in tubulin, locates at the interface between $\alpha$ and $\beta$-tubulin monomers [96]. Colchicine binding site inhibitors (CBSIs) mechanistically decrease cellular motility, alter cell morphology, impair protein assembly, and arrest mitosis [97, 98]. A number of preclinical studies have proven that CBSIs are effective to suppress the overexpression of $\beta$-tubulin isotype $\beta$-III tubulin. CBSIs are also demonstrated to surmount drug-resistance mediated by P-gp, MRP1, MRP2 [99-101]. Thus, despite the fact that there are currently no FDA-approved tubulin inhibitors interacting with the colchicine binding site [96, 102], colchicine binding site represents a great promise and has been extensively investigated. There are many CBSIs have entered clinical trials for cancer treatment, for instance, ABT-751, ZD6126, CA-4P, AVE8062, OXi4503 and NPI-2358 [103], some of which are listed in Figure 1-5.

\section{Survivin as a Therapeutic Target for Cancer Treatment}

\section{Survivin as a therapeutic target}

Due to its important role in anti-apoptosis, cell proliferation, and angiogenesis, survivin is regarded as a highly promising therapeutic target for the development of anticancer agents [104].

Survivin is the smallest member of the family of Inhibitor of Apoptosis Proteins (IAPs). Survivin is almost absent in normal tissues but is highly overexpressed in tumors [105]; it is therefore considered as a significant cancer specific biomarker [106]. Although the anti-apoptotic effect of survivin is well accepted, the mechanism regarding to how survivin mediates inhibition of apoptosis remains debatable. On one hand, it is believed that like other IAP family members survivin can directly bind to caspases and subsequently block their apoptotic activities [107, 108]. On the other hand, it was reported that survivin exerted its anti-apoptotic effect by indirectly inhibiting caspases. It has been demonstrated that survivin can bind to XIAP, another member of IAPs, to protect XIAP from ubiquitination and degradation. This eventually blocks activation of caspase-9 and apoptosis [109]. Additionally, survivin is shown to bind to the mitochondrial protein SMAC and antagonize its pro-apoptotic ability [110]. Overexpression of survivin is reported to associate with multidrug resistance as well as radiation resistance $[111,112]$. Resistance to therapies such as cisplatin and vincristine can be developed easier in tumor cells with high expression of survivin than in tumor cells with low expression of survivin [113].

Selective expression of survivin in tumor cells is validated; the benefit of downregulating survivin expression to treat cancer is therefore obvious. Current strategies employed to block the anti-apoptotic ability of survivin in tumor cells include but are not 


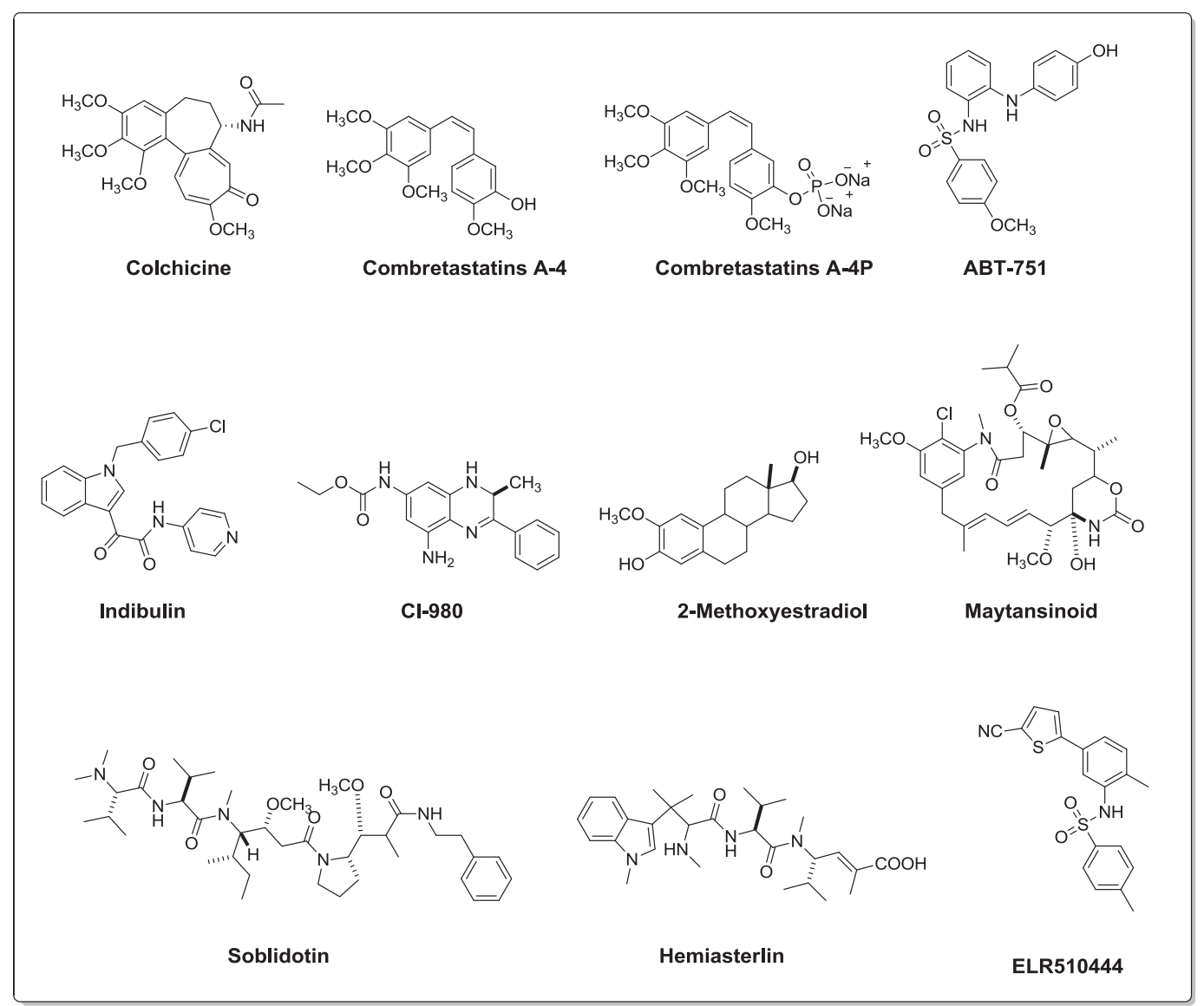

Figure 1-5. Colchicine binding site inhibitors in clinical trials 
limited to introducing recombinant cell-permeable dominant-negative survivin protein [114, 115], obstructing protein translation using antisense oligonucleotides [116], and small-molecule survivin antagonists $[117,118]$.

\section{Major survivin inhibitors}

To date, a few survivin inhibitors have been developed [119-129], the majority of which are listed in Figure 1-6.

\section{Challenges in developing survivin inhibitors as anticancer agents}

Only a small amount of survivin inhibitors has been reported in the last decade, it is therefore not illustrative enough to unlock the potential of survivin for anticancer drug development. Despite the fact that the crystal structure of survivin was obtained in early of the 2000s [130], targeting survivin for direct binding affinity is challenging because no druggable site in survivin has been disclosed to date [130]. Due to that survivin interacts with many other molecules such as Hsp90, Smac, caspases, and INCENP, it is therefore difficult to specify the drug target and evaluate the drug efficacy. Furthermore, although the level of survivin in benign cells is dramatically lower than in malignant tumor cells, it is of significant importance to evaluate the lasting effect of shutting off survivin by survivin inhibitors in normal tissue [105].

\section{Vitamin D3 for Cancer Treatment}

\section{1a,25-dihydroxyvitamin D3 and its limit}

Vitamin D3 is mainly obtained from photoconversion of 7-dehydrocholesterol on the skin. After photoconversion, 7-dehydrocholesterol is converted to pre-vitamin D3 that is subsequently isomerized to vitaminD3. The storage form of vitamin D3, 25hydroxyvitamin D3 (25-OH-D3), is generated through metabolism of vitamin D3 in the liver by 25-hydroxylase (CYP2R1 or CYP27A1) [131]. 25-OH-D3 is metabolized by $1 \alpha-$ hydroxylase (CYP27B1) in the kidney to form the active form of vitamin D3, $1 \alpha, 25$ dihydroxyvitamin $\mathrm{D} 3\left[1,25(\mathrm{OH})_{2} \mathrm{D} 3 \text {, calcitriol] [132]. 1,25(OH }\right)_{2} \mathrm{D} 3$ exerts its extensive biological functions through activation of nuclear vitamin D receptor (VDR), which is distributed in almost all tissues of the body. Those biological functions include but are not limited to antiproliferative effects [133-135], induction of apoptosis [136, 137], antiinflammation [138-140], antiangiogenesis [140, 141] and antimetastatic effects [142, 143]. The $1,25(\mathrm{OH})_{2} \mathrm{D} 3$ represents a promising scaffold for cancer treatment; however, applications of $1,25(\mathrm{OH})_{2} \mathrm{D} 3$ for treatment were greatly hampered by hypercalcemia at pharmacological concentrations [144]. 


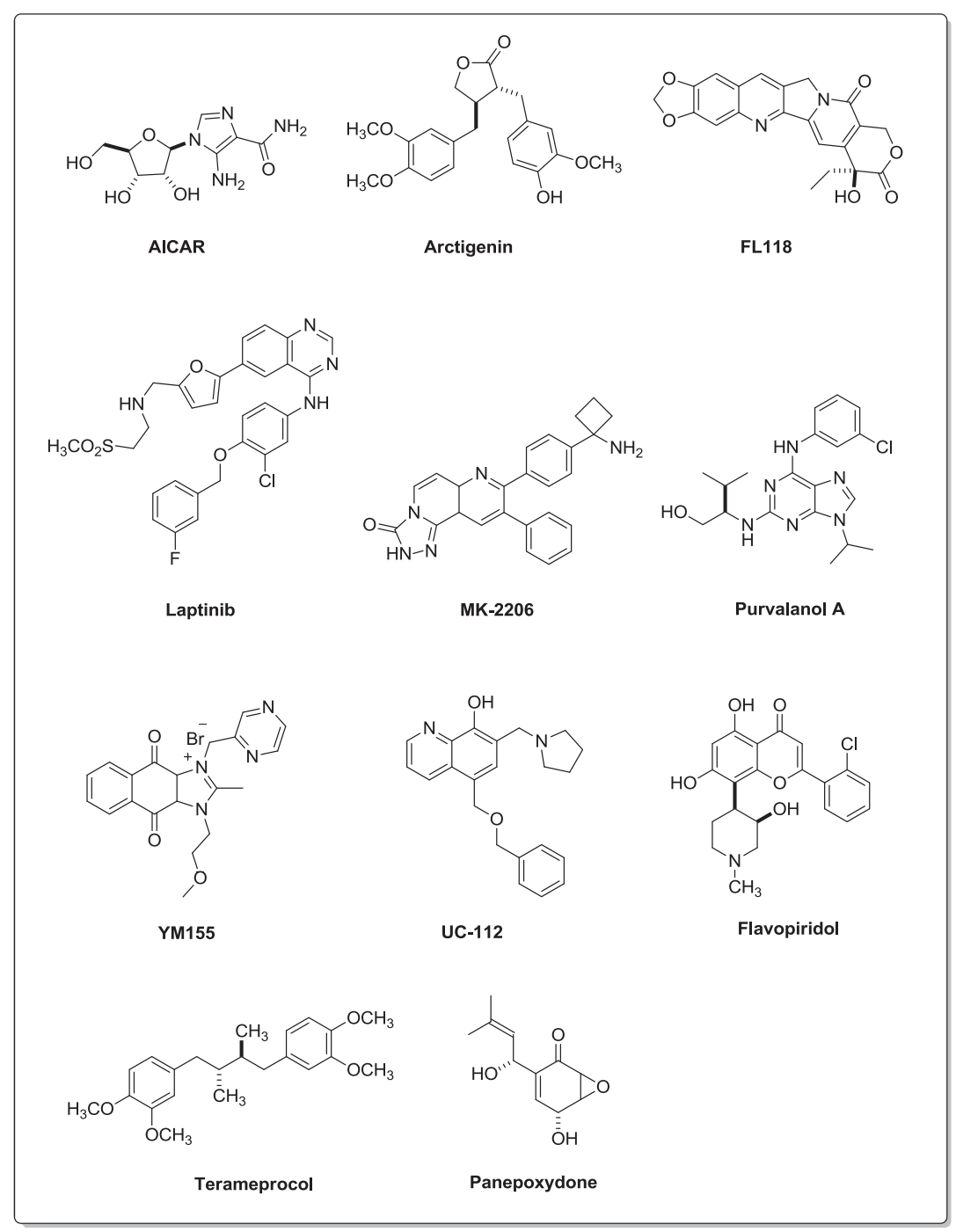

Figure 1-6. Structures of the major survivin inhibitors 


\section{S-hydroxyvitamin D3 as a promising therapy for cancers}

Mammalian cytochrome P450 side-chain cleavage enzyme (P450scc or CYP11A1) cleaves the side chain of cholesterol to produce pregnenolone (precursor of all steroids) $[145,146]$. P450scc also hydroxylates vitamin D3 in a sequential fashion [146-150] starting from C20 to form 20S-hydroxyvitamin D3 [20S-(OH)D3] which is subsequently converted to di- and trihydroxy metabolites [147, 149-152]. Functional studies showed that $20 S-(\mathrm{OH}) \mathrm{D} 3$ not only stimulated keratinocyte differentiation program but also inhibited NF- $\kappa \mathrm{B}$ activity in human keratinocytes [153]. In addition, $20 S-(\mathrm{OH}) \mathrm{D} 3$ has shown antiinflammatory activities, strong antiproliferative effects, antileukemia and tumorostatic effects [153-157], protective effects against ultra-violet B (UVB) induced damage [158], as well as antifibrotic activity in vivo [159]. These activities are mediated either through activation of the VDR [153,160] or inhibition of $\operatorname{ROR} \alpha$ and ROR $\gamma$ transcriptional activities [161]. More importantly, while 20S-(OH)D3 has comparable antiproliferative potency with $1,25(\mathrm{OH})_{2} \mathrm{D} 3$ which has strong hypercalcemic toxicity at a concentration of $1 \mu \mathrm{g} / \mathrm{kg}, 20 S-(\mathrm{OH}) \mathrm{D} 3$ is not hypercalcemic at concentrations as high as $60 \mu \mathrm{g} / \mathrm{kg}[154,156,158,162]$. However, to obtain proper quantity of $20 S-(\mathrm{OH}) \mathrm{D} 3$ amenable for medicinal chemistry program is challenging. Therefore, a chemical synthesis that can prepare the amount of $20 S-(\mathrm{OH}) \mathrm{D} 3$ and enable SAR investigation of this scaffold is of prime importance.

\section{Discussion}

Targeted therapy and immune therapy have achieved substantial success in treating metastatic melanoma. Since 2010, BRAF inhibitors (vemurafenib and dabrafenib), MEK1/2 inhibitors (trametinib and cobimetinib), anti PD-1 antibodies (nivolumab and pembrolizumab) and anti CTLA4 antibody (lpilimumab) have been approved by the FDA for the treatment of advanced melanoma. Nevertheless, patients with advanced melanoma rapidly acquire drug-resistance after a 6-month treatment with targeted therapy. Clinical responses to immune therapy are sometimes reported to be unsatisfactory [163]. IrAEs resulted from unrestrained $\mathrm{T}$ cell activation are challenging and might be fatal if not managed timely $[164,165]$.

Unlike anticancer chemical alone, an antibody-drug conjugate (ADC) resorts to its monoclonal antibody to selectively target antigen on the surface of a tumor instead of normal tissue. As a result, ADC can minimize drug exposure to healthy cells and shows significantly less systemic toxicities or off-target side effect than anticancer chemical alone. Development of a successful ADC is challenging. There are demanding requirements for not only antigen on the surface of tumor but also each part of the ADC. ADC consists of anticancer chemical (payload or warhead), stable monoclonal antibodies, as well as synthetic linkers. The antigen should be mostly if not exclusively expressed in tumor instead of healthy tissue. The antibody should be selective to the antigen on the tumor to exclude off-target effect to healthy tissue. The antibody is also expected to have favorable stability in blood circulation in order to minimize the 
destruction of ADC and maximize the concentration of payload that reaches the tumor. This stability requirement also applies to the synthetic linker.

As the cytotoxic part, the payload is crucial in ADC. Currently, two types of cytotoxic chemicals are mainly subjected to the construction of ADCs: DNA-damaging agents and microtubule inhibitors. Generally, the payload is required to show cytotoxicity in sub-nanomolar range because (1) only limited percentile of injected antibody can be localized to solid tumor (0.003-0.08\% injected dose per gram of tumor); (2) there are limited quantities of antigens on tumor surface; (3) the drug-to-antibody ratio is low (3.54) [166-168]. Although the available pool of cytotoxic chemical is large, the conjugable toxins with "super" potency (sub-nanomolar) are of a limited amount. Thus, the discovery of highly potent inhibitors for different targets is still warranted. In addition, the ability of toxin to circumvent multidrug-resistance is desirable in order to prolong the clinical use.

Because of the critical role of microtubules in many cellular functions, disruption of microtubule dynamics is regarded as an attractive strategy for cancer treatment. MTAs including paclitaxel, docetaxel, and vincristine have achieved great success in the last decade. However, drug resistance resulting from $\mathrm{ABC}$ transporters or overexpression of $\beta$-III tubulin/ MAPs is a major problem for taxanes and vinca alkaloids. Drug discovery based on MTAs has experienced long-term infertility due to significant off-target toxicity. The interest in MTAs is not revived until the FDA approved trastuzumab emtansine in February 2013. Trastuzumab emtansine is applied to the treatment of HER2-postive metastatic breast cancer and is a MTA-based ADC.

ABI-231 is a potent CBSI discovered by our group in 2012 [169]. It has an average $\mathrm{IC}_{50}$ of $5.2 \mathrm{nM}$ against a panel of melanoma and prostate cancer cell lines. It targets the colchicine binding site in tubulin and mechanistically inhibits the microtubule polymerization. Importantly, this molecule is effective in drug-resistant cell lines mediated by overexpression of P-gp and tubulin $\beta$-III isotype. ABI-231, therefore, represents a promising scaffold for developing anti-cancer agents and is worthy in-depth investigation. However, the in-depth SAR investigation of this promising scaffold is hampered by an inefficient synthetic method, through which ABI-231 was achieved within five steps with an overall yield of $0.28 \%$. Hence, an efficient synthetic method that can rapidly generate $\mathrm{ABI}-231$ analogues for SAR evaluation is needed. According to the reported molecular modeling (Figure 1-7) [169], ABI-231 forms three H-bonding interactions with tubulin protein. The interactions include the H-bond between methoxy and $\alpha$-THR179 residue, H-bond between $\mathrm{NH}$ on imidazole and $\beta$-VAL238 as well as NH on indole with $\beta$-ASN167. The molecular modeling suggests the existence of an unoccupied pocket in the vicinity of the indole of ABI-231. We hypothesize that by introducing a small functional group to the indole of ABI-231 the ligand-receptor interaction can be strengthened. With this hypothesis in mind, we have established new generations of synthetic methods to access a variety of novel ABI-231 analogues and RABI analogues. ABI-231 analogues with more potent antiproliferative activities than ABI-231 have been achieved by introducing substituent to the indole moiety or by 


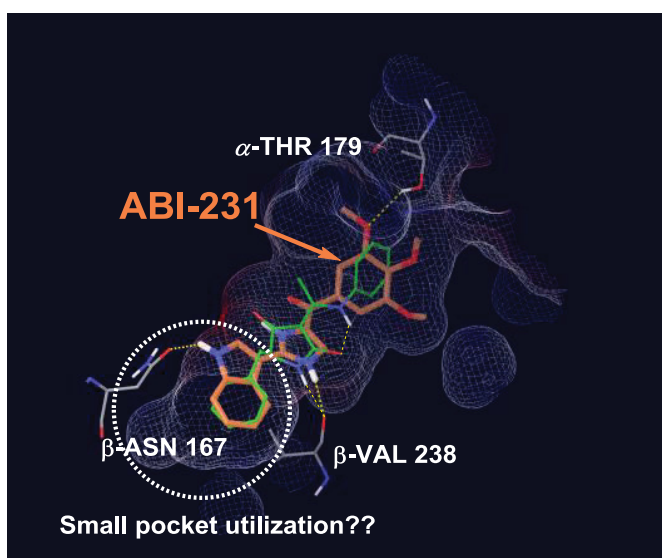

Figure 1-7. Molecule modeling result of ABI-231 in tubulin (PDB: 3HKD) 
isosterically modifying the 3,4,5-trimethoxyphenyl (3,4,5-TMP) in ABI-231. The first RABI analogue with sub-nM activity has also been obtained. These efforts will be shown in Chapter 2 to 4.

UC-112 is discovered as a selective survivin inhibitor through virtual screening by our group in 2014 [126]. It has a low micromolar range $\mathrm{IC}_{50}$ against a panel of melanoma cancer cell lines and is selective to survivin over other IAP family members such as XIAP, cIAP-1, cIAP-2 and livin. A significant tumor growth inhibitory efficacy is observed for UC-112 at a dose of $20 \mathrm{mg} / \mathrm{kg}$ in an A375 human melanoma xenograft model in vivo. Subsequent SAR study of UC-112 has manifested that modifying either the 8-hydroquinoline or the pyrrolidine is detrimental to the activity; introducing hydrophobic substituent to the para-position of the benzyloxy is beneficial to the activity. We hypothesize that the benzyl ether moiety in UC-112 might be too flexible and reducing the flexibility of this benzyloxy tail can increase the antiproliferative activity of this scaffold (Figure 1-8). With theses hypotheses in mind, we have synthesized thirtysix UC-112 analogues replacing the benzyloxy in UC-112 with different moieties. Most of the new analogues show more potent activities than prototype UC-112. Importantly, the new analogues display significant abilities to circumvent P-gp mediated drugresistance. The effort on investigating SAR of UC-112 will be shown in Chapter 5. 


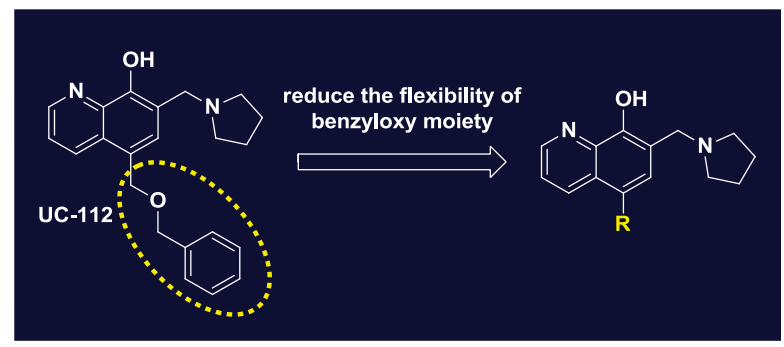

Figure 1-8. Proposed modification of UC-112 by reducing the flexibility of benzyloxy moiety 


\section{CHAPTER 2. STRUCTURE-ACTIVITY RELATIONSHIP STUDY OF ABI-231 LEADS TO IMPROVED ACTIVITIES AGAINST MICROTUBULE POLYMERIZATION}

\section{Introduction}

Microtubules are cylindrical polymers that are of great importance for many cellular functions in the normal cells such as cell division, cell shape maintenance, and cell motility. Microtubules are dynamically involved in the formation of the mitotic spindle and play a critical role in the proliferation of cancer cells [91, 170, 171]. For these reasons, microtubule dynamic is among the most promising therapeutic targets for the development of cancer treatment [171]. MTAs can interfere with the microtubular functions to disrupt the formation of the mitotic spindle, eventually leading to mitotic arrest at the metaphase/anaphase transition. Numerous MTAs have been discovered in the last decades and several of them have been approved by the FDA for the treatment of different cancer types, such as breast cancer, lung cancer, ovarian cancer, etc. [172]. MTAs are generally classified into two categories based on their effect on microtubule at high concentrations: microtubule-stabilizing and microtubule-destabilizing agents. Microtubule-stabilizing agents bind to tubulin polymer and enhance microtubule polymerization. Microtubule-stabilizing agents include, for instance, epothilone, ixabepilone, paclitaxel, and docetaxel. Microtubule-destabilizing agents inhibit polymerization of microtubule and contain such as colchicine, combretastatins A-4 (CA4) and vinca alkaloids [173].

The MTAs have achieved great success in cancer treatment in the last decade. Drug-resistance is, however, acquired over the course of treatment and becomes a tremendous obstacle. Since 22 million new cancer cases are estimated to be diagnosed worldwide in the coming two decades, the importance of developing anticancer agents to treat resistant phenotypes is apparent $[174,175]$. Mechanisms to mediate drug-resistance against MTAs include but are not limited to overexpression of membrane-bound drug efflux proteins such as P-gp, overexpression of $\beta$-tubulin isotypes, and microtubule mutations $[72,176]$. Epothilones are natural products isolated from the So ce90 strain of the myxobacterium sorangium cellulosum. Some of the epothilones have been approved by the FDA for cancer treatment while some are currently at late stages of clinical trials. Different from taxanes and vinca alkaloids, epothilones are not substrates of ATP-binding cassette $(\mathrm{ABC})$ transporters and are able to inhibit the overexpression of tubulin $\beta$-III isotype [177-179].

As one of the many well-documented binding sites in tubulin, colchicine binding site locates at the interface between $\alpha$ and $\beta$-tubulin heterodimers [96]. CBSIs mechanistically decrease cellular motility, alter cell morphology, impair protein assembly, and arrest mitosis [97, 98]. Colchicine, a secondary metabolite isolated from natural source, binds to the colchicines binding site in tubulin. Colchicine has wide-scope mechanisms of action. It, unfortunately, shows systemic toxicities and induces multiorgan dysfunction in a clinical trial for cancer treatment [97]. Other than colchicine 
and its derivatives, a number of other CBSIs have also been discovered in the last decade. Encouragingly, extensive preclinical studies have proven that CBSIs are effective to suppress overexpression of tubulin $\beta$-III isotype and surmount drug-resistance mediated by P-gp, MRP1, MRP2 [99-101].

In our preceding investigations, we have described the discovery of SMART scaffold. SMARTs exhibited nanomolar range antiproliferative activity against a panel of cancer cell lines (Figure 2-1) [180]. Replacing the substituted benezenes in SMARTs with anilines provided the PATs. The PATs showed equipotency to that of SMARTs. Subsequent structural modification of the SMART scaffold by replacing the sulfur in thiazole with NH resulted in the discovery of ABI-I/II (2-aryl-4-benzoyl-imidazole) pharmacophores. ABI-I/IIs showed not only potent activity but also improved bioavailability in comparison with SMARTs (shown in Figure 2-1) [181, 182]. Followup modification of the ABI-I/II gave ABI-III pharmacophore (Figure 2-1) [169, 183]. From the perspective of chemical structure, ABI-IIIs differed from ABI-I/IIs in having bicyclic heterocylces, which are versatile moieties in medicinal chemistry program [184]. From the perspective of bioactivity, ABI-IIIs exhibited more potent antiproliferative activity ( $\mathrm{IC}_{50} \mathrm{~S}$ as low as single-digit nanomolar range) than ABI-I/IIs. Rotation of the imidazole ring in ABI-I/IIs led to the establishment of reverse ABIs (RABIs, shown in Figure 2-1). RABIs had average $\mathrm{IC}_{50} \mathrm{~S}$ as low as $14 \mathrm{nM}$ [185]. Substituting the imidazole and carbonyl linker in ABI-IIIs with bicyclic heterocycles provided the IBIs (shown in Figure 2-1). IBIs displayed similar potency to that of ABI-IIIs. All SMARTs, ABIs, RABIs and IBIs have been demonstrated to share the same mechanism of action: binding to the colchicine binding site in tubulin and inhibiting the tubulin polymerization. Importantly, they were all effective to multidrug-resistant cell lines and can overcome Pgp mediated drug resistance $[169,182,183]$. Among these SMARTs, ABIs, RABIs and IBIs, ABI-231 (shown in Figure 2-1) displayed the optimum activity and had an average $\mathrm{IC}_{50}$ value of $5.2 \mathrm{nM}$ against a panel of cancer cell lines. Molecular modeling study revealed the existence of unoccupied pockets in the vicinity of the indole moiety of ABI231. This pocket might serve as an opportunity to strengthen the ligand-protein interaction [169]. With this hypothesis in mind, we are prompted to conduct comprehensive SAR study of ABI-231 by introducing "indole rotation" and different functional groups to the indole moiety.

\section{Experimental Section}

\section{General chemistry}

Tetrahydrofuran was distilled from sodium-benzophenone. All other solvents and chemical reagents were obtained from commercial sources and directly used without further purification. Glassware was oven-dried before use. All reactions were performed under an argon atmosphere. TLC was performed on silica gel 60 GF254 and monitored under UV light or visualized using phosphomolybdic acid reagent. Flash chromatography 


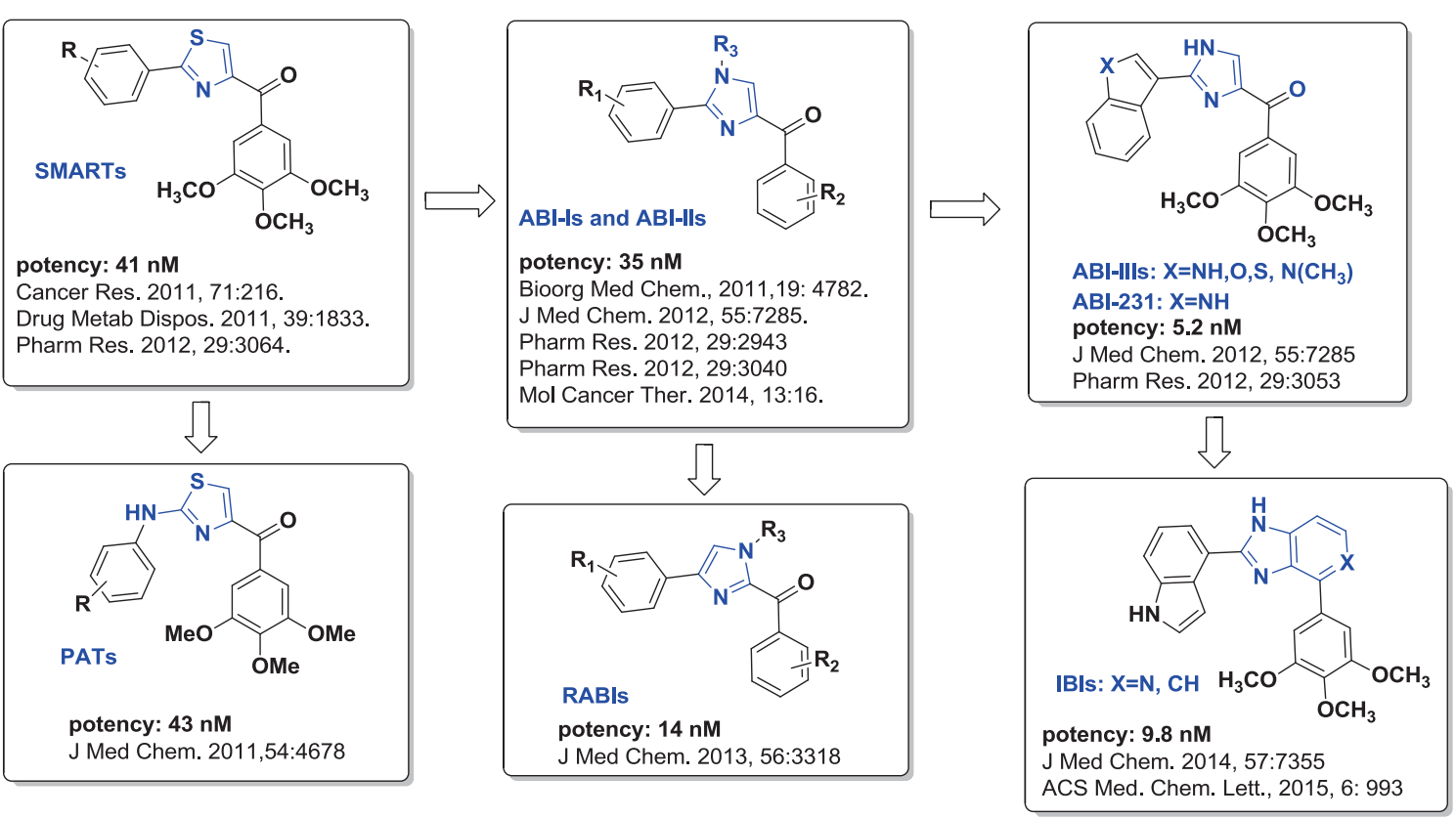

Figure 2-1. Examples of microtubule inhibitors that target colchicine binding sites in tubulin 
was performed on 230-400 mesh silica gel (Fisher Scientific). Melting points were recorded on a MPA100 Automated Melting Point Apparatus. NMR spectra were obtained on a Bruker Ascend 400 (Billerica, MA) spectrometer or a Varian Inova-500 spectrometer (Agilent Technologies, Santa Clara, CA). HR-MS were obtained on Waters Acquity UPLC linked to Waters Acquity Photodiode Array Detector and Waters Acquity Single Quadrupole Mass Detector. Chemical shifts are given in ppm with tetramethylsilane (TMS) as an internal reference. All coupling constants $(J)$ are given in $\operatorname{Hertz}(\mathrm{Hz})$.

\section{Chemical synthesis}

Synthesis of 3-((tert-butyldimethylsilyl)oxy)-3-(3,4,5trimethoxyphenyl)propane-1,2-diol (2). To a solution of 3,4,5-trimethoxybenzaldehyde $(30 \mathrm{~g}, 0.153 \mathrm{~mol})$ in anhydrous THF $(100 \mathrm{~mL})$ at $0{ }^{\circ} \mathrm{C}$ under argon was added vinylmagnesium bromide solution (168 ml, $0.168 \mathrm{~mol}, 1.0 \mathrm{M}$ in THF) dropwise, the resulting mixture was stirred for an hour. On completion reaction was quenched with saturated $\mathrm{NH}_{4} \mathrm{Cl}$. The mixture was then extracted with ethyl acetate, washed with brine and dried with anhydrous $\mathrm{Na}_{2} \mathrm{SO}_{4}$. The combined extracts were evaporated under vacuum to give crude oil which was used directly for next step without purification. Imidazole (15.6 g, $0.229 \mathrm{~mol})$ and tert-butyldimethylsilyl chloride (34.4 g, $0.229 \mathrm{~mol})$ was sequentially added to a solution of the above crude oil in dichloromethane $(150 \mathrm{~mL})$ in a round bottom flask with stirring under argon. The resulting suspension was stirred for 2 hours. Water was then added and the mixture was extracted with dichloromethane, washed with brine and dried with anhydrous $\mathrm{Na}_{2} \mathrm{SO}_{4}$. The combined extracts were evaporated to give crude oil mixture which was purified by flash chromatography on silica. Elution with hexane/ethyl acetate (10:0-10:1) gave racemic mixture 2 as yellowish oil $(44.1 \mathrm{~g}, 85 \%)$.

\section{Synthesis of 3-((tert-butyldimethylsilyl)oxy)-3-(3,4,5-}

trimethoxyphenyl)propane-1,2-diol (3). To a solution of the compound 2 (44.0 g, 0.13 mol) in acetone $(150 \mathrm{~mL})$ was added $N$-methylmorpholine $N$-oxide (22.9 g, $0.195 \mathrm{~mol})$ and osmium tetroxide $(40 \mathrm{mg}, 0.157 \mathrm{mmol})$ in tert-butanol $(5 \mathrm{~mL})$ at room temperature with stirring. After 48 hour, acetone was removed under vacuum, water and ethyl acetate was then added and the organic phase was separated, washed with brine and dried with $\mathrm{Na}_{2} \mathrm{SO}_{4}$. Evaporation under vacuum gave the oily residue which was purified with flash chromatography on silica. Elution with hexane/ethyl acetate (2:1-1:1) gave diol 3 as colorless oil (45.1 g, 93\%).

\section{Synthesis of 3-((tert-butyldimethylsilyl)oxy)-3-(3,4,5-} trimethoxyphenyl)propane-1,2-diyl dimethanesulfonate (4). To a solution of compound 3 (45.0 g, $0.12 \mathrm{~mol})$ and Methanesulfonyl chloride $(23.4 \mathrm{ml}, 0.30 \mathrm{~mol})$ in anhydrous dichloromethane $(100 \mathrm{~mL})$ in a round bottom flask at $0{ }^{\circ} \mathrm{C}$ under argon, trimethylamine $(36.9 \mathrm{ml}, 0.26 \mathrm{~mol})$ was added dropwise with vigorous stirring. The resulting mixture was stirred for overnight, water was then added and the reaction mixture was extracted with dichloromethane, washed with brine and dried with 
anhydrous $\mathrm{Na}_{2} \mathrm{SO}_{4}$. The combined extracts were evaporated under vacuum to give the oily crude which was purified with flash chromatography on silica. Pure mesylates $\mathbf{4}$ was eluted out with hexane/ethyl acetate (3:1-2:1) as colorless oil (45.2 g, 71\%). ${ }^{1} \mathrm{H}$ NMR (400 MHz, Chloroform- $d$ ) $\delta 6.61-6.56(\mathrm{~m}, 2 \mathrm{H}), 4.93(\mathrm{dd}, J=19.9,5.3 \mathrm{~Hz}, 1 \mathrm{H}), 4.79$ (ddd, $J=7.0,4.8,2.4 \mathrm{~Hz}, 1 \mathrm{H}), 4.53-4.41(\mathrm{~m}, 1 \mathrm{H}), 4.36(\mathrm{dd}, J=11.5,2.4 \mathrm{~Hz}, 1 \mathrm{H}), 3.89$ -3.77 (m, 9H), $3.04-2.75$ (m, 6H), $0.90(\mathrm{~d}, J=5.0 \mathrm{~Hz}, 9 \mathrm{H}), 0.12(\mathrm{~d}, J=13.5 \mathrm{~Hz}, 3 \mathrm{H})$, $0.07(\mathrm{~d}, J=1.4 \mathrm{~Hz}, 3 \mathrm{H})$. HRMS: calculated for $\mathrm{C}_{20} \mathrm{H}_{37} \mathrm{O}_{10} \mathrm{~S}_{2} \mathrm{Si}[\mathrm{M}+\mathrm{H}]^{+} 529.1597$, found 529.1562 .

Synthesis of tert-butyl(2,3-diazido-1-(3,4,5-

trimethoxyphenyl)propoxy)dimethylsilane (5). To a solution of mesylates 4 (45.0 g, $0.085 \mathrm{~mol})$ in anhydrous $N, N$-dimethylformamide $(100 \mathrm{~mL})$ in a round bottom flask under argon, sodium azide ( $30 \mathrm{~g}, 0.46 \mathrm{~mol})$ was added in portions with stirring. The resulting mixture was refluxed for overnight. The precipitate was filtered off and washed with dichloromethane. The combined filtration was evaporated under vacuum to give the oily crude which was purified with flash chromatography on silica. Pure azides 5 was eluted out with hexane/ethyl acetate (4:1-3:1) as colorless oil (20.8 g, 58\%). ${ }^{1} \mathrm{H}$ NMR (400 MHz, Chloroform- $d$ ) $\delta 6.55(\mathrm{~d}, J=9.6 \mathrm{~Hz}, 2 \mathrm{H}), 4.64(\mathrm{dd}, J=6.3,4.7 \mathrm{~Hz}, 1 \mathrm{H}), 3.85$ (dd, $J=2.4,1.5 \mathrm{~Hz}, 9 \mathrm{H}), 3.61-3.04(\mathrm{~m}, 3 \mathrm{H}), 0.90$ (d, $J=1.0 \mathrm{~Hz}, 9 \mathrm{H}), 0.10$ (d, $J=9.4$ $\mathrm{Hz}, 3 \mathrm{H}),-0.13(\mathrm{~d}, J=4.1 \mathrm{~Hz}, 3 \mathrm{H})$. HRMS: calculated for $\mathrm{C}_{18} \mathrm{H}_{31} \mathrm{~N}_{6} \mathrm{O}_{4} \mathrm{Si}[\mathrm{M}+\mathrm{H}]^{+}$ 423.2176, found 423.2177.

Synthesis of 3-((tert-butyldimethylsilyl)oxy)-3-(3,4,5trimethoxyphenyl)propane-1,2-diamine (6). A suspension of azides 5 (20.0 g, 0.047 $\mathrm{mol})$ and $10 \% \mathrm{Pd} / \mathrm{C}(0.2 \mathrm{~g})$ in ethylacetate-methanol $(1: 1,50 \mathrm{ml})$ was hydrogenated overnight, the reaction mixture was filtered off and washed with dichloromethanemethanol (1:1). The combined filtration was evaporated under vacuum to give the oily crude which was purified with flash chromatography on silica. Pure diamine 7 was eluted out with dichloromethane/methanol (15:0-15:1) as slightly yellowish oil (10.6 g, 61\%). ${ }^{1} \mathrm{H}$ NMR (400 MHz, Chloroform- $d$ ) $\delta 6.51(\mathrm{~d}, J=13.4 \mathrm{~Hz}, 2 \mathrm{H}), 4.45$ (dd, $J=34.5,5.1$ $\mathrm{Hz}, 1 \mathrm{H}), 3.83$ (d, $J=1.2 \mathrm{~Hz}, 9 \mathrm{H}), 2.97-2.46$ (m, 3H), 0.90 (d, $J=10.8 \mathrm{~Hz}, 9 \mathrm{H}), 0.04$ (d, $J=8.5 \mathrm{~Hz}, 3 \mathrm{H}) .-0.17(\mathrm{~d}, J=8.5 \mathrm{~Hz}, 3 \mathrm{H})$. HRMS: calculated for $\mathrm{C}_{18} \mathrm{H}_{35} \mathrm{~N}_{2} \mathrm{O}_{4} \mathrm{Si}[\mathrm{M}+\mathrm{H}]^{+}$ 371.2366, found 371.2369 .

General procedure for Boc protection of indolecarboxyaldehydes 7aa-7at and $7 \mathbf{b a}-7 \mathrm{be}$. To a solution of the indoles $(1.34 \mathrm{mmol})$ and 4-dimethylaminopyridine $(65 \mathrm{mg}$, $0.54 \mathrm{~mol})$ in anhydrous dichloromethane $(5 \mathrm{~mL})$ under argon was added di-tert-butyl dicarbonate $(351 \mathrm{mg}, 1.61 \mathrm{mmol}$ ) with stirring. After 1 hour, water was then added and the reaction mixture was extracted with dichloromethane, washed with brine and dried with $\mathrm{Na}_{2} \mathrm{SO}_{4}$. Evaporation under vacuum gave the crude solid residue which was purified with flash chromatography on silica. Elution with hexane/ethyl acetate (10:1-3:1) gave pure boc-protected indolecarboxyaldehydes $7 \mathbf{a a}-7$ at and $7 \mathbf{b a - 7 b e}$ as white to yellowish solids.

General procedure for cyclolization to form imidazoline 8aa-8at and $8 \mathrm{ba}-8 \mathrm{be}$. A solution of compound 6 (370 $\mathrm{mg}, 1.0 \mathrm{mmol})$ and boc-protected indole $(1.1 \mathrm{mmol})$ in 
anhydrous dichloromethane $(10 \mathrm{~mL})$ was stirred for one hour under argon, then $\mathrm{N}$ bromosuccinimide $(151 \mathrm{mg}, 0.85 \mathrm{mmol})$ was added at ice temperature and reaction was warmed to room temperature. After 4 hours, the reaction was quenched with saturated sodium thiosulfate solution and extracted with dichloromethane for three times, washed with brine and dried with $\mathrm{Na}_{2} \mathrm{SO}_{4}$. The combined extracts were evaporated to give crude oil, which was purified with flash chromatography on silica. Elution with dichloromethane/ethyl acetate (10:1-1:2) gave diaisostereomers 8aa-8at and 8ba-8be as transparent oil.

General procedure for removal of TBS protecting group. To a stirred solution of compound 8aa-8at $(0.5 \mathrm{mmol})$ in THF $(5.0 \mathrm{~mL})$ was added tetra- $n$-butylammonium fluoride (1.0 M in THF, $1.0 \mathrm{ml}, 1.0 \mathrm{mmol})$ under argon. The reaction was quenched with water, extracted with ethyl acetate for three times, washed with brine and dried with $\mathrm{Na}_{2} \mathrm{SO}_{4}$. The combined extracts were evaporated to give crude oil, which was purified with flash chromatography on silica. Elution with ethyl acetate/methanol $(1: 0-5: 1)$ afforded pure compound 9aa-9at and 9ba-9be as colorless oil.

General procedure for synthesis of 10ab-10at and 10ba-10be. To a stirred solution of compound $9(0.3 \mathrm{mmol})$ in anhydrous dichloromethane $(1.0 \mathrm{~mL})$ was added trifluoroacetic acid $(1.0 \mathrm{~mL})$ under argon at room temperature. After 1 hour, solvent was removed under vacuum to give crude solid which was directly used for next step without purification. To a stirred solution of the above crude in anhydrous dimethyl sulfoxide (2.0 $\mathrm{mL}$ ) under argon was added 2-iodoxybenzoic acid (252 $\mathrm{mg}, 0.9 \mathrm{mmol})$ at room temperature. The reaction mixture was stirred for overnight, extracted with ethyl acetate for three times, washed with brine and dried with $\mathrm{Na}_{2} \mathrm{SO}_{4}$. The combined extracts were evaporated to give crude solid, which was purified with flash chromatography on silica. Elution with hexane/ethyl acetate (4:1) gave pure compound $\mathbf{1 5}$ as yellowish solid.

General procedure for synthesis of 10au-10aw and 10ay. To a stirred solution of compound 10af or 10ak or 10ao or 10as $(0.05 \mathrm{mmol})$ in EtOAc-MeOH $(3 \mathrm{~mL}, 1: 1)$ was added catalytic equivalent of $10 \% \mathrm{Pd} / \mathrm{C}(0.0025 \mathrm{mmol})$ under argon at room temperature. The reaction was then charged with hydrogen and monitored by TLC. Until the disappearance of starting material, the reaction mixture was filtered through celite and was with EtOAc. The combined solvents were evaporated to give crude solid, which was purified with flash chromatography on silica. Elution with Hexanes/ethyl acetate (1:11:4) gave pure compound 10au-10aw and 10ay as yellowish solid.

Synthesis of 10ax. To a stirred solution of compound 10aq in dioxane (1 mL) was added saturated $\mathrm{LiOH}$ solution $(1 \mathrm{~mL})$ and reaction was heated at $50^{\circ} \mathrm{C}$ until the disappearance of starting material. The solvent was removed under reduced pressure and the crude was purified with flash chromatography on silica. Elution with DCM/MeOH (20:1-5:1) gave pure compound 10ax as yellowish solid.

\section{(2-(2-phenyl-1H-indol-3-yl)-1H-imidazol-4-yl)(3,4,5-}

trimethoxyphenyl)methanone (10aa). obtained as a yellowish solid. ${ }^{1} \mathrm{H}$ NMR (400 MHz, Methylene Chloride- $\left.d_{2}\right) \delta 8.15-8.06(\mathrm{~m}, 1 \mathrm{H}), 7.79(\mathrm{~s}, 1 \mathrm{H}), 7.59-7.53(\mathrm{~m}, 2 \mathrm{H})$, 
$7.47-7.41$ (m, 4H), 7.22 (dddd, $J=20.6,8.1,7.1,1.2 \mathrm{~Hz}, 3 \mathrm{H}), 3.89$ (s, 6H), 3.87 (s, $3 \mathrm{H}) .{ }^{13} \mathrm{C}$ NMR $\left(101 \mathrm{MHz}\right.$, Methylene Chloride- $\left.d_{2}\right) \delta 183.45,153.73,142.58,138.59$, $136.68,133.65,132.38,129.72$, 129.63, 129.13, 128.11, 123.63, 121.59, 121.06, 111.94, 111.89, 107.17, 61.19, 56.78. HRMS: calculated for $\mathrm{C}_{27} \mathrm{H}_{24} \mathrm{~N}_{3} \mathrm{O}_{4}[\mathrm{M}+\mathrm{H}]^{+} 454.1767$, found 454.1771 .

\section{(2-(4-methyl-1H-indol-3-yl)-1H-imidazol-4-yl)(3,4,5-}

trimethoxyphenyl)methanone (10ab). obtained as a yellowish solid. ${ }^{1} \mathrm{H}$ NMR (400 MHz, Methylene Chloride- $\left.d_{2}\right) \delta 7.78(\mathrm{~s}, 1 \mathrm{H}), 7.36(\mathrm{~s}, 1 \mathrm{H}), 7.22(\mathrm{~d}, J=16.4 \mathrm{~Hz}, 3 \mathrm{H}), 7.08$ $(\mathrm{t}, J=7.6 \mathrm{~Hz}, 1 \mathrm{H}), 6.93-6.84(\mathrm{~m}, 1 \mathrm{H}), 3.88(\mathrm{~d}, J=2.0 \mathrm{~Hz}, 9 \mathrm{H}), 2.50(\mathrm{~s}, 3 \mathrm{H}) .{ }^{13} \mathrm{C}$ NMR (101 MHz, Methylene Chloride- $d_{2}$ ) $\delta 184.41,153.78,148.55,142.68,137.13,136.97$, $135.76,133.67,133.22,131.08,127.41,127.24,125.09,125.06,123.30,122.79,110.14$, 110.09, 107.17, 106.73, 106.69, 61.21, 56.82, 21.07. HRMS: calculated for $\mathrm{C}_{22} \mathrm{H}_{22} \mathrm{~N}_{3} \mathrm{O}_{4}$ $[\mathrm{M}+\mathrm{H}]^{+}$392.1610, found 392.1603.

2-(4-fluoro-1H-indol-3-yl)-1H-imidazol-4-yl)(3,4,5-

trimethoxyphenyl)methanone (10ac). obtained as a yellowish solid. ${ }^{1} \mathrm{H}$ NMR (400 $\mathrm{MHz}$, Chloroform- $d) \delta 8.04(\mathrm{~s}, 1 \mathrm{H}), 7.71(\mathrm{~s}, 1 \mathrm{H}), 7.24(\mathrm{~d}, J=8.1 \mathrm{~Hz}, 1 \mathrm{H}), 7.19(\mathrm{~s}, 2 \mathrm{H})$, $7.14(\mathrm{td}, J=8.0,5.2 \mathrm{~Hz}, 1 \mathrm{H}), 6.91(\mathrm{dd}, J=12.7,7.8 \mathrm{~Hz}, 1 \mathrm{H}), 3.90(\mathrm{~d}, J=1.1 \mathrm{~Hz}, 9 \mathrm{H})$.

${ }^{13} \mathrm{C}$ NMR (101 MHz, Chloroform- $d$ ) $\delta 181.51,167.73,156.38,154.01,153.47,143.21$, 139.62, 131.22, 130.90, 129.80, 128.82, 124.35, 111.77, 109.92, 107.33, 107.12, 106.31, 61.08, 56.46. HRMS: calculated for $\mathrm{C}_{21} \mathrm{H}_{19} \mathrm{FN}_{3} \mathrm{O}_{4}[\mathrm{M}+\mathrm{H}]^{+}$396.1360, found 396.1364.

(2-(4-bromo-1H-indol-3-yl)-1H-imidazol-4-yl)(3,4,5-

trimethoxyphenyl)methanone (10ad). obtained as a yellowish solid. (EtOAc). ${ }^{1} \mathrm{H}$ NMR (400 MHz, Methylene Chloride- $\left.d_{2}\right) \delta 7.77(\mathrm{~s}, 1 \mathrm{H}), 7.68(\mathrm{~s}, 1 \mathrm{H}), 7.42(\mathrm{~d}, J=8.1 \mathrm{~Hz}, 1 \mathrm{H})$, $7.34(\mathrm{~d}, J=7.6 \mathrm{~Hz}, 1 \mathrm{H}), 7.26(\mathrm{~s}, 2 \mathrm{H}), 7.06(\mathrm{t}, J=7.9 \mathrm{~Hz}, 1 \mathrm{H}), 3.91(\mathrm{~s}, 6 \mathrm{H}), 3.87(\mathrm{~s}, 3 \mathrm{H})$.

${ }^{13} \mathrm{C}$ NMR $\left(101 \mathrm{MHz}\right.$, Methylene Chloride- $\left.d_{2}\right) \delta 184.36,153.80,146.48,142.67,138.16$, 133.68, 129.87, 125.75, 124.76, 123.88, 113.25, 112.31, 112.25, 107.15, 106.35, 61.20, 56.84. HRMS: calculated for $\mathrm{C}_{21} \mathrm{H}_{19} \mathrm{BrN}_{3} \mathrm{O}_{4}[\mathrm{M}+\mathrm{H}]^{+} 456.0559$, found 456.0560.

\section{(2-(4-methoxy-1H-indol-3-yl)-1H-imidazol-4-yl)(3,4,5-}

trimethoxyphenyl)methanone (10ae). obtained as a yellowish solid. ${ }^{1} \mathrm{H}$ NMR (400 $\mathrm{MHz}$, Chloroform-d) $\delta 9.91(\mathrm{~s}, 1 \mathrm{H}), 8.75(\mathrm{~s}, 1 \mathrm{H}), 7.90(\mathrm{~s}, 1 \mathrm{H}), 7.41(\mathrm{~d}, J=8.4 \mathrm{~Hz}, 1 \mathrm{H})$, $7.30(\mathrm{~s}, 2 \mathrm{H}), 7.26(\mathrm{~s}, 2 \mathrm{H}), 6.70(\mathrm{~d}, J=8.4 \mathrm{~Hz}, 1 \mathrm{H}), 4.26(\mathrm{~s}, 3 \mathrm{H}), 4.01(\mathrm{~s}, 3 \mathrm{H}), 4.00(\mathrm{~s}, 6 \mathrm{H})$.

${ }^{13} \mathrm{C}$ NMR (101 MHz, Chloroform-d) $\delta 181.65,153.51,151.42,145.59,143.17,138.93$, $131.25,130.44,128.59,127.66,124.71,113.49,107.27,106.23,102.57,99.65,61.05$, 56.41, 56.09. HRMS: calculated for $\mathrm{C}_{22} \mathrm{H}_{22} \mathrm{~N}_{3} \mathrm{O}_{5}[\mathrm{M}+\mathrm{H}]^{+} 408.1559$, found 408.1564.

\section{(2-(4-(benzyloxy)-1H-indol-3-yl)-1H-imidazol-4-yl)(3,4,5-}

trimethoxyphenyl)methanone (10af). obtained as a yellowish solid. ${ }^{1} \mathrm{H}$ NMR $(400 \mathrm{MHz}$, Methylene Chloride- $\left.\mathrm{d}_{2}\right) \delta 11.96(\mathrm{~s}, 1 \mathrm{H}), 10.50(\mathrm{~s}, 1 \mathrm{H}), 8.07(\mathrm{~d}, \mathrm{~J}=2.6 \mathrm{~Hz}, 1 \mathrm{H}), 7.58-$ $7.51(\mathrm{~m}, 2 \mathrm{H}), 7.47-7.21(\mathrm{~m}, 5 \mathrm{H}), 7.11(\mathrm{~d}, \mathrm{~J}=4.2 \mathrm{~Hz}, 2 \mathrm{H}), 6.74(\mathrm{p}, \mathrm{J}=4.7 \mathrm{~Hz}, 1 \mathrm{H}), 5.48$ $(\mathrm{s}, 2 \mathrm{H}), 4.25-3.89(\mathrm{~m}, 6 \mathrm{H}), 3.87(\mathrm{~d}, \mathrm{~J}=0.8 \mathrm{~Hz}, 3 \mathrm{H}) .{ }^{13} \mathrm{C}$ NMR $(101 \mathrm{MHz}$, Methylene Chloride- $\left.\mathrm{d}_{2}\right) \delta 183.51,153.73,151.84,142.38,139.56,136.73,134.10,129.41,129.04$, 
128.66, 126.85, 124.00, 114.88, 107.16, 107.09, 103.65, 71.70, 61.15, 56.78. HRMS: calculated for $\mathrm{C}_{28} \mathrm{H}_{26} \mathrm{~N}_{3} \mathrm{O}_{5}[\mathrm{M}+\mathrm{H}]^{+} 484.1872$, found 484.1870 .

(2-(5-methyl-1H-indol-3-yl)-1H-imidazol-4-yl)(3,4,5-

trimethoxyphenyl)methanone (10ag). obtained as a yellowish solid. ${ }^{1} \mathrm{H}$ NMR (400 MHz, Methylene Chloride- $\left.\mathrm{d}_{2}\right) \delta 8.03(\mathrm{~s}, 1 \mathrm{H}), 7.88(\mathrm{~d}, \mathrm{~J}=1.6 \mathrm{~Hz}, 1 \mathrm{H}), 7.79(\mathrm{~s}, 1 \mathrm{H}), 7.36$ (dd, J = 8.4, 1.5 Hz, 1H), 7.27 (s, 2H), 7.09 (d, J = 8.4 Hz, 1H), 3.92 (d, J = 1.6 Hz, 6H), $3.88(\mathrm{~d}, \mathrm{~J}=1.6 \mathrm{~Hz}, 3 \mathrm{H}), 2.62-2.40(\mathrm{~m}, 3 \mathrm{H}) .{ }^{13} \mathrm{C}$ NMR $(101 \mathrm{MHz}$, Methylene Chloride$\left.\mathrm{d}_{2}\right) \delta 184.33,153.77,149.36,142.51,135.52,134.01,131.13,126.56,125.50,125.01$, 120.34, 112.08, 107.14, 106.03, 61.22, 56.79, 21.80. HRMS: calculated for $\mathrm{C}_{22} \mathrm{H}_{22} \mathrm{~N}_{3} \mathrm{O}_{4}$ $[\mathrm{M}+\mathrm{H}]^{+}$392.1610, found 392.1611.

(2-(5-fluoro-1H-indol-3-yl)-1H-imidazol-4-yl)(3,4,5trimethoxyphenyl)methanone (10ah). obtained as a yellowish solid. ${ }^{1} \mathrm{H}$ NMR (400 MHz, Methylene Chloride- $\left.\mathrm{d}_{2}\right) \delta 8.00-7.91(\mathrm{~m}, 2 \mathrm{H}), 7.80(\mathrm{~s}, 1 \mathrm{H}), 7.41$ (dd, J = 8.9, 4.5 $\mathrm{Hz}, 1 \mathrm{H}), 7.30(\mathrm{~s}, 2 \mathrm{H}), 7.01(\mathrm{td}, \mathrm{J}=9.0,2.5 \mathrm{~Hz}, 1 \mathrm{H}), 3.92(\mathrm{~s}, 6 \mathrm{H}), 3.88(\mathrm{~s}, 3 \mathrm{H}) .{ }^{13} \mathrm{C} \mathrm{NMR}$ (101 MHz, Methylene Chloride-d 2 ) $\delta$ 184.61, 160.45, 158.11, 153.75, 142.54, 134.00, 133.81, 127.77, 125.96, 125.85, 113.26, 113.17, 111.74, 111.48, 107.28, 106.92, 106.88, 106.21, 105.96, 61.22, 56.79. HRMS: calculated for $\mathrm{C}_{21} \mathrm{H}_{19} \mathrm{FN}_{3} \mathrm{O}_{4}[\mathrm{M}+\mathrm{H}]^{+}$396.1360, found 396.1364 .

(2-(5-chloro-1H-indol-3-yl)-1H-imidazol-4-yl)(3,4,5-

trimethoxyphenyl)methanone (10ai). obtained as a yellowish solid. ${ }^{1} \mathrm{H}$ NMR $(400 \mathrm{MHz}$, Acetone- $\left.\mathrm{d}_{6}\right) \delta 10.93(\mathrm{~s}, 1 \mathrm{H}), 8.64(\mathrm{~d}, \mathrm{~J}=2.2 \mathrm{~Hz}, 1 \mathrm{H}), 8.29(\mathrm{~s}, 1 \mathrm{H}), 7.92(\mathrm{~s}, 1 \mathrm{H}), 7.54(\mathrm{~d}, \mathrm{~J}$ $=8.7 \mathrm{~Hz}, 2 \mathrm{H}), 7.23(\mathrm{dd}, \mathrm{J}=8.7,2.1 \mathrm{~Hz}, 1 \mathrm{H}), 3.97(\mathrm{~s}, 6 \mathrm{H}), 3.85(\mathrm{~s}, 3 \mathrm{H}) .{ }^{13} \mathrm{C}$ NMR $(101$ MHz, Acetone- $\left.\mathrm{d}_{6}\right) \delta 183.80,154.15,142.94,136.18,136.03,134.44,127.60,127.20$, 126.71, 123.53, 121.78, 114.04, 114.00, 107.96, 107.57, 60.71, 56.67. HRMS: calculated for $\mathrm{C}_{21} \mathrm{H}_{19} \mathrm{ClN}_{3} \mathrm{O}_{4}[\mathrm{M}+\mathrm{H}]^{+}$412.1064, found 412.1068.

\section{(2-(5-bromo-1H-indol-3-yl)-1H-imidazol-4-yl)(3,4,5-}

trimethoxyphenyl)methanone (10aj). obtained as a yellowish solid. ${ }^{1} \mathrm{H}$ NMR $(400 \mathrm{MHz}$, Methylene Chloride- $\left.\mathrm{d}_{2}\right) \delta 8.44(\mathrm{dd}, \mathrm{J}=1.9,0.8 \mathrm{~Hz}, 1 \mathrm{H}), 7.90(\mathrm{~s}, 1 \mathrm{H}), 7.80(\mathrm{~s}, 1 \mathrm{H}), 7.39$ $7.26(\mathrm{~m}, 4 \mathrm{H}), 3.93(\mathrm{~s}, 6 \mathrm{H}), 3.88(\mathrm{~s}, 3 \mathrm{H}) .{ }^{13} \mathrm{C}$ NMR $\left(101 \mathrm{MHz}\right.$, Methylene Chloride- $\left.\mathrm{d}_{2}\right) \delta$ 184.63, 153.78, 148.24, 142.61, 135.92, 133.91, 127.33, 127.10, 126.19, 123.58, 114.77, 113.96, 107.29, 106.30, 61.23, 56.84. HRMS: calculated for $\mathrm{C}_{21} \mathrm{H}_{19} \mathrm{BrN}_{3} \mathrm{O}_{4}[\mathrm{M}+\mathrm{H}]^{+}$ 456.0559, found 456.0555 .

(2-(5-(benzyloxy)-1H-indol-3-yl)-1H-imidazol-4-yl)(3,4,5-

trimethoxyphenyl)methanone (10ak). obtained as a yellowish solid. ${ }^{1} \mathrm{H}$ NMR (400 MHz, Acetone- $\left.\mathrm{d}_{6}\right) \delta 10.69(\mathrm{~s}, 1 \mathrm{H}), 8.24(\mathrm{dd}, \mathrm{J}=9.5,2.5 \mathrm{~Hz}, 2 \mathrm{H}), 7.93(\mathrm{~s}, 1 \mathrm{H}), 7.59-$ $7.46(\mathrm{~m}, 4 \mathrm{H}), 7.46-7.35(\mathrm{~m}, 3 \mathrm{H}), 7.35-7.28(\mathrm{~m}, 1 \mathrm{H}), 6.98(\mathrm{dd}, \mathrm{J}=8.8,2.5 \mathrm{~Hz}, 1 \mathrm{H})$, $5.16(\mathrm{~s}, 2 \mathrm{H}), 3.95(\mathrm{~s}, 6 \mathrm{H}), 3.82(\mathrm{~s}, 3 \mathrm{H}) .{ }^{13} \mathrm{C}$ NMR $\left(101 \mathrm{MHz}\right.$, Acetone- $\left.\mathrm{d}_{6}\right) \delta 183.75$, 155.14, 154.15, 142.92, 138.97, 134.58, 133.03, 132.88, 129.20, 128.58, 128.47, 127.12, $126.57,126.40,114.10,113.23,113.18,107.92,107.32,105.98,71.25,60.71,60.54$, 56.69. HRMS: calculated for $\mathrm{C}_{28} \mathrm{H}_{26} \mathrm{~N}_{3} \mathrm{O}_{5}[\mathrm{M}+\mathrm{H}]^{+} 484.1872$, found 484.1875 . 
(2-(6-methyl-1H-indol-3-yl)-1H-imidazol-4-yl)(3,4,5-

trimethoxyphenyl)methanone (10al). obtained as a yellowish solid. ${ }^{1} \mathrm{H}$ NMR (400 MHz, Methylene Chloride- $\left.\mathrm{d}_{2}\right) \delta 8.06(\mathrm{~d}, \mathrm{~J}=8.2 \mathrm{~Hz}, 1 \mathrm{H}), 7.88(\mathrm{~s}, 1 \mathrm{H}), 7.83(\mathrm{~s}, 1 \mathrm{H}), 7.25(\mathrm{~s}, 2 \mathrm{H})$, $7.21(\mathrm{~s}, 1 \mathrm{H}), 7.05(\mathrm{~d}, \mathrm{~J}=8.0 \mathrm{~Hz}, 1 \mathrm{H}), 3.87(\mathrm{~d}, \mathrm{~J}=3.0 \mathrm{~Hz}, 9 \mathrm{H}), 2.41(\mathrm{~s}, 3 \mathrm{H}) .{ }^{13} \mathrm{C} \mathrm{NMR}$ (101 MHz, Methylene Chloride- $\mathrm{d}_{2}$ ) $\delta 183.51,153.86,148.33,142.82,137.43,133.85$, 133.46, 132.01, 125.84, 123.74, 123.03, 120.50, 112.28, 107.08, 106.16, 61.20, 56.83, 21.90. HRMS: calculated for $\mathrm{C}_{22} \mathrm{H}_{22} \mathrm{~N}_{3} \mathrm{O}_{4}[\mathrm{M}+\mathrm{H}]^{+} 392.1610$, found 392.1613 .

(2-(6-fluoro-1H-indol-3-yl)-1H-imidazol-4-yl)(3,4,5-

trimethoxyphenyl)methanone (10am). obtained as a yellowish solid. ${ }^{1} \mathrm{H}$ NMR (400 MHz, Methylene Chloride- $\left.\mathrm{d}_{2}\right) \delta 8.27-8.17(\mathrm{~m}, 1 \mathrm{H}), 7.88(\mathrm{~d}, \mathrm{~J}=2.1 \mathrm{~Hz}, 1 \mathrm{H}), 7.79(\mathrm{~d}, \mathrm{~J}$ $=2.5 \mathrm{~Hz}, 1 \mathrm{H}), 7.30(\mathrm{~d}, \mathrm{~J}=2.1 \mathrm{~Hz}, 2 \mathrm{H}), 7.15(\mathrm{dt}, \mathrm{J}=9.6,2.4 \mathrm{~Hz}, 1 \mathrm{H}), 6.98$ (ddd, J = 9.6, 8.8, $2.4 \mathrm{~Hz}, 1 \mathrm{H}), 3.91(\mathrm{~d}, \mathrm{~J}=2.2 \mathrm{~Hz}, 6 \mathrm{H}), 3.87$ (s, 3H). ${ }^{13} \mathrm{C}$ NMR (101 MHz, Methylene Chloride- $\left.\mathrm{d}_{2}\right) \delta 184.67,161.98,159.62,153.76,148.67,142.55,137.37,137.25,134.00$, 126.67, 126.64, 122.14, 122.10, 122.00, 110.09, 109.85, 107.27, 106.71, 98.65, 98.40, 61.23, 56.77. HRMS: calculated for $\mathrm{C}_{21} \mathrm{H}_{19} \mathrm{FN}_{3} \mathrm{O}_{4}[\mathrm{M}+\mathrm{H}]^{+}$396.1360, found 396.1357.

(2-(6-bromo-1H-indol-3-yl)-1H-imidazol-4-yl)(3,4,5trimethoxyphenyl)methanone (10an). obtained as a yellowish solid. ${ }^{1} \mathrm{H}$ NMR (400 MHz, Methylene Chloride- $\left.\mathrm{d}_{2}\right) \delta 8.17(\mathrm{~d}, \mathrm{~J}=8.5 \mathrm{~Hz}, 1 \mathrm{H}), 7.87(\mathrm{~s}, 1 \mathrm{H}), 7.80(\mathrm{~s}, 1 \mathrm{H}), 7.59$ $(\mathrm{d}, \mathrm{J}=1.9 \mathrm{~Hz}, 1 \mathrm{H}), 7.30(\mathrm{~d}, \mathrm{~J}=10.4 \mathrm{~Hz}, 3 \mathrm{H}), 3.90(\mathrm{~s}, 6 \mathrm{H}), 3.88(\mathrm{~s}, 3 \mathrm{H}) .{ }^{13} \mathrm{C}$ NMR $(101$ MHz, Methylene Chloride- $\left.\mathrm{d}_{2}\right) \delta 184.48,153.73,148.37,142.54,137.94,133.90,126.73$, 124.56, 124.45, 124.42, 122.51, 116.67, 115.32, 115.27, 107.20, 106.91, 61.21, 56.77. HRMS: calculated for $\mathrm{C}_{21} \mathrm{H}_{19} \mathrm{BrN}_{3} \mathrm{O}_{4}[\mathrm{M}+\mathrm{H}]^{+} 456.0559$, found 456.0558.

\section{(2-(6-(benzyloxy)-1H-indol-3-yl)-1H-imidazol-4-yl)(3,4,5-}

trimethoxyphenyl)methanone (10ao). obtained as a yellowish solid. ${ }^{1} \mathrm{H}$ NMR (400 MHz, Methylene Chloride- $\left.\mathrm{d}_{2}\right) \delta 9.54(\mathrm{~s}, 1 \mathrm{H}), 8.21(\mathrm{~d}, \mathrm{~J}=8.6 \mathrm{~Hz}, 1 \mathrm{H}), 7.83(\mathrm{~d}, \mathrm{~J}=7.0 \mathrm{~Hz}$, 2H), $7.49-7.20(\mathrm{~m}, 7 \mathrm{H}), 7.00-6.84(\mathrm{~m}, 2 \mathrm{H}), 4.98(\mathrm{~s}, 2 \mathrm{H}), 3.86(\mathrm{~s}, 3 \mathrm{H}), 3.84(\mathrm{~s}, 6 \mathrm{H})$. ${ }^{13} \mathrm{C}$ NMR $\left(101 \mathrm{MHz}\right.$, Methylene Chloride-d $\left.\mathrm{d}_{2}\right) \delta 183.92,156.66,153.75,142.52,137.89$, $137.81,133.88,129.02$, 128.41, 128.12, 124.92, 122.11, 120.08, 112.30, 107.17, 107.13, 96.74, 70.92, 61.17, 56.75. HRMS: calculated for $\mathrm{C}_{28} \mathrm{H}_{26} \mathrm{~N}_{3} \mathrm{O}_{5}[\mathrm{M}+\mathrm{H}]^{+}$484.1872, found 484.1870.

(2-(6-methoxy-1H-indol-3-yl)-1H-imidazol-4-yl)(3,4,5-

trimethoxyphenyl)methanone (10ap). obtained as a yellowish solid. ${ }^{1} \mathrm{H}$ NMR (400 MHz, Methylene Chloride- $\left.\mathrm{d}_{2}\right) \delta 8.12(\mathrm{dd}, \mathrm{J}=8.7,0.6 \mathrm{~Hz}, 1 \mathrm{H}), 7.79(\mathrm{~d}, \mathrm{~J}=5.8 \mathrm{~Hz}, 2 \mathrm{H})$, 7.27 (s, 2H), 6.94 (d, J = 2.2 Hz, 1H), 6.88 (dd, J = 8.8, $2.3 \mathrm{~Hz}, 1 \mathrm{H}), 3.91$ (s, 6H), 3.87 (s, $3 \mathrm{H}), 3.83(\mathrm{~s}, 3 \mathrm{H}) .{ }^{13} \mathrm{C}$ NMR (101 MHz, Methylene Chloride-d 2$) \delta 184.25,157.54,153.75$, $149.09,142.51,137.98,133.96,125.15,121.60,119.63,111.53,107.14,106.61,95.58$, 95.52, 61.20, 56.78, 56.06. HRMS: calculated for $\mathrm{C}_{22} \mathrm{H}_{22} \mathrm{~N}_{3} \mathrm{O}_{5}[\mathrm{M}+\mathrm{H}]^{+}$408.1559, found 408.1566 .

Methyl 3-(4-(3,4,5-trimethoxybenzoyl)-1H-imidazol-2-yl)-1H-indole-6carboxylate (10aq). obtained as a yellowish solid. ${ }^{1} \mathrm{H}$ NMR $\left(400 \mathrm{MHz}, \mathrm{DMSO}-\mathrm{d}_{6}\right) \delta$ $13.21(\mathrm{~s}, 1 \mathrm{H}), 11.98(\mathrm{~s}, 1 \mathrm{H}), 8.52(\mathrm{~d}, \mathrm{~J}=8.4 \mathrm{~Hz}, 1 \mathrm{H}), 8.45(\mathrm{~s}, 1 \mathrm{H}), 8.15(\mathrm{~s}, 1 \mathrm{H}), 8.00$ (s, 
1H), $7.77(\mathrm{~d}, \mathrm{~J}=8.4 \mathrm{~Hz}, 1 \mathrm{H}), 7.49(\mathrm{~s}, 2 \mathrm{H}), 3.91(\mathrm{~s}, 6 \mathrm{H}), 3.88(\mathrm{~s}, 3 \mathrm{H}), 3.79(\mathrm{~s}, 3 \mathrm{H}) .{ }^{13} \mathrm{C}$ NMR $(101 \mathrm{MHz}$, DMSO-d 6 ) $\delta 182.97,166.98,152.62,141.15,135.65,133.24,129.07$, $128.45,127.98,127.74,127.50,123.27,120.91,120.60,117.93,113.86,106.82,106.36$, 60.14, 55.98, 51.84. HRMS: calculated for $\mathrm{C}_{23} \mathrm{H}_{22} \mathrm{~N}_{3} \mathrm{O}_{6}[\mathrm{M}+\mathrm{H}]^{+} 436.1509$, found 436.1506 .

(2-(7-methyl-1H-indol-3-yl)-1H-imidazol-4-yl)(3,4,5trimethoxyphenyl)methanone (10ar). obtained as a yellowish solid. ${ }^{1} \mathrm{H}$ NMR (400 MHz, Methylene Chloride- $\left.\mathrm{d}_{2}\right) \delta 8.09$ (dt, J = 7.7, 0.9 Hz, 1H), $7.92(\mathrm{~s}, 1 \mathrm{H}), 7.81(\mathrm{~s}, 1 \mathrm{H})$, $7.28(\mathrm{~s}, 2 \mathrm{H}), 7.14(\mathrm{dd}, \mathrm{J}=8.1,7.1 \mathrm{~Hz}, 1 \mathrm{H}), 7.05(\mathrm{dt}, \mathrm{J}=7.2,1.0 \mathrm{~Hz}, 1 \mathrm{H}), 3.90(\mathrm{~s}, 6 \mathrm{H})$, $3.88(\mathrm{~s}, 3 \mathrm{H}), 2.51(\mathrm{~s}, 3 \mathrm{H}) .{ }^{13} \mathrm{C}$ NMR (101 MHz, Methylene Chloride-d $\left.\mathrm{d}_{2}\right) \delta 184.19,153.74$, 149.12 , 142.49, 136.79, 136.65, 133.95, 126.24, 126.08, 124.99, 124.96, 123.86, 121.99, 121.95, 121.75, 118.53, 107.15, 107.08, 107.03, 61.18, 56.76, 16.91. HRMS: calculated for $\mathrm{C}_{22} \mathrm{H}_{22} \mathrm{~N}_{3} \mathrm{O}_{4}[\mathrm{M}+\mathrm{H}]^{+}$392.1610, found 392.1615.

(2-(7-(benzyloxy)-1H-indol-3-yl)-1H-imidazol-4-yl)(3,4,5-

trimethoxyphenyl)methanone (10as). obtained as a yellowish solid. ${ }^{1} \mathrm{H}$ NMR $(400 \mathrm{MHz}$, Methylene Chloride- $\left.\mathrm{d}_{2}\right) \delta 9.29(\mathrm{~s}, 1 \mathrm{H}), 7.95(\mathrm{~d}, \mathrm{~J}=2.9 \mathrm{~Hz}, 1 \mathrm{H}), 7.90(\mathrm{~d}, \mathrm{~J}=8.1 \mathrm{~Hz}, 1 \mathrm{H})$, $7.84(\mathrm{~s}, 1 \mathrm{H}), 7.54-7.47(\mathrm{~m}, 2 \mathrm{H}), 7.44-7.33(\mathrm{~m}, 3 \mathrm{H}), 7.30(\mathrm{~s}, 2 \mathrm{H}), 7.15$ (t, J = $7.9 \mathrm{~Hz}$, $1 \mathrm{H}), 6.82(\mathrm{dd}, \mathrm{J}=7.8,0.7 \mathrm{~Hz}, 1 \mathrm{H}), 5.24(\mathrm{~s}, 2 \mathrm{H}), 3.90(\mathrm{~s}, 6 \mathrm{H}), 3.87(\mathrm{~s}, 3 \mathrm{H}) .{ }^{13} \mathrm{C} \mathrm{NMR}$ (101 MHz, Methylene Chloride- $\mathrm{d}_{2}$ ) $\delta 183.55,153.81,146.12,142.59,137.54,133.81$, 129.15, 128.74, 128.43, 127.78, 126.94, 125.29, 122.36, 114.16, 107.82, 107.07, 104.86, 70.93, 61.17, 56.81. HRMS: calculated for $\mathrm{C}_{28} \mathrm{H}_{26} \mathrm{~N}_{3} \mathrm{O}_{5}[\mathrm{M}+\mathrm{H}]^{+} 484.1872$, found 484.1868.

(2-(7-methoxy-1H-indol-3-yl)-1H-imidazol-4-yl)(3,4,5-

trimethoxyphenyl)methanone (10at). obtained as a yellowish solid. ${ }^{1} \mathrm{H}$ NMR $(400 \mathrm{MHz}$, Methylene Chloride- $\left.\mathrm{d}_{2}\right) \delta 7.88(\mathrm{~s}, 1 \mathrm{H}), 7.85-7.77(\mathrm{~m}, 2 \mathrm{H}), 7.28(\mathrm{~s}, 2 \mathrm{H}), 7.17(\mathrm{t}, \mathrm{J}=7.9$ $\mathrm{Hz}, 1 \mathrm{H}), 6.74(\mathrm{dd}, \mathrm{J}=7.9,0.8 \mathrm{~Hz}, 1 \mathrm{H}), 3.98(\mathrm{~s}, 3 \mathrm{H}), 3.91(\mathrm{~s}, 6 \mathrm{H}), 3.88(\mathrm{~s}, 3 \mathrm{H}) .{ }^{13} \mathrm{C} \mathrm{NMR}$ (101 MHz, Methylene Chloride- $\mathrm{d}_{2}$ ) $\delta 184.15,153.77,147.11,142.55,133.91,127.59$, 126.64, 125.67, 122.28, 113.43, 107.26, 107.12, 103.42, 61.20, 56.79, 56.01. HRMS: calculated for $\mathrm{C}_{22} \mathrm{H}_{22} \mathrm{~N}_{3} \mathrm{O}_{5}[\mathrm{M}+\mathrm{H}]^{+} 408.1559$, found 408.1556 .

(2-(4-hydroxy-1H-indol-3-yl)-1H-imidazol-4-yl)(3,4,5-

trimethoxyphenyl)methanone (10au). obtained as a yellowish solid. ${ }^{1} \mathrm{H}$ NMR (400 MHz, Methylene Chloride- $\left.\mathrm{d}_{2}\right) \delta 8.02(\mathrm{~s}, 1 \mathrm{H}), 7.72(\mathrm{~d}, \mathrm{~J}=3.4 \mathrm{~Hz}, 1 \mathrm{H}), 7.31-7.14(\mathrm{~m}$, $3 \mathrm{H}), 7.07$ (t, J = 7.5 Hz, 1H), 6.92 (d, J = 7.3 Hz, 1H), 6.58 (d, J = 7.7 Hz, 1H), 3.91 (s, $6 \mathrm{H}), 3.88(\mathrm{~s}, 3 \mathrm{H})$. HRMS: calculated for $\mathrm{C}_{21} \mathrm{H}_{20} \mathrm{~N}_{3} \mathrm{O}_{5}[\mathrm{M}+\mathrm{H}]^{+}$394.1403, found 394.1405.

(2-(5-hydroxy-1H-indol-3-yl)-1H-imidazol-4-yl)(3,4,5-

trimethoxyphenyl)methanone (10av). obtained as a yellowish solid. ${ }^{1} \mathrm{H}$ NMR (400 MHz, DMSO-d $\left.{ }_{6}\right) \delta 12.88(\mathrm{~d}, \mathrm{~J}=58.5 \mathrm{~Hz}, 1 \mathrm{H}), 11.48-10.98(\mathrm{~m}, 1 \mathrm{H}), 8.84(\mathrm{~d}, \mathrm{~J}=12.5$ $\mathrm{Hz}, 1 \mathrm{H}), 8.25$ (d, J = 2.8 Hz, 1H), 7.89 (d, J = 3.5 Hz, 1H), 7.83 (q, J = 2.0, $1.3 \mathrm{~Hz}, 1 \mathrm{H}$ ), 7.24 (dd, J = 8.6, $2.3 \mathrm{~Hz}, 1 \mathrm{H}), 7.18$ (s, 1H), 6.69 (ddd, J = 11.2, 8.7, $2.5 \mathrm{~Hz}, 1 \mathrm{H}), 3.84$ (dd, $\mathrm{J}=47.9,6.9 \mathrm{~Hz}, 9 \mathrm{H})$. HRMS: calculated for $\mathrm{C}_{21} \mathrm{H}_{20} \mathrm{~N}_{3} \mathrm{O}_{5}[\mathrm{M}+\mathrm{H}]^{+}$394.1403, found 394.1404. 
(2-(6-hydroxy-1H-indol-3-yl)-1H-imidazol-4-yl)(3,4,5-

trimethoxyphenyl)methanone (10aw). obtained as a yellowish solid. ${ }^{1} \mathrm{H}$ NMR (400 MHz, Methylene Chloride- $\left.\mathrm{d}_{2}\right) \delta 7.89(\mathrm{~s}, 1 \mathrm{H}), 7.79(\mathrm{~s}, 1 \mathrm{H}), 7.71(\mathrm{dd}, \mathrm{J}=8.0,0.9 \mathrm{~Hz}, 1 \mathrm{H})$, 7.27 (s, 2H), 7.09 (t, J = 7.9 Hz, 1H), 6.70 (dd, J = 7.7, $0.8 \mathrm{~Hz}, 1 \mathrm{H}), 3.92(\mathrm{~s}, 6 \mathrm{H}), 3.88$ (s, $3 \mathrm{H})$. HRMS: calculated for $\mathrm{C}_{21} \mathrm{H}_{20} \mathrm{~N}_{3} \mathrm{O}_{5}[\mathrm{M}+\mathrm{H}]^{+}$394.1403, found 394.1401.

\section{3-(4-(3,4,5-trimethoxybenzoyl)-1H-imidazol-2-yl)-1H-indole-6-carboxylic} acid (10ax). obtained as a yellowish solid. ${ }^{1} \mathrm{H}$ NMR (400 MHz, DMSO-d $\left.{ }_{6}\right) \delta 13.79-$ $13.14(\mathrm{~m}, 1 \mathrm{H}), 12.38(\mathrm{~d}, \mathrm{~J}=75.1 \mathrm{~Hz}, 1 \mathrm{H}), 8.83-8.41(\mathrm{~m}, 2 \mathrm{H}), 8.15(\mathrm{~s}, 1 \mathrm{H}), 8.10-7.84$ $(\mathrm{m}, 2 \mathrm{H}), 7.74(\mathrm{dd}, \mathrm{J}=13.7,8.4 \mathrm{~Hz}, 1 \mathrm{H}), 7.20(\mathrm{~s}, 1 \mathrm{H}), 3.86(\mathrm{dd}, \mathrm{J}=50.2,10.6 \mathrm{~Hz}, 9 \mathrm{H})$. HRMS: calculated for $\mathrm{C}_{22} \mathrm{H}_{20} \mathrm{~N}_{3} \mathrm{O}_{6}[\mathrm{M}+\mathrm{H}]^{+} 422.1352$, found 422.1355 .

(2-(1H-indol-2-yl)-1H-imidazol-4-yl)(3,4,5-trimethoxyphenyl)methanone (10ba). obtained as a yellowish solid. ${ }^{1} \mathrm{H}$ NMR (400 MHz, Chloroform-d) $\delta 10.31(\mathrm{~s}, 1 \mathrm{H})$, $8.18(\mathrm{~d}, \mathrm{~J}=7.7 \mathrm{~Hz}, 1 \mathrm{H}), 7.89(\mathrm{~s}, 1 \mathrm{H}), 7.63(\mathrm{t}, \mathrm{J}=8.9 \mathrm{~Hz}, 2 \mathrm{H}), 7.51(\mathrm{t}, \mathrm{J}=7.6 \mathrm{~Hz}, 1 \mathrm{H})$, $7.34(\mathrm{~d}, \mathrm{~J}=8.2 \mathrm{~Hz}, 1 \mathrm{H}), 7.27(\mathrm{~d}, \mathrm{~J}=4.9 \mathrm{~Hz}, 7 \mathrm{H}), 7.15(\mathrm{ddd}, \mathrm{J}=8.0,6.9,1.0 \mathrm{~Hz}, 1 \mathrm{H})$, $3.99(\mathrm{~s}, 3 \mathrm{H}), 3.91(\mathrm{~s}, 6 \mathrm{H}) .{ }^{13} \mathrm{C}$ NMR $\left(101 \mathrm{MHz}, \mathrm{DMSO}-\mathrm{d}_{6}\right) \delta 182.28,152.72,141.89$, $141.11,139.01,136.94,133.12,129.21,128.44,127.86,122.31,120.75,119.66,111.90$, 107.32, 106.16, 101.99, 100.14, 60.12, 56.00. HRMS: calculated for $\mathrm{C}_{21} \mathrm{H}_{20} \mathrm{~N}_{3} \mathrm{O}_{4}[\mathrm{M}+\mathrm{H}]^{+}$ 378.1454 , found 378.1458 .

(2-(1H-indol-4-yl)-1H-imidazol-4-yl)(3,4,5-trimethoxyphenyl)methanone (10bb). obtained as a yellowish solid. ${ }^{1} \mathrm{H}$ NMR (400 MHz, Chloroform-d) $\delta 11.06(\mathrm{~s}, 1 \mathrm{H})$, $8.80(\mathrm{~s}, 1 \mathrm{H}), 7.94(\mathrm{~s}, 1 \mathrm{H}), 7.69(\mathrm{~d}, \mathrm{~J}=7.4 \mathrm{~Hz}, 1 \mathrm{H}), 7.47(\mathrm{dt}, \mathrm{J}=8.2,0.9 \mathrm{~Hz}, 1 \mathrm{H}), 7.33(\mathrm{t}$, $\mathrm{J}=2.9 \mathrm{~Hz}, 2 \mathrm{H}), 7.26(\mathrm{~d}, \mathrm{~J}=1.7 \mathrm{~Hz}, 1 \mathrm{H}), 7.20(\mathrm{t}, \mathrm{J}=7.8 \mathrm{~Hz}, 1 \mathrm{H}), 3.96(\mathrm{~s}, 3 \mathrm{H}), 3.91(\mathrm{~s}$, 6H). ${ }^{13} \mathrm{C}$ NMR (101 MHz, Chloroform-d) $\delta 183.67,153.30,142.36,136.84,133.00$, 126.16, 125.49, 121.97, 120.82, 119.18, 113.41, 106.78, 102.88, 61.15, 56.45. HRMS: calculated for $\mathrm{C}_{21} \mathrm{H}_{20} \mathrm{~N}_{3} \mathrm{O}_{4}[\mathrm{M}+\mathrm{H}]^{+} 378.1454$, found 378.1453 .

\section{(2-(1H-indol-5-yl)-1H-imidazol-4-yl)(3,4,5-trimethoxyphenyl)methanone}

(10bc). obtained as a yellowish solid. ${ }^{1} \mathrm{H}$ NMR (400 MHz, Methylene Chloride-d $\left.\mathrm{d}_{2}\right) \delta 9.34$ $(\mathrm{s}, 1 \mathrm{H}), 8.28(\mathrm{~d}, \mathrm{~J}=1.6 \mathrm{~Hz}, 1 \mathrm{H}), 7.83(\mathrm{dd}, \mathrm{J}=8.6,1.7 \mathrm{~Hz}, 1 \mathrm{H}), 7.80(\mathrm{~s}, 1 \mathrm{H}), 7.51(\mathrm{~d}, \mathrm{~J}=$ $8.6 \mathrm{~Hz}, 1 \mathrm{H}), 7.31$ (dt, J = 2.7, $1.2 \mathrm{~Hz}, 1 \mathrm{H}), 7.26(\mathrm{~s}, 2 \mathrm{H}), 6.61(\mathrm{dt}, \mathrm{J}=3.0,1.3 \mathrm{~Hz}, 1 \mathrm{H})$, $3.91(\mathrm{~s}, 6 \mathrm{H}), 3.88(\mathrm{~s}, 3 \mathrm{H}) .{ }^{13} \mathrm{C}$ NMR $(101 \mathrm{MHz}$, Chloroform-d) $\delta 183.52,153.35,142.35$, 137.06, 133.13, 128.33, 125.77, 120.90, 120.78, 119.55, 111.83, 106.70, 103.64, 61.15, 56.43. HRMS: calculated for $\mathrm{C}_{21} \mathrm{H}_{20} \mathrm{~N}_{3} \mathrm{O}_{4}[\mathrm{M}+\mathrm{H}]^{+} 378.1454$, found 378.1459.

\section{(2-(1H-indol-6-yl)-1H-imidazol-4-yl)(3,4,5-trimethoxyphenyl)methanone} (10bd). obtained as a yellowish solid. ${ }^{1} \mathrm{H}$ NMR (400 MHz, Chloroform-d) $\delta 11.02(\mathrm{~s}, 1 \mathrm{H})$, $8.77(\mathrm{~s}, 1 \mathrm{H}), 7.95(\mathrm{~s}, 1 \mathrm{H}), 7.79-7.65(\mathrm{~m}, 1 \mathrm{H}), 7.49(\mathrm{~d}, \mathrm{~J}=8.1 \mathrm{~Hz}, 1 \mathrm{H}), 7.36(\mathrm{t}, \mathrm{J}=2.8$ $\mathrm{Hz}, 1 \mathrm{H}), 7.32-7.16(\mathrm{~m}, 4 \mathrm{H}), 3.97$ (s, 3H), 3.92 (s, 6H). ${ }^{13} \mathrm{C}$ NMR $(101 \mathrm{MHz}$, Chloroform-d) $\delta 183.29,153.36,151.90,142.38,138.95,136.83,132.97,131.17,126.23$, 125.52, 122.01, 120.72, 119.32, 113.51, 106.55, 102.84, 61.16, 56.45. HRMS: calculated for $\mathrm{C}_{21} \mathrm{H}_{20} \mathrm{~N}_{3} \mathrm{O}_{4}[\mathrm{M}+\mathrm{H}]^{+} 378.1454$, found 378.1453 . 


\section{(2-(1H-indol-7-yl)-1H-imidazol-4-yl)(3,4,5-trimethoxyphenyl)methanone}

(10be). obtained as a yellowish solid. ${ }^{1} \mathrm{H}$ NMR $(400 \mathrm{MHz}$, Chloroform-d) $\delta 8.58(\mathrm{~s}, 1 \mathrm{H})$, $8.24(\mathrm{~d}, \mathrm{~J}=7.5 \mathrm{~Hz}, 1 \mathrm{H}), 7.93(\mathrm{~d}, \mathrm{~J}=3.6 \mathrm{~Hz}, 1 \mathrm{H}), 7.87(\mathrm{dd}, \mathrm{J}=7.8,0.8 \mathrm{~Hz}, 1 \mathrm{H}), 7.72(\mathrm{~s}$, $2 \mathrm{H}), 7.60(\mathrm{t}, \mathrm{J}=7.7 \mathrm{~Hz}, 1 \mathrm{H}), 7.02(\mathrm{~d}, \mathrm{~J}=3.7 \mathrm{~Hz}, 1 \mathrm{H}), 3.97(\mathrm{~d}, \mathrm{~J}=0.9 \mathrm{~Hz}, 9 \mathrm{H}) .{ }^{13} \mathrm{C}$ NMR (101 MHz, Chloroform-d) $\delta$ 186.04, 153.10, 143.96, 143.25, 142.87, 142.05, 132.31, 132.01, 128.20, 125.87, 124.94, 123.97, 121.35, 120.31, 112.94, 110.91, 108.31, 61.14, 56.49. HRMS: calculated for $\mathrm{C}_{21} \mathrm{H}_{20} \mathrm{~N}_{3} \mathrm{O}_{4}[\mathrm{M}+\mathrm{H}]^{+} 378.1454$, found 378.1452 .

\section{Cell culture and reagents}

Human melanoma carcinoma cell lines A375, M14, and WM-164 (American Type Culture Collection or ATCC, Manassas, VA, USA) were cultured in Dulbecco's modified Eagle's medium (DMEM) (Corning, Manasas, VA) supplemented with 10\% (v/v) fetal bovine serum (FBS) (Atlanta Biologicals, Lawernceville, GA) and 1\% antibiotic/antimycotic mixture (Sigma-Aldrich, St. Louis MO). Murine melanoma B16F10 cells (ATCC, Manassas, VA, USA) were cultured in Minimum essential medium (Invitrogen, Carlsbad, CA), supplemented with 5\% heat-inactivated Hyclone FBS (Thermo Scientific, Rockford, IL), $1 \%$ antibiotic-antimycotic mixture (Sigma-Aldrich, St. Louis MO), 1\% Mem-sodium pyruvate (Invitrogen, Carlsbad, CA), 1\% Mem-vitamin (Invitrogen, Carlsbad, CA), L-Glutamine ( $2 \mathrm{mM}$ final concentration) (Invitrogen, Carlsbad, CA), and 1\% Mem NEAA (Invitrogen, Carlsbad, CA). All cell lines were authenticated by ATCC by short tandem repeat profiling. Cultures were maintained to $80-90 \%$ confluency at $37^{\circ} \mathrm{C}$ in a humidified atmosphere containing $5 \% \mathrm{CO}$. Compounds were dissolved in dimethyl sulfoxide (DMSO) (Sigma-Aldrich, St. Louis, MO) to make a stock solution of $20 \mathrm{mM}$. Compound solutions were freshly prepared by diluting stocks with cell culture medium before use.

\section{Cytotoxicity assay}

A375, M14, and WM-164 were seeded in 96-well plates at a concentration of $1,000-5,000$ cells per well, depending on growth rate of the cell line. After overnight incubation, the media was replaced and cells were treated with the test compounds at 10 concentrations ranging from $0.03 \mathrm{nM}$ to $1 \mu \mathrm{M}$ plus a vehicle control for $72 \mathrm{~h}$ in four replicates. Following treatment, the MTS reagent (Promega, Madison, WI) was added to the cells and incubated in dark at $37^{\circ} \mathrm{C}$ for at least 1 hour. Absorbance at $490 \mathrm{~nm}$ was measured using a plate reader (DYNEX Technologies, Chantilly VA). Percentages of cell survival versus drug concentrations were plotted, and the $\mathrm{IC}_{50}$ (concentration that inhibited cell growth by $50 \%$ of untreated control) values were obtained by nonlinear regression analysis using GraphPad Prism (GraphPad Software, San Diego, CA). 


\section{Chemistry}

ABI-231 belongs to the third generation of ABIs developed in our lab. It is composite of a 3,4,5-trimethoxybenzoyl moiety, a 3-indole moiety, as well as a imidazole linker. In the previous SAR studies of ABI-I/II and RABI scaffold, attempts to improve their antiproliferative activities against cancer cell lines by modifying the 3,4,5trimethoxybenzoyl moiety were not successful $[169,182,185,186]$. Considering the structural similarity between ABI-231 and ABI-I/II, we hypothesize that the 3,4,5trimethoxybenzoyl moiety is essential for the activity of ABI-231. Based on the molecular modeling result as shown in Figure 1-7, we also hypothesize that introduction of substituent to the indole can utilize the unoccupied pocket in the vicinity of the indole to enhance the binding affinity of the ABI-231 to tubulin protein. With these hypotheses in mind, we have synthesized ABI-231 analogues with modification of the indole moiety. Thirty new ABI-231 analogues are furnished.

The previously published synthetic method accessed ABI-231 by resorting to an imidazole formation/nucleophilic substitution strategy. This method provided ABI-231 with an overall yield of $0.28 \%$ over five steps, which is not amenable for SAR investigation of ABI-231. Hence, to investigate the SAR of ABI-231, it is of imperativeness to establish a synthetic method that can efficiently and rapidly generate ABI-231 and its analogues. Our proposed synthetic strategy is illustrated in Scheme 2-1. To construct the ABI-231 scaffold, we resort to imidazoline cyclization. The imidazoline can be formed from a diamine intermediate $\mathbf{6}$ and indolylcarboxyaldehydes according to a reported methodology [187]. We envisage that the imidazoline formation can provide resourceful ABI-231 analogues with modifications of the indole moiety because indolylcarboxyaldehydes are broadly commercially available. In this proposed method, accumulation of a large quantity of the diamine intermediate 6 is crucial.

Diamine 6 can be derived from alkene 1 through a series of well-known and highyielding functional group interconversions including Upjohn dihydroxylation, mesylation and hydrogenation. 6 was obtained in six steps as depicted in Scheme 2-2. Starting material 3,4,5-trimethoxybenzaldehyde was treated with Grignard reagent vinylmagnesium bromide to generate the racemic mixture $\mathbf{1}$, which was protected with TBS to give $\mathbf{2}$ ( $87 \%$ for 2 steps). 2 was then subjected to Upjohn reaction in the presence of a catalytic equivalent of $\mathrm{OsO}_{4}$ to form a mixture diastereoisomers 3 in $82 \%$ yield. Diazide 5 was synthesized in two steps by following reported procedures [188]: mesylation of the diol 3 yielded mesylates 4 in $86 \%$ yield; 4 was then refluxed with sodium azide in DMF carefully to give azides 5 in $67 \%$ yield. Hydrogenation of diazide 5 provided diamine 6 in $53 \%$ yield in the presence of $\mathrm{Pd} / \mathrm{C}(10 \%)$.

Synthesis of ABI-231 analogues with substituted 3-indolyls was outlined in Scheme 2-3. Indolecarboxyaldehyde was protected with Boc to give 7.7 then reacted with diamine $\mathbf{6}$ in the presence of $N$-bromosuccinimide in DCM at ice temperature to form imidazoline 8. 8 was subjected to the deprotection of TBS and Boc in the presence of TBAF and TFA to provide 9. Simultaneous oxidation of imidazoline and secondary 

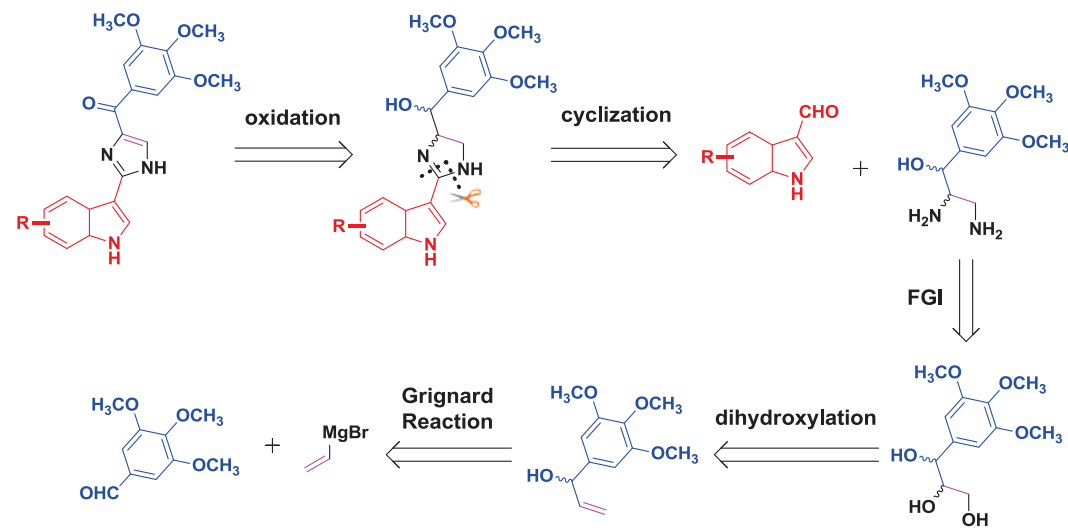

Scheme 2-1. Retrosynthetic analysis of ABI-231 and its analogues

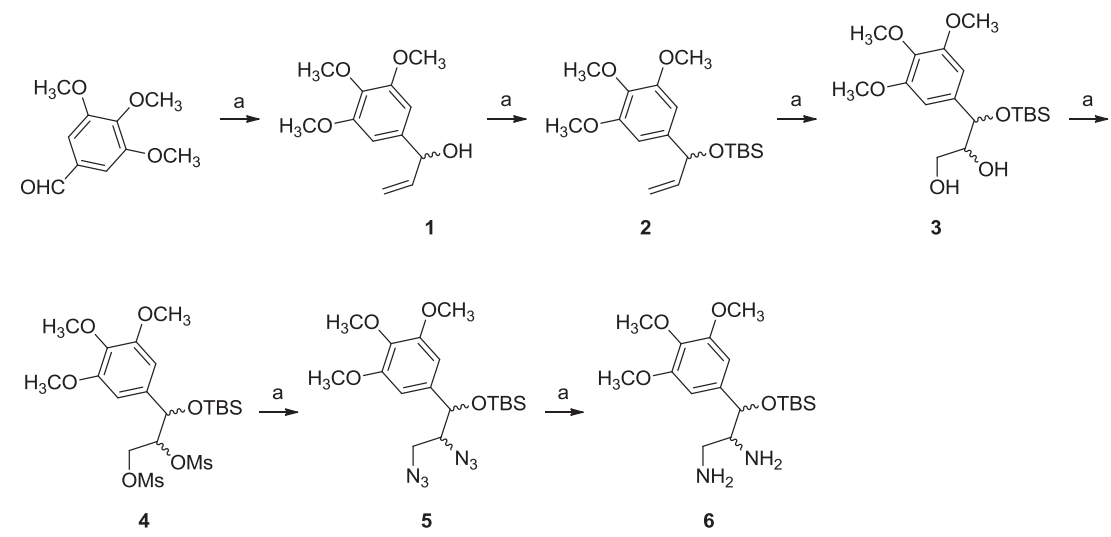

Scheme 2-2. Synthesis of the intermediate 6

Reagents and conditions: (a): vinylmagnesium bromide, THF, $0^{\circ} \mathrm{C}$ to rt; (b): tertbutyldimethylsilyl chloride, imidazole, $\mathrm{DCM}$, $\mathrm{rt}$; (c): $\mathrm{OsO}_{4}, \mathrm{NMO}$, Acetone/t- $\mathrm{BuOH}, \mathrm{rt}$; (d): $\mathrm{MsCl}$, TEA, DCM, rt; (e): $\mathrm{NaN}_{3}, \mathrm{DMF}$, reflux; (f): $\mathrm{H}_{2}, \mathrm{Pd} / \mathrm{C}$ (10\%), EtOAc-MeOH, rt. 


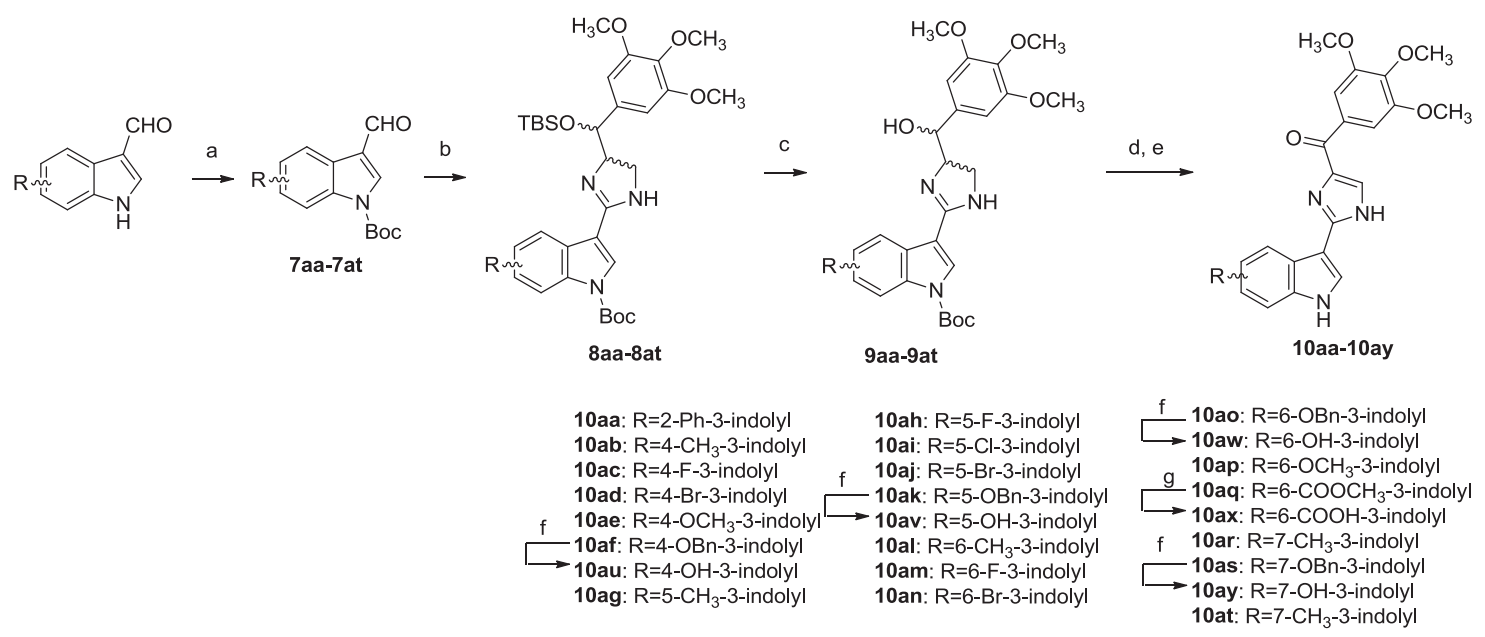

Scheme 2-3. Synthesis of ABI-231 analogues with 3-indolyls

Reagents and conditions: (a): (Boc) ${ }_{2} \mathrm{O}$, DMAP, DCM, rt; (b): NBS, DCM, $0^{\circ} \mathrm{C}$ to rt; (c): TBAF, THF, rt; (d): TFA, DCM, rt; (e): IBX, DMSO,rt; (f): $\mathrm{H}_{2}, \mathrm{Pd} / \mathrm{C}(10 \%)$, EtOAc$\mathrm{MeOH}(1: 1)$, rt; (g): $\mathrm{LiOH}$, Dioxane- $\mathrm{H}_{2} \mathrm{O}$, r.t; 10-20\% over 4 steps. 
alcohol in 9 to imidazole and carbonyl was accomplished in the presence of 3.0-5.0 equivalents of 2-iodoxybenzoic acid (IBX) by referring to a reported method, in which imidazoline was oxidized to imidazole using 1.0 equivalent of IBX [189]. Analogues of ABI-231 10a-10t were given in 10-20\% yield over four steps. Hydrogenation of 10af, 10ak, 10ao and 10as afforded 10au, 10av, 10aw and 10ay, respectively. Saponification of 10aq provided 10ax. Analogs 10ba-10be with indole rotation were synthesized by following similar procedures as outlined in Scheme 2-4.

In summary, we have established an efficient synthetic route for ABI-231 and its analogues. This novel method necessitated the synthesis of a key diamine intermediate 6 and imidazoline formation. 6 was obtained from commercially available 3,4,5trimethoxybenzaldehyde with an overall yield of $22 \%$ in six steps. Rapid generation of ABI-231 analogues modifying the indole moiety was successfully carried out through cyclization between 6 and commercially available indolylcarboxyaldehydes. Thirty ABI231 analogues were prepared from 6 in fours steps with an overall yield of 10-20\%.

\section{Results}

All analogues of ABI-231 were evaluated for their cytotoxicities in human melanoma cell lines including A375, WM1641 and M14. Colchicine was used as a positive control. ABI-231 was used as a prototype for comparison. The antiproliferative effects of the compounds were evaluated by MTT assay. $\mathrm{IC}_{50}$ s were reported in $\mathrm{nM}$ and calculated from at least three independent experiments, each performed in duplicates. Their in vitro growth inhibitory effects were shown in Table 2-1 and Table 2-2. ABI-231 had an average $\mathrm{IC}_{50}$ value of $7.0 \mathrm{nM}$ and was comparable to our previously reported data [169].

\section{In vitro growth inhibitory effects of $\mathrm{ABI}-231$ analogues with 3-indolyls}

Substitution at the 2-position of the indole ring. Compared to the prototype ABI-231, analogue 10aa with a bulky phenyl group on the 2-position of indole moiety showed markedly reduced activity. 10aa had an average $\mathrm{IC}_{50}$ value of more than $1 \mu \mathrm{M}$ against a panel of melanoma cell lines. This indicated that only small substituent on the indole can be tolerated. It is worthy noting that attempts to synthesize analogues with electron-donating functional groups on the 2-position of indole were not successful. For example, the reaction as depicted in Figure 2-2 was performed to obtain 2-methyl-3indole analogue. This reaction can only provide the target imidazoline in less than $10 \%$ yield. The low yield of this reaction is probably due to that the electron-donating property of the 2-methyl can attenuate reactivity of the 3-carboxaldehyde.

Substitution at the 4-position of the indole ring. Six analogues including 10ab-

10af and 10au were synthesized in this series. The best inhibitory effect was observed for 4-methyl analogue 10ab. 10ab exhibited 3-fold improvement of potency compared to 


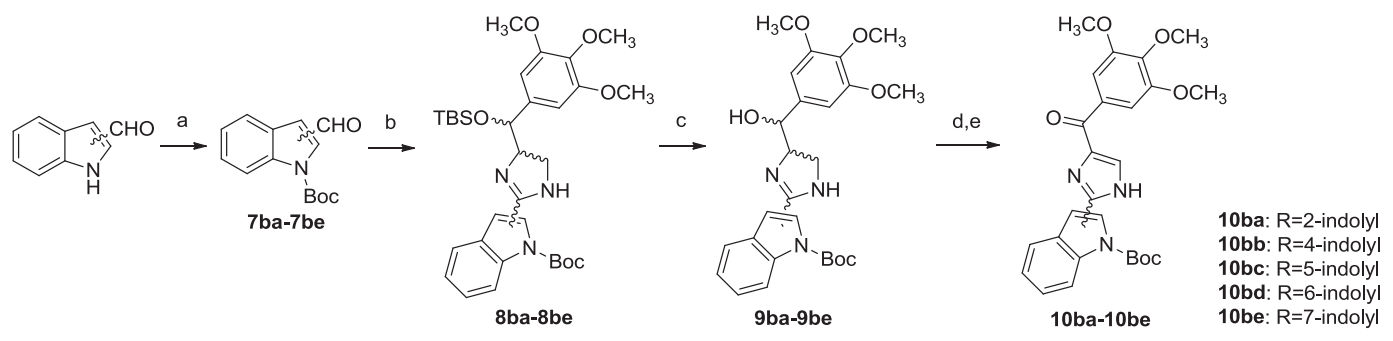

Scheme 2-4. Synthesis of ABI-231 analogues with rotation of indolyls

Reagents and condictions:(a): (Boc) ${ }_{2} \mathrm{O}$, DMAP, DCM, rt; (b): NBS, DCM, $0^{\circ} \mathrm{C}$ to rt; (c): TBAF, THF, rt; (d): TFA, DCM, rt; (e): IBX, DMSO, rt; 10-20\% over 4 steps. 
Table 2-1. In vitro growth inhibitory effects (nM) of ABI-231 analogues with 3indolyls $(\mathrm{n}=\mathbf{3})$

\begin{tabular}{|c|c|c|c|}
\hline Compound & A375 & M14 & WM164 \\
\hline $10 \mathrm{aa}$ & $>1000$ & $>1000$ & $>1000$ \\
\hline 10ab & $1.8 \pm 0.2$ & $1.7 \pm 0.2$ & $3.2 \pm 0.3$ \\
\hline 10ac & $7.2 \pm 0.7$ & $8.2 \pm 0.9$ & $44.5 \pm 15.6$ \\
\hline 10ad & $13.8 \pm 1.7$ & $10.4 \pm 1.2$ & $67.1 \pm 14.5$ \\
\hline 10ae & $>1000$ & $>1000$ & $>1000$ \\
\hline 10af & $>1000$ & $>1000$ & $>1000$ \\
\hline 10au & $9.2 \pm 1.4$ & $8.6 \pm 0.8$ & $19.1 \pm 1.8$ \\
\hline 10ag & $277.7 \pm 36.3$ & $177.4 \pm 16.3$ & $552.3 \pm 108.3$ \\
\hline 10ah & $19.2 \pm 1.5$ & $18.0 \pm 1.3$ & $80.9 \pm 16.6$ \\
\hline 10ai & $61.8 \pm 9.3$ & $64.9 \pm 4.3$ & $159.5 \pm 24.1$ \\
\hline 10aj & $164.2 \pm 16.7$ & $104.3 \pm 5.9$ & $441.7 \pm 110.0$ \\
\hline 10ak & $>1000$ & $>1000$ & $>1000$ \\
\hline $10 \mathrm{av}$ & $>1000$ & $>1000$ & $>1000$ \\
\hline 10al & $21.1 \pm 3.9$ & $21.7 \pm 4.7$ & $23.7 \pm 6.1$ \\
\hline $10 a m$ & $17.5 \pm 3.0$ & $5.8 \pm 0.8$ & $10.3 \pm 1.2$ \\
\hline 10an & $67.8 \pm 10.5$ & $41.2 \pm 7.5$ & $55.4 \pm 7.4$ \\
\hline $10 \mathrm{ao}$ & $>1000$ & $>1000$ & $>1000$ \\
\hline $10 a w$ & $>1000$ & $>1000$ & $>1000$ \\
\hline 10ap & $793.4 \pm 89.9$ & $879.8 \pm 88.2$ & $>1000$ \\
\hline $10 \mathrm{aq}$ & $>1000$ & 196.1 & $>1000$ \\
\hline $10 a x$ & $>1000$ & $>1000$ & $>1000$ \\
\hline 10ar & $13.1 \pm 1.3$ & $10.8 \pm 1.0$ & $61.3 \pm 11.0$ \\
\hline 10as & $>1000$ & $>1000$ & $>1000$ \\
\hline 10ay & $>1000$ & $>1000$ & $>1000$ \\
\hline 10at & $38.3 \pm 3.7$ & $34.1 \pm 3.5$ & $115.4 \pm 25.0$ \\
\hline ABI-231 & $8.1 \pm 1.6$ & $5.6 \pm 0.9$ & $7.2 \pm 0.9$ \\
\hline Colchicine & $14.1 \pm 2.2$ & $16.6 \pm 1.5$ & $10.8 \pm 1.9$ \\
\hline
\end{tabular}


Table 2-2. In vitro growth inhibitory effects ( $\mathrm{nM})$ of $\mathrm{ABI}-231$ analogues with rotation of indolyls $(n=3)$

\begin{tabular}{cccc}
\hline Compound & A375 & M14 & WM164 \\
\hline 10ba & $137.7 \pm 23.7$ & $72.3 \pm 7.8$ & $55.8 \pm 9.5$ \\
10bb & $3.6 \pm 1.0$ & $3.7 \pm 0.8$ & $1.6 \pm 0.3$ \\
10bc & $8.6 \pm 3.3$ & $18.5 \pm 3.7$ & $6.1 \pm 1.2$ \\
10bd & $8.0 \pm 1.0$ & $6.1 \pm 1.1$ & $3.8 \pm 0.5$ \\
10be & $285.5 \pm 28.7$ & $240.6 \pm 21.1$ & $435.8 \pm 38.3$ \\
ABI-231 & $8.1 \pm 1.6$ & $5.6 \pm 0.9$ & $7.2 \pm 0.9$ \\
\hline Colchicine & $14.1 \pm 2.2$ & $16.6 \pm 1.5$ & $10.8 \pm 1.9$ \\
\hline
\end{tabular}

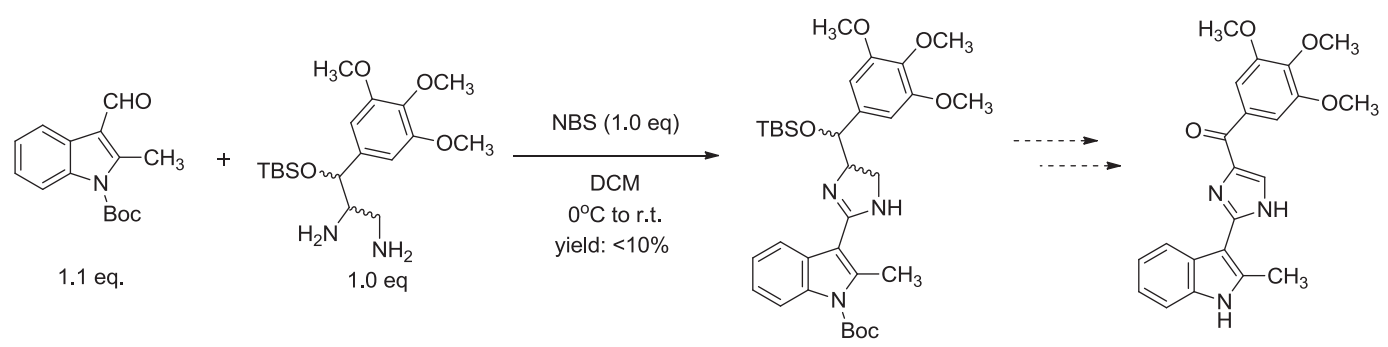

Figure 2-2. Synthesis of an intermediate for 2-methyl-3-indole ABI-231 analogue 
prototype $\mathrm{ABI}-231$ and had an average $\mathrm{IC}_{50}$ value of $2.2 \mathrm{nM}$ against three melanoma cell lines. Analogue 10ac with a small size halogen 4-F displayed equipotent antiproliferative activity to that of $\mathrm{ABI}-231$ and had an average $\mathrm{IC}_{50}$ value of $7.7 \mathrm{nM}$. In contrast, analogue 10ad having a large size halogen 4-bromo was 2-fold less potent than ABI-231 and had an average $\mathrm{IC}_{50}$ value of $12.1 \mathrm{nM}$. For analogues 10ae with a 4-methoxy group and 10af with a 4-benzoxy group, remarkable reduction of activity were observed. Their $\mathrm{IC}_{50} \mathrm{~S}$ were more than $1 \mu \mathrm{M}$. Analogue 10au that derived from deprotection of 10af showed restored antiproliferative activity from an average $\mathrm{IC}_{50}$ of more than $1 \mu \mathrm{M}$ to 12.3 $\mathrm{nM}$. These findings illustrated the importance of the size of substituent on 4-position, which strongly correlated with our hypothesis that only small functional groups can be accommodated in the pocket in the vicinity of the indole moiety.

Substitution at the 5-position of the indole ring. In this series, the best activity was observed in the 5-fluoro analogue 10ah. 10ah had an average $\mathrm{IC}_{50}$ of $39.4 \mathrm{nM}$. Analogue 10ak bearing a bulky benzyloxy showed completely lost antiproliferative activity. Overall, analogues with functional groups on 5-position of the indole in ABI-231 showed markedly decreased antiproliferative activities in comparison with 4-position substituted analogues. For example, 5-fluoro analogue 10ah and 5-bromo analogue 10aj were 2-fold and 10-fold less potent than 10ac and 10ad, respectively. 5-methyl analogue 10ag and 5-hydroxy analogue 10av possessed approximately 100-fold decreased antiproliferative activity compared to 10ab and 10au.

Substitution at the 6-position of the indole ring. In the series of 6-position substituted 3-indolyl analogues, the best activity was observed for the 6-fluoro analogue 10am, which had an average $\mathrm{IC}_{50}$ of $11.2 \mathrm{nM}$. Similar to the series of 4-position substituted and 5-position substituted 3-indolyl analogues, analogues with bulky substituents such as 10ao, 10ap, 10aq lost activities and all had $\mathrm{IC}_{50} \mathrm{~s}$ of more than $1 \mu \mathrm{M}$. For halogen functional groups, fluoro was more favorable than bromo. Hydrogenation of the benzyloxy to hydroxy on the 6-position did not provide any significant activity improvement (10aw). 6-methyl analogue 10al was 10-fold less potent than 4-methyl analogue 10ab whilst it displayed approximately 10-fold higher potency than 5-methyl analogue 10ag.

Substitution at the 7-position of the indole ring. Among the 7-postion substituted 3-indolyl analogues, 10ar with a methyl substitution possessed the most potent inhibitory effect (average $\mathrm{IC}_{50}=28.4 \mathrm{nM}$ ). Interestingly, 10at with a 7-methoxy substituent showed better anticancer activity (average $\mathrm{IC}_{50}=62.6 \mathrm{nM}$ ) than analogues with methoxy on the other positions in the indole moiety.

To summarize the SAR of analogues with 3-indolyls, small substituents (e.g. methyl, fluoro) benefits the inhibitory effect while bulky groups (e.g. phenyl, benzyloxy, methoxy, bromo) abolishes the antiproliferative activities. In terms of the substituting positions of the functional group on the indole, the activity trend follows: 4- > 7- > 6- > 5-postion. 


\section{In vitro growth inhibitory effects of $\mathrm{ABI}-231$ analogues with rotation of indolyls}

Hwang et al have disclosed a series of indolyl-imidazopyridines as CBSIs in 2015 [190]. Their SAR study revealed that replacing the 2-indole with 4-, 5- or 6-indole significantly affected the antiproliferative activities. In view of the structural similarity between ABI-231 and indolyl-imidazopyridines, we hypothesize that rotating the 3indole in ABI-231 to 2, 4, 5, 6, or 7-indole will have an influence on the activity. To test this hypothesis, five ABI-231 analogues were synthesized (Scheme 2-4) and their in vitro growth inhibitory effects were shown in Table 2-2. In this series, 5- and 6-indolyl analogues $10 \mathrm{bc}$ and $\mathbf{1 0 b d}$ showed comparable antiproliferative activities to that of ABI231 and had average $\mathrm{IC}_{50} \mathrm{~s}$ of 11.1 and $6.0 \mathrm{nM}$, respectively. 2- and 7-indolyl analogues 10ba and 10be were significantly less potent than ABI-231. 10ba and 10be both had $\mathrm{IC}_{50} \mathrm{~S}$ of more than $100 \mathrm{nM}$. Replacement of the 3-indolyl in ABI-231 with 4-indolyl resulted in 10bb. 10bb showed approximately 1-fold improvement of activity compared to $\mathrm{ABI}-231$ and had an average $\mathrm{IC}_{50}$ of $3.0 \mathrm{nM}$ against three melanoma cell lines.

To summarize the SAR of analogues with "indole rotation", rotating the indole in ABI-231 affects the antiproliferative activities. Among 10ba-10be and ABI-231, 4-indole analogue $10 \mathrm{bb}$ shows the most potent activity and has an average $\mathrm{IC}_{50}$ of $3.0 \mathrm{nM}$.

\section{Discussion}

Previously, our group has disclosed ABI-231 as a potent tubulin inhibitor. ABI231 showed antiproliferative activity in the nanomolar range. Importantly, ABI-231 was not a substrate of P-gp and was effective to inhibit the expression of $\beta$-III tubulin isotype. Therefore, ABI-231represents a promising scaffold. According to the published molecular modeling result of ABI-231, we hypothesize that introduction of a small substituent to the indole moiety on ABI-231 may strengthen its binding affinity to tubulin protein. We also hypothesize that rotation of the indole in ABI-231 will affect the activity based on the SAR result of indolyl-imidazopyridines published by Hwang et al.

To overcome the earlier limitations, a novel synthetic method is established for ABI-231 and its analogues. In this method, the core structure of ABI is furnished through an imidazoline formation from a crucial diamine intermediate and commercially available indolylcarboxyaldehydes; simultaneous oxidation of the alcohol and imidazoline to 4carbonylimidazole in the presence of IBX is firstly reported. This new method is amicable for a gram-scale synthesis of ABI-231 and can rapidly generate ABI-231 analogues for SAR investigation. Thirty new ABI-231 analogues are accomplished from the newly established synthetic method. The SAR result demonstrates that small substituent such as methyl or fluoro is favorable, which is highly correlated with our hypothesis that only small functional group can be accommodated in the target pocket. Among the thirty analogues, 10ab (4-methyl-3-indolyl analogue) and 10bb (4-indolyl analogue) exhibit the most potent antiproliferative activities and have average $\mathrm{IC}_{50} \mathrm{~s}$ of 2.2 and $3.0 \mathrm{nM}$, respectively. 
The X-ray crystal structure of the most potent analogue 10ab in complex with tubulin has been successfully obtained by our collaborators at Sichuan University in China. The crystallographic data and structure refinement statistics for 10ab is shown in Table 2-3. The co-crystal structure of 10ab in complex with tubulin is shown in Figure 2-3. The result shows that $\mathbf{1 0 a b}$ binds to the colchicine binding site locating at the interface of $\alpha$ and $\beta$-tubulin heterodimers. 10ab forms three $\mathrm{H}$-bond interactions with tubulin: the carbonyl with the residue $\beta$-Asp249 in a distance of $3.4 \AA$; the imidazole NH with the residue $\alpha$-Thr179 in a distance of $2.9 \AA$; indole NH with residue $\beta$-Asn 347 through a water "bridge". The crystal structure suggests that a methylene or NH between the indole and imidazole moiety may force the indole moiety to move toward the $\beta$ Asn347 residue. This movement may allow the formation of a direct H-bond interaction between the indole and $\beta$-Asn347 without resorting to a water "bridge". This is worthy investigating in future effort on structural modification of ABI-231.

In conclusion, we have established an efficient synthetic method for ABI-231 analogues modifying the indole moiety. Thirty new ABI-231 analogues have been synthesized. The most potent analogue 10ab has an average $\mathrm{IC}_{50}$ of $2.2 \mathrm{nM}$ and is 3.2fold more potent than ABI-231. 
Table 2-3. Crystallographic data and structure refinement statistics for 10ab

\begin{tabular}{|c|c|}
\hline Ligand & 10ab \\
\hline X-ray source & SSRF-BL19U1 \\
\hline \multicolumn{2}{|c|}{ Data collection } \\
\hline Wavelength (§) & 0.97853 \\
\hline Resolution range $(\AA)$ & $50-2.80(2.85-2.80)^{\mathrm{a}}$ \\
\hline Space group & P 212121 \\
\hline Unit cell $\left(\AA,{ }^{\circ}\right)$ & $105.2,157.0,182.6$ \\
\hline Total reflections & 503678 \\
\hline Unique reflections & 75002 \\
\hline Multiplicity & $6.7(6.3)$ \\
\hline Completeness (\%) & $100(100)$ \\
\hline Mean I/sigma (I) & $19.3(3.0)$ \\
\hline Rmerge & $0.109(0.576)$ \\
\hline \multicolumn{2}{|c|}{ Structure refinement } \\
\hline R-factor/ R-free ${ }^{b}$ & $0.2174 / 0.2567$ \\
\hline RMS (bonds) & 0.007 \\
\hline RMS (angles) & 1.205 \\
\hline No. of atoms & 17520 \\
\hline Macromolecules & 17435 \\
\hline Ligand & 60 \\
\hline Waters & 25 \\
\hline Average B-factor & 55.92 \\
\hline Macromolecules & 55.91 \\
\hline Ligands (TAJ) & 62.6 \\
\hline Waters & 44.0 \\
\hline \multicolumn{2}{|c|}{ Ramachandran plot statistics } \\
\hline Most favored regions (\%) & 92.3 \\
\hline Allowed regions (\%) & 7.5 \\
\hline Generously allowed regions (\%) & 0.2 \\
\hline Disallowed regions (\%) & 0.0 \\
\hline
\end{tabular}

Note: ${ }^{\mathrm{a}}$ The values for the data in the highest resolution shell are shown in parentheses.

${ }^{\mathrm{b}} \mathrm{R}$-free $=\sum$ Test || Fobs $|-|$ Fcalc ||$/ \sum$ Test $\mid$ Fobs $\mid$, where “Test" is a test set of about 5\% of the total reflections randomly chosen and set aside prior to refinement for the structure. 


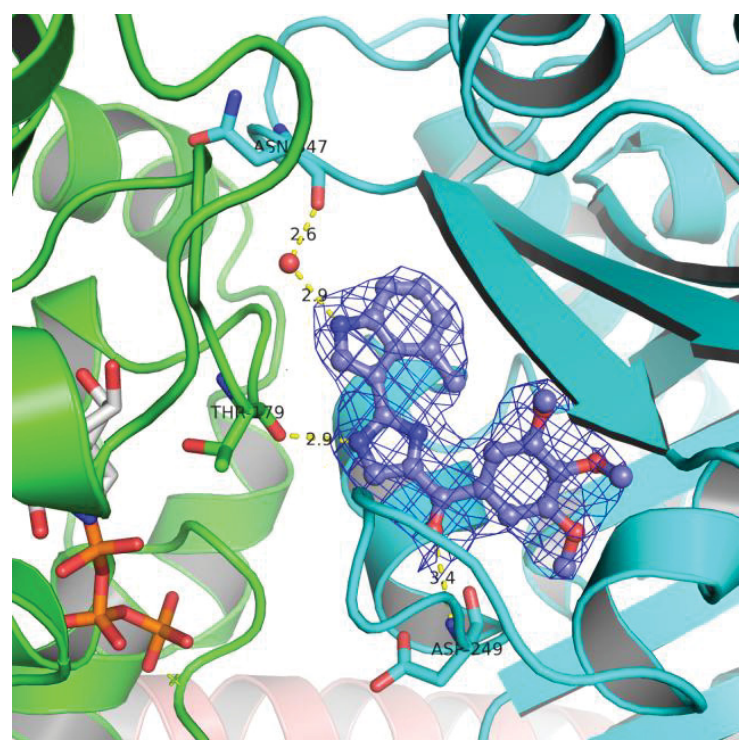

Figure 2-3. Co-crystal structure of 10ab in complex with tubulin 


\section{CHAPTER 3. STRUCTURAL MODIFICATION OF THE 3,4,5- TRIMETHOXYPHENYL MOIETY IN ABI-231 LEADS TO IMPROVED ANTIPROLIFERATIVE ACTIVITIES}

\section{Introduction}

Inhibition of microtubules assembly from $\alpha$ and $\beta$-tubulin heterodimers is an attractive and effective target for developing anticancer therapy. MTAs interrupt the cell cycle and result in mitotic arrest at the metaphase/anaphase transition, and eventually induce apoptosis of cancer cells [91, 191]. Although MTAs have achieved great success in cancer treatment, acquired drug-resistance represented a significant obstacle [88]. Therefore, MTAs that are able to surmount multidrug-resistance mechanisms is imperatively needed for treatment of resistant phenotypes.

CBSIs have shown significant abilities to overcome P-gp or MRP-mediated drug resistance $[99,102]$. A number of CBSIs are also proven to effectively inhibit the overexpression of tubulin $\beta$-III isotype in cancer cells [100]. Thus, colchicine binding site in tubulin represents a promising therapeutic target. Some of the notable examples of CBSIs are outlined in Figure 3-1. Of these CBSIs, they share a common moiety, 3,4,5trimethoxyphenyl (3,4,5-TMP). 3,4,5-TMPs are structurally crucial for many CBSIs to exert their maximum antiproliferative activities [101, 102, 192, 193]. Attempts to modify 3,4,5-TMPs are reported not successful. In colchicine and its derivatives, 3,4,5-TMPs play important roles in increasing the binding affinities and maintaining the suitable molecular conformations [194]. 3,4,5-TMPs in CA-4 and its derivatives are also indispensable in a similar manner. Structural modifications of CA-4 and its derivatives are mainly performed on either the double bond linkage or the 3-hydroxy-4methoxyphenyl moiety, but rarely on the 3,4,5-TMP moiety [101].

In the search for novel MTAs, we have previously described the discovery of a 2aryl-4-benzoyl-imidazole (ABI-I) pharmacophore that had desirable drug-like properties and exhibited potent antiproliferative activity against a panel of cancer cell lines [182]. Subsequent structural modifications of the benzoyl moiety, the aryl moiety, as well as the imidazole fragment in the ABI-I scaffold, result in other pharmacophores, including ABIIIs, ABI-IIIs, RABIs, and IIPs. ABI-231 belongs to ABI-IIIs and had an indole moiety. It shows the most potent antiproliferative activity and had an average $\mathrm{IC}_{50}$ value of $5.2 \mathrm{nM}$ against a panel of cancer cell lines $[169,183,185,190]$. ABI-231 is not a substrate of P$\mathrm{gp}$ and displays a dramatic effect in inhibiting tubulin $\beta$-III isotype in a pancreatic cancer cell model with overexpression of different $\beta$-tubulin isotypes (unpublished data). ABI231 , therefore, is of great promise for developing anticancer therapy.

In Chapter 2, the co-crystal structure of the most potent 4-methyl-3-indole analogue in complex with tubulin suggests that there are extensive H-bond interactions between each moiety of the ABI-231 with the tubulin protein except for the 3,4,5-TMP moiety. The crystal structure also reveals that there is a methionine residue nearby the 


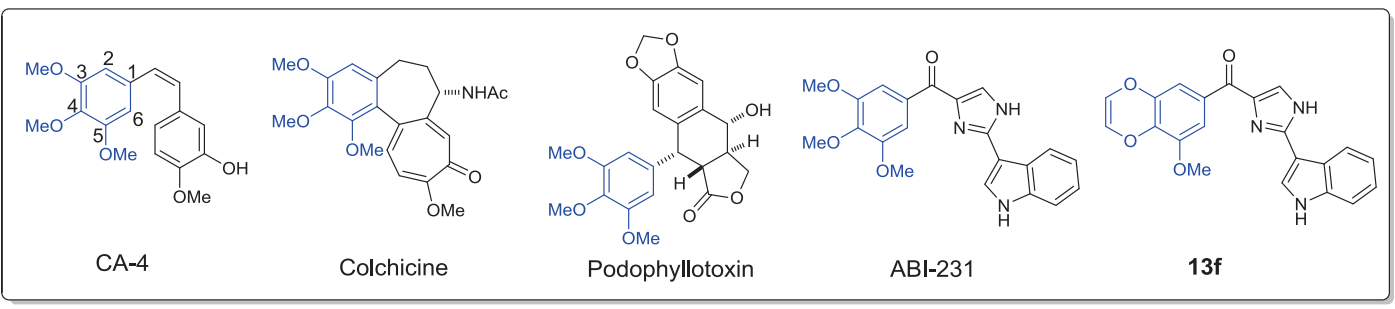

Figure 3-1. Examples of microtubule inhibitors with 3,4,5-TMP moieties targeting colchicine binding sites in tubulin 
3,4,5-TMP moiety. We hypothesize that optimization of the 3,4,5-TMP moiety in ABI231 can potentially introduce a hydrophobic interaction to the methionine residue in tubulin. With this hypothesis, we have carried out the SAR investigation of ABI-231 by modifying the 3,4,5-TMP moiety. In this chapter, we will disclose the establishment of a novel synthetic route to ABI-231 analogues modifying the 3,4,5-TMP moiety. This synthetic method involves a Suzuki coupling/Grignard reaction strategy and can efficiently generate ABI-231 analogues in gram-scale. This novel method can circumvent the involvement of potentially explosive azide reported in the last chapter. Among the eight synthesized ABI-231 analogues, the one containing a unique 3-methoxybenzo[4,5]dioxene moiety exhibits the strongest antiproliferative activity against a panel of melanoma cell lines and has an average $\mathrm{IC}_{50}$ of $1.9 \mathrm{nM}$. To our best knowledge, it represents the most successful instance of modifying the 3,4,5-TMP moiety in CA-4 derivatives isosterically. Currently, the mechanistic study and in vivo efficacy evaluation of these novel ABI-231 analogues are undergoing.

\section{Experimental Section}

\section{General chemistry}

Tetrahydrofuran was distilled from sodium-benzophenone. All other solvents and chemical reagents were obtained from commercial sources and directly used without further purification. Glassware was oven-dried before use. All reactions were performed under an argon atmosphere. TLC was performed on silica gel 60 GF254 and monitored under UV light or visualized using phosphomolybdic acid reagent. Flash chromatography was performed on 230-400 mesh silica gel (Fisher Scientific). Melting points were recorded on a MPA100 Automated Melting Point Apparatus. NMR spectra were obtained on a Bruker Ascend 400 (Billerica, MA) spectrometer or a Varian Inova-500 spectrometer (Agilent Technologies, Santa Clara, CA). HR-MS were obtained on Waters Acquity UPLC linked to Waters Acquity Photodiode Array Detector and Waters Acquity Single Quadrupole Mass Detector. Chemical shifts are given in ppm with tetramethylsilane (TMS) as an internal reference. All coupling constants $(J)$ are given in Hertz $(\mathrm{Hz})$.

\section{Chemical synthesis}

General procedure for synthesis of alkylated methyl benzoate 1a, $1 \mathrm{~b}$ and 4 . To a solution of the methyl 3-methoxy-4,5-dihydroxybenzoate $(2.5 \mathrm{mmol})$ in acetonitrile $(10 \mathrm{~mL})$ was added potassium carbonate $(6.0 \mathrm{mmol})$ and dibromomethane $(2.75 \mathrm{mmol})$ or 1,3-dibromopropane $(2.75 \mathrm{mmol})$ or allyl bromide $(6.0 \mathrm{mmol})$. The mixture was reflux for overnight and then cooled to room temperature; the precipitate was filtered off and washed with dichloromethane. The combined filtration was evaporated under vacuum to give the oily crude which was further purified with flash chromatography on silica. 
Elution with hexane/ethyl acetate (5:1-2:1) gave 1a, 1b and $\mathbf{4}$ as colorless oil (yields: $42 \%$ for $\mathbf{1 a}, 36 \%$ for $\mathbf{1 b}$ and $93 \%$ for $\mathbf{4}$ ).

Methyl 7-methoxybenzo[d][1,3]dioxole-5-carboxylate (1a). ${ }^{1} \mathrm{H}$ NMR (400 MHz, Chloroform-d) $\delta 7.32$ (d, J = 1.4 Hz, 1H), 7.19 (d, J = 1.4 Hz, 1H), 6.04 (s, 2H), $3.93(\mathrm{~s}, 3 \mathrm{H}), 3.87(\mathrm{~s}, 3 \mathrm{H})$. HRMS: calculated for $\mathrm{C}_{10} \mathrm{H}_{11} \mathrm{O}_{5}[\mathrm{M}+\mathrm{H}]^{+}$211.0606, found 211.0607.

Methyl 9-methoxy-3,4-dihydro-2H-benzo[b][1,4]dioxepine-7-carboxylate (1b). ${ }^{1} \mathrm{H}$ NMR (400 MHz, Chloroform-d) $\delta 7.31$ (d, J = 2.0 Hz, 1H), 7.25 (d, J = 2.0 Hz, 1H), $4.39-4.22(\mathrm{~m}, 6 \mathrm{H}), 3.88(\mathrm{~s}, 3 \mathrm{H}), 2.22(\mathrm{q}, \mathrm{J}=5.8 \mathrm{~Hz}, 2 \mathrm{H}), 1.35(\mathrm{t}, \mathrm{J}=7.1 \mathrm{~Hz}, 3 \mathrm{H})$. HRMS: calculated for $\mathrm{C}_{12} \mathrm{H}_{15} \mathrm{O}_{5}[\mathrm{M}+\mathrm{H}]^{+} 239.0919$, found 239.0917 .

Methyl 3,4-bis(allyloxy)-5-methoxybenzoate (4). ${ }^{1} \mathrm{H}$ NMR (400 MHz, Chloroform-d) $\delta 7.27(\mathrm{~s}, 2 \mathrm{H}), 6.12-5.99(\mathrm{~m}, 2 \mathrm{H}), 5.42(\mathrm{dq}, \mathrm{J}=17.3,1.6 \mathrm{~Hz}, 1 \mathrm{H}), 5.34-$ $5.24(\mathrm{~m}, 2 \mathrm{H}), 5.17$ (ddt, J = 10.3, 1.9, $1.1 \mathrm{~Hz}, 1 \mathrm{H}), 4.59$ (ddt, $\mathrm{J}=6.1,5.0,1.5 \mathrm{~Hz}, 4 \mathrm{H})$, $3.87(\mathrm{~d}, \mathrm{~J}=0.7 \mathrm{~Hz}, 6 \mathrm{H})$. HRMS: calculated for $\mathrm{C}_{15} \mathrm{H}_{19} \mathrm{O}_{5}[\mathrm{M}+\mathrm{H}]^{+} 279.1232$, found 279.1236.

General procedure for the synthesis of benzoic acids $2 \mathrm{a}, \mathbf{2 b}$ and 7 . To a solution of the methyl benzoate $\mathbf{1 a}, \mathbf{1 b}$ or $\mathbf{6}(1.0 \mathrm{mmol})$ in dioxane $(5 \mathrm{~mL})$ was added solution of lithium hydroxide $(1.5 \mathrm{mmol})$ in water $(3 \mathrm{ml})$. The mixture was stirred at $50^{\circ} \mathrm{C}$ until the TLC indicated the completion of the reaction. The solvents were removed under reduced pressure and the resulted residue was partitioned between water $(10 \mathrm{ml})$ and $\mathrm{DCM}(10 \mathrm{ml}), \mathrm{pH}$ value was adjusted to 5 using $1 \mathrm{M} \mathrm{HCl}$ solution. The organic solvents were then combined, dried over $\mathrm{Na} 2 \mathrm{SO} 4$, filtered and evaporated under reduced pressure. The crude was purified with flash chromatography on silica. Elution with hexane/ethyl acetate (4:1-1:1) gave $\mathbf{2 a}, \mathbf{2 b}$ and 7 as colorless oil (yields: $88 \%$ for $\mathbf{2 a}, 91 \%$ for $\mathbf{2 b}$ and $84 \%$ for 7$)$.

7-methoxybenzo[d][1,3]dioxole-5-carboxylic acid (2a). ${ }^{1} \mathrm{H}$ NMR (400 MHz, Acetone- $\left.\mathrm{d}_{6}\right) \delta 11.11(\mathrm{~s}, 1 \mathrm{H}), 7.34(\mathrm{~d}, \mathrm{~J}=1.5 \mathrm{~Hz}, 1 \mathrm{H}), 7.15(\mathrm{~d}, \mathrm{~J}=1.5 \mathrm{~Hz}, 1 \mathrm{H}), 6.10$ (s, $2 \mathrm{H}), 3.93(\mathrm{~s}, 3 \mathrm{H})$. HRMS: calculated for $\mathrm{C}_{9} \mathrm{H}_{9} \mathrm{O}_{5}[\mathrm{M}+\mathrm{H}]^{+}$197.0450, found 197.0451.

9-methoxy-3,4-dihydro-2H-benzo[b][1,4]dioxepine-7-carboxylic acid (2b). ${ }^{1} \mathrm{H}$ NMR (400 MHz, Chloroform-d) $\delta 10.87$ (s, 1H), 7.39 (d, J = 2.0 Hz, 1H), 7.31 (d, J = 2.0 $\mathrm{Hz}, 1 \mathrm{H}), 4.41(\mathrm{t}, \mathrm{J}=5.8 \mathrm{~Hz}, 2 \mathrm{H}), 4.29(\mathrm{t}, \mathrm{J}=5.9 \mathrm{~Hz}, 2 \mathrm{H}), 3.90(\mathrm{~s}, 3 \mathrm{H}), 2.25$ (p, J = 5.8 $\mathrm{Hz}, 2 \mathrm{H})$. HRMS: calculated for $\mathrm{C}_{11} \mathrm{H}_{13} \mathrm{O}_{5}[\mathrm{M}+\mathrm{H}]^{+}$225.0763, found 225.0765.

8-methoxybenzo[b][1,4]dioxine-6-carboxylic acid (7). ${ }^{1} \mathrm{H}$ NMR $(400 \mathrm{MHz}$, Acetone- $\left.\mathrm{d}_{6}\right) \delta 7.25(\mathrm{~d}, \mathrm{~J}=1.8 \mathrm{~Hz}, 1 \mathrm{H}), 6.91(\mathrm{~d}, \mathrm{~J}=1.8 \mathrm{~Hz}, 1 \mathrm{H}), 6.15(\mathrm{~d}, \mathrm{~J}=3.6 \mathrm{~Hz}, 1 \mathrm{H})$, $6.12(\mathrm{~d}, \mathrm{~J}=3.6 \mathrm{~Hz}, 1 \mathrm{H}), 3.86(\mathrm{~s}, 3 \mathrm{H})$. HRMS: calculated for $\mathrm{C}_{10} \mathrm{H}_{9} \mathrm{O}_{5}[\mathrm{M}+\mathrm{H}]^{+}$209.0450, found 209.0447 .

General procedure for synthesis of benzoyl chloride $\mathbf{3 a}, \mathbf{3 b}$ and 8 . To a solution of the benzoic acid $\mathbf{2 a}, \mathbf{2 b}$ or $\mathbf{7}(0.8 \mathrm{mmol})$ in DCM $(5 \mathrm{~mL})$ was added thionyl 
chloride $(1.5 \mathrm{ml})$. The mixture was stirred at $50^{\circ} \mathrm{C}$ for 3 hours. The solvents were then removed under reduced pressure and the corresponding crude benzoyl chloride was directly used for next step.

\section{Synthesis of methyl methyl 3-methoxy-4,5-bis(prop-1-en-1-yloxy)benzoate} (5). To a solution of 4 (279 $\mathrm{mg}, 1.0 \mathrm{mmol})$ in toluene $(5 \mathrm{~mL})$ was added carbonylchlorohydridotris(triphenylphosphine)ruthenium(II) $(95 \mathrm{mg}, 0.1 \mathrm{mmol})$. The mixture was refluxed for $36 \mathrm{hr}$. Water was then added and the reaction mixture was extracted with ethyl acetate, washed with brine and dried with anhydrous $\mathrm{Na}_{2} \mathrm{SO}_{4}$. The combined extracts were evaporated under vacuum to give crude product which was purified with flash chromatography on silica. Elution with hexane/ethyl acetate (8:1-3:1) gave 5 as colorless oil (218 mg, 78\%). ${ }^{1} \mathrm{H}$ NMR (400 MHz, Chloroform- $d$ ) $\delta 7.35(\mathrm{~s}, 2 \mathrm{H})$, $6.47-6.11(\mathrm{~m}, 2 \mathrm{H}), 5.44-4.60(\mathrm{~m}, 2 \mathrm{H}), 3.90(\mathrm{~d}, J=2.0 \mathrm{~Hz}, 6 \mathrm{H}), 1.80-1.55(\mathrm{~m}, 6 \mathrm{H})$. HRMS: calculated for $\mathrm{C}_{15} \mathrm{H}_{19} \mathrm{O}_{5}[\mathrm{M}+\mathrm{H}]^{+} 279.1232$, found 279.1234 .

Synthesis of methyl 8-methoxybenzo[b][1,4]dioxine-6-carboxylate (6). To a solution of $5(200 \mathrm{mg}, 0.72 \mathrm{mmol})$ in toluene $(5 \mathrm{~mL})$ was added Grubbs ` catalyst $2^{\text {nd }}$ generation ( $95 \mathrm{mg}, 0.072 \mathrm{mmol}$ ). The mixture was refluxed for $24 \mathrm{hr}$. Water was then added and the reaction mixture was extracted with ethyl acetate, washed with brine and dried with anhydrous $\mathrm{Na}_{2} \mathrm{SO}_{4}$. The combined extracts were evaporated under vacuum to give crude product which was purified with flash chromatography on silica. Elution with hexane/ethyl acetate (8:1-3:1) gave 6 as colorless oil (131 mg, 82\%). ${ }^{1} \mathrm{H}$ NMR (400 MHz, Chloroform- $d$ ) $\delta 7.14(\mathrm{~d}, J=1.9 \mathrm{~Hz}, 1 \mathrm{H}), 6.89(\mathrm{~d}, J=1.9 \mathrm{~Hz}, 1 \mathrm{H}), 5.91$ (d, $J=3.6$ $\mathrm{Hz}, 1 \mathrm{H}), 5.83(\mathrm{~d}, J=3.6 \mathrm{~Hz}, 1 \mathrm{H}), 3.81(\mathrm{~d}, J=0.9 \mathrm{~Hz}, 6 \mathrm{H})$. HRMS: calculated for $\mathrm{C}_{11} \mathrm{H}_{11} \mathrm{O}_{5}[\mathrm{M}+\mathrm{H}]^{+}$223.0606, found 223.0607.

Synthesis of 2,4,5-tribromo-1-((2-(trimethylsilyl)ethoxy)methyl)-1Himidazole (9). To a stirred solution of 2,4,5-tribromoimidazole $(9.5 \mathrm{~g}, 31.1 \mathrm{mmol})$ in anhydrous THF $(100 \mathrm{~mL})$ at ice temperature was added sodium hydride $(1.5 \mathrm{~g}, 40.6$ mmol) in portions under argon. The mixture was stirred for $1 \mathrm{hr}$ at this temperature and was added 2-(trimethylsilyl)ethoxymethyl chloride $(6.7 \mathrm{ml}, 35.8 \mathrm{mmol})$ dropwise. Reaction was then warmed to room temperature and stirred for another $1.5 \mathrm{hr}$. Water was then added at ice temperature carefully and the reaction mixture was extracted with ethyl acetate, washed with brine and dried with $\mathrm{Na}_{2} \mathrm{SO}_{4}$. The combined extracts were evaporated under vacuum to give the oily residue which was purified with flash chromatography on silica. Elution with hexane/ethyl acetate (10:0-10:1) gave 9 as slightly yellowish solid (12.6 g, 93\%). ${ }^{1} \mathrm{H}$ NMR (400 MHz, Chloroform-d) $\delta 5.30(\mathrm{~s}, 2 \mathrm{H})$, $3.65-3.49(\mathrm{~m}, 2 \mathrm{H}), 0.94-0.87(\mathrm{~m}, 2 \mathrm{H}),-0.03(\mathrm{~s}, 9 \mathrm{H})$. HRMS: calculated for $\mathrm{C}_{9} \mathrm{H}_{16} \mathrm{Br}_{3} \mathrm{~N}_{2} \mathrm{OSi}[\mathrm{M}+\mathrm{H}]^{+}$432.8582, found 432.8588 .

Synthesis of 10 and 16. To a mixture of 1-(Phenylsulfonyl)-3-indolylboronic acid pinacol ester $(5.0 \mathrm{~g}, 13.1 \mathrm{mmol})$ or $\mathbf{1 5}, 9(6.8 \mathrm{~g}, 15.7 \mathrm{mmol})$, and sodium carbonate $(2.8$ $\mathrm{g}, 26.1 \mathrm{mmol})$ in toluene $(50 \mathrm{ml})$, methanol $(5 \mathrm{ml})$ and $(2.5 \mathrm{ml})$ was added 2 dicyclohexylphosphino-2',4',6'-triisopropylbiphenyl (935 mg, $2.0 \mathrm{mmol}$ ) and tris(dibenzylideneacetone)dipalladium $(600 \mathrm{mg}, 0.66 \mathrm{mmol})$ under argon. The mixture was refluxed for overnight. Water was then added and the reaction mixture was extracted 
with ethyl acetate, washed with brine and dried with anhydrous $\mathrm{Na}_{2} \mathrm{SO}_{4}$. The combined extracts were evaporated under vacuum to give crude product which was purified with flash chromatography on silica. Elution with hexane/ethyl acetate (15:1-4:1) gave $\mathbf{1 0}$ or 16 as pale-yellow solid (for 10: $34 \%$ yield; for 16: $31 \%$ yield).

3-(4,5-dibromo-1-((2-(trimethylsilyl)ethoxy)methyl)-1H-imidazol-2-yl)-1(phenylsulfonyl)-1H-indole (10). ${ }^{1} \mathrm{H}$ NMR (400 MHz, Chloroform-d) $\delta 8.20(\mathrm{~s}, 1 \mathrm{H})$, $8.17(\mathrm{dt}, \mathrm{J}=7.7,1.1 \mathrm{~Hz}, 1 \mathrm{H}), 8.05-8.00(\mathrm{~m}, 1 \mathrm{H}), 7.92-7.85(\mathrm{~m}, 2 \mathrm{H}), 7.58-7.51(\mathrm{~m}$, $1 \mathrm{H}), 7.47-7.36(\mathrm{~m}, 3 \mathrm{H}), 7.32(\mathrm{td}, \mathrm{J}=7.7,1.1 \mathrm{~Hz}, 1 \mathrm{H}), 5.35(\mathrm{~s}, 2 \mathrm{H}), 3.80-3.68(\mathrm{~m}, 2 \mathrm{H})$, $1.09-0.98(\mathrm{~m}, 2 \mathrm{H}), 0.05$ (s, 9H). HRMS: calculated for $\mathrm{C}_{23} \mathrm{H}_{26} \mathrm{Br}_{2} \mathrm{~N}_{3} \mathrm{O}_{3} \mathrm{SSi}[\mathrm{M}+\mathrm{H}]^{+}$ 609.9831, found 609.9822.

4-(4,5-dibromo-1-((2-(trimethylsilyl)ethoxy)methyl)-1H-imidazol-2-yl)-1(phenylsulfonyl)-1H-indole (16). ${ }^{1} \mathrm{H}$ NMR (400 MHz, Chloroform-d) $\delta 8.11$ (dd, $\mathrm{J}=8.4$, $1.0 \mathrm{~Hz}, 1 \mathrm{H}), 7.86(\mathrm{dd}, \mathrm{J}=8.0,1.4 \mathrm{~Hz}, 2 \mathrm{H}), 7.64(\mathrm{~d}, \mathrm{~J}=3.7 \mathrm{~Hz}, 1 \mathrm{H}), 7.57-7.50(\mathrm{~m}, 2 \mathrm{H})$, $7.41(\mathrm{dt}, \mathrm{J}=20.0,7.8 \mathrm{~Hz}, 3 \mathrm{H}), 6.97(\mathrm{~d}, \mathrm{~J}=3.7 \mathrm{~Hz}, 1 \mathrm{H}), 5.25(\mathrm{~s}, 2 \mathrm{H}), 3.49(\mathrm{dd}, \mathrm{J}=8.8$, $7.6 \mathrm{~Hz}, 2 \mathrm{H}), 0.85(\mathrm{dd}, \mathrm{J}=8.8,7.6 \mathrm{~Hz}, 2 \mathrm{H}),-0.06$ (s, 9H). HRMS: calculated for $\mathrm{C}_{23} \mathrm{H}_{26} \mathrm{Br}_{2} \mathrm{~N}_{3} \mathrm{O}_{3} \mathrm{SSi}[\mathrm{M}+\mathrm{H}]^{+}$609.9831, found 609.9834.

General procedure for synthesis of 11a-11f, 17 and 23. To a stirred solution of compound $\mathbf{1 0}$ or $\mathbf{1 6}$ or $\mathbf{2 1}(1.0 \mathrm{mmol})$ in anhydrous THF $(3.0 \mathrm{~mL})$ under argon was added isopropylmagnesium chloride lithium chloride complex solution (1.3 M in THF, $0.92 \mathrm{ml}$, $1.2 \mathrm{mmol}$ ) at room temperature. The mixture was stirred for $1 \mathrm{hr}$ and was added benzoyl chlorides $(1.3 \mathrm{mmol})$ in anhydrous THF $(\mathrm{mL})$. Reaction was kept stirring at room temperature for 1 hour and then refluxed for 30 minute. Saturated $\mathrm{NH}_{4} \mathrm{Cl}$ solution was then added to quench the reaction. Reaction mixture was extracted with ethyl acetate, washed with brine and dried with $\mathrm{Na}_{2} \mathrm{SO}_{4}$. The combined extracts were evaporated under vacuum to give the crude product which was purified with flash chromatography on silica. Elution with hexane/ethyl acetate (10:1-3:1) gave pure 11a-11f, 17 and 22 as paleyellow to yellowish solids (yields: $31-48 \%$ ).

(4-bromo-2-(1-(phenylsulfonyl)-1H-indol-3-yl)-1-((2(trimethylsilyl)ethoxy)methyl)-1H-imidazol-5-yl)(2,3-dihydrobenzo[b][1,4]dioxin-6yl)methanone (11a). ${ }^{1} \mathrm{H}$ NMR (400 MHz, Chloroform-d) $\delta 8.30$ (s, 1H), 8.19 (ddd, J $=$ 7.7, 1.3, $0.7 \mathrm{~Hz}, 1 \mathrm{H}), 8.05(\mathrm{dt}, \mathrm{J}=8.4,1.0 \mathrm{~Hz}, 1 \mathrm{H}), 7.97-7.87(\mathrm{~m}, 2 \mathrm{H}), 7.59-7.54(\mathrm{~m}$, $1 \mathrm{H}), 7.49-7.32(\mathrm{~m}, 6 \mathrm{H}), 5.62(\mathrm{~s}, 2 \mathrm{H}), 4.42-4.33(\mathrm{~m}, 2 \mathrm{H}), 4.30(\mathrm{dt}, \mathrm{J}=5.7,1.6 \mathrm{~Hz}, 2 \mathrm{H})$, $3.64-3.53(\mathrm{~m}, 2 \mathrm{H}), 0.98-0.90(\mathrm{~m}, 2 \mathrm{H}),-0.07$ (s, 9H). HRMS: calculated for $\mathrm{C}_{32} \mathrm{H}_{33} \mathrm{BrN}_{3} \mathrm{O}_{6} \mathrm{SSi}[\mathrm{M}+\mathrm{H}]^{+}$694.1043, found 694.1045.

Benzo[d][1,3]dioxol-5-yl(4-bromo-2-(1-(phenylsulfonyl)-1H-indol-3-yl)-1-((2(trimethylsilyl)ethoxy)methyl)-1 H-imidazol-5-yl)methanone (11b). ${ }^{1} \mathrm{H}$ NMR (400 $\mathrm{MHz}$, Chloroform-d) $\delta 8.29$ (s, 1H), 8.19 (ddd, J = 7.9, 1.4, $0.7 \mathrm{~Hz}, 1 \mathrm{H}), 8.05(\mathrm{dt}, \mathrm{J}=8.3$, $1.0 \mathrm{~Hz}, 1 \mathrm{H}), 7.95-7.87(\mathrm{~m}, 2 \mathrm{H}), 7.59-7.50(\mathrm{~m}, 2 \mathrm{H}), 7.49-7.32(\mathrm{~m}, 5 \mathrm{H}), 6.90(\mathrm{dd}, \mathrm{J}=$ $8.2,1.3 \mathrm{~Hz}, 1 \mathrm{H}), 6.10(\mathrm{~s}, 2 \mathrm{H}), 5.62(\mathrm{~s}, 2 \mathrm{H}), 3.66-3.50(\mathrm{~m}, 2 \mathrm{H}), 0.99-0.90(\mathrm{~m}, 2 \mathrm{H}),-$ 0.06 (s, 9H). HRMS: calculated for $\mathrm{C}_{31} \mathrm{H}_{31} \mathrm{BrN}_{3} \mathrm{O}_{6} \mathrm{SSi}[\mathrm{M}+\mathrm{H}]^{+}$680.0886, found 680.0881. 
(4-bromo-2-(1-(phenylsulfonyl)-1H-indol-3-yl)-1-((2(trimethylsilyl)ethoxy)methyl)-1H-imidazol-5-yl)(8-methoxy-2,3dihydrobenzo[b][1,4] dioxin-6-yl)methanone (11c). ${ }^{1} \mathrm{H}$ NMR $(400 \mathrm{MHz}$, Chloroform-d) $\delta 8.34(\mathrm{~s}, 1 \mathrm{H}), 8.15(\mathrm{~d}, \mathrm{~J}=7.8 \mathrm{~Hz}, 1 \mathrm{H}), 8.04(\mathrm{dd}, \mathrm{J}=8.4,1.0 \mathrm{~Hz}, 1 \mathrm{H}), 7.97-7.89(\mathrm{~m}$, 2H), 7.56 (t, J = 7.4 Hz, 1H), $7.49-7.39$ (m, 3H), 7.35 (td, J = 7.6, 1.1 Hz, 1H), $7.20-$ $7.11(\mathrm{~m}, 3 \mathrm{H}), 5.62(\mathrm{~s}, 2 \mathrm{H}), 4.41(\mathrm{dd}, \mathrm{J}=3.8,1.8 \mathrm{~Hz}, 2 \mathrm{H}), 4.30(\mathrm{dd}, \mathrm{J}=3.8,1.8 \mathrm{~Hz}, 2 \mathrm{H})$, $3.95(\mathrm{~s}, 3 \mathrm{H}), 3.62-3.53(\mathrm{~m}, 2 \mathrm{H}), 0.96-0.89(\mathrm{~m}, 2 \mathrm{H}),-0.08(\mathrm{~s}, 9 \mathrm{H})$. HRMS: calculated for $\mathrm{C}_{33} \mathrm{H}_{35} \mathrm{BrN}_{3} \mathrm{O}_{7} \mathrm{SSi}[\mathrm{M}+\mathrm{H}]^{+}$724.1148, found 724.1144 .

(4-bromo-2-(1-(phenylsulfonyl)-1H-indol-3-yl)-1-((2(trimethylsilyl)ethoxy)methyl)-1H-imidazol-5-yl)(7-methoxybenzo[d][1,3]dioxol-5yl)methanone (11d). ${ }^{1} \mathrm{H}$ NMR $(400 \mathrm{MHz}$, Chloroform-d) $\delta 8.30$ (s, 1H), 8.20 (ddd, J = 7.9, 1.4, $0.7 \mathrm{~Hz}, 1 \mathrm{H}), 8.05(\mathrm{dt}, \mathrm{J}=8.2,1.0 \mathrm{~Hz}, 1 \mathrm{H}), 7.94-7.90(\mathrm{~m}, 2 \mathrm{H}), 7.60-7.53(\mathrm{~m}$, $1 \mathrm{H}), 7.48-7.33(\mathrm{~m}, 4 \mathrm{H}), 7.22(\mathrm{~d}, \mathrm{~J}=1.5 \mathrm{~Hz}, 1 \mathrm{H}), 7.12(\mathrm{~d}, \mathrm{~J}=1.5 \mathrm{~Hz}, 1 \mathrm{H}), 6.11(\mathrm{~s}, 2 \mathrm{H})$, $5.63(\mathrm{~s}, 2 \mathrm{H}), 3.95(\mathrm{~s}, 3 \mathrm{H}), 3.65-3.57(\mathrm{~m}, 2 \mathrm{H}), 1.00-0.91(\mathrm{~m}, 2 \mathrm{H}),-0.06(\mathrm{~s}, 9 \mathrm{H})$. HRMS: calculated for $\mathrm{C}_{32} \mathrm{H}_{33} \mathrm{BrN}_{3} \mathrm{O}_{7} \mathrm{SSi}[\mathrm{M}+\mathrm{H}]^{+} 710.0992$, found 710.0999 .

(4-bromo-2-(1-(phenylsulfonyl)-1H-indol-3-yl)-1-((2(trimethylsilyl)ethoxy)methyl)-1H-imidazol-5-yl)(9-methoxy-3,4-dihydro-2Hbenzo[b][1,4]dioxepin-7-yl)methanone (11e). ${ }^{1} \mathrm{H}$ NMR (400 MHz, Chloroform-d) $\delta$ $8.30(\mathrm{~s}, 1 \mathrm{H}), 8.23-8.17(\mathrm{~m}, 1 \mathrm{H}), 8.05(\mathrm{dt}, \mathrm{J}=8.4,1.0 \mathrm{~Hz}, 1 \mathrm{H}), 7.94-7.89(\mathrm{~m}, 2 \mathrm{H}), 7.60$ $-7.53(\mathrm{~m}, 1 \mathrm{H}), 7.49-7.32(\mathrm{~m}, 4 \mathrm{H}), 7.22(\mathrm{~d}, \mathrm{~J}=2.0 \mathrm{~Hz}, 1 \mathrm{H}), 7.18(\mathrm{~d}, \mathrm{~J}=2.0 \mathrm{~Hz}, 1 \mathrm{H})$, $5.63(\mathrm{~s}, 2 \mathrm{H}), 4.46(\mathrm{t}, \mathrm{J}=5.7 \mathrm{~Hz}, 2 \mathrm{H}), 4.30(\mathrm{t}, \mathrm{J}=5.9 \mathrm{~Hz}, 2 \mathrm{H}), 3.93(\mathrm{~s}, 3 \mathrm{H}), 3.64-3.56(\mathrm{~m}$, 2H), 2.28 (p, J = 5.8 Hz, 2H), $0.99-0.90$ (m, 2H), -0.06 (s, 9H). HRMS: calculated for $\mathrm{C}_{34} \mathrm{H}_{37} \mathrm{BrN}_{3} \mathrm{O}_{7} \mathrm{SSi}[\mathrm{M}+\mathrm{H}]^{+}$738.1305, found 738.1313 .

(4-bromo-2-(1-(phenylsulfonyl)-1H-indol-3-yl)-1-((2(trimethylsilyl)ethoxy)methyl)-1H-imidazol-5-yl)(8-methoxybenzo[b] [1,4]dioxin-6yl)methanone (11f). ${ }^{1} \mathrm{H}$ NMR $\left(400 \mathrm{MHz}\right.$, Acetone- $\left.\mathrm{d}_{6}\right) \delta 8.54(\mathrm{~s}, 1 \mathrm{H}), 8.35$ (ddd, $\mathrm{J}=8.0$, 1.3, $0.7 \mathrm{~Hz}, 1 \mathrm{H}), 8.18-8.09(\mathrm{~m}, 3 \mathrm{H}), 7.79-7.73(\mathrm{~m}, 1 \mathrm{H}), 7.72-7.63(\mathrm{~m}, 2 \mathrm{H}), 7.52$ (ddd, $\mathrm{J}=8.4,7.3,1.4 \mathrm{~Hz}, 1 \mathrm{H}), 7.44$ (ddd, $\mathrm{J}=8.2,7.2,1.1 \mathrm{~Hz}, 1 \mathrm{H}), 7.31$ (d, J = 1.9 Hz, $1 \mathrm{H}), 6.92(\mathrm{~d}, \mathrm{~J}=1.9 \mathrm{~Hz}, 1 \mathrm{H}), 6.24(\mathrm{~d}, \mathrm{~J}=3.6 \mathrm{~Hz}, 1 \mathrm{H}), 6.20(\mathrm{~d}, \mathrm{~J}=3.6 \mathrm{~Hz}, 1 \mathrm{H}), 5.81$ (s, 2H), $3.93(\mathrm{~s}, 3 \mathrm{H}), 3.76-3.67$ (m, 2H), $1.06-0.95$ (m, 2H), 0.00 (s, 9H). HRMS: calculated for $\mathrm{C}_{33} \mathrm{H}_{33} \mathrm{BrN}_{3} \mathrm{O}_{7} \mathrm{SSi}[\mathrm{M}+\mathrm{H}]^{+}$722.0992, found 722.0989.

(4-bromo-2-(1-(phenylsulfonyl)-1H-indol-4-yl)-1-((2(trimethylsilyl)ethoxy)methyl)-1H-imidazol-5-yl)(8-methoxybenzo[b][1,4]dioxin-6yl)methanone (17). ${ }^{1} \mathrm{H}$ NMR (400 MHz, Chloroform-d) $\delta 8.16(\mathrm{~d}, \mathrm{~J}=8.3 \mathrm{~Hz}, 1 \mathrm{H}), 7.88$ $(\mathrm{dd}, \mathrm{J}=8.4,1.3 \mathrm{~Hz}, 2 \mathrm{H}), 7.68(\mathrm{~d}, \mathrm{~J}=3.7 \mathrm{~Hz}, 1 \mathrm{H}), 7.59-7.53(\mathrm{~m}, 2 \mathrm{H}), 7.48-7.39$ (m, $3 \mathrm{H}), 7.13(\mathrm{~d}, \mathrm{~J}=1.9 \mathrm{~Hz}, 1 \mathrm{H}), 6.96(\mathrm{~d}, \mathrm{~J}=3.7 \mathrm{~Hz}, 1 \mathrm{H}), 6.88(\mathrm{~d}, \mathrm{~J}=1.8 \mathrm{~Hz}, 1 \mathrm{H}), 6.00$ (d, J $=3.6 \mathrm{~Hz}, 1 \mathrm{H}), 5.91(\mathrm{~d}, \mathrm{~J}=3.5 \mathrm{~Hz}, 1 \mathrm{H}), 5.50(\mathrm{~s}, 2 \mathrm{H}), 3.90(\mathrm{~s}, 3 \mathrm{H}), 3.34-3.27(\mathrm{~m}, 2 \mathrm{H})$, $0.76-0.67(\mathrm{~m}, 2 \mathrm{H}),-0.15(\mathrm{~s}, 9 \mathrm{H})$. HRMS: calculated for $\mathrm{C}_{33} \mathrm{H}_{33} \mathrm{BrN}_{3} \mathrm{O}_{7} \mathrm{SSi}[\mathrm{M}+\mathrm{H}]^{+}$ 722.0992 , found 722.0996 .

(4-bromo-2-(4-methyl-1-(phenylsulfonyl)-1H-indol-3-yl)-1-((2(trimethylsilyl)ethoxy)methyl)-1H-imidazol-5-yl)(8-methoxybenzo[b][1,4]dioxin-6- 
yl)methanone (23). ${ }^{1} \mathrm{H}$ NMR (400 MHz, Chloroform-d) $\delta 7.92-7.83$ (m, 4H), 7.54 (dd, $\mathrm{J}=8.3,6.5 \mathrm{~Hz}, 1 \mathrm{H}), 7.47-7.39(\mathrm{~m}, 2 \mathrm{H}), 7.25-7.20(\mathrm{~m}, 1 \mathrm{H}), 7.10(\mathrm{~d}, \mathrm{~J}=1.9 \mathrm{~Hz}, 1 \mathrm{H})$, $7.01(\mathrm{~d}, \mathrm{~J}=7.5 \mathrm{~Hz}, 1 \mathrm{H}), 6.84(\mathrm{~s}, 1 \mathrm{H}), 6.00-5.91(\mathrm{~m}, 1 \mathrm{H}), 5.88(\mathrm{dd}, \mathrm{J}=3.3,1.8 \mathrm{~Hz}, 1 \mathrm{H})$, $5.36(\mathrm{~d}, \mathrm{~J}=1.8 \mathrm{~Hz}, 2 \mathrm{H}), 3.87(\mathrm{~d}, \mathrm{~J}=1.7 \mathrm{~Hz}, 3 \mathrm{H}), 3.39-3.29(\mathrm{~m}, 2 \mathrm{H}), 2.18(\mathrm{~s}, 3 \mathrm{H}), 0.79$ $-0.66(\mathrm{~m}, 2 \mathrm{H}),-0.14(\mathrm{~d}, \mathrm{~J}=1.5 \mathrm{~Hz}, 9 \mathrm{H})$. HRMS: calculated for $\mathrm{C}_{34} \mathrm{H}_{35} \mathrm{BrN}_{3} \mathrm{O}_{7} \mathrm{SSi}$ $[\mathrm{M}+\mathrm{H}]^{+} 736.1148$, found 736.1155 .

General procedure for synthesis of $12 \mathrm{a}-12 \mathrm{f}, 18$ and 24 . To a suspension of 11a11 or 17 or $23(0.5 \mathrm{mmol})$, potassium carbonate $(276 \mathrm{mg}, 2.0 \mathrm{mmol})$, and triphenylphosphine $(26 \mathrm{mg}, 0.1 \mathrm{mmol})$ in $n$ - $\mathrm{BuOH}(3 \mathrm{~mL})$ was added palladium acetate (5.6 mg, $0.025 \mathrm{mmol}$ ). The mixture was heated to reflux for $4 \mathrm{hr} . n-\mathrm{BuOH}$ was removed under reduced pressure. The residue was partitioned between water $(10 \mathrm{ml})$ and EtOAc $(10 \mathrm{ml})$. The combined organic solvents were then evaporated under reduced pressure. The crude was purified with flash chromatography on silica. Elution with hexane/ethyl acetate (10:1-3:1) gave pure 12a-12f, 18 and $\mathbf{2 4}$ as pale-yellow to yellowish solids (yields: 76-89\%).

(2-(1H-indol-3-yl)-1-((2-(trimethylsilyl)ethoxy)methyl)-1H-imidazol-5yl)(benzo[d][1,3]dioxol-5-yl)methanone (12b). ${ }^{1} \mathrm{H}$ NMR (400 MHz, Chloroform-d) $\delta$ $9.35(\mathrm{~s}, 1 \mathrm{H}), 8.30-8.17(\mathrm{~m}, 1 \mathrm{H}), 7.94(\mathrm{~d}, \mathrm{~J}=2.8 \mathrm{~Hz}, 1 \mathrm{H}), 7.74(\mathrm{~s}, 1 \mathrm{H}), 7.51$ (dd, J = 8.1, $1.7 \mathrm{~Hz}, 1 \mathrm{H}), 7.41(\mathrm{dd}, \mathrm{J}=7.2,1.7 \mathrm{~Hz}, 2 \mathrm{H}), 7.29-7.18(\mathrm{~m}, 3 \mathrm{H}), 6.91(\mathrm{~d}, \mathrm{~J}=8.1 \mathrm{~Hz}, 1 \mathrm{H})$, $6.08(\mathrm{~s}, 2 \mathrm{H}), 5.88(\mathrm{~s}, 2 \mathrm{H}), 3.78-3.64(\mathrm{~m}, 2 \mathrm{H}), 1.00-0.86(\mathrm{~m}, 2 \mathrm{H}),-0.06(\mathrm{~s}, 9 \mathrm{H})$. HRMS: calculated for $\mathrm{C}_{25} \mathrm{H}_{28} \mathrm{~N}_{3} \mathrm{O}_{4} \mathrm{Si}[\mathrm{M}+\mathrm{H}]^{+} 462.1849$, found 462.1852 .

(2-(1H-indol-3-yl)-1-((2-(trimethylsilyl)ethoxy)methyl)-1H-imidazol-5-yl)(8methoxy-2,3-dihydrobenzo[b][1,4]dioxin-6-yl)methanone (12c). ${ }^{1} \mathrm{H}$ NMR $(400 \mathrm{MHz}$, Chloroform-d) $\delta 9.24(\mathrm{~s}, 1 \mathrm{H}), 8.19(\mathrm{~d}, \mathrm{~J}=7.2 \mathrm{~Hz}, 1 \mathrm{H}), 7.95(\mathrm{~s}, 1 \mathrm{H}), 7.81(\mathrm{~s}, 1 \mathrm{H}), 7.50-$ $7.42(\mathrm{~m}, 1 \mathrm{H}), 7.30-7.20(\mathrm{~m}, 2 \mathrm{H}), 7.18(\mathrm{~d}, \mathrm{~J}=2.0 \mathrm{~Hz}, 1 \mathrm{H}), 7.11(\mathrm{~d}, \mathrm{~J}=2.0 \mathrm{~Hz}, 1 \mathrm{H}), 5.88$ $(\mathrm{s}, 2 \mathrm{H}), 4.42(\mathrm{dd}, \mathrm{J}=3.9,1.7 \mathrm{~Hz}, 2 \mathrm{H}), 4.33(\mathrm{dd}, \mathrm{J}=3.7,1.7 \mathrm{~Hz}, 2 \mathrm{H}), 3.96(\mathrm{~s}, 3 \mathrm{H}), 3.77-$ $3.64(\mathrm{~m}, 2 \mathrm{H}), 1.00-0.87(\mathrm{~m}, 2 \mathrm{H}),-0.05(\mathrm{~s}, 9 \mathrm{H})$. HRMS: calculated for $\mathrm{C}_{27} \mathrm{H}_{32} \mathrm{~N}_{3} \mathrm{O}_{5} \mathrm{Si}$ $[\mathrm{M}+\mathrm{H}]^{+}$506.2111, found 506.2113.

(2-(1H-indol-3-yl)-1-((2-(trimethylsilyl)ethoxy)methyl)-1H-imidazol-5-yl)(7methoxybenzo[d][1,3]dioxol-5-yl)methanone (12d). ${ }^{1} \mathrm{H}$ NMR (400 MHz, Chloroform-d) $\delta 8.79(\mathrm{~s}, 1 \mathrm{H}), 8.35-8.25(\mathrm{~m}, 1 \mathrm{H}), 8.03(\mathrm{~d}, \mathrm{~J}=2.8 \mathrm{~Hz}, 1 \mathrm{H}), 7.77(\mathrm{~s}, 1 \mathrm{H}), 7.46-7.42(\mathrm{~m}$, $1 \mathrm{H}), 7.30-7.27(\mathrm{~m}, 1 \mathrm{H}), 7.20(\mathrm{~d}, \mathrm{~J}=1.5 \mathrm{~Hz}, 1 \mathrm{H}), 7.13(\mathrm{~d}, \mathrm{~J}=1.5 \mathrm{~Hz}, 1 \mathrm{H}), 6.10(\mathrm{~s}, 2 \mathrm{H})$, $5.91(\mathrm{~s}, 2 \mathrm{H}), 3.96(\mathrm{~s}, 3 \mathrm{H}), 3.80-3.70(\mathrm{~m}, 2 \mathrm{H}), 0.94(\mathrm{~d}, \mathrm{~J}=8.3 \mathrm{~Hz}, 2 \mathrm{H}),-0.05(\mathrm{~s}, 9 \mathrm{H})$. HRMS: calculated for $\mathrm{C}_{26} \mathrm{H}_{30} \mathrm{~N}_{3} \mathrm{O}_{5} \mathrm{Si}[\mathrm{M}+\mathrm{H}]^{+} 492.1955$, found 492.1957 .

(2-(1H-indol-3-yl)-1-((2-(trimethylsilyl)ethoxy)methyl)-1H-imidazol-5-yl)(9methoxy-3,4-dihydro-2H-benzo[b][1,4]dioxepin-7-yl)methanone (12e). ${ }^{1} \mathrm{H}$ NMR (400 MHz, Chloroform-d) $\delta 8.66(\mathrm{~s}, 1 \mathrm{H}), 8.36-8.23(\mathrm{~m}, 1 \mathrm{H}), 8.05(\mathrm{~d}, \mathrm{~J}=2.8 \mathrm{~Hz}, 1 \mathrm{H}), 7.79$ (s, $1 \mathrm{H}), 7.51-7.40(\mathrm{~m}, 1 \mathrm{H}), 7.33-7.24(\mathrm{~m}, 4 \mathrm{H}), 7.22(\mathrm{~d}, \mathrm{~J}=2.1 \mathrm{~Hz}, 1 \mathrm{H}), 7.16(\mathrm{~d}, \mathrm{~J}=2.0$ $\mathrm{Hz}, 1 \mathrm{H}), 5.92(\mathrm{~s}, 2 \mathrm{H}), 4.44(\mathrm{t}, \mathrm{J}=5.7 \mathrm{~Hz}, 2 \mathrm{H}), 4.32$ (t, J = 5.9 Hz, 2H), $3.92(\mathrm{~s}, 3 \mathrm{H}), 3.81$ $-3.71(\mathrm{~m}, 2 \mathrm{H}), 2.34-2.20(\mathrm{~m}, 2 \mathrm{H}), 1.00-0.91(\mathrm{~m}, 2 \mathrm{H}),-0.04$ (s, 9H). HRMS: calculated for $\mathrm{C}_{28} \mathrm{H}_{34} \mathrm{~N}_{3} \mathrm{O}_{5} \mathrm{Si}[\mathrm{M}+\mathrm{H}]^{+}$520.2268, found 520.2272. 
(2-(1H-indol-3-yl)-1-((2-(trimethylsilyl)ethoxy)methyl)-1H-imidazol-5-yl)(8methoxybenzo[b][1,4]dioxin-6-yl)methanone (12f). ${ }^{1} \mathrm{H}$ NMR $(400 \mathrm{MHz}$, Chloroform-d) $\delta 10.02(\mathrm{~d}, \mathrm{~J}=2.8 \mathrm{~Hz}, 1 \mathrm{H}), 8.36-8.27(\mathrm{~m}, 1 \mathrm{H}), 7.94(\mathrm{~d}, \mathrm{~J}=2.8 \mathrm{~Hz}, 1 \mathrm{H}), 7.87(\mathrm{~s}, 1 \mathrm{H})$, $7.38-7.31(\mathrm{~m}, 1 \mathrm{H}), 7.30-7.22(\mathrm{~m}, 2 \mathrm{H}), 7.16(\mathrm{~d}, \mathrm{~J}=1.9 \mathrm{~Hz}, 1 \mathrm{H}), 6.95(\mathrm{~d}, \mathrm{~J}=1.9 \mathrm{~Hz}$, $1 \mathrm{H}), 6.04(\mathrm{~d}, \mathrm{~J}=3.6 \mathrm{~Hz}, 1 \mathrm{H}), 5.98-5.88(\mathrm{~m}, 3 \mathrm{H}), 3.92(\mathrm{~s}, 3 \mathrm{H}), 3.83-3.67(\mathrm{~m}, 2 \mathrm{H}), 1.03$ $-0.89(\mathrm{~m}, 2 \mathrm{H}), 0.00(\mathrm{~s}, 9 \mathrm{H})$. HRMS: calculated for $\mathrm{C}_{27} \mathrm{H}_{30} \mathrm{~N}_{3} \mathrm{O}_{5} \mathrm{Si}[\mathrm{M}+\mathrm{H}]^{+}$504.1955, found 504.1952.

(2-(1H-indol-4-yl)-1-((2-(trimethylsilyl)ethoxy)methyl)-1H-imidazol-5-yl)(8methoxybenzo[b][1,4]dioxin-6-yl)methanone (18). ${ }^{1} \mathrm{H}$ NMR $(400 \mathrm{MHz}$, Chloroform-d) $\delta 8.47(\mathrm{~s}, 1 \mathrm{H}), 7.76(\mathrm{~s}, 1 \mathrm{H}), 7.55(\mathrm{~d}, \mathrm{~J}=8.2 \mathrm{~Hz}, 1 \mathrm{H}), 7.50$ (d, J = 7.3 Hz, 1H), $7.34-7.29$ $(\mathrm{m}, 2 \mathrm{H}), 7.15(\mathrm{~d}, \mathrm{~J}=1.8 \mathrm{~Hz}, 1 \mathrm{H}), 6.93(\mathrm{~d}, \mathrm{~J}=1.8 \mathrm{~Hz}, 1 \mathrm{H}), 6.73(\mathrm{~s}, 1 \mathrm{H}), 6.01(\mathrm{~d}, \mathrm{~J}=3.6$ $\mathrm{Hz}, 1 \mathrm{H}), 5.92(\mathrm{~d}, \mathrm{~J}=3.7 \mathrm{~Hz}, 1 \mathrm{H}), 5.78(\mathrm{~s}, 2 \mathrm{H}), 3.91(\mathrm{~s}, 3 \mathrm{H}), 3.43-3.33(\mathrm{~m}, 2 \mathrm{H}), 0.80-$ $0.73(\mathrm{~m}, 2 \mathrm{H}),-0.13(\mathrm{~s}, 9 \mathrm{H})$. HRMS: calculated for $\mathrm{C}_{27} \mathrm{H}_{30} \mathrm{~N}_{3} \mathrm{O}_{5} \mathrm{Si}[\mathrm{M}+\mathrm{H}]^{+}$504.1955, found 504.1965.

(8-methoxybenzo[b] [1,4]dioxin-6-yl)(2-(4-methyl-1H-indol-3-yl)-1-((2(trimethylsilyl)ethoxy)methyl)-1H-imidazol-5-yl)methanone (24). ${ }^{1} \mathrm{H}$ NMR (400 MHz, Chloroform-d) $\delta 9.17(\mathrm{~s}, 1 \mathrm{H}), 7.36(\mathrm{~s}, 1 \mathrm{H}), 7.21(\mathrm{~d}, \mathrm{~J}=8.2 \mathrm{~Hz}, 1 \mathrm{H}), 7.15(\mathrm{~s}, 1 \mathrm{H}), 7.12$ (d, $\mathrm{J}=7.4 \mathrm{~Hz}, 1 \mathrm{H}), 6.94(\mathrm{~d}, \mathrm{~J}=7.2 \mathrm{~Hz}, 1 \mathrm{H}), 6.90(\mathrm{q}, \mathrm{J}=1.6 \mathrm{~Hz}, 1 \mathrm{H}), 6.01(\mathrm{t}, \mathrm{J}=2.4 \mathrm{~Hz}, 1 \mathrm{H})$, $5.92(\mathrm{t}, \mathrm{J}=2.8 \mathrm{~Hz}, 1 \mathrm{H}), 5.46(\mathrm{~s}, 2 \mathrm{H}), 3.91(\mathrm{~s}, 3 \mathrm{H}), 3.31(\mathrm{t}, \mathrm{J}=8.1 \mathrm{~Hz}, 2 \mathrm{H}), 2.34(\mathrm{~s}, 3 \mathrm{H})$, $0.70(\mathrm{t}, \mathrm{J}=8.1 \mathrm{~Hz}, 2 \mathrm{H}),-0.14(\mathrm{~d}, \mathrm{~J}=1.5 \mathrm{~Hz}, 9 \mathrm{H})$. HRMS: calculated for $\mathrm{C}_{28} \mathrm{H}_{32} \mathrm{~N}_{3} \mathrm{O}_{5} \mathrm{Si}$ $[\mathrm{M}+\mathrm{H}]^{+}$518.2111, found 518.2108.

General procedure for synthesis of $13 a-13 f, 19$ and 25 . To a solution of $12 a-$ $12 \mathrm{f}$ or 18 or 24 in DCM $(1 \mathrm{ml})$ was added trifluoroacetic acid $(1 \mathrm{ml})$. The reaction was stirred for $2 \mathrm{hr}$ and solvent was evaporated under reduced pressure. The residue was partitioned between saturated $\mathrm{NaHCO} 3$ solution and EtOAc. The combined organic solvents were then evaporated under reduced pressure. The crude was purified with flash chromatography on silica. Elution with hexane/ethyl acetate (4:1-1:2) gave pure 13a-13f, 19 and 25 as yellowish solids (yields: 79-92\%).

(2-(1H-indol-3-yl)-1H-imidazol-5-yl)(2,3-dihydrobenzo[b][1,4]dioxin-6yl)methanone (13a). ${ }^{1} \mathrm{H}$ NMR $\left(400 \mathrm{MHz}, \mathrm{DMSO}_{6}\right) \delta 13.14(\mathrm{~s}, 1 \mathrm{H}), 11.62(\mathrm{~s}, 1 \mathrm{H}), 8.47$ $-8.36(\mathrm{~m}, 1 \mathrm{H}), 8.30-8.17(\mathrm{~m}, 1 \mathrm{H}), 7.87(\mathrm{~s}, 1 \mathrm{H}), 7.68(\mathrm{~s}, 2 \mathrm{H}), 7.48(\mathrm{dt}, \mathrm{J}=8.2,0.9 \mathrm{~Hz}$, 1H), $7.25-7.12(\mathrm{~m}, 2 \mathrm{H}), 7.04(\mathrm{~d}, \mathrm{~J}=8.8 \mathrm{~Hz}, 1 \mathrm{H}), 4.52-4.27$ (m, 4H). HRMS: calculated for $\mathrm{C}_{20} \mathrm{H}_{16} \mathrm{~N}_{3} \mathrm{O}_{3}[\mathrm{M}+\mathrm{H}]^{+} 346.1192$, found 346.1190 .

(2-(1H-indol-3-yl)-1H-imidazol-5-yl)(benzo[d][1,3]dioxol-5-yl)methanone (13b). ${ }^{1} \mathrm{H}$ NMR (400 MHz, DMSO-d 6 ) $\delta 13.36$ (s, 1H), 11.67 (s, 1H), $8.42-8.32$ (m, $1 \mathrm{H}), 8.23(\mathrm{~d}, \mathrm{~J}=2.7 \mathrm{~Hz}, 1 \mathrm{H}), 7.92(\mathrm{~s}, 1 \mathrm{H}), 7.81(\mathrm{~d}, \mathrm{~J}=7.1 \mathrm{~Hz}, 1 \mathrm{H}), 7.71-7.56(\mathrm{~m}, 1 \mathrm{H})$, 7.49 (dt, J = 8.2, $0.9 \mathrm{~Hz}, 1 \mathrm{H}), 7.19$ (dtd, J = 17.2, 7.1, $1.3 \mathrm{~Hz}, 2 \mathrm{H}), 7.11(\mathrm{~d}, \mathrm{~J}=8.1 \mathrm{~Hz}$, $1 \mathrm{H}), 6.18(\mathrm{~s}, 2 \mathrm{H})$. HRMS: calculated for $\mathrm{C}_{19} \mathrm{H}_{14} \mathrm{~N}_{3} \mathrm{O}_{3}[\mathrm{M}+\mathrm{H}]^{+} 332.1035$, found 332.1036 . 
(2-(1H-indol-3-yl)-1H-imidazol-5-yl)(8-methoxy-2,3-

dihydrobenzo[b][1,4]dioxin-6-yl)methanone (13c). ${ }^{1} \mathrm{H}$ NMR $(400 \mathrm{MHz}$, Chloroform-d) $\delta 8.02(\mathrm{~s}, 1 \mathrm{H}), 7.92(\mathrm{~s}, 1 \mathrm{H}), 7.81(\mathrm{~s}, 1 \mathrm{H}), 7.40(\mathrm{dd}, \mathrm{J}=10.9,7.7 \mathrm{~Hz}, 1 \mathrm{H}), 7.16(\mathrm{dd}, \mathrm{J}=7.0$, $3.0 \mathrm{~Hz}, 3 \mathrm{H}), 7.07(\mathrm{~s}, 1 \mathrm{H}), 4.41-4.32(\mathrm{~m}, 2 \mathrm{H}), 4.32-4.22(\mathrm{~m}, 2 \mathrm{H}), 3.91$ (s, 3H). HRMS: calculated for $\mathrm{C}_{21} \mathrm{H}_{18} \mathrm{~N}_{3} \mathrm{O}_{4}[\mathrm{M}+\mathrm{H}]^{+} 376.1297$, found 376.1294 .

(2-(1H-indol-3-yl)-1H-imidazol-5-yl)(7-methoxybenzo[d][1,3] dioxol-5yl)methanone (13d). ${ }^{1} \mathrm{H}$ NMR $(400 \mathrm{MHz}$, Chloroform-d) $\delta 8.16-8.07(\mathrm{~m}, 1 \mathrm{H}), 7.90$ (s, $1 \mathrm{H}), 7.74(\mathrm{~s}, 1 \mathrm{H}), 7.46-7.37(\mathrm{~m}, 1 \mathrm{H}), 7.25-7.20(\mathrm{~m}, 3 \mathrm{H}), 7.14(\mathrm{~d}, \mathrm{~J}=1.5 \mathrm{~Hz}, 1 \mathrm{H}), 6.06$ $(\mathrm{s}, 2 \mathrm{H}), 3.93(\mathrm{~s}, 3 \mathrm{H})$. HRMS: calculated for $\mathrm{C}_{20} \mathrm{H}_{16} \mathrm{~N}_{3} \mathrm{O}_{4}[\mathrm{M}+\mathrm{H}]^{+}$362.1141, found 362.1136 .

(2-(1H-indol-3-yl)-1H-imidazol-5-yl)(9-methoxy-3,4-dihydro-2Hbenzo[b][1,4]dioxepin-7-yl)methanone (13e). ${ }^{1} \mathrm{H}$ NMR (400 MHz, Chloroform-d) $\delta$ $8.16(\mathrm{dd}, \mathrm{J}=6.5,2.9 \mathrm{~Hz}, 1 \mathrm{H}), 7.87$ (d, J = 3.0 Hz, 1H), 7.74 (d, J = 3.4 Hz, 1H), 7.62 $7.48(\mathrm{~m}, 1 \mathrm{H}), 7.42(\mathrm{dt}, \mathrm{J}=6.0,3.0 \mathrm{~Hz}, 1 \mathrm{H}), 7.25-7.20(\mathrm{~m}, 2 \mathrm{H}), 7.20-7.13(\mathrm{~m}, 1 \mathrm{H})$, $4.38(\mathrm{t}, \mathrm{J}=5.8 \mathrm{~Hz}, 2 \mathrm{H}), 4.34-4.23(\mathrm{~m}, 2 \mathrm{H}), 3.89(\mathrm{~s}, 3 \mathrm{H}), 2.24(\mathrm{dd}, \mathrm{J}=7.0,4.5 \mathrm{~Hz}, 2 \mathrm{H})$. HRMS: calculated for $\mathrm{C}_{22} \mathrm{H}_{20} \mathrm{~N}_{3} \mathrm{O}_{4}[\mathrm{M}+\mathrm{H}]^{+} 390.1454$, found 390.1457 .

(2-(1H-indol-3-yl)-1H-imidazol-5-yl)(8-methoxybenzo[b][1,4]dioxin-6yl)methanone (13f). ${ }^{1} \mathrm{H}$ NMR $\left(400 \mathrm{MHz}, \mathrm{DMSO}_{\mathrm{d}}\right) \delta 13.02(\mathrm{~s}, 1 \mathrm{H}), 11.55(\mathrm{~s}, 1 \mathrm{H}), 8.40$ (d, J = 7.8 Hz, 1H), 7.94 (s, 2H), 7.47 (d, J = 7.9 Hz, 1H), 7.16 (dtd, J = 16.1, 8.1, 7.6, 6.4 $\mathrm{Hz}, 2 \mathrm{H}), 6.30(\mathrm{~d}, \mathrm{~J}=9.2 \mathrm{~Hz}, 2 \mathrm{H}), 3.88(\mathrm{~s}, 3 \mathrm{H})$. HRMS: calculated for $\mathrm{C}_{21} \mathrm{H}_{16} \mathrm{~N}_{3} \mathrm{O}_{4}$ $[\mathrm{M}+\mathrm{H}]^{+}$374.1141, found 374.1142.

(2-(1H-indol-4-yl)-1H-imidazol-5-yl)(8-methoxybenzo[b][1,4]dioxin-6yl)methanone (19). ${ }^{1} \mathrm{H}$ NMR (400 MHz, Chloroform-d) $\delta 10.59$ (s, 1H), $8.51(\mathrm{~s}, 1 \mathrm{H})$, $7.90(\mathrm{~s}, 1 \mathrm{H}), 7.68(\mathrm{~d}, \mathrm{~J}=7.2 \mathrm{~Hz}, 1 \mathrm{H}), 7.51(\mathrm{~d}, \mathrm{~J}=8.1 \mathrm{~Hz}, 1 \mathrm{H}), 7.38$ (t, J = 2.9 Hz, 1H), $7.29(\mathrm{~d}, \mathrm{~J}=7.8 \mathrm{~Hz}, 1 \mathrm{H}), 7.25(\mathrm{~s}, 1 \mathrm{H}), 7.19(\mathrm{~s}, 1 \mathrm{H}), 7.01(\mathrm{~s}, 1 \mathrm{H}), 6.01(\mathrm{~d}, \mathrm{~J}=3.6 \mathrm{~Hz}, 1 \mathrm{H})$, $5.93(\mathrm{~d}, \mathrm{~J}=3.6 \mathrm{~Hz}, 1 \mathrm{H}), 3.90(\mathrm{~s}, 3 \mathrm{H})$. HRMS: calculated for $\mathrm{C}_{21} \mathrm{H}_{16} \mathrm{~N}_{3} \mathrm{O}_{4}[\mathrm{M}+\mathrm{H}]^{+}$ 374.1141 , found 374.1144 .

(8-methoxybenzo[b][1,4] dioxin-6-yl)(2-(4-methyl-1H-indol-3-yl)-1Himidazol-5-yl)methanone (25). ${ }^{1} \mathrm{H}$ NMR (400 MHz, Methylene Chloride-d $\left.\mathrm{d}_{2}\right) \delta 9.11$ (s, $1 \mathrm{H}), 7.74(\mathrm{~d}, \mathrm{~J}=2.0 \mathrm{~Hz}, 1 \mathrm{H}), 7.30(\mathrm{~s}, 1 \mathrm{H}), 7.24(\mathrm{~d}, \mathrm{~J}=8.3 \mathrm{~Hz}, 1 \mathrm{H}), 7.19(\mathrm{~s}, 1 \mathrm{H}), 7.10$ (t, $\mathrm{J}=7.8 \mathrm{~Hz}, 1 \mathrm{H}), 6.98(\mathrm{~s}, 1 \mathrm{H}), 6.90(\mathrm{~d}, \mathrm{~J}=7.1 \mathrm{~Hz}, 1 \mathrm{H}), 6.00(\mathrm{~d}, \mathrm{~J}=2.7 \mathrm{~Hz}, 1 \mathrm{H}), 5.95(\mathrm{t}, \mathrm{J}$ $=2.8 \mathrm{~Hz}, 1 \mathrm{H}), 3.83(\mathrm{~s}, 3 \mathrm{H}), 2.47(\mathrm{~s}, 3 \mathrm{H})$. HRMS: calculated for $\mathrm{C}_{22} \mathrm{H}_{18} \mathrm{~N}_{3} \mathrm{O}_{4}[\mathrm{M}+\mathrm{H}]^{+}$ 388.1297, found 388.1303 .

Synthesis of 4-bromo-1-(phenylsulfonyl)-1H-indole (14). To a solution of 4bromoindole $(1.0 \mathrm{~g}, 5.1 \mathrm{mmol})$ in THF $(10 \mathrm{ml})$ was added sodium hydride $(314 \mathrm{mg}, 7.6$ mmol) in portions under ice temperature. After $1 \mathrm{hr}$, benzenesulfonyl chloride $(0.81 \mathrm{ml}$, $6.1 \mathrm{mmol}$ ) was added dropwise. The reaction was stirred at room temperature for $2 \mathrm{hr}$. Water was then added and the reaction mixture was extracted with ethyl acetate, washed with brine and dried with anhydrous $\mathrm{Na}_{2} \mathrm{SO}_{4}$. The combined extracts were evaporated under vacuum to give crude product which was purified with flash chromatography on 
silica. Elution with hexane/ethyl acetate (20:1-6:1) gave $\mathbf{1 4}$ as colorless solid (1.6 g, 93\%). ${ }^{1} \mathrm{H}$ NMR (400 MHz, Chloroform-d) $\delta 7.96(\mathrm{dd}, J=8.4,0.8 \mathrm{~Hz}, 1 \mathrm{H}), 7.91-7.84$ $(\mathrm{m}, 2 \mathrm{H}), 7.64(\mathrm{~d}, J=3.7 \mathrm{~Hz}, 1 \mathrm{H}), 7.57-7.50(\mathrm{~m}, 1 \mathrm{H}), 7.44(\mathrm{dd}, J=8.5,7.1 \mathrm{~Hz}, 2 \mathrm{H})$, $7.39(\mathrm{~d}, J=7.8 \mathrm{~Hz}, 1 \mathrm{H}), 7.18(\mathrm{t}, J=8.0 \mathrm{~Hz}, 1 \mathrm{H}), 6.74(\mathrm{~d}, J=3.7 \mathrm{~Hz}, 1 \mathrm{H})$. HRMS: calculated for $\mathrm{C}_{14} \mathrm{H}_{11} \mathrm{BrNO}_{2} \mathrm{~S}[\mathrm{M}+\mathrm{H}]^{+}$335.9694, found 335.9691 .

Synthesis of 1-(phenylsulfonyl)-4-(4,4,5,5-tetramethyl-1,3,2-dioxaborolan-2yl)-1H-indole (15). To a solution of $14(0.86 \mathrm{~g}, 2.5 \mathrm{mmol})$ in dioxane $(10 \mathrm{ml})$ was added bis(pinacolato)diboron (1.9 g, $7.5 \mathrm{mmol})$, potassium acetate $(0.75 \mathrm{~g}, 7.5 \mathrm{mmol})$ and $\left[1,1^{\prime}-\right.$ Bis(diphenylphosphino)ferrocene]dichloropalladium complex with dichloromethane (220 $\mathrm{mg}, 0.125 \mathrm{mmol}$ ). The mixture was heated to reflux for overnight. Dioxane was removed under reduced pressure and then water was partitioned between water and EtOAc. The combined extracts were evaporated under vacuum to give crude product which was purified with flash chromatography on silica. Elution with hexane/ethyl acetate $(20: 1)$ gave 15 as colorless solid (2.47 g, 86\%). ${ }^{1} \mathrm{H}$ NMR (400 MHz, Chloroform- $d$ ) $\delta 8.11$ (dt, $J$ $=8.4,0.9 \mathrm{~Hz}, 1 \mathrm{H}), 7.88-7.82(\mathrm{~m}, 2 \mathrm{H}), 7.71(\mathrm{dd}, J=7.2,1.0 \mathrm{~Hz}, 1 \mathrm{H}), 7.60(\mathrm{~d}, J=3.7$ $\mathrm{Hz}, 1 \mathrm{H}), 7.53-7.47(\mathrm{~m}, 1 \mathrm{H}), 7.40(\mathrm{dd}, J=8.5,7.0 \mathrm{~Hz}, 2 \mathrm{H}), 7.32(\mathrm{dd}, J=8.3,7.3 \mathrm{~Hz}$, $1 \mathrm{H}), 7.21(\mathrm{~d}, J=3.6 \mathrm{~Hz}, 1 \mathrm{H}), 1.35(\mathrm{~s}, 12 \mathrm{H})$. HRMS: calculated for $\mathrm{C}_{20} \mathrm{H}_{23} \mathrm{BNO}_{4} \mathrm{~S}$ $[\mathrm{M}+\mathrm{H}]^{+}$384.1441, found 384.1438.

Synthesis of 21. Compound 21 was synthesized following our previously reported procedures [169].

Synthesis of 22. To a solution of 21 (1.0 g, $3.3 \mathrm{mmol})$ in THF $(10 \mathrm{ml})$ was added $\mathrm{N}$-bromosuccinimide $(1.07 \mathrm{~g}, 6.0 \mathrm{mmol})$ in portions. The reaction was stirred for $1.5 \mathrm{hr}$, quenched with saturated $\mathrm{Na}_{2} \mathrm{~S}_{2} \mathrm{O}_{3}$ solution, and extracted with EtOAc. The combined extracts were evaporated under reduced pressure and dried under vacuum to give crude product. The crude was dissolved in anhydrous THF $(10 \mathrm{~mL})$ at ice temperature; sodium hydride (122 mg, $3.3 \mathrm{mmol})$ was added in portions under argon. The mixture was stirred for another $1 \mathrm{hr}$ at this temperature and was added 2-(trimethylsilyl)ethoxymethyl chloride $(0.62 \mathrm{ml}, 3.3 \mathrm{mmol})$ dropwise. Reaction was then warmed to room temperature and stirred for $1.5 \mathrm{hr}$. Water was then added and the reaction mixture was extracted with ethyl acetate, washed with brine and dried with $\mathrm{Na}_{2} \mathrm{SO}_{4}$. The combined extracts were evaporated under vacuum to give the oily residue which was purified with flash chromatography on silica. Elution with hexane/ethyl acetate (10:0-10:1) gave 22 as paleyellow solid (1.4 g, 70\%).

\section{Cell culture and reagents}

Human melanoma carcinoma cell lines A375, M14, and RPMI7951 (American Type Culture Collection or ATCC, Manassas, VA, USA) were cultured in Dulbecco's modified Eagle's medium (DMEM) (Corning, Manasas, VA) supplemented with 10\% (v/v) fetal bovine serum (FBS) (Atlanta Biologicals, Lawernceville, GA) and 1\% antibiotic/antimycotic mixture (Sigma-Aldrich, St. Louis MO). Murine melanoma B16F10 cells (ATCC, Manassas, VA, USA) were cultured in Minimum essential medium 
(Invitrogen, Carlsbad, CA), supplemented with 5\% heat-inactivated Hyclone FBS (Thermo Scientific, Rockford, IL), $1 \%$ antibiotic-antimycotic mixture (Sigma-Aldrich, St. Louis MO), 1\% Mem-sodium pyruvate (Invitrogen, Carlsbad, CA), 1\% Mem-vitamin (Invitrogen, Carlsbad, CA), L-Glutamine (2mM final concentration) (Invitrogen, Carlsbad, CA), and 1\% Mem NEAA (Invitrogen, Carlsbad, CA). All cell lines were authenticated by ATCC by short tandem repeat profiling. Cultures were maintained to $80-90 \%$ confluency at $37^{\circ} \mathrm{C}$ in a humidified atmosphere containing 5\% CO2. Compounds were dissolved in dimethyl sulfoxide (DMSO) (Sigma-Aldrich, St. Louis, MO) to make a stock solution of $20 \mathrm{mM}$. Compound solutions were freshly prepared by diluting stocks with cell culture medium before use.

\section{Cytotoxicity assay}

A375, M14, and RPMI7951were seeded in 96-well plates at a concentration of 1,000-5,000 cells per well, depending on growth rate of the cell line. After overnight incubation, the media was replaced and cells were treated with the test compounds at 10 concentrations ranging from $0.03 \mathrm{nM}$ to $1 \mu \mathrm{M}$ plus a vehicle control for $72 \mathrm{~h}$ in four replicates. Following treatment, the MTS reagent (Promega, Madison, WI) was added to the cells and incubated in dark at $37^{\circ} \mathrm{C}$ for at least 1 hour. Absorbance at $490 \mathrm{~nm}$ was measured using a plate reader (DYNEX Technologies, Chantilly VA). Percentages of cell survival versus drug concentrations were plotted, and the $\mathrm{IC}_{50}$ (concentration that inhibited cell growth by $50 \%$ of untreated control) values were obtained by nonlinear regression analysis using GraphPad Prism (GraphPad Software, San Diego, CA).

\section{Chemistry}

Scheme 3-1 showed the synthetic method we followed to access the commercially expensive or unavailable benzoyl chlorides. Commercially available methyl 3-methoxy-4,5-dihydroxybenzoate was treated with dibromomethane or 1,3dibromopropane to form $\mathbf{1 a}$ and $\mathbf{1 b}$ in the presence of potassium carbonate. The cyclized benzoates were then hydrolyzed under basic condition to provide carboxylic acids $\mathbf{2 a}$ and 2b. $2 \mathbf{a}$ and $\mathbf{2 b}$ subsequently refluxed with thionyl chloride in DCM to generate benzoyl chlorides $\mathbf{3 a}$ and $\mathbf{3 b}$, which were used directly for next step without purification.

Another commercially unavailable benzoyl chloride $\mathbf{8}$ was prepared following Scheme 3-2. Methyl 3-methoxy-4,5-dihydroxybenzoate refluxed together with allyl bromide in the presence of potassium carbonate to generate alkylated methyl benzoate 4 . An isomerization/ring closing metathesis strategy as reported in the literature [195] was followed to furnish the dioxene moiety in $\mathbf{6}$. In brief, 4 was treated with a catalytic equivalent of $\left(\mathrm{Ph}_{3} \mathrm{P}\right)_{3} \mathrm{Ru}(\mathrm{CO})(\mathrm{Cl}) \mathrm{H}$ in toluene to provide $\mathbf{5}$, which was subjected to Grubbs 'reaction to afford $\mathbf{6}$. Hydrolysis of the methyl ester under basic condition provided 7, which was converted to benzoyl chloride 8 by refluxing with thionyl chloride. 8 was used directly for next step without purification. 


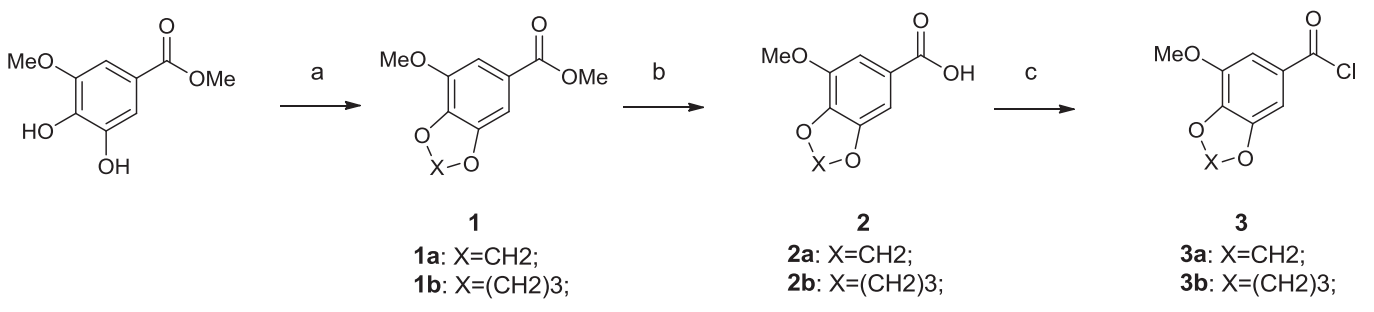

\section{Scheme 3-1. Synthesis of the benzoyl chlorides 3a-3b}

Reagents and conditions: (a): dibromomethane or 1,3-dibromopropane, $\mathrm{K}_{2} \mathrm{CO}_{3}$, acetonitrile, reflux; (b): $\mathrm{LiOH}$, dioxane- $\mathrm{H}_{2} \mathrm{O}(2: 1), 50^{\circ} \mathrm{C}$; (c): $\mathrm{SO}_{2} \mathrm{Cl}$, DCM, reflux.
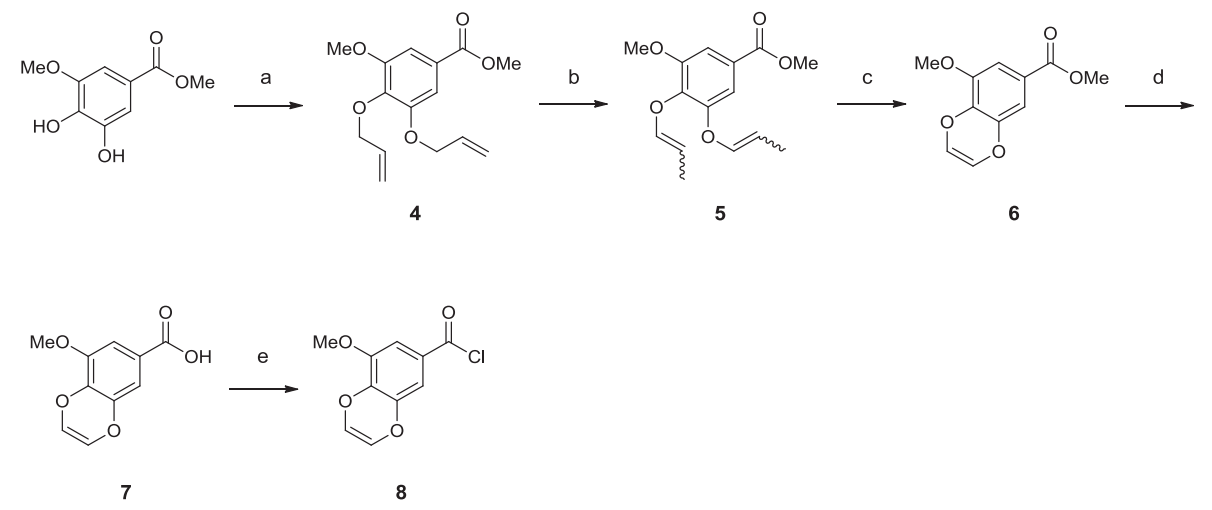

\section{Scheme 3-2. Synthesis of the benzoyl chloride 8}

Reagents and conditions: (a): allyl bromide, $\mathrm{K}_{2} \mathrm{CO}_{3}$, acetonitrile, reflux; (b): $\left(\mathrm{Ph}_{3} \mathrm{P}\right)_{3} \mathrm{Ru}(\mathrm{CO})(\mathrm{Cl}) \mathrm{H}$, toluene, reflux; (c): Grubbs' catalyst $2^{\text {nd }}$ generation, toluene, reflux; (d): $\mathrm{LiOH}$, dioxane- $\mathrm{H}_{2} \mathrm{O}(2: 1), 50^{\circ} \mathrm{C} ;(\mathrm{e}): \mathrm{SO}_{2} \mathrm{Cl}, \mathrm{DCM}$, reflux. 
ABI structure was constructed through a Suzuki coupling/Grignard reaction strategy as depicted in Scheme 3-3. In short, SEM-protected compound 9 was obtained from the treatment of 2,4,5-tribromoimidazole with $\mathrm{SEMCl}$ in the presence of sodium hydride. 9 coupled with 1-(Phenylsulfonyl)-3-indolylboronic acid pinacol ester in the presence of $\mathrm{Pd}_{2}(\mathrm{dba})_{3}$ and 2-dicyclohexylphosphino-2',4',6'-triisopropylbiphenyl to provide 10 in 34\% yield. It is worthy mentioning that Suzuki coupling reaction of this tribromo substrate under current condition was not regioselective. Coupling reactions happening on the 4- or 5-bromo were also observed. 10 was treated with $i$ - $\mathrm{PrMgCl}(\mathrm{LiCl})$ and benzoyl chlorides to furnish compounds 11a-11f in 31-48\% yields. Bromo on the imidazole moiety and benzenesulfonyl were simultaneously removed in the presence of $\mathrm{Pd}(\mathrm{OAc})_{2}, \mathrm{PPh}_{3}$ and $\mathrm{K}_{2} \mathrm{CO}_{3}$ in $n$-BuOH under reflux condition, giving 12a-12f in $76-89 \%$ yields. Deprotection of SEM using TFA in DCM finally provided ABI-231 analogues 13a-13f in 79-92\% yields.

Analogue 19 was synthesized according to Scheme 3-4. In brief, 4-bromoindole was treated with benzenesulfonyl chloride in the presence of sodium hydride to provide 14 in 93\% yield. 14 was then subjected Miyaura borylation catalyzed by $\mathrm{Pd}(\mathrm{pddf})_{2} \mathrm{Cl}_{2} \cdot \mathrm{CH}_{2} \mathrm{Cl}_{2}$ to generate 15 in $86 \%$ yield. The boronic ester 15 was then subjected to Suzuki coupling, Grignard reaction and deprotections to eventually yield analog 19.

To synthesize analog $\mathbf{2 5}$, we followed the synthetic method as shown in Scheme 3-5. 20 was prepared by following a reported procedure [169]. Bromination of imidazole 20 using $N$-bromosuccinimide in THF was followed by protection in the presence of SEMCl and sodium hydride to afford intermediate $\mathbf{2 2}$ in $70 \%$ yield over two steps. 22 was then subject to Grignard reaction and deprotections to provide analogue 25.

\section{Results}

All analogues of ABI-231 were evaluated for their cytotoxicities in human melanoma cell lines including A375, WM1641 and M14. Colchicine was used as a positive control. The antiproliferative effects of the compounds were evaluated by MTT assay. $\mathrm{IC}_{50} \mathrm{~S}$ were reported in $\mathrm{nM}$ and calculated from at least three independent experiments, each performed in duplicates. In vitro growth inhibitory effects of the new analogues were shown in Table 3-1.

13a structurally replaced the 3,4,5-TMP in ABI-231 with a benzo[4,5]-dioxane moiety. It exhibited remarkable loss of cytotoxicity in several cell lines and had an average $\mathrm{IC}_{50}$ of more than $150 \mathrm{nM}$. Shrinkage of the benzo[4,5]-dioxane to benzo[4,5]dioxole resulted in analogue $\mathbf{1 3 b}$, which showed comparable antiproliferative activity to that of 13a. In contrast to 13a, 3-methoxy counterpart 3-methoxybenzo[4,5]-dioxane analogue $13 \mathbf{c}$ showed dramatically increased inhibitory effect with an average $\mathrm{IC}_{50}$ of 21 $\mathrm{nM}$, suggesting the importance of the 3-methoxy in this scaffold. The same phenomenon was observed for 13d. When 3-methoxy was introduced to benzo[4,5]-dioxole analogue 


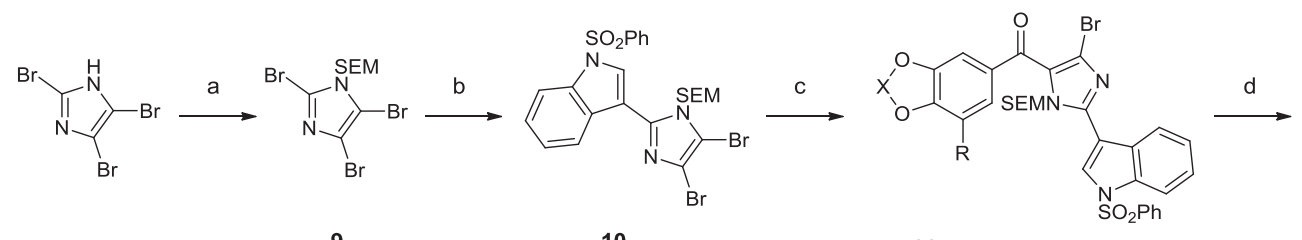

$9 \quad 10$

11a: $\mathrm{X}=\left(\mathrm{CH}_{2}\right)_{2}, \mathrm{R}=\mathrm{H}$;

11b: $X=\mathrm{CH}_{2}, \mathrm{R}=\mathrm{H}$;

11c: $\mathrm{X}=\left(\mathrm{CH}_{2}\right)_{2}, \mathrm{R}=\mathrm{OMe}$;

11d: $\mathrm{X}=\mathrm{CH}_{2}, \mathrm{R}=\mathrm{OMe}$

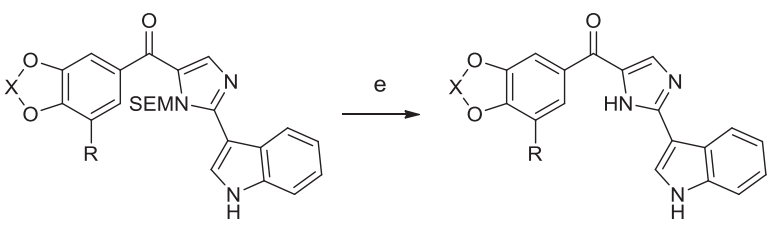

11e: $\mathrm{X}=\left(\mathrm{CH}_{2}\right)_{3}, \mathrm{R}=\mathrm{OMe}$;

11f: $\mathrm{X}=(\mathrm{CH})_{2}, \mathrm{R}=\mathrm{OMe}$;

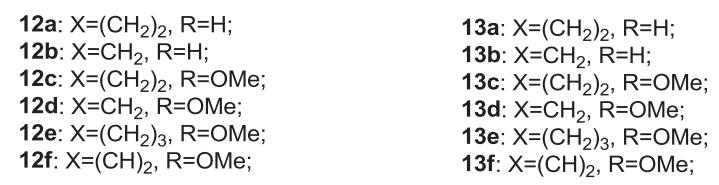

\section{Scheme 3-3. Synthesis of the ABI-231 analogues 13a-13f}

Reagents and conditions: (a): SEMCl, NaH, THF, $0^{\circ} \mathrm{C}$ to rt; (b): $\operatorname{Pd}_{2}(\mathrm{dba})_{3}, 2-$ dicyclohexylphosphino-2',4',6'-triisopropylbiphenyl, $\mathrm{Na}_{2} \mathrm{CO}_{3}$, toluene-MeOH- $\mathrm{H}_{2} \mathrm{O}$ (20:4:1), reflux; (c): benzoyl chlorides, $i$-PrMgCl(LiCl), THF, rt to reflux; $(\mathrm{d}): \mathrm{Pd}(\mathrm{OAc})_{2}$, $\mathrm{K}_{2} \mathrm{CO}_{3}, \mathrm{PPh}_{3}, n-\mathrm{BuOH}$, reflux; (e): TFA, DCM, rt.
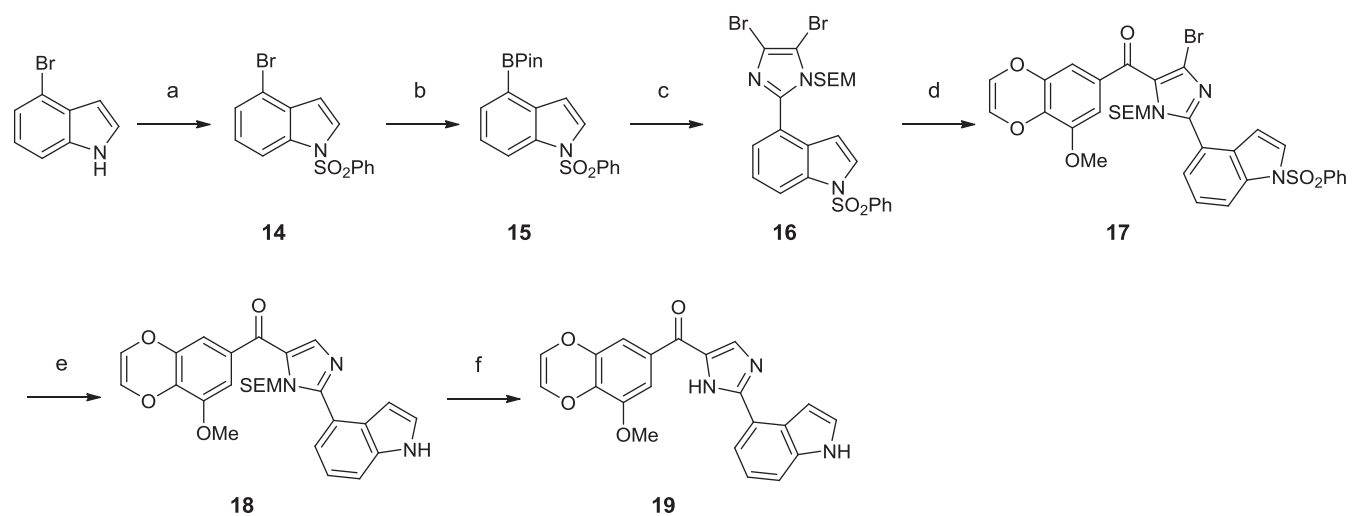

\section{Scheme 3-4. Synthesis of 19}

Reagents and conditions: (a): $\mathrm{PhSO}_{2} \mathrm{Cl}, \mathrm{NaH}, \mathrm{THF}, 0^{\circ} \mathrm{C}$ to rt; (b): bis(pinacolato)diboron, $\mathrm{Pd}(\mathrm{dppf})_{2} \cdot \mathrm{CH}_{2} \mathrm{Cl}_{2}, \mathrm{KOAc}$, dioxane, $80^{\circ} \mathrm{C}$; (c): $\mathrm{Pd}_{2}(\mathrm{dba})_{3}$, 2-dicyclohexylphosphino2',4',6'-triisopropylbiphenyl, $\mathrm{Na}_{2} \mathrm{CO}_{3}$, toluene- $\mathrm{MeOH}-\mathrm{H}_{2} \mathrm{O}$ (20:4:1), reflux; (d): 8, $i$ $\mathrm{PrMgCl}(\mathrm{LiCl}), \mathrm{THF}$, rt to reflux; (e): $\mathrm{Pd}(\mathrm{OAc})_{2}, \mathrm{~K}_{2} \mathrm{CO}_{3}, \mathrm{PPh}_{3}, n$-BuOH, reflux; (f): TFA, DCM, rt. 

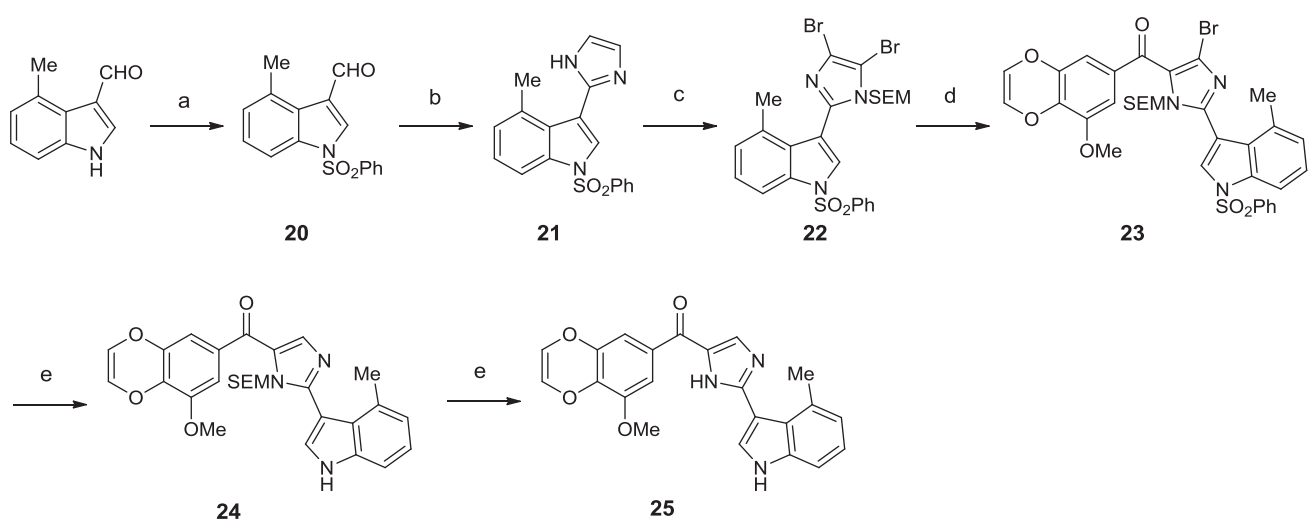

Scheme 3-5. Synthesis of 25

Reagents and conditions: (a): $\mathrm{PhSO}_{2} \mathrm{Cl}, \mathrm{NaH}, \mathrm{THF}, 0^{\circ} \mathrm{C}$ to rt; (b): $\mathrm{NH}_{4} \mathrm{OH}$, glyoxal, ethanol, reflux; (c): NBS, THF, $0^{\circ} \mathrm{C}$ to rt; (d): 8, $i-\mathrm{PrMgCl}(\mathrm{LiCl})$, THF, rt to reflux; (e): $\mathrm{Pd}(\mathrm{OAc})_{2}, \mathrm{~K}_{2} \mathrm{CO}_{3}, \mathrm{PPh}_{3}, n$-BuOH, reflux; (f): TFA, DCM, rt.

Table 3-1. In vitro growth inhibitory effects (nM) of ABI-231 analogues modifying the 3,4,5-TMP moiety $(n=3)$

\begin{tabular}{cccc}
\hline Compound & A375 & M14 & RPMI7951 \\
\hline 13a & $158.7 \pm 16.4$ & $118.8 \pm 14.3$ & $213.7 \pm 17.1$ \\
\hline 13b & $190.6 \pm 16.8$ & $154.6 \pm 10.4$ & $235.6 \pm 19.3$ \\
13c & $21.0 \pm 1.6$ & $11.3 \pm 0.8$ & $29.2 \pm 1.7$ \\
\hline 13d & $3.5 \pm 0.4$ & $5.6 \pm 0.6$ & $5.6 \pm 0.5$ \\
13e & $32.2 \pm 3.4$ & $38.2 \pm 3.5$ & $47.7 \pm 3.9$ \\
\hline $\mathbf{1 3 f}$ & $1.1 \pm 0.1$ & $1.2 \pm 0.2$ & $3.3 \pm 0.3$ \\
$\mathbf{1 9}$ & $17.1 \pm 1.1$ & $13.8 \pm 0.9$ & $34.8 \pm 2.2$ \\
$\mathbf{2 5}$ & $6.1 \pm 0.2$ & $6.1 \pm 0.2$ & $8.8 \pm 0.5$ \\
\hline Colchicine & $3.6 \pm 0.2$ & $4.8 \pm 0.4$ & $4.3 \pm 0.6$ \\
\hline
\end{tabular}


13b, 3-methoxybenzo[4,5]-dioxole analogue 13d was resulted in. 13d had an average $\mathrm{IC}_{50}$ value of $5.0 \mathrm{nM}$ and was comparable to that of ABI-231. It showed more than 30fold enhancement of activity compared to $\mathbf{1 3 b}$. 13d was $\sim 2$-fold more potent than $\mathbf{1 3 c}$. While 3-methoxy was crucial for the activities of ABI-231 analogues, the size of the cyclic rings on the phenyl moiety also mattered (13c vs 13d). Increasing the five or sixmembered rings to seven-membered ring resulted in 3-methoxybenzo[4,5]dioxepin analogue 13e, which had an average $\mathrm{IC}_{50}$ value of $39.4 \mathrm{nM}$. Taken 13c, 13d and 13e together, five-membered dioxole ring was preferred to both six-membered dioxane ring and seven-membered dioxepin ring. The likely explanation for this phenomenon is that the pocket in tubulin where the 3,4,5-TMP fit was so shallow that only small moieties (five or six-membered rings) instead of large moieties (seven-membered ring) can be accommodated. Among all the analogues modifying the 3,4,5-TMPs, 13f, a unique 3methoxybenzo[4,5]-dioxene analogue, exhibited the most potent antiproliferative activity and had an average $\mathrm{IC}_{50}$ of $1.9 \mathrm{nM}$ against a panel of melanoma cell lines. This significant improvement of activity might result from an extra hydrophobic interaction between the double bond of the dioxene and the methionine residue nearby. The current effort is on obtaining the co-crystal structure of $\mathbf{1 3 f}$ in complex with tubulin to clarify the additional interaction between dioxene moiety and tubulin.

Our previous SAR study of ABI-231 has demonstrated that ABI-231 analogues with a 4-indoly or a 4-methyl-3-indolyl moiety showed the most potent antiproliferative activities. After optimization of the 3,4,5-TMP moiety, we, therefore, have produced analogues $\mathbf{1 9}$ and $\mathbf{2 5}$. The purpose of synthesis of $\mathbf{1 9}$ and $\mathbf{2 5}$ is to investigate the combinational effect of the unique 3-methoxybenzo[4,5]-dioxene moiety with 4-indolyl moiety or 4-methyl-3-indolyl moiety. Surprisingly, the 4-indolyl analogue 19 exhibited 11 folds reduced antiproliferative activity compared to $\mathbf{1 3 f}$. This might due to the disappearance of the H-bond interaction between the NH of 4-indolyl in 19 and $\alpha$ THR179 or the absence of hydrophobic interaction between the dioxene moiety and methionine residue. Compared to 19, the 4-methyl-3-indolyl analogue 25 showed much stronger antiproliferative activity and had an average $\mathrm{IC}_{50}$ of $7.0 \mathrm{nM}$.

To summarize the SAR, 3-methoxy is indispensable in the related scaffolds. Cyclizing 4,5-dimethoxy of the 3,4,5-TMP in ABI-231 to large heterocycle (e.g. dioxepin) is detrimental to inhibitory activity. 13f with a unique 3-methoxybenzo[4,5]dioxene moiety shows the most potent activity, indicating a possible hydrophobic interaction between the dioxene and nearby residue in tubulin.

\section{Discussion}

Reported CBSIs such as colchicine, CA-4, podophyllotoxin share a common character, the 3,4,5-TMP moiety. While most structural modifications of CA-4 focus on either the double bond linkage or the 3-hydroxy-4-methoxy benzene moiety, a rare modification has been conducted on the 3,4,5-TMP moiety. 
ABI-231 showed potent antiproliferative activity and ability to surmount major drug-resistance mechanisms (e.g. overexpression of P-gp or tubulin $\beta$-III isotype). Thus, ABI-231 represents a promising scaffold for the development of anticancer agents. ABI231 consists of 3,4,5-TMP, carbonyl, imidazole and indole moieties. In Chapter 2, we have shown our effort on investigating the SAR of ABI-231 by modifying the indole moiety. The co-crystal structure of the most potent 4-methyl-3-indole analogue reported in the last chapter indicates the existence of a methionine residue nearby the 3,4,5-TMP in tubulin. We assume that this methionine residue can serve as an opportunity to introduce a hydrophobic interaction to ABI-231 scaffold. With this hypothesis in mind, we have carried out the SAR investigation of ABI-231 by modifying the 3,4,5-TMP moiety.

We herein have established a concise alternative that can efficiently generate ABI-231 analogues in gram-scale. This method circumvents the involvement of a potentially explosive azide intermediate that is reported in Chapter 2. The novel strategy involves Suzuki coupling and Grignard reactions to yield eight new ABI-231 analogues. Among the eight analogues, analogue $\mathbf{1 3 f}$ exhibits the strongest antiproliferative activity against a panel of melanoma cell lines. It has a unique 3-methoxybenzo[4,5]-dioxene moiety and an average $\mathrm{IC}_{50}$ of $1.9 \mathrm{nM}$. To the best of our knowledge, this analogue represents the most successful instance of isosterically modifying the 3,4,5-TMP moiety in CA-4 derivatives. To validate the significant potency of 13f, obtaining the co-crystal structure of $\mathbf{1 3 f}$ in complex with tubulin is currently undergoing.

In conclusion, we have established a concise synthetic method for ABI-231 analogues modifying the 3,4,5-TMP moiety. Eight new ABI-231 analogues are synthesized. The most potent analogue $\mathbf{1 3 f}$ has an average $\mathrm{IC}_{50}$ of $1.9 \mathrm{nM}$ and was 3.7fold more potent than ABI-231. 


\section{CHAPTER 4. DESIGN AND SYNTHESIS OF NOVEL RABI ANALOGUES AS POTENT ANTITUBULINS}

\section{Introduction}

Immunotherapy includes the adoptive cellular therapy and the monoclonal antibody. Immunotherapy has brought unprecedented improved survival rate for cancer patients in advanced stages and is advancing at an inspiring pace [45, 196]. However, cancer cells are able to develop multiple resistant mechanisms to circumvent the surveillance of normal host immune systems. The resistant mechanisms include but are not limited to tumor heterogeneity and metastasis, production of immune suppressive mediators, and down-modulating antigens $[197,198]$. Current cancer treatments, therefore, still rely on targeted therapy and chemotherapy. Microtubules, the hollow cylinders, are composed of $\alpha$ and $\beta$-tubulin heterodimers. Microtubules are of great importance for a variety of cellular functions in all eukaryotes [199]. During mitosis, microtubules are responsible for the formation of mitotic spindles, which segregate sister chromatids into daughter cells [200]. Disruption of the microtubule dynamics can lead to the mitotic arrest and eventually apoptosis. Thus, microtubule dynamics are targetable for developing cancer therapy [91].

Most of the MTAs are summarized well in several reviews published recently [101, 102, 201, 202]. Due to their significant off-target effects, MTAs are infertile to produce an FDA-approved drug in the last years. Different from toxin alone, ADC utilizes its monoclonal antibody part to specifically expose the anticancer agent to cancerous cells rather than healthy cells; this results in limited undesirable off-target toxicity [203]. In February 2013, the FDA approved trastuzumab emtansine, a tubulin inhibitor based ADC, for the treatment of HER2 positive breast cancer.

In order to develop a successful ADC, it is of great cruciality for the payload to possess extremely potent cytotoxicity (typically $\mathrm{IC}_{50}$ in sub-nanomolar range) because minimal of the payloads (approximately 1-2\%) can penetrate tumor cells [204]. In our previous search for potent anti-tubulins, a variety of scaffolds (Figure 4-1) including SMARTs, ABI-Is, ABI-IIs and RABIs were designed, synthesized and biologically evaluated. The SAR has shown that replacement of the phenyl moieties in ABI-I/IIs with indole moiety can improve the $\mathrm{IC}_{50}$ from double-digit nanomolar range to single-digit nanomolar range [169]. In view of the structural similarity between ABI-I/IIs and RABIs, we hypothesize that replacing the benzene moiety in RABIs with indole moiety can significantly boost the cytotoxicity (Figure 4-2). With this hypothesis in mind, we herein report the establishment of a novel and concise synthetic route for RABI scaffold. Twelve new RABI analogues with modifications of the benzene moiety are synthesized and tested for biological activities. 

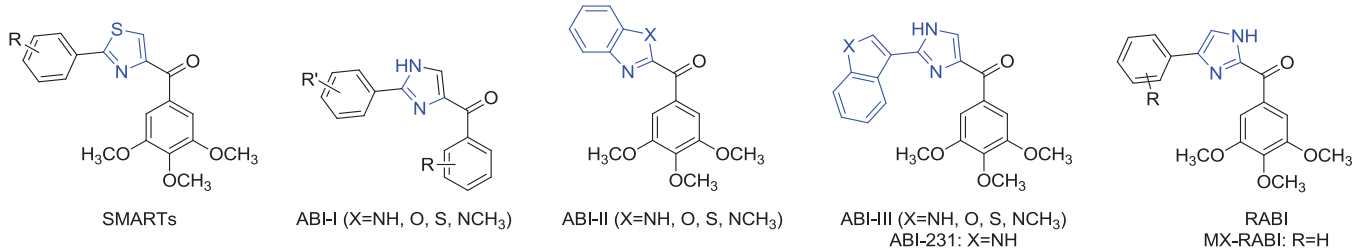

Figure 4-1. Examples of microtubule inhibitors binding to the colchicine binding sites in tubulin
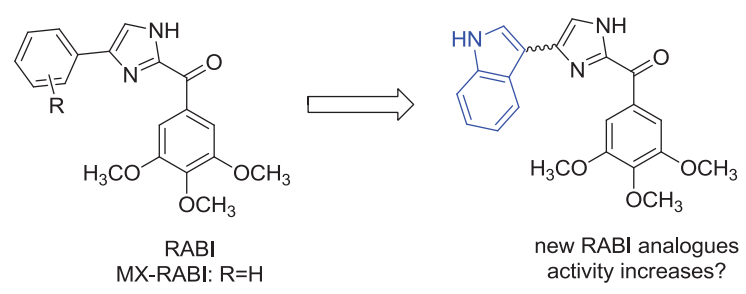

Figure 4-2. Hypothesis: modifying the benzene in RABI to indole can increase activity 


\section{Experimental Section}

\section{General chemistry}

Tetrahydrofuran was distilled from sodium-benzophenone. All other solvents and chemical reagents were obtained from commercial sources and directly used without further purification. Glassware was oven-dried before use. All reactions were performed under an argon atmosphere. TLC was performed on silica gel 60 GF254 and monitored under UV light or visualized using phosphomolybdic acid reagent. Flash chromatography was performed on 230-400 mesh silica gel (Fisher Scientific). Melting points were recorded on a MPA100 Automated Melting Point Apparatus. NMR spectra were obtained on a Bruker Ascend 400 (Billerica, MA) spectrometer or a Varian Inova-500 spectrometer (Agilent Technologies, Santa Clara, CA). HR-MS were obtained on Waters Acquity UPLC linked to Waters Acquity Photodiode Array Detector and Waters Acquity Single Quadrupole Mass Detector. Chemical shifts are given in ppm with tetramethylsilane (TMS) as an internal reference. All coupling constants $(J)$ are given in $\operatorname{Hertz}(\mathrm{Hz})$.

\section{Chemical synthesis}

General procedure for Boc protection. To a solution of indole or indazole or imidazole or pyrrolo[2,3-b]pyridine $(1.34 \mathrm{mmol})$ and 4-dimethylaminopyridine $(65 \mathrm{mg}$, $0.54 \mathrm{~mol})$ in anhydrous dichloromethane $(5 \mathrm{~mL})$ under argon was added di-tert-butyl dicarbonate $(351 \mathrm{mg}, 1.61 \mathrm{mmol})$ while stirring. After 1 hour, water was added and the reaction mixture was extracted with dichloromethane, washed with brine and dried with $\mathrm{Na}_{2} \mathrm{SO}_{4}$. Evaporation under vacuum gave the crude solid residue which was purified with flash chromatography on silica. Elution with hexane/ethyl acetate (10:1-3:1) gave pure boc-protected compounds as white to yellowish solids (55-94\% yield).

Tert-butyl 4-bromo-1H-indazole-1-carboxylate (1b). ${ }^{1} \mathrm{H}$ NMR $(400 \mathrm{MHz}$, Chloroform-d) $\delta 8.12(\mathrm{~d}, \mathrm{~J}=2.0 \mathrm{~Hz}, 1 \mathrm{H}), 8.08(\mathrm{dd}, \mathrm{J}=8.1,2.0 \mathrm{~Hz}, 1 \mathrm{H}), 7.38(\mathrm{dd}, \mathrm{J}=7.7$, $2.0 \mathrm{~Hz}, 1 \mathrm{H}), 7.35-7.28(\mathrm{~m}, 1 \mathrm{H}), 1.69(\mathrm{~s}, 9 \mathrm{H})$. HRMS: calculated for $\mathrm{C}_{12} \mathrm{H}_{14} \mathrm{BrN}_{2} \mathrm{O}_{2}$ $[\mathrm{M}+\mathrm{H}]^{+} 297.0239$, found 297.0241 .

Tert-butyl 4-bromo-1H-pyrrolo[2,3-b]pyridine-1-carboxylate (1d). ${ }^{1} \mathrm{H}$ NMR (400 MHz, Chloroform-d) $\delta 8.30-8.20(\mathrm{~m}, 1 \mathrm{H}), 7.64(\mathrm{t}, \mathrm{J}=2.9 \mathrm{~Hz}, 1 \mathrm{H}), 7.35-7.29$ (m, $1 \mathrm{H}), 6.51(\mathrm{t}, \mathrm{J}=2.9 \mathrm{~Hz}, 1 \mathrm{H}), 1.62(\mathrm{~s}, 9 \mathrm{H})$. HRMS: calculated for $\mathrm{C}_{12} \mathrm{H}_{14} \mathrm{BrN}_{2} \mathrm{O}_{2}[\mathrm{M}+\mathrm{H}]^{+}$ 297.0239, found 297.0237.

4-bromo-1-(phenylsulfonyl)indoline (2). ${ }^{1} \mathrm{H}$ NMR (400 MHz, Chloroform-d) $\delta$ $7.85-7.77(\mathrm{~m}, 2 \mathrm{H}), 7.62-7.53(\mathrm{~m}, 2 \mathrm{H}), 7.46(\mathrm{dd}, \mathrm{J}=8.4,7.1 \mathrm{~Hz}, 2 \mathrm{H}), 7.14-7.03$ (m, 2H), $3.95(\mathrm{t}, \mathrm{J}=8.5 \mathrm{~Hz}, 2 \mathrm{H}), 2.91(\mathrm{t}, \mathrm{J}=8.5 \mathrm{~Hz}, 2 \mathrm{H})$. HRMS: calculated for $\mathrm{C}_{14} \mathrm{H}_{13} \mathrm{BrNO}_{2} \mathrm{~S}[\mathrm{M}+\mathrm{H}]^{+}$337.9850, found 337.9855. 
5-bromoquinoline (5). ${ }^{1} \mathrm{H}$ NMR (400 MHz, Chloroform-d) $\delta 8.85$ (dd, J = 4.2, $1.7 \mathrm{~Hz}, 1 \mathrm{H}), 8.40(\mathrm{dt}, \mathrm{J}=8.5,1.2 \mathrm{~Hz}, 1 \mathrm{H}), 8.00(\mathrm{dt}, \mathrm{J}=8.5,1.0 \mathrm{~Hz}, 1 \mathrm{H}), 7.71(\mathrm{dd}, \mathrm{J}=7.5$, $1.1 \mathrm{~Hz}, 1 \mathrm{H}), 7.46$ (dd, J = 8.5, 7.5 Hz, 1H), 7.37 (dd, J = 8.5, 4.2 Hz, 1H). HRMS: calculated for $\mathrm{C}_{9} \mathrm{H}_{7} \mathrm{BrN}[\mathrm{M}+\mathrm{H}]^{+}$207.9762, found 207.9763.

General procedure for synthesis of boronic ester 6a-6d, 7, 8, 9, 10a-10b, 11. To a solution of bromide $(1.0 \mathrm{mmol})$ in dioxane $(10 \mathrm{~mL})$ under argon was added bis(pinacolato)diboron (3.0 mmol), $\mathrm{Pd}(\mathrm{dppf})_{2} . \mathrm{CH}_{2} \mathrm{Cl}_{2}(0.05 \mathrm{mmol}), \mathrm{KOAc}(3.0$ mmol). The reaction was kept stirring at $90{ }^{\circ} \mathrm{C}$ overnight. Dioxane was removed uder reduced pressure. Water was added and the reaction mixture was extracted with dichloromethane, washed with brine and dried with $\mathrm{Na}_{2} \mathrm{SO}_{4}$. Evaporation under vacuum gave the crude solid residue which was purified with flash chromatography on silica. Elution with hexane/ethyl acetate (30:1-10:1) gave pure boronic esters as white to yellowish oil (31-87\% yield).

Tert-butyl 4-(4,4,5,5-tetramethyl-1,3,2-dioxaborolan-2-yl)-1H-indole-1carboxylate (6a). ${ }^{1} \mathrm{H}$ NMR (400 MHz, Chloroform-d) $\delta 8.26(\mathrm{~d}, \mathrm{~J}=8.3 \mathrm{~Hz}, 1 \mathrm{H}), 7.72$ $(\mathrm{dd}, \mathrm{J}=7.2,1.1 \mathrm{~Hz}, 1 \mathrm{H}), 7.63(\mathrm{~d}, \mathrm{~J}=3.7 \mathrm{~Hz}, 1 \mathrm{H}), 7.32(\mathrm{dd}, \mathrm{J}=8.3,7.2 \mathrm{~Hz}, 1 \mathrm{H}), 7.15-$ $7.06(\mathrm{~m}, 1 \mathrm{H}), 1.68(\mathrm{~s}, 9 \mathrm{H}), 1.39(\mathrm{~s}, 12 \mathrm{H})$. HRMS: calculated for $\mathrm{C}_{19} \mathrm{H}_{27} \mathrm{BNO}_{4}[\mathrm{M}+\mathrm{H}]^{+}$ 344.2033 , found 344.2034 .

Tert-butyl 4-(4,4,5,5-tetramethyl-1,3,2-dioxaborolan-2-yl)-1H-indazole-1carboxylate (6b). ${ }^{1} \mathrm{H}$ NMR (400 MHz, Chloroform-d) $\delta 8.49(\mathrm{~d}, \mathrm{~J}=2.0 \mathrm{~Hz}, 1 \mathrm{H}), 8.19$ (d, $\mathrm{J}=8.4 \mathrm{~Hz}, 1 \mathrm{H}), 7.70(\mathrm{dd}, \mathrm{J}=7.0,1.9 \mathrm{~Hz}, 1 \mathrm{H}), 7.48-7.40(\mathrm{~m}, 1 \mathrm{H}), 1.65(\mathrm{~s}, 9 \mathrm{H}), 1.31$ (s, 12H). HRMS: calculated for $\mathrm{C}_{18} \mathrm{H}_{26} \mathrm{BN}_{2} \mathrm{O}_{4}[\mathrm{M}+\mathrm{H}]^{+} 345.1986$, found 345.1988.

Tert-butyl 4-(4,4,5,5-tetramethyl-1,3,2-dioxaborolan-2-yl)-1Hbenzo[d]imidazole-1-carboxylate (6c). ${ }^{1} \mathrm{H}$ NMR $(400 \mathrm{MHz}$, Chloroform-d) $\delta 8.55$ (s, $1 \mathrm{H}), 8.08(\mathrm{dd}, \mathrm{J}=8.2,1.3 \mathrm{~Hz}, 1 \mathrm{H}), 7.83(\mathrm{dd}, \mathrm{J}=7.3,1.2 \mathrm{~Hz}, 1 \mathrm{H}), 7.37(\mathrm{dd}, \mathrm{J}=8.1,7.3$ $\mathrm{Hz}, 1 \mathrm{H}), 1.68(\mathrm{~s}, 9 \mathrm{H}), 1.41(\mathrm{~s}, 12 \mathrm{H})$. HRMS: calculated for $\mathrm{C}_{18} \mathrm{H}_{26} \mathrm{BN}_{2} \mathrm{O}_{4}[\mathrm{M}+\mathrm{H}]^{+}$ 345.1986 , found 345.1987 .

Tert-butyl 4-(4,4,5,5-tetramethyl-1,3,2-dioxaborolan-2-yl)-1H-pyrrolo[2,3b]pyridine-1-carboxylate (6d). ${ }^{1} \mathrm{H}$ NMR $(400 \mathrm{MHz}$, Chloroform-d) $\delta 8.48(\mathrm{t}, \mathrm{J}=3.5 \mathrm{~Hz}$, $1 \mathrm{H}), 7.62(\mathrm{t}, \mathrm{J}=3.3 \mathrm{~Hz}, 1 \mathrm{H}), 7.51(\mathrm{t}, \mathrm{J}=3.6 \mathrm{~Hz}, 1 \mathrm{H}), 6.90(\mathrm{t}, \mathrm{J}=3.2 \mathrm{~Hz}, 1 \mathrm{H}), 1.63(\mathrm{~d}, \mathrm{~J}=$ $2.8 \mathrm{~Hz}, 9 \mathrm{H}), 1.34(\mathrm{~d}, \mathrm{~J}=2.5 \mathrm{~Hz}, 12 \mathrm{H})$. HRMS: calculated for $\mathrm{C}_{18} \mathrm{H}_{26} \mathrm{BN}_{2} \mathrm{O}_{4}[\mathrm{M}+\mathrm{H}]^{+}$ 345.1986 , found 345.1988 .

1-(phenylsulfonyl)-4-(4,4,5,5-tetramethyl-1,3,2-dioxaborolan-2-yl)indoline (7). ${ }^{1} \mathrm{H}$ NMR (400 MHz, Chloroform-d) $\delta 7.77$ (ddd, J = 17.2, 8.2, 1.1 Hz, 3H), 7.56 - 7.49 $(\mathrm{m}, 1 \mathrm{H}), 7.46-7.38(\mathrm{~m}, 3 \mathrm{H}), 7.22-7.16(\mathrm{~m}, 1 \mathrm{H}), 3.90(\mathrm{t}, \mathrm{J}=8.5 \mathrm{~Hz}, 2 \mathrm{H}), 3.11(\mathrm{t}, \mathrm{J}=$ $8.5 \mathrm{~Hz}, 2 \mathrm{H}), 1.27$ (s, 12H). HRMS: calculated for $\mathrm{C}_{20} \mathrm{H}_{25} \mathrm{BNO}_{4} \mathrm{~S}[\mathrm{M}+\mathrm{H}]^{+}$386.1597, found 386.1597.

Tert-butyl 6-(4,4,5,5-tetramethyl-1,3,2-dioxaborolan-2-yl)-1H-indole-1carboxylate (9). ${ }^{1} \mathrm{H}$ NMR (400 MHz, Chloroform-d) $\delta 8.66(\mathrm{~s}, 1 \mathrm{H}), 7.65(\mathrm{dd}, \mathrm{J}=7.8,0.9$ 
$\mathrm{Hz}, 1 \mathrm{H}), 7.62(\mathrm{~d}, \mathrm{~J}=3.7 \mathrm{~Hz}, 1 \mathrm{H}), 7.55(\mathrm{dd}, \mathrm{J}=7.8,0.8 \mathrm{~Hz}, 1 \mathrm{H}), 6.59-6.51(\mathrm{~m}, 1 \mathrm{H})$, $1.68(\mathrm{~s}, 9 \mathrm{H}), 1.26(\mathrm{~s}, 12 \mathrm{H})$. HRMS: calculated for $\mathrm{C}_{19} \mathrm{H}_{27} \mathrm{BNO}_{4}[\mathrm{M}+\mathrm{H}]^{+} 344.2033$, found 344.2029 .

Tert-butyl 3-(4,4,5,5-tetramethyl-1,3,2-dioxaborolan-2-yl)-1H-indole-1carboxylate (10a). HRMS: calculated for $\mathrm{C}_{19} \mathrm{H}_{27} \mathrm{BNO}_{4}[\mathrm{M}+\mathrm{H}]^{+} 344.2033$, found 344.2035 .

Tert-butyl 4-methyl-3-(4,4,5,5-tetramethyl-1,3,2-dioxaborolan-2-yl)-1Hindole-1-carboxylate (10b). ${ }^{1} \mathrm{H}$ NMR $(400 \mathrm{MHz}$, Chloroform-d) $\delta 8.05$ (d, J = 8.5 Hz, $1 \mathrm{H}), 8.01(\mathrm{~d}, \mathrm{~J}=2.3 \mathrm{~Hz}, 1 \mathrm{H}), 7.23-7.16(\mathrm{~m}, 1 \mathrm{H}), 7.04(\mathrm{dd}, \mathrm{J}=7.3,2.1 \mathrm{~Hz}, 1 \mathrm{H}), 2.71(\mathrm{~d}$, $\mathrm{J}=2.4 \mathrm{~Hz}, 3 \mathrm{H}), 1.67(\mathrm{~d}, \mathrm{~J}=2.3 \mathrm{~Hz}, 9 \mathrm{H}), 1.40-1.34(\mathrm{~m}, 12 \mathrm{H})$. HRMS: calculated for $\mathrm{C}_{20} \mathrm{H}_{29} \mathrm{BNO}_{4}[\mathrm{M}+\mathrm{H}]^{+}$358.2190, found 358.2192.

5-(4,4,5,5-tetramethyl-1,3,2-dioxaborolan-2-yl)quinolone (11). ${ }^{1} \mathrm{H}$ NMR (400 $\mathrm{MHz}$, Chloroform-d) $\delta 9.10(\mathrm{ddd}, \mathrm{J}=8.5,1.8,0.9 \mathrm{~Hz}, 1 \mathrm{H}), 8.89$ (dd, J = 4.1, $1.7 \mathrm{~Hz}, 1 \mathrm{H})$, $8.18(\mathrm{dt}, \mathrm{J}=8.4,1.0 \mathrm{~Hz}, 1 \mathrm{H}), 8.13(\mathrm{dd}, \mathrm{J}=6.9,1.3 \mathrm{~Hz}, 1 \mathrm{H}), 7.69(\mathrm{dd}, \mathrm{J}=8.4,6.9 \mathrm{~Hz}$, $1 \mathrm{H}), 7.41(\mathrm{dd}, \mathrm{J}=8.6,4.2 \mathrm{~Hz}, 1 \mathrm{H}), 1.39(\mathrm{~s}, 12 \mathrm{H})$. HRMS: calculated for $\mathrm{C}_{15} \mathrm{H}_{19} \mathrm{BNO}_{2}$ $[\mathrm{M}+\mathrm{H}]^{+}$256.1509, found 256.1510.

Synthesis of 4-bromo-1-((2-(trimethylsilyl)ethoxy)methyl)-1H-imidazole (12). To a stirred solution of 4-bromoimidazole $(25.0 \mathrm{~g}, 0.17 \mathrm{~mol})$ in anhydrous THF $(300 \mathrm{~mL})$ at ice temperature was added sodium hydride $(7.5 \mathrm{~g}, 0.187 \mathrm{~mol})$ in portions under argon. The mixture was stirred for $1 \mathrm{hr}$ at this temperature and was added 2(trimethylsilyl)ethoxymethyl chloride $(33.0 \mathrm{ml}, 0.187 \mathrm{~mol})$ dropwise. Reaction was then warmed to room temperature and stirred for another $2 \mathrm{hr}$. Water was then added at ice temperature carefully and the reaction mixture was extracted with ethyl acetate, washed with brine and dried with $\mathrm{Na}_{2} \mathrm{SO}_{4}$. The combined extracts were evaporated under vacuum to give the oily residue which was purified with flash chromatography on silica. Elution with hexane/ethyl acetate (10:1) gave 12 as slightly yellowish oil $\left(40.5 \mathrm{~g}, 86 \%\right.$ yield). ${ }^{1} \mathrm{H}$ NMR (400 MHz, Chloroform- $d$ ) $\delta 7.46(\mathrm{~s}, 1 \mathrm{H}), 7.01(\mathrm{~s}, 1 \mathrm{H}), 5.22(\mathrm{~s}, 2 \mathrm{H}), 3.53-3.40(\mathrm{~m}$, $2 \mathrm{H}), 0.95-0.85(\mathrm{~m}, 2 \mathrm{H}),-0.01(\mathrm{~s}, 9 \mathrm{H})$. HRMS: calculated for $\mathrm{C}_{9} \mathrm{H}_{18} \mathrm{BrN}_{2} \mathrm{OSi}[\mathrm{M}+\mathrm{H}]^{+}$ 277.0372 , found 277.0370 .

Synthesis of (4-bromo-1-((2-(trimethylsilyl)ethoxy)methyl)-1H-imidazol-2yl)(3,4,5-trimethoxyphenyl)methanone (13). To a stirring solution of compound 12 $(2.77 \mathrm{~g}, 10.0 \mathrm{mmol})$ in anhydrous THF $(15.0 \mathrm{~mL})$ under argon was added isopropylmagnesium chloride lithium chloride complex solution (1.3 M in THF, $9.3 \mathrm{ml}$, $12.0 \mathrm{mmol}$ ) at room temperature. The mixture was stirred for $1 \mathrm{hr}$ and was added freshly made 3,4,5-trimethoxybenzoyl chloride $(2.76 \mathrm{~g}, 12.0 \mathrm{mmol})$ in anhydrous THF ( 15.0 $\mathrm{mL})$. Reaction was kept stirring at room temperature for another $4 \mathrm{hr}$ and then saturated $\mathrm{NH}_{4} \mathrm{Cl}$ solution was added to quench the reaction. Reaction mixture was extracted with ethyl acetate, washed with brine and dried with $\mathrm{Na}_{2} \mathrm{SO}_{4}$. The combined extracts were evaporated under vacuum to give the crude product which was purified with flash chromatography on silica. Elution with hexane/ethyl acetate (20:1-5:1) gave 13 as paleyellow oil (1.1 g, 24\% yield). ${ }^{1} \mathrm{H}$ NMR (400 MHz, Chloroform- $d$ ) $\delta 7.72$ (s, 2H), 7.40 (s, 
1H), $5.81(\mathrm{~s}, 2 \mathrm{H}), 3.97$ (d, $J=2.8 \mathrm{~Hz}, 9 \mathrm{H}), 3.70-3.63(\mathrm{~m}, 2 \mathrm{H}), 1.03-0.95(\mathrm{~m}, 2 \mathrm{H}), 0.02$ (s, 9H). HRMS: calculated for $\mathrm{C}_{19} \mathrm{H}_{28} \mathrm{BrN} 2 \mathrm{O} 5 \mathrm{Si}[\mathrm{M}+\mathrm{H}]^{+} 471.0951$, found 471.0955 .

General procedure for the synthesis of 14a-14k. To the mixture of 13 (1.0 $\mathrm{mmol})$, boronate $(1.1 \mathrm{mmol})$, sodium carbonate $(2.0 \mathrm{mmol})$

tris(dibenzylideneacetone)dipalladium $(0.05 \mathrm{mmol})$ and 2-dicyclohexylphosphino2',4',6'-triisopropyl-1,1'-biphenyl $(0.15 \mathrm{mmol})$ was added $6.25 \mathrm{~mL}$ mixed solvent $\mathrm{PhCH}_{3}$ $\mathrm{MeOH}-\mathrm{H}_{2} \mathrm{O}$ (20:4:1). After refluxed for $4 \mathrm{hr}$, water was added and the reaction mixture was extracted with ethyl acetate $(3 * 10 \mathrm{~mL})$, washed with brine and dried with $\mathrm{Na}_{2} \mathrm{SO}_{4}$. Evaporation under vacuum gave the crude product which was purified with flash chromatography on silica. Elution with hexane/ethyl acetate (10:1-3:1) gave 14a-14k pale-yellow to yellowish solids or oil (yield: 27-74\%).

Tert-butyl 3-(2-(3,4,5-trimethoxybenzoyl)-1-((2(trimethylsilyl)ethoxy)methyl)-1H-imidazol-4-yl)-1H-indole-1-carboxylate (14a). ${ }^{1} \mathrm{H}$ NMR (400 MHz, Chloroform-d) $\delta 8.15$ (d, J = 7.9 Hz, 1H), 8.05 (d, J = 8.3 Hz, 1H), 7.97 $(\mathrm{d}, \mathrm{J}=1.8 \mathrm{~Hz}, 1 \mathrm{H}), 7.94-7.85(\mathrm{~m}, 4 \mathrm{H}), 7.71(\mathrm{~d}, \mathrm{~J}=1.9 \mathrm{~Hz}, 1 \mathrm{H}), 7.55-7.47(\mathrm{~m}, 1 \mathrm{H})$, $7.46-7.34(\mathrm{~m}, 3 \mathrm{H}), 7.29(\mathrm{t}, \mathrm{J}=7.4 \mathrm{~Hz}, 1 \mathrm{H}), 5.88$ (d, J = 1.9 Hz, 2H), $3.96(\mathrm{~s}, 9 \mathrm{H}), 3.74-$ $3.62(\mathrm{~m}, 2 \mathrm{H}), 1.04-0.95(\mathrm{~m}, 2 \mathrm{H}),-0.02(\mathrm{~s}, 9 \mathrm{H})$. HRMS: calculated for $\mathrm{C}_{32} \mathrm{H}_{42} \mathrm{~N}_{3} \mathrm{O}_{7} \mathrm{Si}$ $[\mathrm{M}+\mathrm{H}]^{+}$608.2792, found 608.2799.

Tert-butyl 4-(2-(3,4,5-trimethoxybenzoyl)-1-((2(trimethylsilyl)ethoxy)methyl)-1H-imidazol-4-yl)-1H-indole-1-carboxylate (14b). ${ }^{1} \mathrm{H}$ NMR (400 MHz, Chloroform-d) $\delta 8.16$ (d, J = 8.2 Hz, 1H), 7.95 (s, 2H), $7.80(\mathrm{~s}, 1 \mathrm{H})$, $7.72-7.58(\mathrm{~m}, 2 \mathrm{H}), 7.41(\mathrm{~d}, \mathrm{~J}=3.7 \mathrm{~Hz}, 1 \mathrm{H}), 7.36(\mathrm{t}, \mathrm{J}=7.9 \mathrm{~Hz}, 1 \mathrm{H}), 5.91(\mathrm{~s}, 2 \mathrm{H}), 3.97$ $(\mathrm{d}, \mathrm{J}=8.7 \mathrm{~Hz}, 9 \mathrm{H}), 3.70$ (dd, J = 8.9, $7.5 \mathrm{~Hz}, 2 \mathrm{H}), 1.69$ (s, 9H), 0.99 (dd, J = 8.9, $7.7 \mathrm{~Hz}$, $2 \mathrm{H}),-0.01$ (s, 9H). HRMS: calculated for $\mathrm{C}_{32} \mathrm{H}_{42} \mathrm{~N}_{3} \mathrm{O}_{7} \mathrm{Si}[\mathrm{M}+\mathrm{H}]^{+}$608.2792, found 608.2783 .

Tert-butyl 4-methyl-3-(2-(3,4,5-trimethoxybenzoyl)-1-((2(trimethylsilyl)ethoxy)methyl)-1H-imidazol-4-yl)-1 H-indole-1-carboxylate (14d). ${ }^{1} \mathrm{H}$ NMR (400 MHz, Chloroform-d) $\delta 8.12$ (d, J = 8.3 Hz, 1H), $7.92-7.83$ (m, 2H), 7.69 (t, J $=1.7 \mathrm{~Hz}, 1 \mathrm{H}), 7.52-7.45(\mathrm{~m}, 1 \mathrm{H}), 7.25(\mathrm{td}, \mathrm{J}=8.2,1.9 \mathrm{~Hz}, 1 \mathrm{H}), 7.02(\mathrm{~d}, \mathrm{~J}=7.4 \mathrm{~Hz}, 1 \mathrm{H})$, $5.95-5.83(\mathrm{~m}, 2 \mathrm{H}), 3.93(\mathrm{~s}, 3 \mathrm{H}), 3.91(\mathrm{~s}, 6 \mathrm{H}), 3.69(\mathrm{td}, \mathrm{J}=8.9,2.1 \mathrm{~Hz}, 2 \mathrm{H}), 2.49(\mathrm{~s}, 3 \mathrm{H})$, $1.67(\mathrm{~s}, 9 \mathrm{H}), 1.04-0.94(\mathrm{~m}, 2 \mathrm{H}),-0.00(\mathrm{~s}, 9 \mathrm{H})$. HRMS: calculated for $\mathrm{C}_{33} \mathrm{H}_{44} \mathrm{~N}_{3} \mathrm{O}_{7} \mathrm{Si}$ $[\mathrm{M}+\mathrm{H}]^{+}$622.2949, found 622.2955 .

(4-(quinolin-5-yl)-1-((2-(trimethylsilyl)ethoxy)methyl)-1H-imidazol-2yl)(3,4,5-trimethoxyphenyl)methanone (14e). ${ }^{1} \mathrm{H}$ NMR (400 MHz, Chloroform-d) $\delta$ 9.20 (ddd, J = 8.6, 1.7, $0.8 \mathrm{~Hz}, 1 \mathrm{H}), 8.95(\mathrm{dd}, \mathrm{J}=4.1,1.8 \mathrm{~Hz}, 1 \mathrm{H}), 8.13(\mathrm{dt}, \mathrm{J}=8.1,1.2$ $\mathrm{Hz}, 1 \mathrm{H}), 7.96$ (s, 2H), $7.82-7.73$ (m, 2H), 7.72 (s, 1H), 7.39 (dd, J = 8.6, 4.2 Hz, 1H), $5.94(\mathrm{~s}, 2 \mathrm{H}), 3.95(\mathrm{~s}, 3 \mathrm{H}), 3.93(\mathrm{~s}, 6 \mathrm{H}), 3.80-3.65(\mathrm{~m}, 2 \mathrm{H}), 1.05-0.96(\mathrm{~m}, 2 \mathrm{H}),-0.00(\mathrm{~s}$, $9 \mathrm{H})$. HRMS: calculated for $\mathrm{C}_{28} \mathrm{H}_{34} \mathrm{~N}_{3} \mathrm{O}_{5} \mathrm{Si}[\mathrm{M}+\mathrm{H}]^{+}$520.2268, found 520.2277.

(4-(1-(phenylsulfonyl)indolin-4-yl)-1-((2-(trimethylsilyl)ethoxy)methyl)-1Himidazol-2-yl)(3,4,5-trimethoxyphenyl)methanone (14f). ${ }^{1} \mathrm{H}$ NMR (400 MHz, 
Chloroform-d) $\delta 7.88-7.82(\mathrm{~m}, 5 \mathrm{H}), 7.67(\mathrm{dd}, \mathrm{J}=8.0,0.9 \mathrm{~Hz}, 1 \mathrm{H}), 7.59-7.53(\mathrm{~m}, 3 \mathrm{H})$, $7.46(\mathrm{dd}, \mathrm{J}=8.4,7.1 \mathrm{~Hz}, 2 \mathrm{H}), 7.31(\mathrm{t}, \mathrm{J}=7.9 \mathrm{~Hz}, 1 \mathrm{H}), 5.86(\mathrm{~s}, 2 \mathrm{H}), 4.03(\mathrm{~d}, \mathrm{~J}=8.4 \mathrm{~Hz}$, 2H), 3.99 (s, 3H), $3.94(\mathrm{~s}, 6 \mathrm{H}), 3.70-3.65(\mathrm{~m}, 2 \mathrm{H}), 3.27(\mathrm{t}, \mathrm{J}=8.4 \mathrm{~Hz}, 2 \mathrm{H}), 1.01-0.96$ $(\mathrm{m}, 2 \mathrm{H}), 0.00(\mathrm{~s}, 9 \mathrm{H})$. HRMS: calculated for $\mathrm{C}_{33} \mathrm{H}_{40} \mathrm{~N}_{3} \mathrm{O}_{7} \mathrm{SSi}[\mathrm{M}+\mathrm{H}]^{+} 650.2356$, found 650.2351 .

4-(2-(3,4,5-trimethoxybenzoyl)-1-((2-(trimethylsilyl)ethoxy)methyl)-1Himidazol-4-yl)indolin-2-one (14h). ${ }^{1} \mathrm{H}$ NMR (400 MHz, Chloroform-d) $\delta 9.06$ (s, 1H), $7.87(\mathrm{~d}, \mathrm{~J}=2.1 \mathrm{~Hz}, 2 \mathrm{H}), 7.67(\mathrm{~d}, \mathrm{~J}=2.1 \mathrm{~Hz}, 1 \mathrm{H}), 7.56(\mathrm{dd}, \mathrm{J}=8.1,2.0 \mathrm{~Hz}, 1 \mathrm{H}), 7.36$ $7.24(\mathrm{~m}, 1 \mathrm{H}), 6.93-6.83(\mathrm{~m}, 1 \mathrm{H}), 5.88(\mathrm{~d}, \mathrm{~J}=2.1 \mathrm{~Hz}, 2 \mathrm{H}), 3.99(\mathrm{dd}, \mathrm{J}=4.8,2.2 \mathrm{~Hz}, 9 \mathrm{H})$, $3.87(\mathrm{~s}, 2 \mathrm{H}), 3.74-3.64(\mathrm{~m}, 2 \mathrm{H}), 1.08-0.93(\mathrm{~m}, 2 \mathrm{H}), 0.00(\mathrm{~s}, 9 \mathrm{H})$. HRMS: calculated for $\mathrm{C}_{27} \mathrm{H}_{34} \mathrm{~N}_{3} \mathrm{O}_{6} \mathrm{Si}[\mathrm{M}+\mathrm{H}]^{+}$524.2217, found 524.2210.

Tert-butyl 4-(2-(3,4,5-trimethoxybenzoyl)-1-((2(trimethylsilyl)ethoxy)methyl)-1H-imidazol-4-yl)-1H-benzo[d]imidazole-1carboxylate (14j). ${ }^{1} \mathrm{H}$ NMR $(400 \mathrm{MHz}$, Chloroform-d) $\delta 8.63(\mathrm{~s}, 1 \mathrm{H}), 8.48(\mathrm{~s}, 1 \mathrm{H}), 8.15$ $(\mathrm{dd}, \mathrm{J}=7.8,1.1 \mathrm{~Hz}, 1 \mathrm{H}), 7.96(\mathrm{~s}, 2 \mathrm{H}), 7.92(\mathrm{dd}, \mathrm{J}=8.2,1.1 \mathrm{~Hz}, 1 \mathrm{H}), 7.45(\mathrm{t}, \mathrm{J}=7.9 \mathrm{~Hz}$, $1 \mathrm{H}), 5.92(\mathrm{~s}, 2 \mathrm{H}), 3.98(\mathrm{~s}, 6 \mathrm{H}), 3.97(\mathrm{~s}, 3 \mathrm{H}), 3.73-3.66(\mathrm{~m}, 2 \mathrm{H}), 1.72(\mathrm{~s}, 9 \mathrm{H}), 1.01-$ $0.95(\mathrm{~m}, 2 \mathrm{H}),-0.04(\mathrm{~s}, 9 \mathrm{H})$. HRMS: calculated for $\mathrm{C}_{31} \mathrm{H}_{41} \mathrm{~N}_{4} \mathrm{O}_{7} \mathrm{Si}[\mathrm{M}+\mathrm{H}]^{+} 609.2745$, found 609.2751 .

Tert-butyl 4-(2-(3,4,5-trimethoxybenzoyl)-1-((2(trimethylsilyl)ethoxy)methyl)-1H-imidazol-4-yl)-1H-pyrrolo[2,3-b]pyridine-1carboxylate (14k). ${ }^{1} \mathrm{H}$ NMR (400 MHz, Chloroform-d) $\delta 8.54(\mathrm{dd}, \mathrm{J}=5.4,2.2 \mathrm{~Hz}, 1 \mathrm{H})$, $7.95(\mathrm{t}, \mathrm{J}=1.5 \mathrm{~Hz}, 1 \mathrm{H}), 7.91(\mathrm{t}, \mathrm{J}=1.6 \mathrm{~Hz}, 2 \mathrm{H}), 7.68(\mathrm{t}, \mathrm{J}=3.2 \mathrm{~Hz}, 1 \mathrm{H}), 7.57(\mathrm{dd}, \mathrm{J}=5.6$, $2.2 \mathrm{~Hz}, 1 \mathrm{H}), 7.29(\mathrm{q}, \mathrm{J}=2.2,1.4 \mathrm{~Hz}, 1 \mathrm{H}), 5.91(\mathrm{~s}, 2 \mathrm{H}), 4.00(\mathrm{~s}, 3 \mathrm{H}), 3.96(\mathrm{~s}, 6 \mathrm{H}), 3.75$ $3.68(\mathrm{~m}, 2 \mathrm{H}), 1.70(\mathrm{~s}, 9 \mathrm{H}), 1.05-0.98(\mathrm{~m}, 2 \mathrm{H}), 0.00(\mathrm{~s}, 9 \mathrm{H})$. HRMS: calculated for $\mathrm{C}_{31} \mathrm{H}_{41} \mathrm{~N}_{4} \mathrm{O}_{7} \mathrm{Si}[\mathrm{M}+\mathrm{H}]^{+}$609.2745, found 609.2740.

General procedure for synthesis of $\mathbf{1 5 a - 1 5 k}$. For deprotection of protecting group $\mathrm{PhSO}_{2}$ and SEM: To a solution of 14a-14k $(0.3 \mathrm{mmol})$ in $\mathrm{MeOH}(3 \mathrm{~mL})$ was added $40 \% \mathrm{NaOH}(1.0 \mathrm{~mL})$. The mixture was refluxed for $2 \mathrm{hr}$, solvent was removed under reduced pressure. Water was added and the reaction mixture was extracted with ethyl acetate $\left(3^{*} 10 \mathrm{~mL}\right)$. Combined solvent was evaporated under reduced pressure to provide crude product. To the crude was then added trifluoroacetic acid in dichloromethane $(1: 1,2 \mathrm{~mL})$. After 2 hour, solvent was removed under reduced pressure. Saturated $\mathrm{NaHCO} 3$ solution and ethyl acetate was then added and the organic phase was separated, washed with brine and dried with $\mathrm{Na}_{2} \mathrm{SO}_{4}$. Evaporation under vacuum gave the solid residue which was purified with flash chromatography on silica. Elution with hexane/ethyl acetate (3:1-1:3) gave 15a-15k as pale-yellow to yellowish solids (yield: 39 $76 \%$ over two steps). For deprotection of Boc and SEM: To a solution of $14 \mathrm{a}-14 \mathrm{k}(0.2$ $\mathrm{mmol})$ in dichloromethane $(1.5 \mathrm{~mL})$ was added trifluoroacetic acid $(1.5 \mathrm{~mL})$. The mixture was stirred for $2 \mathrm{hr}$. Solvent was removed under reduced pressure. Saturated NaHCO3 solution and ethyl acetate was then added and the organic phase was separated, washed with brine and dried with $\mathrm{Na}_{2} \mathrm{SO}_{4}$. Evaporation under vacuum gave the solid residue 
which was purified with flash chromatography on silica. Elution with hexane/ethyl acetate (3:1-1:3) gave 15a-15k as pale-yellow to yellowish solids (yield: 33-81\%).

(4-(1H-indol-3-yl)-1H-imidazol-2-yl)(3,4,5-trimethoxyphenyl)methanone (15a). ${ }^{1} \mathrm{H}$ NMR $\left(400 \mathrm{MHz}\right.$, Methylene Chloride- $\left.\mathrm{d}_{2}\right) \delta 8.58(\mathrm{~s}, 1 \mathrm{H}), 8.16(\mathrm{~s}, 2 \mathrm{H}), 8.06(\mathrm{~s}$, 1H), 7.67 (s, 1H), 7.60 (d, J = 2.0 Hz, 1H), 7.48 (d, J = 8.1 Hz, 1H), 7.25 (dt, J = 22.6, 7.4 $\mathrm{Hz}, 2 \mathrm{H}), 3.97$ (s, 6H), 3.90 (s, 3H). HRMS: calculated for $\mathrm{C}_{21} \mathrm{H}_{20} \mathrm{~N}_{3} \mathrm{O}_{4}[\mathrm{M}+\mathrm{H}]^{+} 378.1454$, found 378.1453 .

(4-(1H-indol-4-yl)-1H-imidazol-2-yl)(3,4,5-trimethoxyphenyl)methanone (15b). ${ }^{1} \mathrm{H}$ NMR (400 MHz, Chloroform-d) $\delta 11.09$ (d, J = 64.7 Hz, 1H), 8.56 (d, J = 64.0 $\mathrm{Hz}, 1 \mathrm{H}), 8.32$ (s, 1H), 8.07 (s, 1H), 7.76 (dd, J = 27.3, 1.9 Hz, 1H), 7.65 (d, J = 7.3 Hz, 1H), $7.47-7.36(\mathrm{~m}, 2 \mathrm{H}), 7.36-7.22(\mathrm{~m}, 3 \mathrm{H}), 6.85(\mathrm{t}, \mathrm{J}=2.6 \mathrm{~Hz}, 1 \mathrm{H}), 4.00(\mathrm{~d}, \mathrm{~J}=10.8$ $\mathrm{Hz}, 9 \mathrm{H})$. HRMS: calculated for $\mathrm{C}_{21} \mathrm{H}_{20} \mathrm{~N}_{3} \mathrm{O}_{4}[\mathrm{M}+\mathrm{H}]^{+} 378.1454$, found 378.1451 .

(4-(1H-indol-6-yl)-1H-imidazol-2-yl)(3,4,5-trimethoxyphenyl)methanone (15c), HRMS: calculated for $\mathrm{C}_{21} \mathrm{H}_{20} \mathrm{~N}_{3} \mathrm{O}_{4}[\mathrm{M}+\mathrm{H}]^{+} 378.1454$, found 378.1455.

(4-(4-methyl-1H-indol-3-yl)-1H-imidazol-2-yl)(3,4,5trimethoxyphenyl)methanone (15d). ${ }^{1} \mathrm{H}$ NMR (400 MHz, Methylene Chloride- $\left.\mathrm{d}_{2}\right) \delta$ $7.98(\mathrm{~d}, \mathrm{~J}=2.1 \mathrm{~Hz}, 2 \mathrm{H}), 7.34(\mathrm{~d}, \mathrm{~J}=2.0 \mathrm{~Hz}, 1 \mathrm{H}), 7.30(\mathrm{~d}, \mathrm{~J}=2.1 \mathrm{~Hz}, 1 \mathrm{H}), 7.25$ (d, J = $8.2 \mathrm{~Hz}, 1 \mathrm{H}), 7.15-7.04$ (m, 1H), 6.89 (d, J = 7.1 Hz, 1H), 3.90 (s, 6H), 3.88 (s, 3H), 2.46 (s, 3H). HRMS: calculated for $\mathrm{C}_{20} \mathrm{H}_{22} \mathrm{~N}_{3} \mathrm{O}_{4}[\mathrm{M}+\mathrm{H}]^{+}$392.1610, found 392.1606.

(4-(quinolin-5-yl)-1H-imidazol-2-yl)(3,4,5-trimethoxyphenyl)methanone (15e). ${ }^{1} \mathrm{H}$ NMR (400 MHz, Chloroform-d) $\delta 11.95$ (s, 1H), 9.31 (ddd, J = 8.6, 1.7, $\left.0.9 \mathrm{~Hz}, 1 \mathrm{H}\right)$, $8.98(\mathrm{dd}, \mathrm{J}=4.2,1.7 \mathrm{~Hz}, 1 \mathrm{H}), 8.25$ (s, 2H), $8.14(\mathrm{dt}, \mathrm{J}=8.0,1.2 \mathrm{~Hz}, 1 \mathrm{H}), 7.81-7.67$ (m, 2H), $7.62(\mathrm{~d}, \mathrm{~J}=2.4 \mathrm{~Hz}, 1 \mathrm{H}), 7.40(\mathrm{dd}, \mathrm{J}=8.7,4.2 \mathrm{~Hz}, 1 \mathrm{H}), 3.94(\mathrm{~d}, \mathrm{~J}=15.7 \mathrm{~Hz}, 9 \mathrm{H})$. HRMS: calculated for $\mathrm{C}_{22} \mathrm{H}_{20} \mathrm{~N}_{3} \mathrm{O}_{4}[\mathrm{M}+\mathrm{H}]^{+} 390.1454$, found 390.1455 .

(4-(1-(phenylsulfonyl)indolin-4-yl)-1H-imidazol-2-yl)(3,4,5-

trimethoxyphenyl)methanone (15f). ${ }^{1} \mathrm{H}$ NMR $(400 \mathrm{MHz}$, Chloroform-d) $\delta 7.96(\mathrm{~s}, 2 \mathrm{H})$, $7.79-7.71(\mathrm{~m}, 2 \mathrm{H}), 7.56(\mathrm{~d}, \mathrm{~J}=8.0 \mathrm{~Hz}, 1 \mathrm{H}), 7.52-7.45(\mathrm{~m}, 1 \mathrm{H}), 7.38(\mathrm{dd}, \mathrm{J}=8.4,7.1$ $\mathrm{Hz}, 3 \mathrm{H}), 7.34$ (s, 1H), 7.22 (t, J = 7.9 Hz, 1H), 3.93 (t, J = 8.4 Hz, 2H), $3.88(\mathrm{~s}, 3 \mathrm{H}), 3.87$ $(\mathrm{s}, 6 \mathrm{H}), 3.16(\mathrm{dd}, \mathrm{J}=16.8,8.6 \mathrm{~Hz}, 2 \mathrm{H})$. HRMS: calculated for $\mathrm{C}_{27} \mathrm{H}_{26} \mathrm{~N}_{3} \mathrm{O}_{6} \mathrm{~S}[\mathrm{M}+\mathrm{H}]^{+}$ 520.1542 , found 520.1554 .

(4-(indolin-4-yl)-1H-imidazol-2-yl)(3,4,5-trimethoxyphenyl)methanone (15g). ${ }^{1} \mathrm{H}$ NMR (400 MHz, Chloroform-d) $\delta 10.90$ (d, J = 15.6 Hz, 1H), 8.23 (s, 1H), 8.05 (s, 1H), $7.55-7.41(\mathrm{~m}, 1 \mathrm{H}), 7.27(\mathrm{~d}, \mathrm{~J}=7.8 \mathrm{~Hz}, 1 \mathrm{H}), 7.16-7.03(\mathrm{~m}, 1 \mathrm{H}), 6.64(\mathrm{dd}, \mathrm{J}=7.9$, $4.3 \mathrm{~Hz}, 1 \mathrm{H}), 3.98(\mathrm{~d}, \mathrm{~J}=5.3 \mathrm{~Hz}, 9 \mathrm{H}), 3.65(\mathrm{dt}, \mathrm{J}=11.5,8.3 \mathrm{~Hz}, 2 \mathrm{H}), 3.40(\mathrm{t}, \mathrm{J}=8.3 \mathrm{~Hz}$, $1 \mathrm{H}), 3.25(\mathrm{t}, \mathrm{J}=8.4 \mathrm{~Hz}, 1 \mathrm{H})$. HRMS: calculated for $\mathrm{C}_{21} \mathrm{H}_{22} \mathrm{~N}_{3} \mathrm{O}_{4}[\mathrm{M}+\mathrm{H}]^{+} 380.1610$, found 380.1605 .

4-(2-(3,4,5-trimethoxybenzoyl)-1H-imidazol-4-yl)indolin-2-one (15h). ${ }^{1} \mathrm{H}$ NMR (400 MHz, DMSO-d 6 ) $\delta 13.68$ (s, 1H), 10.47 (s, 1H), 8.02 (d, J = 21.6 Hz, 3H), 
$7.54(\mathrm{~d}, \mathrm{~J}=8.0 \mathrm{~Hz}, 1 \mathrm{H}), 7.24(\mathrm{t}, \mathrm{J}=7.9 \mathrm{~Hz}, 1 \mathrm{H}), 6.76(\mathrm{~d}, \mathrm{~J}=7.6 \mathrm{~Hz}, 1 \mathrm{H}), 3.92(\mathrm{~s}, 6 \mathrm{H})$, $3.84(\mathrm{~s}, 2 \mathrm{H}), 3.80(\mathrm{~s}, 3 \mathrm{H})$. HRMS: calculated for $\mathrm{C}_{21} \mathrm{H}_{20} \mathrm{~N}_{3} \mathrm{O}_{5}[\mathrm{M}+\mathrm{H}]^{+} 378.1454$, found 378.1452 .

(4-(1H-indazol-4-yl)-1H-imidazol-2-yl)(3,4,5-trimethoxyphenyl)methanone (15i). ${ }^{1} \mathrm{H}$ NMR (400 MHz, DMSO-d 6 ) $\delta 13.80(\mathrm{~s}, 1 \mathrm{H}), 13.18(\mathrm{~s}, 1 \mathrm{H}), 8.82(\mathrm{~s}, 1 \mathrm{H}), 8.29(\mathrm{~s}$, $1 \mathrm{H}), 8.13(\mathrm{~s}, 2 \mathrm{H}), 7.72(\mathrm{~d}, \mathrm{~J}=6.6 \mathrm{~Hz}, 1 \mathrm{H}), 7.48(\mathrm{dd}, \mathrm{J}=28.9,7.4 \mathrm{~Hz}, 2 \mathrm{H}), 3.97$ (s, 6H), 3.87 (s, 3H). HRMS: calculated for $\mathrm{C}_{20} \mathrm{H}_{19} \mathrm{~N}_{4} \mathrm{O}_{4}[\mathrm{M}+\mathrm{H}]^{+} 379.1406$, found 379.1409 .

(4-(1H-benzo[d]imidazol-4-yl)-1H-imidazol-2-yl)(3,4,5-

trimethoxyphenyl)methanone (15j). ${ }^{1} \mathrm{H}$ NMR $(400 \mathrm{MHz}$, Chloroform-d) $\delta 8.00(\mathrm{~s}, 1 \mathrm{H})$, $7.74(\mathrm{~d}, \mathrm{~J}=24.9 \mathrm{~Hz}, 3 \mathrm{H}), 7.63-7.24(\mathrm{~m}, 2 \mathrm{H}), 7.23-7.13(\mathrm{~m}, 1 \mathrm{H}), 3.83(\mathrm{~d}, \mathrm{~J}=4.3 \mathrm{~Hz}$, 9H). HRMS: calculated for $\mathrm{C}_{20} \mathrm{H}_{19} \mathrm{~N}_{4} \mathrm{O}_{4}[\mathrm{M}+\mathrm{H}]^{+} 379.1406$, found 379.1407 .

(4-(1H-pyrrolo[2,3-b]pyridin-4-yl)-1H-imidazol-2-yl)(3,4,5trimethoxyphenyl)methanone (15k). ${ }^{1} \mathrm{H}$ NMR (400 MHz, DMSO-d $\left.\mathrm{d}_{6}\right) \delta 14.05-13.58$ (m, 1H), $11.68(\mathrm{~s}, 1 \mathrm{H}), 8.39-8.19(\mathrm{~m}, 2 \mathrm{H}), 8.11(\mathrm{~s}, 2 \mathrm{H}), 7.57(\mathrm{dd}, \mathrm{J}=29.4,3.7 \mathrm{~Hz}, 2 \mathrm{H})$, $7.20(\mathrm{~s}, 1 \mathrm{H}), 3.93(\mathrm{~s}, 6 \mathrm{H}), 3.82(\mathrm{~s}, 3 \mathrm{H})$. HRMS: calculated for $\mathrm{C}_{20} \mathrm{H}_{19} \mathrm{~N}_{4} \mathrm{O}_{4}[\mathrm{M}+\mathrm{H}]^{+}$ 379.1406 , found 379.1403 .

Synthesis of (4-bromo-1-((2-(trimethylsilyl)ethoxy)methyl)-1H-imidazol-2yl)(8-methoxybenzo[b] $[1,4]$ dioxin-6-yl)methanone (16). To a stirring solution of compound $12(1.38 \mathrm{~g}, 5.0 \mathrm{mmol})$ in anhydrous THF $(10.0 \mathrm{~mL})$ under argon was added isopropylmagnesium chloride lithium chloride complex solution (1.3 M in THF, $4.6 \mathrm{ml}$, $6.0 \mathrm{mmol}$ ) at room temperature. The mixture was stirred for $1 \mathrm{hr}$ and was added 3methoxy[4,5]dioxene benzoyl chloride $(1.5 \mathrm{~g}, 6.5 \mathrm{mmol})$ in anhydrous THF $(7.0 \mathrm{~mL})$. Reaction was kept stirring at room temperature for another $4 \mathrm{hr}$ and then saturated $\mathrm{NH}_{4} \mathrm{Cl}$ solution was added to quench the reaction. Reaction mixture was extracted with ethyl acetate, washed with brine and dried with $\mathrm{Na}_{2} \mathrm{SO}_{4}$. The combined extracts were evaporated under vacuum to give the crude product which was purified with flash chromatography on silica. Elution with hexane/ethyl acetate (20:1-5:1) gave $\mathbf{1 6}$ as paleyellow oil ( $0.74 \mathrm{~g}, 32 \%$ yield). ${ }^{1} \mathrm{H}$ NMR $(400 \mathrm{MHz}$, Chloroform- $d$ ) $\delta 7.59(\mathrm{~s}, 1 \mathrm{H}), 7.44$ (s, $1 \mathrm{H}), 7.36-7.30(\mathrm{~m}, 1 \mathrm{H}), 5.98(\mathrm{dd}, J=3.7,1.6 \mathrm{~Hz}, 1 \mathrm{H}), 5.90(\mathrm{dd}, J=3.8,1.5 \mathrm{~Hz}$, $1 \mathrm{H}), 5.79-5.70(\mathrm{~m}, 2 \mathrm{H}), 3.96-3.82(\mathrm{~m}, 3 \mathrm{H}), 3.61(\mathrm{td}, J=8.4,1.4 \mathrm{~Hz}, 2 \mathrm{H}), 1.00-0.90$ (m, 2H), -0.01 (s, 9H). HRMS: calculated for $\mathrm{C}_{19} \mathrm{H}_{24} \mathrm{BrN}_{2} \mathrm{O}_{5} \mathrm{Si}[\mathrm{M}+\mathrm{H}]^{+} 467.0638$, found 467.0644 .

Synthesis of tert-butyl 4-(2-(8-methoxybenzo[b][1,4]dioxine-6-carbonyl)-1((2-(trimethylsilyl)ethoxy)methyl)-1H-imidazol-4-yl)-3-methyl-1H-indole-1carboxylate (17). To the mixture of 16 (467 $\mathrm{mg}, 1.0 \mathrm{mmol}), 10 \mathrm{~b}(392 \mathrm{mg}, 1.1 \mathrm{mmol})$, sodium carbonate $(2.0 \mathrm{mmol})$ tris (dibenzylideneacetone)dipalladium $(0.05 \mathrm{mmol})$ and 2dicyclohexylphosphino-2', $4^{\prime}, 6^{\prime}$-triisopropyl-1,1'-biphenyl $(0.15 \mathrm{mmol})$ was added 6.25 $\mathrm{mL}$ mixed solvent $\mathrm{PhCH}_{3}-\mathrm{MeOH}-\mathrm{H}_{2} \mathrm{O}$ (20:4:1). After refluxed for $4 \mathrm{hr}$, water was added and the reaction mixture was extracted with ethyl acetate $(3 * 10 \mathrm{~mL})$, washed with brine and dried with $\mathrm{Na}_{2} \mathrm{SO}_{4}$. Evaporation under vacuum gave the crude product which was purified with flash chromatography on silica. Elution with hexane/ethyl acetate (10:1-3:1) 
gave 17 as yellowish solid (376 mg, 61\%). ${ }^{1} \mathrm{H}$ NMR (400 MHz, Chloroform- $d$ ) $\delta 8.25(\mathrm{~d}$, $J=8.3 \mathrm{~Hz}, 1 \mathrm{H}), 7.82(\mathrm{~d}, J=1.9 \mathrm{~Hz}, 1 \mathrm{H}), 7.62(\mathrm{~d}, J=1.9 \mathrm{~Hz}, 1 \mathrm{H}), 7.45$ (s, 1H), 7.39 (d, $J$ $=2.1 \mathrm{~Hz}, 1 \mathrm{H}), 7.33(\mathrm{dd}, J=8.3,7.4 \mathrm{~Hz}, 1 \mathrm{H}), 7.29-7.24(\mathrm{~m}, 1 \mathrm{H}), 5.97(\mathrm{~d}, J=3.6 \mathrm{~Hz}$, $1 \mathrm{H}), 5.92-5.86(\mathrm{~m}, 3 \mathrm{H}), 3.88(\mathrm{~s}, 3 \mathrm{H}), 3.71-3.64(\mathrm{~m}, 2 \mathrm{H}), 2.06(\mathrm{~d}, J=1.3 \mathrm{~Hz}, 3 \mathrm{H}), 1.68$ $(\mathrm{s}, 9 \mathrm{H}), 1.02-0.96(\mathrm{~m}, 2 \mathrm{H}), 0.00(\mathrm{~s}, 9 \mathrm{H})$. HRMS: calculated for $\mathrm{C}_{33} \mathrm{H}_{40} \mathrm{~N}_{3} \mathrm{O}_{7} \mathrm{Si}[\mathrm{M}+\mathrm{H}]^{+}$ 618.2636, found 618.2628.

Synthesis of (8-methoxybenzo[b][1,4]dioxin-6-yl)(4-(3-methyl-1H-indol-4-yl)1H-imidazol-2-yl)methanone (18). To a solution of $17(0.1 \mathrm{mmol})$ in dichloromethane $(1.5 \mathrm{~mL})$ was added trifluoroacetic acid $(1.5 \mathrm{~mL})$. The mixture was stirred for $2 \mathrm{hr}$. Solvent was removed under reduced pressure. Saturated $\mathrm{NaHCO} 3$ solution and ethyl acetate was then added and the organic phase was separated, washed with brine and dried with $\mathrm{Na}_{2} \mathrm{SO}_{4}$. Evaporation under vacuum gave the solid residue which was purified with flash chromatography on silica. Elution with hexane/ethyl acetate (3:1-1:3) gave 18 as yellowish solid (28 mg, 74\%). ${ }^{1} \mathrm{H}$ NMR (400 MHz, Chloroform- $d$ ) $\delta 11.36(\mathrm{~s}, 1 \mathrm{H}), 8.30$ (s, 1H), 7.85 (s, 1H), 7.63 (s, 1H), $7.40(\mathrm{~d}, J=22.8 \mathrm{~Hz}, 2 \mathrm{H}), 7.15$ (dd, $J=24.1,7.4 \mathrm{~Hz}$, 2H), $6.98(\mathrm{~s}, 1 \mathrm{H}), 5.95(\mathrm{dd}, J=29.6,3.5 \mathrm{~Hz}, 2 \mathrm{H}), 3.87(\mathrm{~s}, 3 \mathrm{H}), 2.05$ (s, 3H). HRMS: calculated for $\mathrm{C}_{22} \mathrm{H}_{18} \mathrm{~N}_{3} \mathrm{O}_{4}[\mathrm{M}+\mathrm{H}]^{+} 388.1297$, found 388.1301 .

\section{Cell culture and reagents}

Human melanoma carcinoma cell lines A375, M14, and RPMI7951 (American Type Culture Collection or ATCC, Manassas, VA, USA) were cultured in Dulbecco's modified Eagle's medium (DMEM) (Corning, Manasas, VA) supplemented with 10\% (v/v) fetal bovine serum (FBS) (Atlanta Biologicals, Lawernceville, GA) and 1\% antibiotic/antimycotic mixture (Sigma-Aldrich, St. Louis MO). Murine melanoma B16F10 cells (ATCC, Manassas, VA, USA) were cultured in Minimum essential medium (Invitrogen, Carlsbad, CA), supplemented with 5\% heat-inactivated Hyclone FBS (Thermo Scientific, Rockford, IL), $1 \%$ antibiotic-antimycotic mixture (Sigma-Aldrich, St. Louis MO), 1\% Mem-sodium pyruvate (Invitrogen, Carlsbad, CA), 1\% Mem-vitamin (Invitrogen, Carlsbad, CA), L-Glutamine (2mM final concentration) (Invitrogen, Carlsbad, CA), and 1\% Mem NEAA (Invitrogen, Carlsbad, CA). All cell lines were authenticated by ATCC by short tandem repeat profiling. Cultures were maintained to $80-90 \%$ confluency at $37^{\circ} \mathrm{C}$ in a humidified atmosphere containing 5\% CO2. Compounds were dissolved in dimethyl sulfoxide (DMSO) (Sigma-Aldrich, St. Louis, MO) to make a stock solution of $20 \mathrm{mM}$. Compound solutions were freshly prepared by diluting stocks with cell culture medium before use.

\section{Cytotoxicity assay}

A375, M14, and RPMI7951were seeded in 96-well plates at a concentration of 1,000-5,000 cells per well, depending on growth rate of the cell line. After overnight incubation, the media was replaced and cells were treated with the test compounds at 10 concentrations ranging from $0.03 \mathrm{nM}$ to $1 \mu \mathrm{M}$ plus a vehicle control for $72 \mathrm{~h}$ in four 
replicates. Following treatment, the MTS reagent (Promega, Madison, WI) was added to the cells and incubated in dark at $37^{\circ} \mathrm{C}$ for at least 1 hour. Absorbance at $490 \mathrm{~nm}$ was measured using a plate reader (DYNEX Technologies, Chantilly VA). Percentages of cell survival versus drug concentrations were plotted, and the $\mathrm{IC}_{50}$ (concentration that inhibited cell growth by $50 \%$ of untreated control) values were obtained by nonlinear regression analysis using GraphPad Prism (GraphPad Software, San Diego, CA).

\section{Chemistry}

Our proposed synthetic strategy for RABI analogues is illustrated in Scheme 4-1. To construct the RABI scaffold, we resort to Suzuki coupling reaction using boronic esters and bromides. The bromides are afforded by Grignard reactions, in which 4bromoimidazole is treated with benzoyl chlorides.

Preparation of the boronic esters was carried out according to reported procedures [205-207] as outlined in Scheme 4-2. In brief, bromides were protected with Boc or benzenesulfonyl, followed by Miyaura borylation in the presence of $\operatorname{Pd}(\mathrm{dppf})_{2}$ in complex with $\mathrm{CH}_{2} \mathrm{Cl}_{2}$ and potassium acetate to provide boronates 6a-6d and 7-11.

RABI analogues 15a-15k were accomplished by following the synthetic approach as depicted in Scheme 4-3. Commercially available 4-bromoimidazole reacted with $\mathrm{SEMCl}$ in the presence of sodium hydride to provide SEM protected product $\mathbf{1 2}$ in $86 \%$ yield. Treatment of 12 with Grignard reagent $i$-PrMgCl( $\mathrm{LiCl})$ and 3,4,5trimethoxybenzoyl chloride provided 13 in 24\% yield. Suzuki cross-coupling of 13 with pinacol boronic esters in the presence of $\operatorname{Pd}_{2}(\mathrm{dba})_{3}$ and 2-dicyclohexylphosphino-2', $4^{\prime}, 6^{\prime}-$ triisopropylbiphenyl afforded compounds 14a-14k. 14a-14k were subjected to the deprotection of benzensulfonyl, Boc and 2-(Trimethylsilyl)ethoxymethyl to furnish target RABI analogues 15a-15k. Cleavage of the protecting groups of 2(Trimethylsilyl)ethoxymethyl and boc in $\mathbf{1 5 a - 1 5 k}$ can be simultaneously achieved using trifluoroacetic acid while benzenesulfonyl group can be removed by refluxing in sodium hydroxide solution.

Analogue 18 was obtained in a similar manner to that of $\mathbf{1 5 a - 1 5 k}$. Its synthesis was outlined in Scheme 4-4. The synthesis of the starting material 3methoxy[4,5]dioxene benzoyl chloride was described in Chapter 3.

\section{Results}

All new RABI analogues were evaluated for their cytotoxicity in human melanoma cell lines including A375, M14 and RMPI7951. Colchicine was used as a positive control. The antiproliferative effects of all the compounds were evaluated using MTT assay. $\mathrm{IC}_{50}$ s were reported in $\mathrm{nM}$ and calculated from at least three independent experiments, each of which were performed in duplicates. The in vitro assay result was 


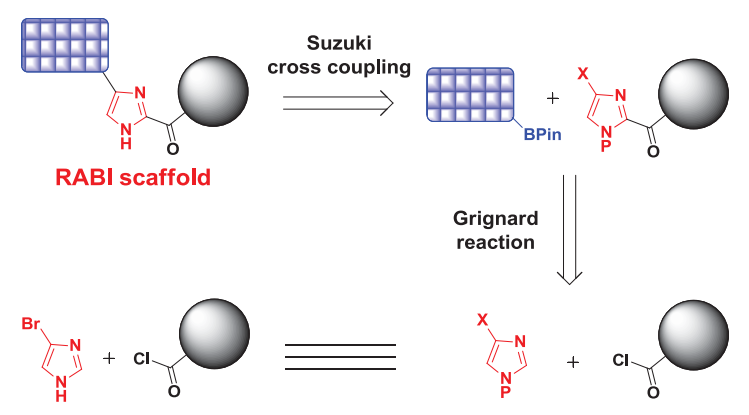

Scheme 4-1. Retrosynthetic analysis of RABI analogues
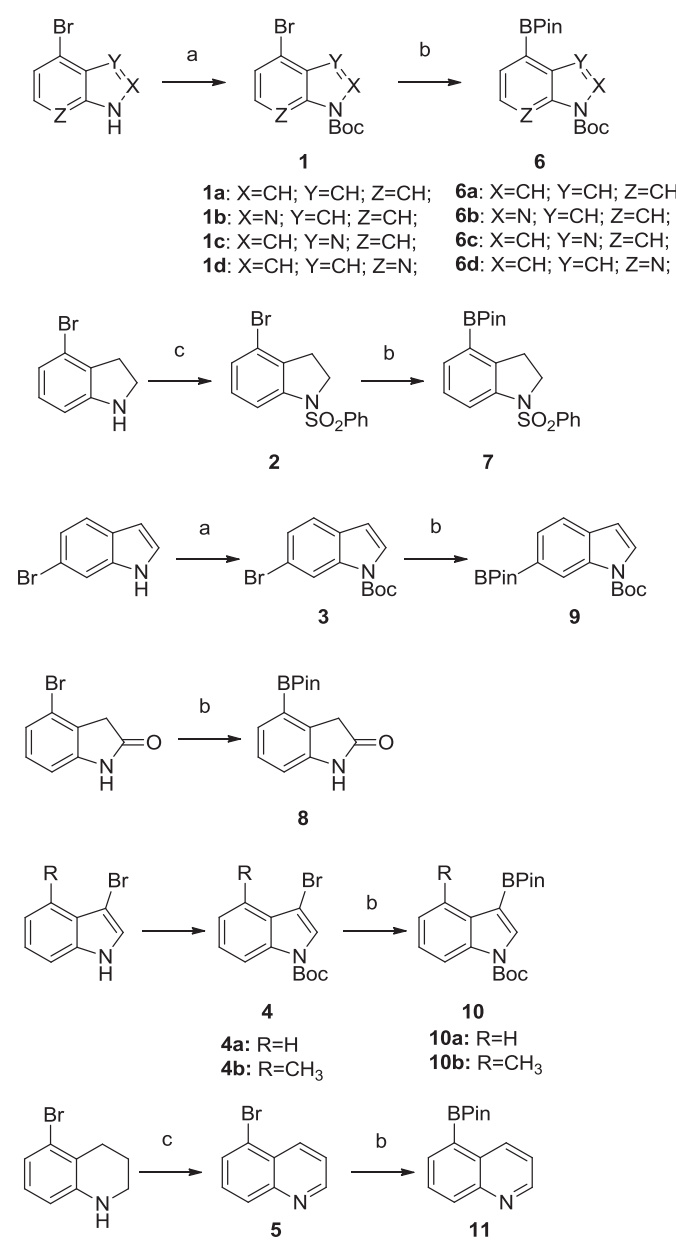

Scheme 4-2. Synthesis of boronic esters

Reagents and conditions: (a): $\mathrm{Boc}_{2} \mathrm{O}$, DMAP, DCM, rt; (b): bis(pinacolato)diboron, $\mathrm{Pd}(\mathrm{dppf})_{2} . \mathrm{CH}_{2} \mathrm{Cl}_{2}$, KOAc, dioxane, $80^{\circ} \mathrm{C}$; (c): $\mathrm{PhSO}_{2} \mathrm{Cl}$, $\mathrm{NaH}, \mathrm{THF}, 0^{\circ} \mathrm{C}$ to rt. 


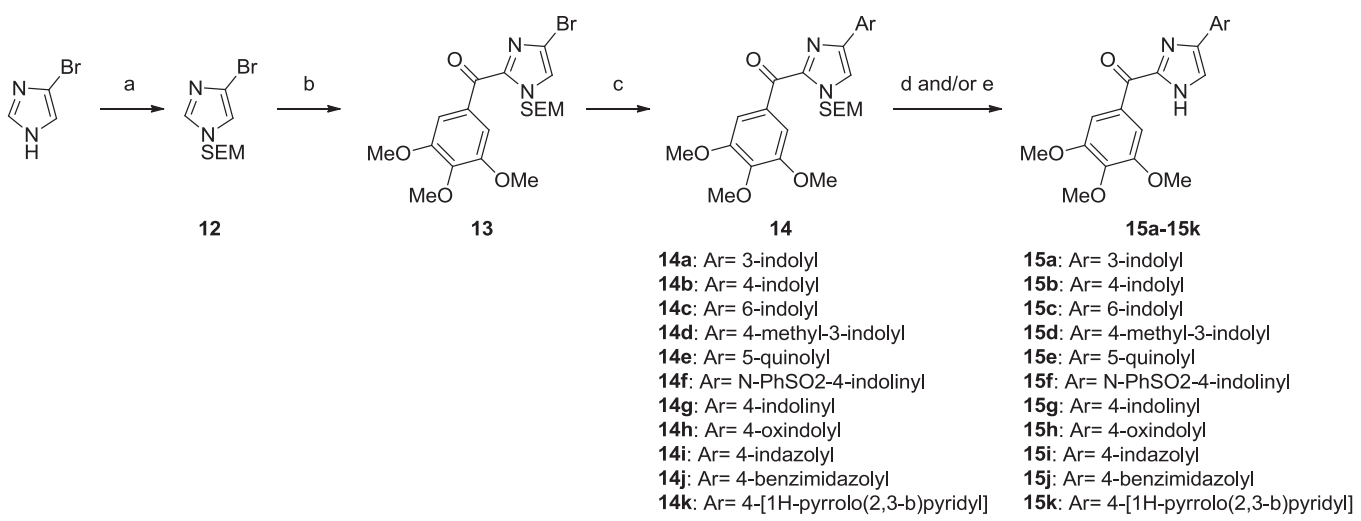

Scheme 4-3. Synthesis of RABI analogues 15a-15k

Reagents and conditions: (a): $\mathrm{SEMCl}, \mathrm{NaH}, \mathrm{THF}, 0^{\circ} \mathrm{C}$ to $\mathrm{rt}$; (b): 3,4,5-trimethoxybenzoyl chloride, $i$-PrMgCl(LiCl), THF, rt; (c): $\mathrm{Pd}_{2}(\mathrm{dba})_{3}$, 2-dicyclohexylphosphino-2', 4',6'triisopropylbiphenyl, $\mathrm{Na}_{2} \mathrm{CO}_{3}$, toluene-MeOH- $\mathrm{H}_{2} \mathrm{O}$ (20:4:1), reflux; (d): $\mathrm{NaOH}(40 \%$ in $\left.\mathrm{H}_{2} \mathrm{O}\right), \mathrm{MeOH}$, reflux; (e): TFA, DCM, rt.

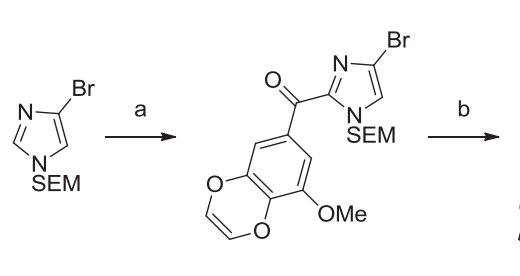

16

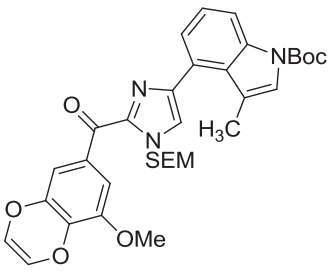

17

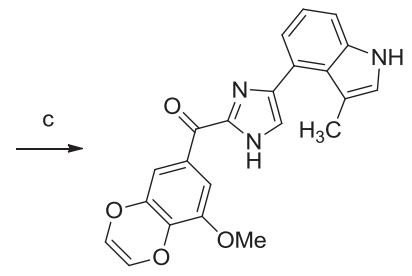

18

Scheme 4-4. Synthesis of RABI analog 18

Reagents and conditions: (a): 3 -methoxy[4,5]dioxene benzoyl chloride, $i$-PrMgCl( $\mathrm{LiCl})$, THF, rt; (b): $\mathrm{Pd}_{2}(\mathrm{dba})_{3}$, 2-dicyclohexylphosphino-2',4',6'-triisopropylbiphenyl, $\mathrm{Na}_{2} \mathrm{CO}_{3}$, toluene-MeOH- $\mathrm{H}_{2} \mathrm{O}$ (20:4:1), reflux; (c): TFA, DCM, rt. 
shown in Table 4-1.

In our previously disclosed RABI series, the most potent analogue MX-RABI had an average $\mathrm{IC}_{50}$ of $14 \mathrm{nM}$ against a panel of melanoma and prostate cancer cell lines. When the benzene moiety in MX-RABI was replaced with a 3-indolyl group, compound 15a was resulted in. 15a was 2.5-fold less active than the MX-RABI. Our previous SAR study of ABI-231 in Chapter 2 showed that rotation of the indole ring or introduction of small substituents to the indole ring in ABI-231 can significantly improve antitubulin activity. To further develop SAR, we synthesized 4-indolyl, 6-indolyl and 4-methyl-3indolyl RABI analogues $\mathbf{1 5 b}, \mathbf{1 5 c}$ and $\mathbf{1 5 d}$. It turned out that neither altering the 3 -indolyl to 6-indolyl (15c) nor adding a 4-methyl group to 3-indolyl (15d) was beneficial to the antiproliferative activity. $\mathbf{1 5 b}$, an analogue resulted from alteration of the 3 -indolyl to 4indolyl, exhibited greatly enhanced antiproliferative activity and had an average $\mathrm{IC}_{50}$ of $3.5 \mathrm{nM}$. 15b was 4-fold and $\sim$-fold more cytotoxic than MX-RABI and ABI-231, respectively. Having shown that a 4-indolyl moiety significantly improved the antiproliferative activity, we shifted our effort to investigate SAR by replacing 4-indole with structurally similar bicyclic heterocycles. With this aim in mind, we have synthesized analogues 15e-15k. When the 4-indolyl was enlarged to 5-quinolyl (15e), antiproliferative activity was markedly lost, suggesting the crucial role of the NH in4indolyl. Replacement of the N-PhSO 2 in $\mathbf{1 5 f}$ with $\mathrm{N}-\mathrm{H}(\mathbf{1 5 g})$ restored the activity from micromolar range to $21 \mathrm{nM}$, which supported the significance of the free $\mathrm{NH}$ in 4indoline. Analogue $\mathbf{1 5 h}$ with a 4-oxindolyl substructure showed equipotent activity to MX-RABI and had an average $\mathrm{IC}_{50}$ of $13.7 \mathrm{nM}$. Adding extra nitrogen to the 4-indolyl analogue (15b) formed a 4-indazoyl analogue 15i. 15i had an average $\mathrm{IC}_{50}$ of $0.8 \mathrm{nM}$. It was $>4$-fold more cytotoxic than $\mathbf{1 5 b}$; its antiproliferative activity increased by approximately 18-fold compared to that of MX-RABI; its activity enhanced by nearly an order of magnitude when compared to that of ABI-231. Encouraged by this observation, we have synthesized another two analogues $\mathbf{1 5} \mathbf{j}$ and $\mathbf{1 5 k}$. 15j shifted the nitrogen on the 2-position of indazole to the 3-position while $\mathbf{1 5 k}$ relocated that to the 7-position. $\mathbf{1 5} \mathbf{j}$ and 15k both were significantly less active than $\mathbf{1 5 i}$ although showed potent activities with $\mathrm{IC}_{50} \mathrm{~S}$ in double-digit nanomolar range.

\section{Discussion}

RABI compounds structurally resulted from the rotation of imidazole in ABI scaffold. RABIs are potent tubulin inhibitors with antiproliferative activities in doubledigit nanomolar range. In our continuing effort on improving the biological activities of RABIs, we hypothesize that replacing the benzene moiety in MX-RABI with indoles can improve its inhibitory activity.

In our initial attempt to establish the RABI scaffold, we followed the synthetic method reported previously [185] and have tried the Debus-Radziszewski imidazole synthesis as shown in Figure 4-3. The tested reaction involved indolyl 3-glyoxal and 3,4,5-trimethoxyphenyl glyoxal as reactants. Disappointingly, only the product with two 
Table 4-1. In vitro growth inhibitory effects $(\mathrm{nM})$ of $\mathrm{RABI}$ analogues $(\mathrm{n}=3)$

\begin{tabular}{cccc}
\hline Compound & A375 & M14 & RMPI7951 \\
\hline 15a & $26.8 \pm 1.0$ & $29.1 \pm 1.2$ & $49.9 \pm 3.2$ \\
$\mathbf{1 5 b}$ & $3.2 \pm 0.2$ & $2.3 \pm 0.2$ & $5.1 \pm 0.3$ \\
$\mathbf{1 5 c}$ & $37.9 \pm 2.0$ & $38.5 \pm 3.8$ & $85.2 \pm 7.0$ \\
$\mathbf{1 5 d}$ & $101.4 \pm 2.4$ & $99.7 \pm 3.4$ & $134.4 \pm 5.9$ \\
$\mathbf{1 5} \mathbf{e}$ & $>1000.0$ & $>1000.0$ & $>1000.0$ \\
$\mathbf{1 5 f}$ & $>1000.0$ & $>1000.0$ & $>1000.0$ \\
$\mathbf{1 5 g}$ & $16.3 \pm 0.7$ & $21.0 \pm 1.7$ & $25.7 \pm 1.6$ \\
$\mathbf{1 5 h}$ & $12.7 \pm 0.8$ & $13.4 \pm 0.6$ & $15.0 \pm 0.7$ \\
$\mathbf{1 5 i}$ & $0.7 \pm 0.1$ & $0.7 \pm 0.1$ & $1.1 \pm 0.1$ \\
$\mathbf{1 5 j}$ & $34.6 \pm 2.1$ & $38.5 \pm 2.4$ & $43.1 \pm 2.9$ \\
$\mathbf{1 5 k}$ & $18.7 \pm 1.1$ & $18.4 \pm 0.8$ & $32.0 \pm 1.4$ \\
$\mathbf{1 8}$ & $281.8 \pm 23.7$ & $249.1 \pm 19.9$ & $376.2 \pm 65.7$ \\
\hline
\end{tabular}



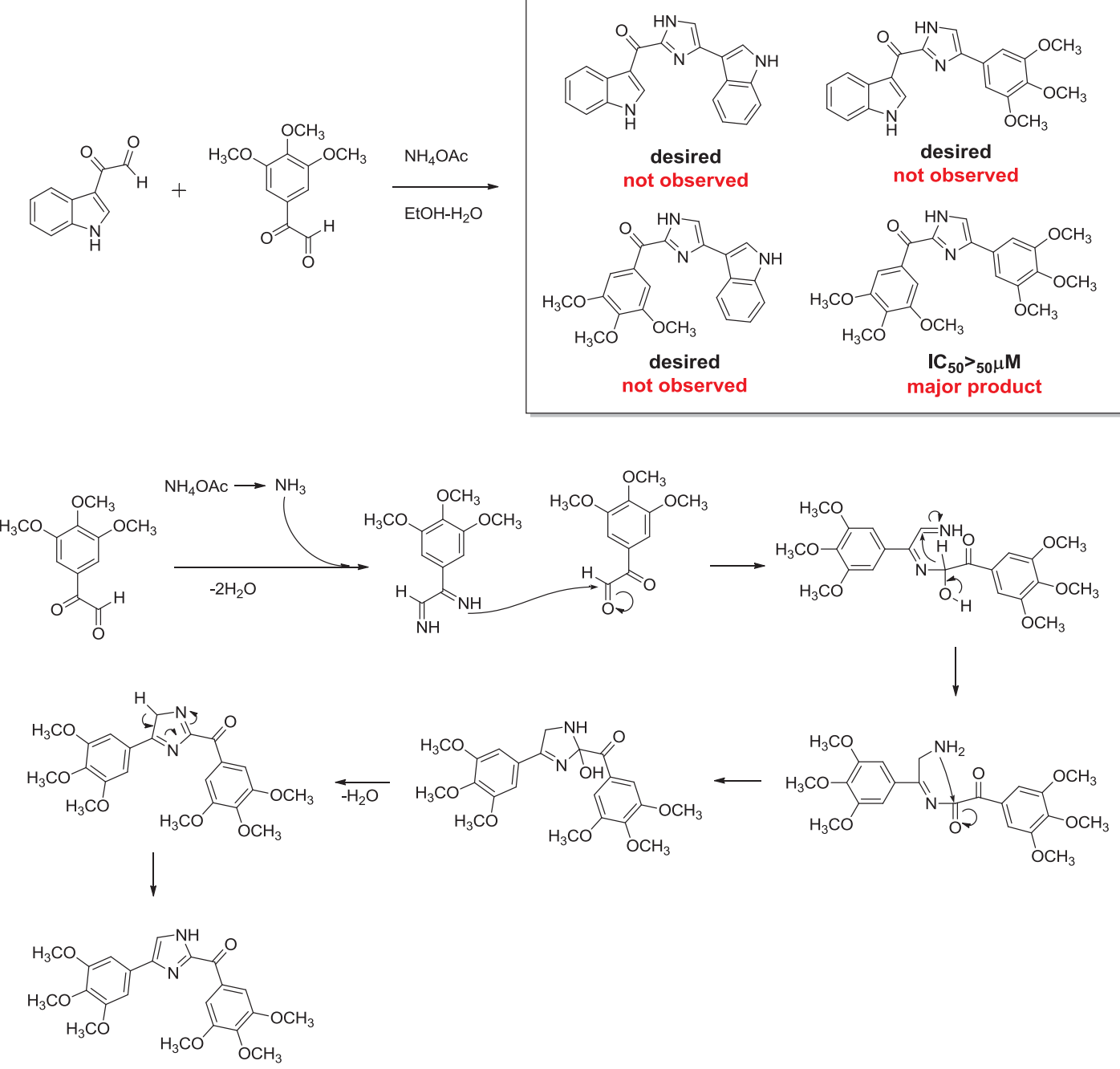

Figure 4-3. Synthesis of RABI scaffolds and proposed mechanism toward the observed major product 
3,4,5-TMP moieties was observed while the other three products were absent. This might because that (1) 3,4,5-trimethoxyphenyl glyoxal is more active than indolyl 3-glyoxal to form diimine intermediate (2) 3,4,5-trimethoxyphenyl glyoxal is more active than indolyl 3 -glyoxal to react with the formed diimine intermediate. The possible mechanism is illustrated in Figure 4-3.

During our exploration of a synthetic method to establish ABI-231 analogues modifying the 3,4,5-TMP moiety, a reaction as depicted in Figure 4-4 was conducted. In this reaction, we expected the occurrence of magnesium-halogen exchange to form the target product. However, the targeted product was not obtained. Instead, a moiety of the RABI scaffold was generated. The possible explanation is that the proton on the 2position of imidazole was more susceptible (too acidic ?) than the bromo to $i$ $\mathrm{PrMgCl}(\mathrm{LiCl})$. Despite this, this unexpected reaction provided us an opportunity to investigate the SAR of MX-RABI by modifying the 3,4,5-TMP and the benzene moieties.

Among the twelve RABI analogues, 15a, an ABI-231 based RABI analogue, showed less potent antiproliferative activity than ABI-231. According to the co-crystal structure of the 4-methyl-3-indole ABI-231 analogue reported in Chapter 2, $\mathrm{NH}$ on the imidazole formed an H-bond interaction with the $\alpha$-Thr179 residue. The observed decreased activity in 15a might due to the absence of an $\mathrm{H}$-bond interaction between $\mathrm{NH}$ on the imidazole of 15a and the $\alpha$-Thr179 residue (Figure 4-5). Analogues 15b with a 4indole moiety and 15i with a 4-indazole moiety exhibited markedly improved anticancer activities; they had average $\mathrm{IC}_{50} \mathrm{~S}$ of 3.5 and $0.8 \mathrm{nM}$, respectively. Compared to MXRABI, 15b and 15i displayed 4-fold and 17.5- fold improvements of antiproliferative activities, respectively. The difference in the activity of $\mathbf{1 5 b}$ and $\mathbf{1 5 i}$ may suggest an extra $\mathrm{H}$-bond interaction is formed between nitrogen on the 2-position of indazole with nearby residue (Figure 4-5). We are currently exerting effort on obtaining a co-crystal structure of $\mathbf{1 5 i}$ in complex with tubulin protein to rationalize its strong activity.

In conclusion, we have established a concise synthetic method for RABI scaffold and have synthesized twelve new RABI analogues. The most potent analogue 15i has an average $\mathrm{IC}_{50}$ of $0.8 \mathrm{nM}$. 15i represents the first CBSI with sub-nM activity in the related scaffold. 


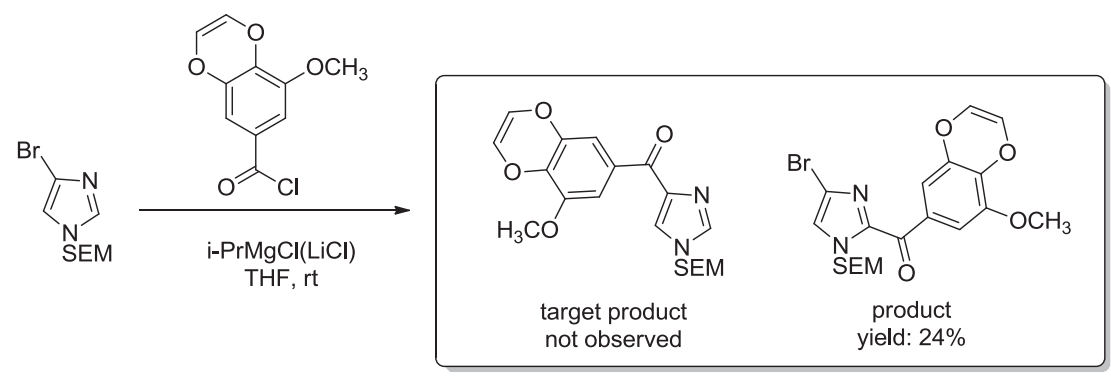

Figure 4-4. Synthesis of an intermediate for ABI-231 analogue
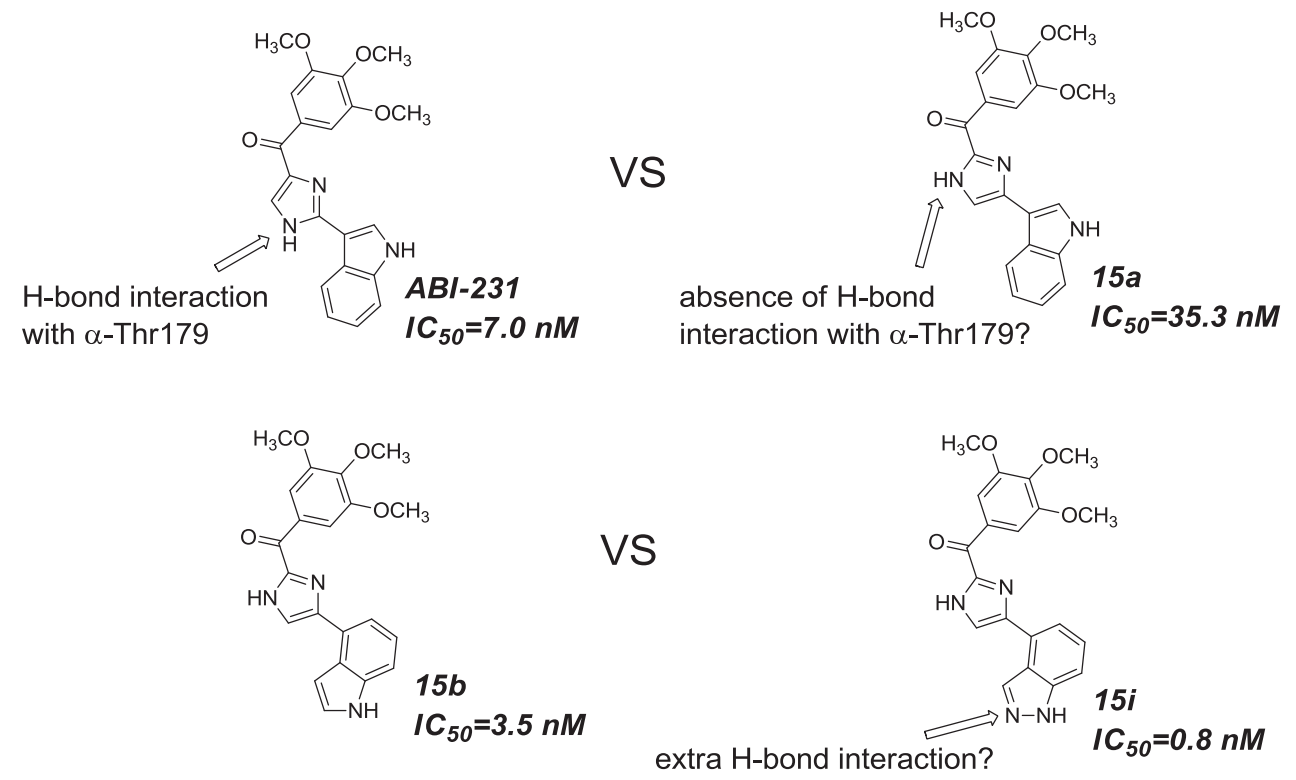

Figure 4-5. Structure and IC50 comparisons between ABI-231 and 15a, 15b and $15 i$ 


\section{CHAPTER 5. DESIGN, SYNTHESIS AND STRUCTURE-ACTIVITY RELATIONSHIP STUDY OF NOVEL UC-112 ANALOGUES}

\section{Introduction}

Survivin is the smallest member in the family of the Inhibitor of Apoptosis Protein (IAP). It is almost absent in healthy tissues while is highly overexpressed in tumors [105]. Survivin is therefore considered as a cancer specific biomarker [106]. Regardless of the apparent role of survivin in anti-apoptosis, the biological mechanism how survivin promotes anti-apoptosis remains debatable. On one hand, it is demonstrated that survivin can directly bind to the caspases and subsequently block their apoptotic activities $[107,108]$. On the other hand, survivin is reported to exert its anti-apoptotic function by indirectly binding to caspases. Evidence has shown that survivin interacts with XIAP and HBXIP, another two members of the IAP family [109]; these interactions can protect XIAP or HBXIP from ubiquitination and thereafter block activation of caspase-9. Alternatively, survivin may bind to the mitochondrial protein SMAC to antagonized its pro-apoptotic ability [110]. Besides its role in anti-apoptosis, survivin is also responsible for multidrug resistance and radiation resistance $[111,112]$. The tumor cells with high expression of survivin are shown to develop resistance more easily to cisplatin and vincristine than the tumor cells with low expression of survivin [113]. Due to its specific expression in tumor cells and important role in regulating cellular functions, survivin is regarded as a promising therapeutic target for the development of anticancer therapy [104].

Selective expression of survivin in tumor cells has been validated thus downregulating survivin expression to treat cancer may be effective. Many strategies have been applied to block the anti-apoptotic ability of survivin. These strategies include but are not limited to introducing recombinant cell-permeable dominant-negative survivin protein $[114,115]$, obstructing protein translation using antisense oligonucleotides [116], and small-molecule based survivin antagonists $[117,118]$. The crystal structure of human survivin was revealed in the early of this century, indicating this protein is an unusual bow tie-shape dimer [130]. Targeting survivin by employing small-molecule survivin inhibitors is challenging because no binding pocket in survivin has been identified. The challenge in developing survivin specific small-molecule inhibitor also lies in that survivin interacts with many other molecules such as P53, STAT3, caspases and notch signaling pathway to mediate apoptosis and mitosis [208-211]; it is therefore difficult to specify the drug target and evaluate the drug efficacy. A number of survivin inhibitors have been released so far, including YM155, FL118, shepherdin, 5-deazaflavin analogues, panepoxydone, terameprocol and MK2206; only YM155, LY2181308 and SPC3042 have successfully reached clinical trials [212], however, none of them has been granted an approval by the FDA. YM155 was discovered by Astellas Pharma in 2007, it has an $\mathrm{IC}_{50}$ in sub-nanomolar range against several types of cancer cell lines [125]. In clinical trials, YM155 was evaluated as monotherapy or combinational forms for many cancer types including blood cancer and solid tumors [213]. YM155 was withdrawn in phase II clinical trial due to its systemic toxicity. 
In our previous exploration, we have disclosed the identification of [5((benzyloxy)methyl)-7-(pyrrolidin-1-ylmethyl)quinolin-8-ol] (UC-112, the structure is shown in Figure 5-1) through virtual screening [126]. UC-112 is a potent and selective survivin inhibitor. UC-112 promoted apoptosis by mechanistically lowering the level of survivin protein and activating caspases $3 / 7$ and 9 . UC-112 is demonstrated to be effective for the P-gp overexpressed multidrug-resistant cancer cell lines. Subsequent SAR study of UC-112 results in MX-106 (Figure 5-1), which shows a significant effect in suppressing survivin expression. The in vivo efficacy of MX-106 to inhibit tumor growth is also demonstrated by using an A375 human melanoma xenograft model [214]. The SAR result indicates that both the 8-hydroxyquinoline and the pyrrolidine in UC-112 are essential for maximum activity; hydrophobic substituent on the benzene is beneficial to activity. Based on this SAR result, we hypothesize that (1): the benzyloxy moiety in UC-112 is amicable to modify; (2) the benzyloxy moiety is too flexible in this molecule; reducing the flexibility of the benzyloxy moiety can improve the activity (Figure 1-8). With these hypotheses in mind, we herein show our extensive effort on modifying the benzyloxy moiety in UC-112. Thirty-six UC-112 analogues are synthesized and evaluated for activities.

\section{Experimental Section}

\section{General chemistry}

Tetrahydrofuran was distilled from sodium-benzophenone. All other solvents and chemical reagents were obtained from commercial sources and directly used without further purification. Glassware was oven-dried before use. All reactions were performed under an argon atmosphere. TLC was performed on silica gel 60 GF254 and monitored under UV light or visualized using phosphomolybdic acid reagent. Flash chromatography was performed on 230-400 mesh silica gel (Fisher Scientific). Melting points were recorded on a MPA100 Automated Melting Point Apparatus. NMR spectra were obtained on a Bruker Ascend 400 (Billerica, MA) spectrometer or a Varian Inova-500 spectrometer (Agilent Technologies, Santa Clara, CA). HR-MS were obtained on Waters Acquity UPLC linked to Waters Acquity Photodiode Array Detector and Waters Acquity Single Quadrupole Mass Detector. Chemical shifts are given in ppm with tetramethylsilane (TMS) as an internal reference. All coupling constants $(J)$ are given in $\operatorname{Hertz}(\mathrm{Hz})$.

\section{Chemical synthesis}

General procedure for synthesis of $1 \mathbf{a}-1 \mathrm{~g}, 9 \mathbf{a}-9 \mathbf{y}$. To a stirred suspension of 5chloromethyl-8-quinolinol hydrochloride $(1.0 \mathrm{mmol}, 230 \mathrm{mg})$, sodium carbonate $(6.0$ $\mathrm{mmol}, 636 \mathrm{mg})$ and amine or indole $(1.1 \mathrm{mmol})$ in acetonitrile $(10 \mathrm{~mL})$ was added 


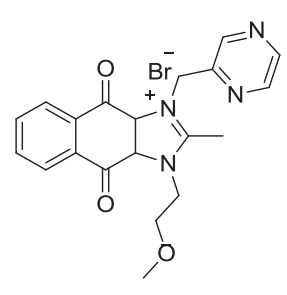

YM155

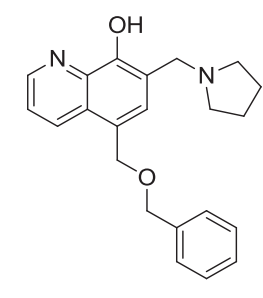

UC-112

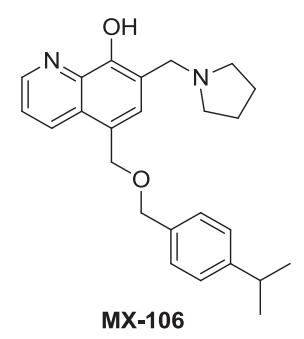

MX-106

Figure 5-1. Example of reported survivin inhibitors 
potassium iodide $(0.3 \mathrm{mmol}, 50 \mathrm{mg})$. The mixture was refluxed for $6 \mathrm{hr}$ and then filtered; the residue was washed with acetonitrile. The combined solution was evaporated under vacuum to give the crude which was purified with flash chromatography on silica. Elution with hexane/ethyl acetate (10:1-1:1) gave desired compounds 1a-1g, 9a-9g (yield: 21-72\%).

5-((5-fluoro-1H-indazol-1-yl)methyl)quinolin-8-ol (1a). ${ }^{1} \mathrm{H}$ NMR $(400 \mathrm{MHz}$, DMSO-d $\left._{6}\right) \delta 10.08(\mathrm{~s}, 1 \mathrm{H}), 8.87(\mathrm{dd}, \mathrm{J}=4.2,1.5 \mathrm{~Hz}, 1 \mathrm{H}), 8.67(\mathrm{dd}, \mathrm{J}=8.6,1.6 \mathrm{~Hz}, 1 \mathrm{H})$, $8.39(\mathrm{~d}, \mathrm{~J}=0.9 \mathrm{~Hz}, 1 \mathrm{H}), 7.67$ (ddt, J = 9.3, 4.7, $0.9 \mathrm{~Hz}, 1 \mathrm{H}), 7.64-7.51(\mathrm{~m}, 2 \mathrm{H}), 7.40$ (ddd, J = 9.6, 2.5, 0.7 Hz, 1H), $7.22-7.05(\mathrm{~m}, 2 \mathrm{H}), 6.05(\mathrm{~s}, 2 \mathrm{H})$.

5-((1H-benzo[d][1,2,3]triazol-1-yl)methyl)quinolin-8-ol (1b). ${ }^{1} \mathrm{H}$ NMR $(400$ MHz, DMSO-d 6 ) $\delta 10.09$ (s, 1H), $8.84(\mathrm{dd}, \mathrm{J}=4.1,1.6 \mathrm{~Hz}, 1 \mathrm{H}), 8.72(\mathrm{dd}, \mathrm{J}=8.6,1.6 \mathrm{~Hz}$, $1 \mathrm{H}), 8.01(\mathrm{dt}, \mathrm{J}=8.3,1.0 \mathrm{~Hz}, 1 \mathrm{H}), 7.80(\mathrm{dt}, \mathrm{J}=8.4,1.0 \mathrm{~Hz}, 1 \mathrm{H}), 7.64(\mathrm{~d}, \mathrm{~J}=7.9 \mathrm{~Hz}, 1 \mathrm{H})$, 7.59 (dd, J = 8.6, 4.2 Hz, 1H), 7.45 (ddd, $\mathrm{J}=8.2,6.9,1.0 \mathrm{~Hz}, 1 \mathrm{H}), 7.32$ (ddd, J = 8.1, 6.9, $1.0 \mathrm{~Hz}, 1 \mathrm{H}), 7.11(\mathrm{~d}, \mathrm{~J}=7.8 \mathrm{~Hz}, 1 \mathrm{H}), 6.37$ (s, $2 \mathrm{H})$.

1-((8-hydroxyquinolin-5-yl)methyl)-2,3-dihydroquinolin-4(1H)-one (1d). ${ }^{1} \mathrm{H}$ NMR (400 MHz, DMSO-d 6 ) $\delta 9.83(\mathrm{~s}, 1 \mathrm{H}), 8.92(\mathrm{dd}, \mathrm{J}=4.2,1.5 \mathrm{~Hz}, 1 \mathrm{H}), 8.50(\mathrm{dd}, \mathrm{J}=$ 8.6, 1.6 Hz, 1H), $7.76(\mathrm{dd}, \mathrm{J}=7.9,1.7 \mathrm{~Hz}, 1 \mathrm{H}), 7.63(\mathrm{dd}, \mathrm{J}=8.6,4.1 \mathrm{~Hz}, 1 \mathrm{H}), 7.51-7.28$ $(\mathrm{m}, 2 \mathrm{H}), 7.04(\mathrm{~d}, \mathrm{~J}=7.8 \mathrm{~Hz}, 1 \mathrm{H}), 6.86(\mathrm{~d}, \mathrm{~J}=8.6 \mathrm{~Hz}, 1 \mathrm{H}), 6.72(\mathrm{t}, \mathrm{J}=7.4 \mathrm{~Hz}, 1 \mathrm{H}), 4.95$ (s, 2H), 3.54 (dd, J = 7.7, 6.2 Hz, 2H), 2.62 (dd, J = 7.8, $6.2 \mathrm{~Hz}, 2 \mathrm{H})$.

5-(((1-phenyl-1H-benzo[d]imidazol-2-yl)amino)methyl)quinolin-8-ol (1e). ${ }^{1} \mathrm{H}$ NMR $\left(400 \mathrm{MHz}\right.$, Acetone-d $\left.\mathrm{d}_{6}\right) \delta 8.79(\mathrm{dd}, \mathrm{J}=4.2,1.6 \mathrm{~Hz}, 1 \mathrm{H}), 8.75-8.64(\mathrm{~m}, 1 \mathrm{H}), 8.61$ $(\mathrm{dd}, \mathrm{J}=8.6,1.6 \mathrm{~Hz}, 1 \mathrm{H}), 7.53-7.41(\mathrm{~m}, 2 \mathrm{H}), 7.34(\mathrm{~d}, \mathrm{~J}=7.8 \mathrm{~Hz}, 1 \mathrm{H}), 7.19(\mathrm{td}, \mathrm{J}=6.7$, $5.8,3.1 \mathrm{~Hz}, 3 \mathrm{H}), 7.12-7.04(\mathrm{~m}, 3 \mathrm{H}), 7.00(\mathrm{dd}, \mathrm{J}=7.7,2.3 \mathrm{~Hz}, 2 \mathrm{H}), 6.91(\mathrm{td}, \mathrm{J}=7.6,1.2$ $\mathrm{Hz}, 1 \mathrm{H}), 6.41(\mathrm{t}, \mathrm{J}=5.5 \mathrm{~Hz}, 1 \mathrm{H}), 5.27(\mathrm{~s}, 2 \mathrm{H}), 5.07(\mathrm{~d}, \mathrm{~J}=5.1 \mathrm{~Hz}, 2 \mathrm{H})$.

Tert-butyl (R)-(1-(((8-hydroxyquinolin-5-yl)methyl)amino)-1-oxo-3(phenylthio)propan-2-yl)carbamate (1f). ${ }^{1} \mathrm{H}$ NMR (400 MHz, Chloroform-d) $\delta 8.79$ (dd, J = 4.2, $1.5 \mathrm{~Hz}, 1 \mathrm{H}), 8.33$ (dd, J = 8.6, $1.5 \mathrm{~Hz}, 1 \mathrm{H}), 7.46(\mathrm{dd}, \mathrm{J}=8.6,4.2 \mathrm{~Hz}, 1 \mathrm{H})$, $7.38(\mathrm{~d}, \mathrm{~J}=7.8 \mathrm{~Hz}, 1 \mathrm{H}), 7.26-7.15(\mathrm{~m}, 5 \mathrm{H}), 7.09(\mathrm{~d}, \mathrm{~J}=7.8 \mathrm{~Hz}, 1 \mathrm{H}), 6.43(\mathrm{~s}, 1 \mathrm{H}), 5.22$ (s, 1H), $4.77(\mathrm{~d}, \mathrm{~J}=5.5 \mathrm{~Hz}, 2 \mathrm{H}), 4.19(\mathrm{~d}, \mathrm{~J}=6.1 \mathrm{~Hz}, 1 \mathrm{H}), 3.75-3.59(\mathrm{~m}, 2 \mathrm{H}), 2.88$ (dd, J $=13.9,5.8 \mathrm{~Hz}, 1 \mathrm{H}), 2.74(\mathrm{dd}, \mathrm{J}=13.8,6.8 \mathrm{~Hz}, 1 \mathrm{H}), 1.35(\mathrm{~s}, 9 \mathrm{H})$.

5-((1H-indol-1-yl)methyl)quinolin-8-ol (9a). ${ }^{1} \mathrm{H}$ NMR (400 MHz, Methanol-d $\left.\mathrm{d}_{4}\right)$ $\delta 8.68(\mathrm{dd}, \mathrm{J}=4.2,1.6 \mathrm{~Hz}, 1 \mathrm{H}), 8.34(\mathrm{dd}, \mathrm{J}=8.6,1.6 \mathrm{~Hz}, 1 \mathrm{H}), 7.46(\mathrm{dt}, \mathrm{J}=8.0,1.0 \mathrm{~Hz}$, $1 \mathrm{H}), 7.32(\mathrm{dt}, \mathrm{J}=8.1,1.0 \mathrm{~Hz}, 1 \mathrm{H}), 7.30-7.24(\mathrm{~m}, 2 \mathrm{H}), 7.08(\mathrm{ddd}, \mathrm{J}=8.2,6.9,1.1 \mathrm{~Hz}$, 1H), $7.00(\mathrm{~d}, \mathrm{~J}=7.8 \mathrm{~Hz}, 1 \mathrm{H}), 6.96(\mathrm{ddd}, \mathrm{J}=8.0,7.0,1.0 \mathrm{~Hz}, 1 \mathrm{H}), 6.70(\mathrm{~d}, \mathrm{~J}=1.1 \mathrm{~Hz}$, 1H), 4.34 (s, 2H).

5-((2-methyl-1H-indol-1-yl)methyl)quinolin-8-ol (9b). ${ }^{1} \mathrm{H}$ NMR $(400 \mathrm{MHz}$, DMSO-d $\left._{6}\right) \delta 10.84(\mathrm{~s}, 1 \mathrm{H}), 9.55(\mathrm{~s}, 1 \mathrm{H}), 8.84(\mathrm{dd}, \mathrm{J}=4.1,1.6 \mathrm{~Hz}, 1 \mathrm{H}), 8.58(\mathrm{dd}, \mathrm{J}=8.6$, $1.6 \mathrm{~Hz}, 1 \mathrm{H}), 7.54$ (dd, J = 8.6, 4.1 Hz, 1H), 7.27 (d, J = 8.0 Hz, 1H), 7.18 (d, J = 7.8 Hz, 
$1 \mathrm{H}), 7.11(\mathrm{~d}, \mathrm{~J}=7.9 \mathrm{~Hz}, 1 \mathrm{H}), 7.01-6.90(\mathrm{~m}, 2 \mathrm{H}), 6.82(\mathrm{ddd}, \mathrm{J}=8.0,7.0,1.1 \mathrm{~Hz}, 1 \mathrm{H})$, $4.35(\mathrm{~s}, 2 \mathrm{H}), 2.33(\mathrm{~s}, 3 \mathrm{H})$.

5-((2-ethyl-1H-indol-1-yl)methyl)quinolin-8-ol (9c). ${ }^{1} \mathrm{H}$ NMR (400 MHz, Chloroform-d) $\delta 8.84(\mathrm{~s}, 1 \mathrm{H}), 8.57(\mathrm{~d}, \mathrm{~J}=8.6 \mathrm{~Hz}, 1 \mathrm{H}), 8.30(\mathrm{~s}, 1 \mathrm{H}), 7.96(\mathrm{~s}, 1 \mathrm{H}), 7.59-$ $7.33(\mathrm{~m}, 3 \mathrm{H}), 7.24-7.00(\mathrm{~m}, 4 \mathrm{H}), 4.46(\mathrm{~s}, 2 \mathrm{H}), 2.75(\mathrm{t}, \mathrm{J}=7.5 \mathrm{~Hz}, 2 \mathrm{H}), 1.25$ (d, J = 7.9 $\mathrm{Hz}, 3 \mathrm{H})$.

5-((4-fluoro-1H-indol-1-yl)methyl)quinolin-8-ol (9d). ${ }^{1} \mathrm{H}$ NMR (400 MHz, $\left.\mathrm{DMSO}_{-} \mathrm{d}_{6}\right) \delta 11.14(\mathrm{~s}, 1 \mathrm{H}), 9.61(\mathrm{~s}, 1 \mathrm{H}), 8.85(\mathrm{dd}, \mathrm{J}=4.1,1.6 \mathrm{~Hz}, 1 \mathrm{H}), 8.55(\mathrm{dd}, \mathrm{J}=8.6$, $1.6 \mathrm{~Hz}, 1 \mathrm{H}), 7.55(\mathrm{dd}, \mathrm{J}=8.6,4.1 \mathrm{~Hz}, 1 \mathrm{H}), 7.23(\mathrm{dd}, \mathrm{J}=19.3,8.0 \mathrm{~Hz}, 2 \mathrm{H}), 7.15-6.95$ $(\mathrm{m}, 2 \mathrm{H}), 6.88(\mathrm{~d}, \mathrm{~J}=2.4 \mathrm{~Hz}, 1 \mathrm{H}), 6.72(\mathrm{dd}, \mathrm{J}=11.5,7.7 \mathrm{~Hz}, 1 \mathrm{H}), 4.50(\mathrm{~s}, 2 \mathrm{H})$.

5-((4-nitro-1H-indol-1-yl)methyl)quinolin-8-ol (9e). ${ }^{1} \mathrm{H}$ NMR (400 MHz, Acetone- $\left.\mathrm{d}_{6}\right) \delta 10.91(\mathrm{~s}, 1 \mathrm{H}), 8.86-8.81(\mathrm{~m}, 1 \mathrm{H}), 8.52(\mathrm{dd}, \mathrm{J}=8.5,1.6 \mathrm{~Hz}, 1 \mathrm{H}), 7.85(\mathrm{~d}, \mathrm{~J}$ $=8.1 \mathrm{~Hz}, 1 \mathrm{H}), 7.79(\mathrm{~d}, \mathrm{~J}=7.8 \mathrm{~Hz}, 1 \mathrm{H}), 7.54(\mathrm{dd}, \mathrm{J}=8.5,4.1 \mathrm{~Hz}, 1 \mathrm{H}), 7.29(\mathrm{t}, \mathrm{J}=8.0 \mathrm{~Hz}$, $1 \mathrm{H}), 7.15(\mathrm{~d}, \mathrm{~J}=7.8 \mathrm{~Hz}, 1 \mathrm{H}), 7.07$ (d, J = 2.3 Hz, 1H), $7.01(\mathrm{t}, \mathrm{J}=7.3 \mathrm{~Hz}, 1 \mathrm{H}), 4.58$ (s, $2 \mathrm{H})$.

5-((5-fluoro-1H-indol-1-yl)methyl)quinolin-8-ol (9f). ${ }^{1} \mathrm{H}$ NMR (400 MHz, Chloroform-d) $\delta 8.76(\mathrm{dd}, \mathrm{J}=4.2,1.5 \mathrm{~Hz}, 1 \mathrm{H}), 8.32(\mathrm{dd}, \mathrm{J}=8.5,1.6 \mathrm{~Hz}, 1 \mathrm{H}), 7.95(\mathrm{~s}$, $1 \mathrm{H}), 7.41-7.33(\mathrm{~m}, 2 \mathrm{H}), 7.30-7.20(\mathrm{~m}, 2 \mathrm{H}), 7.11(\mathrm{~d}, \mathrm{~J}=7.7 \mathrm{~Hz}, 1 \mathrm{H}), 6.96(\mathrm{td}, \mathrm{J}=9.0$, $2.5 \mathrm{~Hz}, 1 \mathrm{H}), 6.70(\mathrm{dt}, \mathrm{J}=2.4,1.1 \mathrm{~Hz}, 1 \mathrm{H}), 4.38(\mathrm{~s}, 2 \mathrm{H})$.

5-((5-chloro-1H-indol-1-yl)methyl)quinolin-8-ol (9g). ${ }^{1} \mathrm{H}$ NMR (400 MHz, Chloroform-d) $\delta 8.79(\mathrm{dd}, \mathrm{J}=4.2,1.5 \mathrm{~Hz}, 1 \mathrm{H}), 8.38(\mathrm{~s}, 1 \mathrm{H}), 8.09(\mathrm{dd}, \mathrm{J}=8.6,1.5 \mathrm{~Hz}$, $1 \mathrm{H}), 7.61(\mathrm{~d}, \mathrm{~J}=2.0 \mathrm{~Hz}, 1 \mathrm{H}), 7.41(\mathrm{dd}, \mathrm{J}=8.5,4.2 \mathrm{~Hz}, 1 \mathrm{H}), 7.30(\mathrm{~d}, \mathrm{~J}=8.7 \mathrm{~Hz}, 1 \mathrm{H})$, $7.21-7.13(\mathrm{~m}, 2 \mathrm{H}), 7.09(\mathrm{~d}, \mathrm{~J}=7.9 \mathrm{~Hz}, 1 \mathrm{H}), 6.95(\mathrm{~d}, \mathrm{~J}=3.2 \mathrm{~Hz}, 1 \mathrm{H}), 6.43(\mathrm{dd}, \mathrm{J}=3.2$, $0.8 \mathrm{~Hz}, 1 \mathrm{H}), 5.58(\mathrm{~s}, 2 \mathrm{H})$.

1-((8-hydroxyquinolin-5-yl)methyl)-1H-indole-5-carbonitrile (9h). ${ }^{1} \mathrm{H}$ NMR (400 MHz, Chloroform-d) $\delta 8.82$ (dd, J = 4.2, $1.5 \mathrm{~Hz}, 1 \mathrm{H}), 8.40$ (s, 1H), 8.09 (dd, J = 8.5, $1.5 \mathrm{~Hz}, 1 \mathrm{H}), 7.99$ (t, J = 1.1 Hz, 1H), $7.48-7.39(\mathrm{~m}, 3 \mathrm{H}), 7.21-7.14(\mathrm{~m}, 1 \mathrm{H}), 7.11(\mathrm{~d}, \mathrm{~J}$ $=7.9 \mathrm{~Hz}, 1 \mathrm{H}), 7.06(\mathrm{~d}, \mathrm{~J}=3.3 \mathrm{~Hz}, 1 \mathrm{H}), 6.57(\mathrm{~d}, \mathrm{~J}=3.2 \mathrm{~Hz}, 1 \mathrm{H}), 5.65(\mathrm{~s}, 2 \mathrm{H})$.

5-((5-nitro-1H-indol-1-yl)methyl)quinolin-8-ol (9i). ${ }^{1} \mathrm{H}$ NMR $(400 \mathrm{MHz}$, DMSO-d $\left._{6}\right) \delta 9.91(\mathrm{~s}, 1 \mathrm{H}), 8.90(\mathrm{dd}, \mathrm{J}=4.2,1.5 \mathrm{~Hz}, 1 \mathrm{H}), 8.61(\mathrm{~d}, \mathrm{~J}=2.3 \mathrm{~Hz}, 1 \mathrm{H}), 8.52$ $(\mathrm{dd}, \mathrm{J}=8.6,1.6 \mathrm{~Hz}, 1 \mathrm{H}), 8.03(\mathrm{dd}, \mathrm{J}=9.1,2.4 \mathrm{~Hz}, 1 \mathrm{H}), 7.76(\mathrm{~d}, \mathrm{~J}=9.1 \mathrm{~Hz}, 1 \mathrm{H}), 7.70-$ $7.54(\mathrm{~m}, 2 \mathrm{H}), 7.15-6.93(\mathrm{~m}, 2 \mathrm{H}), 6.80(\mathrm{~d}, \mathrm{~J}=3.2 \mathrm{~Hz}, 1 \mathrm{H}), 5.93$ (s, 2H).

Ethyl 1-((8-hydroxyquinolin-5-yl)methyl)-1H-indole-5-carboxylate $(9 \mathrm{j}) .{ }^{1} \mathrm{H}$ NMR (400 MHz, Acetone-d $)_{6} \delta 10.43(\mathrm{~s}, 1 \mathrm{H}), 8.82(\mathrm{dt}, \mathrm{J}=4.2,1.1 \mathrm{~Hz}, 1 \mathrm{H}), 8.58(\mathrm{dt}, \mathrm{J}=$ 8.6, 1.1 Hz, 1H), 8.35 (d, J = 1.5 Hz, 1H), $7.84(\mathrm{dd}, \mathrm{J}=8.8,1.6 \mathrm{~Hz}, 1 \mathrm{H}), 7.53$ (dd, J = 8.6, $4.3 \mathrm{~Hz}, 1 \mathrm{H}), 7.48(\mathrm{~d}, \mathrm{~J}=8.6 \mathrm{~Hz}, 1 \mathrm{H}), 7.44(\mathrm{~d}, \mathrm{~J}=7.7 \mathrm{~Hz}, 1 \mathrm{H}), 7.10(\mathrm{~d}, \mathrm{~J}=7.8 \mathrm{~Hz}, 1 \mathrm{H})$, $7.04(\mathrm{~d}, \mathrm{~J}=1.3 \mathrm{~Hz}, 1 \mathrm{H}), 4.63-4.41(\mathrm{~m}, 2 \mathrm{H}), 4.33$ (dd, J = 7.1, $0.8 \mathrm{~Hz}, 2 \mathrm{H}), 1.36$ (td, J = 7.1, $0.8 \mathrm{~Hz}, 3 \mathrm{H})$. 
5-((6-fluoro-1H-indol-1-yl)methyl)quinolin-8-ol (9k). ${ }^{1} \mathrm{H}$ NMR (400 MHz, Chloroform-d) $\delta 8.80(\mathrm{dd}, \mathrm{J}=4.2,1.5 \mathrm{~Hz}, 1 \mathrm{H}), 8.44(\mathrm{~s}, 1 \mathrm{H}), 8.12(\mathrm{dd}, \mathrm{J}=8.5,1.5 \mathrm{~Hz}$, $1 \mathrm{H}), 7.57(\mathrm{dd}, \mathrm{J}=8.7,5.4 \mathrm{~Hz}, 1 \mathrm{H}), 7.42(\mathrm{dd}, \mathrm{J}=8.6,4.2 \mathrm{~Hz}, 1 \mathrm{H}), 7.21-7.15(\mathrm{~m}, 1 \mathrm{H})$, $7.11(\mathrm{~d}, \mathrm{~J}=7.8 \mathrm{~Hz}, 1 \mathrm{H}), 7.07(\mathrm{dd}, \mathrm{J}=9.8,2.3 \mathrm{~Hz}, 1 \mathrm{H}), 6.96-6.89(\mathrm{~m}, 2 \mathrm{H}), 6.48(\mathrm{dd}, \mathrm{J}=$ 3.2, $0.9 \mathrm{~Hz}, 1 \mathrm{H}), 5.54(\mathrm{~s}, 2 \mathrm{H})$.

5-((6-chloro-1H-indol-1-yl)methyl)quinolin-8-ol (9l). ${ }^{1} \mathrm{H}$ NMR $(400 \mathrm{MHz}$, Methanol-d $\left.{ }_{4}\right) \delta 8.77(\mathrm{dd}, \mathrm{J}=4.2,1.6 \mathrm{~Hz}, 1 \mathrm{H}), 8.46(\mathrm{dd}, \mathrm{J}=8.6,1.6 \mathrm{~Hz}, 1 \mathrm{H}), 7.46-7.40$ $(\mathrm{m}, 2 \mathrm{H}), 7.36-7.30(\mathrm{~m}, 2 \mathrm{H}), 7.04(\mathrm{~d}, \mathrm{~J}=7.8 \mathrm{~Hz}, 1 \mathrm{H}), 6.95(\mathrm{dd}, \mathrm{J}=8.5,1.9 \mathrm{~Hz}, 1 \mathrm{H})$, $6.80(\mathrm{~d}, \mathrm{~J}=1.1 \mathrm{~Hz}, 1 \mathrm{H}), 4.43(\mathrm{~s}, 2 \mathrm{H})$.

5-((6-bromo-1H-indol-1-yl)methyl)quinolin-8-ol (9m). ${ }^{1} \mathrm{H}$ NMR (400 MHz, Chloroform-d) $\delta 8.80$ (dd, J = 4.2, $1.5 \mathrm{~Hz}, 1 \mathrm{H}), 8.38$ (dd, J = 8.4, $1.8 \mathrm{~Hz}, 1 \mathrm{H}), 8.09$ (dd, J $=8.5,1.5 \mathrm{~Hz}, 1 \mathrm{H}), 7.56(\mathrm{dt}, \mathrm{J}=1.5,0.6 \mathrm{~Hz}, 1 \mathrm{H}), 7.53-7.48(\mathrm{~m}, 1 \mathrm{H}), 7.41(\mathrm{dd}, \mathrm{J}=8.6$, $4.2 \mathrm{~Hz}, 1 \mathrm{H}), 7.25-7.22(\mathrm{~m}, 1 \mathrm{H}), 7.17-7.12(\mathrm{~m}, 1 \mathrm{H}), 7.09(\mathrm{~d}, \mathrm{~J}=7.8 \mathrm{~Hz}, 1 \mathrm{H}), 6.88(\mathrm{~d}, \mathrm{~J}$ $=3.3 \mathrm{~Hz}, 1 \mathrm{H}), 6.45(\mathrm{dd}, \mathrm{J}=3.2,0.9 \mathrm{~Hz}, 1 \mathrm{H}), 5.54(\mathrm{~s}, 2 \mathrm{H})$.

5-((6-nitro-1H-indol-1-yl)methyl)quinolin-8-ol (9n). ${ }^{1} \mathrm{H}$ NMR (400 MHz, Chloroform-d) $\delta 8.74$ (ddt, J = 7.8, 3.6, 1.8 Hz, 1H), $8.47-8.14$ (m, 1H), $7.46-7.20$ (m, 3H), 7.09 (ddd, J = 9.8, 7.7, 3.0 Hz, 1H), 6.97 (dddd, J = 9.5, 7.8, 4.7, 2.3 Hz, 1H), 6.92 $6.82(\mathrm{~m}, 1 \mathrm{H}), 6.71-6.64(\mathrm{~m}, 1 \mathrm{H}), 4.49-4.33(\mathrm{~m}, 2 \mathrm{H})$.

5-((6-methoxy-1H-indol-1-yl)methyl)quinolin-8-ol (9o). ${ }^{1} \mathrm{H}$ NMR $(400 \mathrm{MHz}$, Chloroform-d) $\delta 8.75(\mathrm{dd}, \mathrm{J}=4.2,1.5 \mathrm{~Hz}, 1 \mathrm{H}), 8.35(\mathrm{dd}, \mathrm{J}=8.5,1.5 \mathrm{~Hz}, 1 \mathrm{H}), 7.78(\mathrm{~s}$, 1H), $7.46(\mathrm{~d}, \mathrm{~J}=8.7 \mathrm{~Hz}, 1 \mathrm{H}), 7.40-7.34(\mathrm{~m}, 2 \mathrm{H}), 7.10(\mathrm{~d}, \mathrm{~J}=7.8 \mathrm{~Hz}, 1 \mathrm{H}), 6.86(\mathrm{~d}, \mathrm{~J}=$ $2.1 \mathrm{~Hz}, 1 \mathrm{H}), 6.79(\mathrm{dd}, \mathrm{J}=8.6,2.3 \mathrm{~Hz}, 1 \mathrm{H}), 6.54(\mathrm{dt}, \mathrm{J}=2.3,1.2 \mathrm{~Hz}, 1 \mathrm{H}), 4.40(\mathrm{~s}, 2 \mathrm{H})$, $3.85(\mathrm{~s}, 3 \mathrm{H})$.

5-((7-fluoro-1H-indol-1-yl)methyl)quinolin-8-ol (9p). ${ }^{1} \mathrm{H}$ NMR $(400 \mathrm{MHz}$, Chloroform-d) $\delta 8.83$ (dd, J = 4.2, 1.5 Hz, 1H), 8.45 (dd, J = 1.8, 1.0 Hz, 1H), 8.08 (ddd, $\mathrm{J}=15.1,8.7,1.8 \mathrm{~Hz}, 2 \mathrm{H}), 7.70(\mathrm{dd}, \mathrm{J}=8.8,0.5 \mathrm{~Hz}, 1 \mathrm{H}), 7.46(\mathrm{dd}, \mathrm{J}=8.6,4.2 \mathrm{~Hz}, 1 \mathrm{H})$, $7.25-7.21(\mathrm{~m}, 1 \mathrm{H}), 7.19(\mathrm{~d}, \mathrm{~J}=3.2 \mathrm{~Hz}, 1 \mathrm{H}), 7.13(\mathrm{~d}, \mathrm{~J}=7.9 \mathrm{~Hz}, 1 \mathrm{H}), 6.59$ (dd, J = 3.2, $0.9 \mathrm{~Hz}, 1 \mathrm{H}), 5.71(\mathrm{~d}, \mathrm{~J}=0.9 \mathrm{~Hz}, 2 \mathrm{H})$.

5-((7-methyl-1H-indol-1-yl)methyl)quinolin-8-ol (9q). ${ }^{1} \mathrm{H}$ NMR (400 MHz, Acetone- $\left.\mathrm{d}_{6}\right) \delta 9.97(\mathrm{~s}, 1 \mathrm{H}), 8.80(\mathrm{dd}, \mathrm{J}=4.2,1.6 \mathrm{~Hz}, 1 \mathrm{H}), 8.65(\mathrm{~s}, 1 \mathrm{H}), 8.55(\mathrm{dd}, \mathrm{J}=8.5$, $1.6 \mathrm{~Hz}, 1 \mathrm{H}), 7.49(\mathrm{dd}, \mathrm{J}=8.6,4.2 \mathrm{~Hz}, 1 \mathrm{H}), 7.42(\mathrm{~d}, \mathrm{~J}=7.7 \mathrm{~Hz}, 2 \mathrm{H}), 7.09$ (d, J = 7.9 Hz, $1 \mathrm{H}), 7.05-6.78(\mathrm{~m}, 3 \mathrm{H}), 4.47(\mathrm{~s}, 2 \mathrm{H}), 2.49(\mathrm{~s}, 3 \mathrm{H})$.

5-((2,3-dimethyl-1H-indol-1-yl)methyl)quinolin-8-ol (9r). ${ }^{1} \mathrm{H}$ NMR (400 MHz, Chloroform-d) $\delta 8.86(\mathrm{dd}, \mathrm{J}=4.2,1.5 \mathrm{~Hz}, 1 \mathrm{H}), 8.40(\mathrm{dd}, \mathrm{J}=8.5,1.5 \mathrm{~Hz}, 1 \mathrm{H}), 7.66-7.51$ $(\mathrm{m}, 2 \mathrm{H}), 7.22-7.06(\mathrm{~m}, 3 \mathrm{H}), 6.95(\mathrm{~d}, \mathrm{~J}=7.9 \mathrm{~Hz}, 1 \mathrm{H}), 6.55-6.38(\mathrm{~m}, 1 \mathrm{H}), 5.62(\mathrm{~d}, \mathrm{~J}=$ $1.2 \mathrm{~Hz}, 2 \mathrm{H}), 2.35(\mathrm{~s}, 3 \mathrm{H}), 2.27(\mathrm{~s}, 3 \mathrm{H})$. 
5-((5-methoxy-2-methyl-1H-indol-1-yl)methyl)quinolin-8-ol (9s). ${ }^{1} \mathrm{H}$ NMR $\left(400 \mathrm{MHz}, \mathrm{DMSO}_{-} \mathrm{d}_{6}\right) \delta 10.70(\mathrm{~s}, 1 \mathrm{H}), 9.60(\mathrm{~s}, 1 \mathrm{H}), 8.86(\mathrm{dd}, \mathrm{J}=4.1,1.6 \mathrm{~Hz}, 1 \mathrm{H}), 8.60$ $(\mathrm{dd}, \mathrm{J}=8.6,1.6 \mathrm{~Hz}, 1 \mathrm{H}), 7.56(\mathrm{dd}, \mathrm{J}=8.6,4.2 \mathrm{~Hz}, 1 \mathrm{H}), 7.17(\mathrm{dd}, \mathrm{J}=15.5,8.3 \mathrm{~Hz}, 2 \mathrm{H})$, $7.01(\mathrm{~d}, \mathrm{~J}=7.8 \mathrm{~Hz}, 1 \mathrm{H}), 6.71(\mathrm{~d}, \mathrm{~J}=2.4 \mathrm{~Hz}, 1 \mathrm{H}), 6.64(\mathrm{dd}, \mathrm{J}=8.7,2.4 \mathrm{~Hz}, 1 \mathrm{H}), 4.34$ (s, $2 \mathrm{H}), 3.61(\mathrm{~s}, 3 \mathrm{H}), 2.31(\mathrm{~s}, 3 \mathrm{H})$.

5-((2-ethyl-5-fluoro-1H-indol-1-yl)methyl)quinolin-8-ol (9t). ${ }^{1} \mathrm{H}$ NMR (400 $\mathrm{MHz}$, Acetone- $\left.\mathrm{d}_{6}\right) \delta 10.97(\mathrm{~s}, 1 \mathrm{H}), 8.84(\mathrm{dd}, \mathrm{J}=4.2,1.5 \mathrm{~Hz}, 1 \mathrm{H}), 8.76(\mathrm{dd}, \mathrm{J}=8.6,1.5$ $\mathrm{Hz}, 1 \mathrm{H}), 8.61(\mathrm{~s}, 1 \mathrm{H}), 7.60(\mathrm{dd}, \mathrm{J}=8.6,4.2 \mathrm{~Hz}, 1 \mathrm{H}), 7.55(\mathrm{ddd}, \mathrm{J}=8.9,4.5,0.7 \mathrm{~Hz}, 1 \mathrm{H})$, $7.19(\mathrm{dt}, \mathrm{J}=7.9,1.1 \mathrm{~Hz}, 1 \mathrm{H}), 7.15-7.10(\mathrm{~m}, 1 \mathrm{H}), 7.10-7.05(\mathrm{~m}, 1 \mathrm{H}), 7.03(\mathrm{~d}, \mathrm{~J}=7.9$ $\mathrm{Hz}, 1 \mathrm{H}), 4.92(\mathrm{~d}, \mathrm{~J}=1.0 \mathrm{~Hz}, 2 \mathrm{H}), 4.36(\mathrm{q}, \mathrm{J}=7.1 \mathrm{~Hz}, 2 \mathrm{H}), 1.26(\mathrm{t}, \mathrm{J}=7.1 \mathrm{~Hz}, 3 \mathrm{H})$.

1-((8-hydroxyquinolin-5-yl)methyl)-6-methoxy-1H-indole-3-carbonitrile (9u). ${ }^{1} \mathrm{H}$ NMR (400 MHz, DMSO-d 6 ) $\delta 10.72(\mathrm{~s}, 1 \mathrm{H}), 9.74(\mathrm{~s}, 1 \mathrm{H}), 8.86(\mathrm{dd}, \mathrm{J}=4.1,1.5 \mathrm{~Hz}$, $1 \mathrm{H}), 8.53(\mathrm{dd}, \mathrm{J}=8.5,1.5 \mathrm{~Hz}, 1 \mathrm{H}), 7.57(\mathrm{dd}, \mathrm{J}=8.6,4.1 \mathrm{~Hz}, 1 \mathrm{H}), 7.44(\mathrm{~d}, \mathrm{~J}=8.6 \mathrm{~Hz}$, $1 \mathrm{H}), 7.19(\mathrm{~d}, \mathrm{~J}=7.9 \mathrm{~Hz}, 1 \mathrm{H}), 7.05(\mathrm{~d}, \mathrm{~J}=7.8 \mathrm{~Hz}, 1 \mathrm{H}), 6.81$ (d, J = 2.3 Hz, 1H), 6.71 (dd, $\mathrm{J}=8.6,2.3 \mathrm{~Hz}, 1 \mathrm{H}), 4.48(\mathrm{~s}, 2 \mathrm{H}), 3.73$ (s, 3H).

5-((4,5-difluoro-1H-indol-1-yl)methyl)quinolin-8-ol (9v). ${ }^{1} \mathrm{H}$ NMR (400 MHz, $\mathrm{DMSO}_{\left.-\mathrm{d}_{6}\right)} \delta 10.97(\mathrm{~s}, 1 \mathrm{H}), 9.58(\mathrm{~s}, 1 \mathrm{H}), 8.83(\mathrm{dd}, \mathrm{J}=4.0,1.6 \mathrm{~Hz}, 1 \mathrm{H}), 8.53(\mathrm{dd}, \mathrm{J}=8.6$, $1.6 \mathrm{~Hz}, 1 \mathrm{H}), 7.52$ (dd, J = 8.6, 4.1 Hz, 1H), 7.43 (dd, J = 11.5, 8.0 Hz, 1H), 7.38 (d, J = $7.8 \mathrm{~Hz}, 1 \mathrm{H}), 7.32(\mathrm{dd}, \mathrm{J}=11.3,7.0 \mathrm{~Hz}, 1 \mathrm{H}), 7.06(\mathrm{~d}, \mathrm{~J}=2.4 \mathrm{~Hz}, 1 \mathrm{H}), 7.02(\mathrm{~d}, \mathrm{~J}=7.8 \mathrm{~Hz}$, $1 \mathrm{H}), 4.37(\mathrm{~s}, 2 \mathrm{H})$.

5-((5,6-difluoro-1H-indol-1-yl)methyl)quinolin-8-ol (9w). ${ }^{1} \mathrm{H}$ NMR (400 MHz, Acetone- $\left.\mathrm{d}_{6}\right) \delta 10.24(\mathrm{~s}, 1 \mathrm{H}), 8.79(\mathrm{dd}, \mathrm{J}=4.2,1.6 \mathrm{~Hz}, 1 \mathrm{H}), 8.52(\mathrm{dd}, \mathrm{J}=8.6,1.6 \mathrm{~Hz}, 1 \mathrm{H})$, $7.48(\mathrm{dd}, \mathrm{J}=8.6,4.2 \mathrm{~Hz}, 1 \mathrm{H}), 7.44-7.35(\mathrm{~m}, 2 \mathrm{H}), 7.31(\mathrm{dd}, \mathrm{J}=11.2,7.0 \mathrm{~Hz}, 1 \mathrm{H}), 7.08$ $(\mathrm{d}, \mathrm{J}=7.8 \mathrm{~Hz}, 1 \mathrm{H}), 7.05-6.99(\mathrm{~m}, 1 \mathrm{H}), 4.43(\mathrm{~d}, \mathrm{~J}=1.0 \mathrm{~Hz}, 2 \mathrm{H})$.

5-((6-chloro-5-fluoro-1H-indol-1-yl)methyl)quinolin-8-ol (9x). ${ }^{1} \mathrm{H}$ NMR (400 $\mathrm{MHz}$, Acetone- $\left.\mathrm{d}_{6}\right) \delta 10.28(\mathrm{~s}, 1 \mathrm{H}), 8.80(\mathrm{dd}, \mathrm{J}=4.2,1.6 \mathrm{~Hz}, 1 \mathrm{H}), 8.53(\mathrm{dd}, \mathrm{J}=8.6,1.6$ $\mathrm{Hz}, 1 \mathrm{H}), 7.54-7.47(\mathrm{~m}, 2 \mathrm{H}), 7.41$ (t, J = 8.6 Hz, 2H), $7.12-7.05$ (m, 2H), 4.45 (s, 2H).

5-((5,6-dichloro-1H-indol-1-yl)methyl)quinolin-8-ol (9y). ${ }^{1} \mathrm{H}$ NMR (400 MHz, DMSO-d $\left._{6}\right) \delta 11.30-10.99(\mathrm{~m}, 1 \mathrm{H}), 9.63(\mathrm{~s}, 1 \mathrm{H}), 8.84(\mathrm{dd}, \mathrm{J}=4.1,1.4 \mathrm{~Hz}, 1 \mathrm{H}), 8.52(\mathrm{dd}$, $\mathrm{J}=8.5,1.6 \mathrm{~Hz}, 1 \mathrm{H}), 7.72(\mathrm{~s}, 1 \mathrm{H}), 7.60(\mathrm{~s}, 1 \mathrm{H}), 7.53(\mathrm{dd}, \mathrm{J}=8.5,4.1 \mathrm{~Hz}, 1 \mathrm{H}), 7.37(\mathrm{~d}, \mathrm{~J}=$ $7.8 \mathrm{~Hz}, 1 \mathrm{H}), 7.13$ (d, J = 2.3 Hz, 1H), 7.04 (d, J = 7.7 Hz, 1H), 4.40 (s, 2H).

General procedure for synthesis of $2 \mathrm{a}-2 \mathrm{f}, 6 \mathrm{a}-6 \mathrm{f}, 8$ and 10a-10y. To a stirred suspension of 1a-1g or 5a-5g or 7 or $9 \mathbf{a}-9 \mathbf{y}(0.5 \mathrm{mmol})$ and paraformaldehyde $(0.5 \mathrm{mmol}$, $15 \mathrm{mg})$ in ethanol $(6 \mathrm{~mL})$ was added pyrrolidine $(0.45 \mathrm{mmol}, 32 \mathrm{mg})$. The mixture was refluxed for 1-5 hr and solvent was evaporated under reduced pressure to give the crude which was purified with flash chromatography on silica. Elution with dichloromethanemethanol (10:0-10:1) gave desired compounds 2a-2f, 6a-6f, 8 and 10a-10y $(34-81 \%$ yield). 
5-((5-fluoro-1H-indazol-1-yl)methyl)-7-(pyrrolidin-1-ylmethyl)quinolin-8-ol (2a). ${ }^{1} \mathrm{H}$ NMR (400 MHz, Chloroform-d) $\delta 8.84$ (dd, J = 4.1, $\left.1.6 \mathrm{~Hz}, 1 \mathrm{H}\right), 8.74$ (dd, J = 4.2, $1.7 \mathrm{~Hz}, 1 \mathrm{H}), 8.19$ (dd, J = 8.6, 1.6 Hz, 1H), 7.68 (ddt, J = 9.2, 4.6, $1.0 \mathrm{~Hz}, 1 \mathrm{H}), 7.64$ $(\mathrm{d}, \mathrm{J}=0.9 \mathrm{~Hz}, 1 \mathrm{H}), 7.38-7.29(\mathrm{~m}, 2 \mathrm{H}), 7.10-6.99(\mathrm{~m}, 2 \mathrm{H}), 5.87(\mathrm{~s}, 2 \mathrm{H}), 4.02(\mathrm{~s}, 2 \mathrm{H})$, $2.84-2.62(\mathrm{~m}, 4 \mathrm{H}), 1.88(\mathrm{p}, \mathrm{J}=3.3 \mathrm{~Hz}, 4 \mathrm{H})$.

5-((1H-benzo[d] [1,2,3]triazol-1-yl)methyl)-7-(pyrrolidin-1-ylmethyl)quinolin8-ol (2b). ${ }^{1} \mathrm{H}$ NMR (400 MHz, Chloroform-d) $\delta 10.42$ (s, 1H), 8.78 (dd, J = 4.2, $1.6 \mathrm{~Hz}$, $1 \mathrm{H}), 8.44(\mathrm{dd}, \mathrm{J}=8.6,1.6 \mathrm{~Hz}, 1 \mathrm{H}), 7.96(\mathrm{dt}, \mathrm{J}=7.9,1.2 \mathrm{~Hz}, 1 \mathrm{H}), 7.44-7.17(\mathrm{~m}, 5 \mathrm{H})$, $6.11(\mathrm{~s}, 2 \mathrm{H}), 3.95(\mathrm{~s}, 2 \mathrm{H}), 2.64(\mathrm{td}, \mathrm{J}=5.6,4.5,2.3 \mathrm{~Hz}, 4 \mathrm{H}), 1.81$ (p, J = 3.4 Hz, 4H).

5-((6-chloro-9H-purin-9-yl)methyl)-7-(pyrrolidin-1-ylmethyl)quinolin-8-ol (2c). ${ }^{1} \mathrm{H}$ NMR (400 MHz, Chloroform-d) $\delta 8.83(\mathrm{~s}, 1 \mathrm{H}), 8.79(\mathrm{dd}, \mathrm{J}=4.2,1.5 \mathrm{~Hz}, 1 \mathrm{H})$, $8.69(\mathrm{~s}, 1 \mathrm{H}), 8.60(\mathrm{dd}, \mathrm{J}=8.6,1.5 \mathrm{~Hz}, 1 \mathrm{H}), 8.46(\mathrm{~s}, 1 \mathrm{H}), 7.49(\mathrm{dd}, \mathrm{J}=8.6,4.2 \mathrm{~Hz}, 1 \mathrm{H})$, $5.80(\mathrm{~s}, 2 \mathrm{H}), 4.45(\mathrm{~s}, 2 \mathrm{H}), 3.30(\mathrm{~s}, 4 \mathrm{H}), 2.16-2.11(\mathrm{~m}, 4 \mathrm{H})$.

\section{1-((8-hydroxy-7-(pyrrolidin-1-ylmethyl)quinolin-5-yl)methyl)-2,3-} dihydroquinolin-4(1H)-one (2d). ${ }^{1} \mathrm{H}$ NMR (400 MHz, Chloroform-d) $\delta 8.95$ (d, J = 4.1 $\mathrm{Hz}, 1 \mathrm{H}), 8.31(\mathrm{dd}, \mathrm{J}=8.5,2.2 \mathrm{~Hz}, 1 \mathrm{H}), 8.05-7.96(\mathrm{~m}, 1 \mathrm{H}), 7.50-7.37(\mathrm{~m}, 2 \mathrm{H}), 7.23$ (s, $1 \mathrm{H}), 6.93-6.78(\mathrm{~m}, 2 \mathrm{H}), 4.82(\mathrm{~s}, 2 \mathrm{H}), 4.01(\mathrm{~d}, \mathrm{~J}=1.9 \mathrm{~Hz}, 2 \mathrm{H}), 3.46(\mathrm{t}, \mathrm{J}=6.7 \mathrm{~Hz}, 2 \mathrm{H})$, $2.73(\mathrm{~d}, \mathrm{~J}=6.1 \mathrm{~Hz}, 4 \mathrm{H}), 2.65(\mathrm{t}, \mathrm{J}=6.9 \mathrm{~Hz}, 2 \mathrm{H}), 1.90(\mathrm{p}, \mathrm{J}=3.3,2.6 \mathrm{~Hz}, 4 \mathrm{H})$.

5-(((1-phenyl-1H-benzo[d]imidazol-2-yl)amino)methyl)-7-(pyrrolidin-1ylmethyl)quinolin-8-ol (2e). ${ }^{1} \mathrm{H}$ NMR $(400 \mathrm{MHz}$, Chloroform-d) $\delta 8.84$ (dd, J = 4.2, 1.6 $\mathrm{Hz}, 1 \mathrm{H}), 8.21$ (dd, J = 8.5, 1.6 Hz, 1H), 7.60 (dt, J=7.8, $0.9 \mathrm{~Hz}, 1 \mathrm{H}), 7.29$ (dd, J = 8.5, $4.1 \mathrm{~Hz}, 1 \mathrm{H}), 7.19$ (ddd, J = 9.9, 5.3, 2.3 Hz, 5H), $7.12-7.07(\mathrm{~m}, 2 \mathrm{H}), 7.06-7.01$ (m, $2 \mathrm{H}), 5.05(\mathrm{~s}, 2 \mathrm{H}), 5.01-4.92(\mathrm{~m}, 2 \mathrm{H}), 4.21(\mathrm{~s}, 1 \mathrm{H}), 3.96(\mathrm{~s}, 2 \mathrm{H}), 2.81-2.58(\mathrm{~m}, 4 \mathrm{H})$, $1.88(\mathrm{p}, \mathrm{J}=3.3 \mathrm{~Hz}, 4 \mathrm{H})$.

Tert-butyl (R)-(1-(((8-hydroxy-7-(pyrrolidin-1-ylmethyl)quinolin-5yl)methyl)amino)-1-oxo-3-(phenylthio)propan-2-yl)carbamate (2f). ${ }^{1} \mathrm{H}$ NMR (400 MHz, Chloroform-d) $\delta 8.81(\mathrm{~s}, 1 \mathrm{H}), 8.41(\mathrm{~d}, \mathrm{~J}=8.6 \mathrm{~Hz}, 1 \mathrm{H}), 7.88(\mathrm{~s}, 1 \mathrm{H}), 7.52(\mathrm{~s}, 1 \mathrm{H})$, $7.32-7.07(\mathrm{~m}, 5 \mathrm{H}), 5.96(\mathrm{~s}, 1 \mathrm{H}), 4.97(\mathrm{~s}, 1 \mathrm{H}), 4.68(\mathrm{~d}, \mathrm{~J}=15.4 \mathrm{~Hz}, 1 \mathrm{H}), 4.47(\mathrm{~s}, 1 \mathrm{H})$, $4.39-4.16(\mathrm{~m}, 2 \mathrm{H}), 3.75(\mathrm{~d}, \mathrm{~J}=2.0 \mathrm{~Hz}, 2 \mathrm{H}), 3.21(\mathrm{~s}, 4 \mathrm{H}), 3.03-2.88(\mathrm{~m}, 2 \mathrm{H}), 2.10$ (s, $4 \mathrm{H}), 1.41(\mathrm{~s}, 9 \mathrm{H})$.

N-((8-hydroxy-7-(pyrrolidin-1-ylmethyl)quinolin-5-yl)methyl)-2-(3,4,5trimethoxyphenyl)acetamide (6a). ${ }^{1} \mathrm{H}$ NMR $\left(400 \mathrm{MHz}\right.$, Methanol- $\left.\mathrm{d}_{4}\right) \delta 8.78(\mathrm{~d}, \mathrm{~J}=4.1$ $\mathrm{Hz}, 1 \mathrm{H}), 8.33$ (d, J = 8.3 Hz, 1H), 7.40 (dd, J = 8.5, 4.2 Hz, 1H), 7.31 (s, 1H), 6.55 (s, 2H), $4.74(\mathrm{~s}, 1 \mathrm{H}), 3.97(\mathrm{~s}, 2 \mathrm{H}), 3.75(\mathrm{~s}, 3 \mathrm{H}), 3.70(\mathrm{~s}, 6 \mathrm{H}), 3.45(\mathrm{~s}, 2 \mathrm{H}), 3.37$ (d, J = $1.7 \mathrm{~Hz}$, 2H), $2.72(\mathrm{~s}, 4 \mathrm{H}), 1.89(\mathrm{~s}, 4 \mathrm{H})$.

N-((8-hydroxy-7-(pyrrolidin-1-ylmethyl)quinolin-5-yl)methyl)-2-(4nitrophenyl)acetamide (6b). ${ }^{1} \mathrm{H}$ NMR $\left(400 \mathrm{MHz}, \mathrm{DMSO}_{\mathrm{d}}\right) \delta 8.85$ (dd, J = 4.1, $1.5 \mathrm{~Hz}$, $1 \mathrm{H}), 8.66(\mathrm{t}, \mathrm{J}=5.6 \mathrm{~Hz}, 1 \mathrm{H}), 8.37$ (dd, $\mathrm{J}=8.5,1.6 \mathrm{~Hz}, 1 \mathrm{H}), 8.23-8.12(\mathrm{~m}, 2 \mathrm{H}), 7.60-$ 
$7.47(\mathrm{~m}, 3 \mathrm{H}), 7.39(\mathrm{~s}, 1 \mathrm{H}), 4.64(\mathrm{~d}, \mathrm{~J}=5.5 \mathrm{~Hz}, 2 \mathrm{H}), 3.78(\mathrm{~s}, 2 \mathrm{H}), 3.64(\mathrm{~s}, 2 \mathrm{H}), 2.51$ (dt, J $=3.7,1.8 \mathrm{~Hz}, 4 \mathrm{H}), 1.73(\mathrm{p}, \mathrm{J}=3.0 \mathrm{~Hz}, 4 \mathrm{H})$.

2-(4-fluorophenyl)-N-((8-hydroxy-7-(pyrrolidin-1-ylmethyl)quinolin-5yl)methyl)acetamide (6c). ${ }^{1} \mathrm{H}$ NMR $\left(400 \mathrm{MHz}, \mathrm{DMSO}-\mathrm{d}_{6}\right) \delta 8.92$ (dd, J = 4.1, $1.5 \mathrm{~Hz}$, $1 \mathrm{H}), 8.60$ (t, J = 5.5 Hz, 1H), $8.43(\mathrm{dd}, \mathrm{J}=8.6,1.6 \mathrm{~Hz}, 1 \mathrm{H}), 7.70-7.49$ (m, 2H), $7.36-$ $7.23(\mathrm{~m}, 2 \mathrm{H}), 7.18-7.04(\mathrm{~m}, 2 \mathrm{H}), 4.63$ (d, J = 5.5 Hz, 2H), 4.25 (s, 2H), 3.47 (s, 2H), $3.04(\mathrm{~s}, 4 \mathrm{H}), 1.89(\mathrm{p}, \mathrm{J}=3.4 \mathrm{~Hz}, 4 \mathrm{H})$.

N-((8-hydroxy-7-(pyrrolidin-1-ylmethyl)quinolin-5-yl)methyl)-2-(4(trifluoromethyl)phenyl)acetamide (6d). ${ }^{1} \mathrm{H}$ NMR (400 MHz, Chloroform-d) $\delta 8.86$ (dd, $\mathrm{J}=4.1,1.6 \mathrm{~Hz}, 1 \mathrm{H}), 8.20(\mathrm{dd}, \mathrm{J}=8.6,1.6 \mathrm{~Hz}, 1 \mathrm{H}), 7.61-7.51(\mathrm{~m}, 2 \mathrm{H}), 7.44-7.30(\mathrm{~m}$, $3 \mathrm{H}), 7.15(\mathrm{~s}, 1 \mathrm{H}), 5.76(\mathrm{~s}, 1 \mathrm{H}), 4.75(\mathrm{~d}, \mathrm{~J}=5.4 \mathrm{~Hz}, 2 \mathrm{H}), 3.95(\mathrm{~s}, 2 \mathrm{H}), 3.61(\mathrm{~s}, 2 \mathrm{H}), 2.71$ $(\mathrm{td}, \mathrm{J}=5.4,4.4,2.3 \mathrm{~Hz}, 4 \mathrm{H}), 1.88(\mathrm{p}, \mathrm{J}=3.3 \mathrm{~Hz}, 4 \mathrm{H})$.

N-(8-hydroxy-7-(pyrrolidin-1-ylmethyl)quinolin-5-yl)-2-(4nitrophenyl)acetamide (6e). ${ }^{1} \mathrm{H}$ NMR $\left(400 \mathrm{MHz}\right.$, Methanol- $\left.\mathrm{d}_{4}\right) \delta 8.93(\mathrm{dd}, \mathrm{J}=4.2,1.6$ $\mathrm{Hz}, 1 \mathrm{H}), 8.34(\mathrm{dd}, \mathrm{J}=8.6,1.6 \mathrm{~Hz}, 1 \mathrm{H}), 8.32-8.22(\mathrm{~m}, 2 \mathrm{H}), 7.80-7.67(\mathrm{~m}, 5 \mathrm{H}), 7.64$ $(\mathrm{dd}, \mathrm{J}=8.6,4.2 \mathrm{~Hz}, 1 \mathrm{H}), 7.60(\mathrm{~s}, 1 \mathrm{H}), 7.40-7.29(\mathrm{~m}, 3 \mathrm{H}), 4.58(\mathrm{~s}, 2 \mathrm{H}), 4.02(\mathrm{~s}, 2 \mathrm{H})$, $3.49-3.40(\mathrm{~m}, 4 \mathrm{H}), 3.37(\mathrm{~s}, 1 \mathrm{H}), 2.11(\mathrm{p}, \mathrm{J}=4.0 \mathrm{~Hz}, 4 \mathrm{H})$.

N-(8-hydroxy-7-(pyrrolidin-1-ylmethyl)quinolin-5-yl)-2-(4(trifluoromethyl)phenyl)acetamide (6f). ${ }^{1} \mathrm{H}$ NMR $\left(400 \mathrm{MHz}\right.$, Methanol- $\left.\mathrm{d}_{4}\right) \delta 8.88(\mathrm{dd}$, $\mathrm{J}=4.2,1.6 \mathrm{~Hz}, 1 \mathrm{H}), 8.27(\mathrm{dd}, \mathrm{J}=8.5,1.6 \mathrm{~Hz}, 1 \mathrm{H}), 7.68(\mathrm{q}, \mathrm{J}=8.4 \mathrm{~Hz}, 4 \mathrm{H}), 7.62-7.52$ $(\mathrm{m}, 2 \mathrm{H}), 7.49$ (d, J = 3.3 Hz, 2H), 4.33 (s, 2H), 3.95 (s, 2H), 3.57 (s, 1H), $3.19-3.05$ (m, 4H), $2.07-1.94(\mathrm{~m}, 4 \mathrm{H})$.

1-(4-bromobenzyl)-3-((8-hydroxy-7-(pyrrolidin-1-ylmethyl)quinolin-5yl)methyl)urea (8). ${ }^{1} \mathrm{H} \mathrm{NMR}(400 \mathrm{MHz}$, Methanol-d 4$) \delta 8.83(\mathrm{dd}, \mathrm{J}=4.2,1.6 \mathrm{~Hz}, 1 \mathrm{H})$, $8.50(\mathrm{dd}, \mathrm{J}=8.6,1.6 \mathrm{~Hz}, 1 \mathrm{H}), 7.53(\mathrm{dd}, \mathrm{J}=8.6,4.2 \mathrm{~Hz}, 1 \mathrm{H}), 7.50-7.41$ (m, 2H), 7.35 (s, $1 \mathrm{H}), 7.29-7.14(\mathrm{~m}, 2 \mathrm{H}), 4.71(\mathrm{~s}, 2 \mathrm{H}), 4.32(\mathrm{~s}, 2 \mathrm{H}), 4.06(\mathrm{~s}, 2 \mathrm{H}), 3.00-2.64(\mathrm{~m}, 4 \mathrm{H})$, $1.92(\mathrm{p}, \mathrm{J}=3.3 \mathrm{~Hz}, 4 \mathrm{H})$.

5-((1H-indol-1-yl)methyl)-7-(pyrrolidin-1-ylmethyl)quinolin-8-ol (10a). ${ }^{1} \mathrm{H}$ NMR (400 MHz, Acetone-d $\left.{ }_{6}\right) \delta 9.88(\mathrm{~s}, 1 \mathrm{H}), 8.63(\mathrm{dd}, \mathrm{J}=4.1,1.5 \mathrm{~Hz}, 1 \mathrm{H}), 8.37(\mathrm{dd}, \mathrm{J}=$ 8.6, $1.6 \mathrm{~Hz}, 1 \mathrm{H}), 7.43(\mathrm{dt}, \mathrm{J}=7.9,1.0 \mathrm{~Hz}, 1 \mathrm{H}), 7.39(\mathrm{~s}, 1 \mathrm{H}), 7.30$ (dd, J = 8.5, $4.1 \mathrm{~Hz}$, $1 \mathrm{H}), 7.23$ (dt, J = 8.1, 0.9 Hz, 1H), 6.94 (ddd, J = 8.2, 7.1, $1.2 \mathrm{~Hz}, 1 \mathrm{H}), 6.84$ (ddd, J = 8.0, 7.0, 1.0 Hz, 1H), 6.79 (p, J = 1.1 Hz, 1H), 4.33 (s, 2H), $3.73(\mathrm{~s}, 2 \mathrm{H}), 2.48-2.35$ (m, 4H), $1.61(\mathrm{p}, \mathrm{J}=3.2 \mathrm{~Hz}, 4 \mathrm{H})$.

5-((2-methyl-1H-indol-1-yl)methyl)-7-(pyrrolidin-1-ylmethyl)quinolin-8-ol (10b). ${ }^{1} \mathrm{H}$ NMR (400 MHz, Chloroform-d) $\delta 10.51$ (s, 1H), $9.06-8.84$ (m, 1H), $8.70-$ $8.31(\mathrm{~m}, 2 \mathrm{H}), 7.55-7.25(\mathrm{~m}, 3 \mathrm{H}), 7.21-7.08(\mathrm{~m}, 1 \mathrm{H}), 7.01(\mathrm{t}, \mathrm{J}=7.5 \mathrm{~Hz}, 1 \mathrm{H}), 6.96(\mathrm{~s}$, $1 \mathrm{H}), 4.39(\mathrm{~s}, 2 \mathrm{H}), 3.86(\mathrm{~s}, 2 \mathrm{H}), 2.63(\mathrm{~d}, \mathrm{~J}=6.1 \mathrm{~Hz}, 4 \mathrm{H}), 1.99-1.64(\mathrm{~m}, 4 \mathrm{H})$. 
5-((2-ethyl-1H-indol-1-yl)methyl)-7-(pyrrolidin-1-ylmethyl)quinolin-8-ol (10c). ${ }^{1} \mathrm{H}$ NMR (400 MHz, Chloroform-d) $\delta 8.90$ (dd, J = 4.2, $\left.1.5 \mathrm{~Hz}, 1 \mathrm{H}\right), 8.46$ (dd, J = 8.6, $1.5 \mathrm{~Hz}, 1 \mathrm{H}), 8.15(\mathrm{~s}, 1 \mathrm{H}), 7.39$ (dd, J = 8.5, 4.1 Hz, 1H), 7.34 (dt, J = 8.0, $1.3 \mathrm{~Hz}$, $2 \mathrm{H}), 7.17-7.10(\mathrm{~m}, 1 \mathrm{H}), 7.05-6.99(\mathrm{~m}, 1 \mathrm{H}), 6.95(\mathrm{~s}, 1 \mathrm{H}), 4.42(\mathrm{~s}, 2 \mathrm{H}), 3.88(\mathrm{~s}, 2 \mathrm{H})$, $2.73-2.61(\mathrm{~m}, 6 \mathrm{H}), 1.84(\mathrm{~h}, \mathrm{~J}=3.2 \mathrm{~Hz}, 4 \mathrm{H}), 1.19(\mathrm{t}, \mathrm{J}=7.6 \mathrm{~Hz}, 3 \mathrm{H})$.

5-((4-fluoro-1H-indol-1-yl)methyl)-7-(pyrrolidin-1-ylmethyl)quinolin-8-ol (10d). ${ }^{1} \mathrm{H}$ NMR (400 MHz, Chloroform-d) $\delta 8.75$ (dd, J = 4.1, 1.6 Hz, 1H), $8.35-8.24$ $(\mathrm{m}, 1 \mathrm{H}), 8.22(\mathrm{~d}, \mathrm{~J}=16.3 \mathrm{~Hz}, 1 \mathrm{H}), 7.26(\mathrm{dd}, \mathrm{J}=8.5,4.1 \mathrm{~Hz}, 1 \mathrm{H}), 7.19(\mathrm{~d}, \mathrm{~J}=4.0 \mathrm{~Hz}, 2 \mathrm{H})$, $7.14-6.96(\mathrm{~m}, 2 \mathrm{H}), 6.69$ (ddd, J = 11.2, 7.4, $1.3 \mathrm{~Hz}, 1 \mathrm{H}), 6.43$ (s, 1H), 4.48 (s, 2H), 3.98 $(\mathrm{s}, 2 \mathrm{H}), 2.75(\mathrm{t}, \mathrm{J}=5.3 \mathrm{~Hz}, 4 \mathrm{H}), 1.83(\mathrm{p}, \mathrm{J}=3.3 \mathrm{~Hz}, 4 \mathrm{H})$.

\section{5-((4-nitro-1H-indol-1-yl)methyl)-7-(pyrrolidin-1-ylmethyl)quinolin-8-ol}

(10e). ${ }^{1} \mathrm{H}$ NMR (400 MHz, Chloroform-d) $\delta 9.42$ (s, 1H), 8.71 (dd, J = 4.1, $1.6 \mathrm{~Hz}, 1 \mathrm{H}$ ), $8.15(\mathrm{dd}, \mathrm{J}=8.5,1.6 \mathrm{~Hz}, 1 \mathrm{H}), 7.76(\mathrm{dd}, \mathrm{J}=7.9,0.9 \mathrm{~Hz}, 1 \mathrm{H}), 7.56(\mathrm{dd}, \mathrm{J}=8.1,0.9 \mathrm{~Hz}$, $1 \mathrm{H}), 7.23-7.16(\mathrm{~m}, 2 \mathrm{H}), 7.13(\mathrm{t}, \mathrm{J}=8.0 \mathrm{~Hz}, 1 \mathrm{H}), 6.98(\mathrm{~s}, 1 \mathrm{H}), 6.50(\mathrm{~s}, 1 \mathrm{H}), 4.43(\mathrm{~s}, 2 \mathrm{H})$, 3.86 (s, 2H), 2.60 (q, J = 5.0, 4.0 Hz, 4H), 1.75 (p, J = 3.2 Hz, 4H).

5-((5-fluoro-1H-indol-1-yl)methyl)-7-(pyrrolidin-1-ylmethyl)quinolin-8-ol (10f). ${ }^{1} \mathrm{H}$ NMR (400 MHz, Methanol-d 4 ) $\delta 8.76$ (dd, J = 4.2, 1.6 Hz, 1H), 8.47 (dd, J = 8.6, 1.6 Hz, 1H), 7.43 (dd, J = 8.6, 4.2 Hz, 1H), $7.33-7.24(\mathrm{~m}, 2 \mathrm{H}), 7.09$ (dd, J = 9.9, 2.5 $\mathrm{Hz}, 1 \mathrm{H}), 6.88(\mathrm{~s}, 1 \mathrm{H}), 6.83(\mathrm{td}, \mathrm{J}=9.1,2.5 \mathrm{~Hz}, 1 \mathrm{H}), 4.41(\mathrm{~s}, 2 \mathrm{H}), 3.98(\mathrm{~s}, 2 \mathrm{H}), 2.79$ $2.62(\mathrm{~m}, 4 \mathrm{H}), 1.86(\mathrm{p}, \mathrm{J}=3.3 \mathrm{~Hz}, 4 \mathrm{H})$.

5-((5-chloro-1H-indol-1-yl)methyl)-7-(pyrrolidin-1-ylmethyl)quinolin-8-ol (10g). ${ }^{1} \mathrm{H}$ NMR (400 MHz, Chloroform-d) $\delta 8.89$ (dd, J = 4.1, $\left.1.6 \mathrm{~Hz}, 1 \mathrm{H}\right), 8.05$ (dd, J = 8.5, $1.6 \mathrm{~Hz}, 1 \mathrm{H}), 7.62(\mathrm{dd}, \mathrm{J}=2.1,0.5 \mathrm{~Hz}, 1 \mathrm{H}), 7.35(\mathrm{dd}, \mathrm{J}=8.6,4.1 \mathrm{~Hz}, 1 \mathrm{H}), 7.31$ (dt, J $=8.7,0.7 \mathrm{~Hz}, 1 \mathrm{H}), 7.17(\mathrm{dd}, \mathrm{J}=8.7,2.0 \mathrm{~Hz}, 1 \mathrm{H}), 6.97-6.91(\mathrm{~m}, 2 \mathrm{H}), 6.43(\mathrm{dd}, \mathrm{J}=3.2$, $0.8 \mathrm{~Hz}, 1 \mathrm{H}), 5.58(\mathrm{~d}, \mathrm{~J}=0.8 \mathrm{~Hz}, 2 \mathrm{H}), 3.93(\mathrm{~s}, 2 \mathrm{H}), 2.67$ (d, J = 6.3 Hz, 4H), 1.87 (p, J = $3.3 \mathrm{~Hz}, 4 \mathrm{H})$.

1-((8-hydroxy-7-(pyrrolidin-1-ylmethyl)quinolin-5-yl)methyl)-1H-indole-5carbonitrile (10h). ${ }^{1} \mathrm{H}$ NMR (400 MHz, Chloroform-d) $\delta 8.90$ (dd, J = 4.2, $\left.1.6 \mathrm{~Hz}, 1 \mathrm{H}\right)$, $8.05-7.98(\mathrm{~m}, 2 \mathrm{H}), 7.46(\mathrm{~d}, \mathrm{~J}=1.1 \mathrm{~Hz}, 2 \mathrm{H}), 7.37(\mathrm{dd}, \mathrm{J}=8.6,4.1 \mathrm{~Hz}, 1 \mathrm{H}), 7.05(\mathrm{~d}, \mathrm{~J}=$ $3.3 \mathrm{~Hz}, 1 \mathrm{H}), 6.97(\mathrm{~s}, 1 \mathrm{H}), 6.57(\mathrm{~d}, \mathrm{~J}=3.3 \mathrm{~Hz}, 1 \mathrm{H}), 5.63(\mathrm{~d}, \mathrm{~J}=0.8 \mathrm{~Hz}, 2 \mathrm{H}), 3.95(\mathrm{~s}, 2 \mathrm{H})$, $2.78-2.59(\mathrm{~m}, 4 \mathrm{H}), 1.88(\mathrm{p}, \mathrm{J}=3.3 \mathrm{~Hz}, 4 \mathrm{H})$.

5-((5-nitro-1H-indol-1-yl)methyl)-7-(pyrrolidin-1-ylmethyl)quinolin-8-ol (10i). ${ }^{1} \mathrm{H}$ NMR (400 MHz, Chloroform-d) $\delta 10.95$ (s, 1H), 8.90 (dd, J = 4.1, $\left.1.6 \mathrm{~Hz}, 1 \mathrm{H}\right), 8.59$ $(\mathrm{d}, \mathrm{J}=2.2 \mathrm{~Hz}, 1 \mathrm{H}), 8.11(\mathrm{dd}, \mathrm{J}=9.1,2.2 \mathrm{~Hz}, 1 \mathrm{H}), 8.03(\mathrm{dd}, \mathrm{J}=8.6,1.6 \mathrm{~Hz}, 1 \mathrm{H}), 7.43(\mathrm{~d}$, $\mathrm{J}=9.1 \mathrm{~Hz}, 1 \mathrm{H}), 7.36(\mathrm{dd}, \mathrm{J}=8.6,4.1 \mathrm{~Hz}, 1 \mathrm{H}), 7.08(\mathrm{~d}, \mathrm{~J}=3.3 \mathrm{~Hz}, 1 \mathrm{H}), 6.97(\mathrm{~s}, 1 \mathrm{H}), 6.66$ $(\mathrm{dd}, \mathrm{J}=3.3,0.8 \mathrm{~Hz}, 1 \mathrm{H}), 5.71-5.52(\mathrm{~m}, 2 \mathrm{H}), 3.94(\mathrm{~s}, 2 \mathrm{H}), 2.68(\mathrm{td}, \mathrm{J}=5.8,4.9,2.5 \mathrm{~Hz}$, $4 \mathrm{H}), 1.94-1.77(\mathrm{~m}, 4 \mathrm{H})$.

Ethyl 1-((8-hydroxy-7-(pyrrolidin-1-ylmethyl)quinolin-5-yl)methyl)-1Hindole-5-carboxylate (10j). ${ }^{1} \mathrm{H}$ NMR $(400 \mathrm{MHz}$, Chloroform-d) $\delta 10.22$ (s, 1H), 9.53 (s, 
$1 \mathrm{H}), 8.82(\mathrm{dd}, \mathrm{J}=4.1,1.5 \mathrm{~Hz}, 1 \mathrm{H}), 8.43(\mathrm{~d}, \mathrm{~J}=1.5 \mathrm{~Hz}, 1 \mathrm{H}), 8.25(\mathrm{dd}, \mathrm{J}=8.6,1.6 \mathrm{~Hz}$, $1 \mathrm{H}), 7.91(\mathrm{dd}, \mathrm{J}=8.6,1.6 \mathrm{~Hz}, 1 \mathrm{H}), 7.35(\mathrm{~d}, \mathrm{~J}=8.6 \mathrm{~Hz}, 1 \mathrm{H}), 7.33-7.25(\mathrm{~m}, 1 \mathrm{H}), 7.15$ (s, $1 \mathrm{H}), 6.64(\mathrm{~s}, 1 \mathrm{H}), 4.86-4.35(\mathrm{~m}, 4 \mathrm{H}), 3.94(\mathrm{~s}, 2 \mathrm{H}), 2.68(\mathrm{~d}, \mathrm{~J}=6.1 \mathrm{~Hz}, 4 \mathrm{H}), 2.15-1.72$ (m, 4H), $1.42(\mathrm{t}, \mathrm{J}=7.1 \mathrm{~Hz}, 3 \mathrm{H})$.

\section{5-((6-fluoro-1H-indol-1-yl)methyl)-7-(pyrrolidin-1-ylmethyl)quinolin-8-ol} (10k). ${ }^{1} \mathrm{H}$ NMR (400 MHz, Chloroform-d) $\delta 8.89$ (dd, J = 4.1, $\left.1.6 \mathrm{~Hz}, 1 \mathrm{H}\right), 8.06$ (dd, J = 8.6, 1.6 Hz, 1H), $7.55(\mathrm{dd}, \mathrm{J}=8.7,5.4 \mathrm{~Hz}, 1 \mathrm{H}), 7.35(\mathrm{dd}, \mathrm{J}=8.6,4.1 \mathrm{~Hz}, 1 \mathrm{H}), 7.07$ (dd, J $=10.0,2.3 \mathrm{~Hz}, 1 \mathrm{H}), 6.98(\mathrm{~s}, 1 \mathrm{H}), 6.94-6.84(\mathrm{~m}, 2 \mathrm{H}), 6.46(\mathrm{dd}, \mathrm{J}=3.3,0.9 \mathrm{~Hz}, 1 \mathrm{H}), 5.52$ (s, 2H), $3.94(\mathrm{~s}, 2 \mathrm{H}), 2.84-2.54(\mathrm{~m}, 4 \mathrm{H}), 1.87(\mathrm{p}, \mathrm{J}=3.3 \mathrm{~Hz}, 4 \mathrm{H})$.

5-((6-chloro-1H-indol-1-yl)methyl)-7-(pyrrolidin-1-ylmethyl)quinolin-8-ol (10I). ${ }^{1} \mathrm{H}$ NMR (400 MHz, Chloroform-d) $\delta 8.89$ (dd, J = 4.2, $\left.1.6 \mathrm{~Hz}, 1 \mathrm{H}\right), 8.06(\mathrm{dd}, \mathrm{J}=$ 8.6, $1.6 \mathrm{~Hz}, 1 \mathrm{H}), 7.55(\mathrm{dd}, \mathrm{J}=8.5,0.6 \mathrm{~Hz}, 1 \mathrm{H}), 7.44-7.33(\mathrm{~m}, 2 \mathrm{H}), 7.19-7.03(\mathrm{~m}, 2 \mathrm{H})$, $6.93(\mathrm{~d}, \mathrm{~J}=3.2 \mathrm{~Hz}, 1 \mathrm{H}), 6.46(\mathrm{dd}, \mathrm{J}=3.3,0.9 \mathrm{~Hz}, 1 \mathrm{H}), 5.56(\mathrm{~d}, \mathrm{~J}=0.8 \mathrm{~Hz}, 2 \mathrm{H}), 4.03$ (s, 2H), $2.79(\mathrm{~s}, 4 \mathrm{H}), 1.91(\mathrm{~s}, 4 \mathrm{H})$.

5-((6-bromo-1H-indol-1-yl)methyl)-7-(pyrrolidin-1-ylmethyl)quinolin-8-ol (10m). ${ }^{1} \mathrm{H}$ NMR (400 MHz, Chloroform-d) $\delta 10.37$ (s, 1H), 8.88 (dd, J = 4.1, $\left.1.6 \mathrm{~Hz}, 1 \mathrm{H}\right)$, $8.02(\mathrm{dd}, \mathrm{J}=8.5,1.6 \mathrm{~Hz}, 1 \mathrm{H}), 7.60-7.53(\mathrm{~m}, 1 \mathrm{H}), 7.50$ (d, J = 8.4 Hz, 1H), 7.34 (dd, J = 8.5, 4.1 Hz, 1H), 7.23 (dd, J = 8.4, 1.7 Hz, 1H), $6.95(\mathrm{~s}, 1 \mathrm{H}), 6.87(\mathrm{~d}, \mathrm{~J}=3.2 \mathrm{~Hz}, 1 \mathrm{H})$, $6.44(\mathrm{dd}, \mathrm{J}=3.3,0.9 \mathrm{~Hz}, 1 \mathrm{H}), 5.51(\mathrm{~s}, 2 \mathrm{H}), 3.93(\mathrm{~s}, 2 \mathrm{H}), 2.68(\mathrm{p}, \mathrm{J}=3.9,3.5 \mathrm{~Hz}, 4 \mathrm{H})$, $1.86(\mathrm{p}, \mathrm{J}=3.3 \mathrm{~Hz}, 4 \mathrm{H})$.

\section{5-((6-nitro-1H-indol-1-yl)methyl)-7-(pyrrolidin-1-ylmethyl)quinolin-8-ol} (10n). ${ }^{1} \mathrm{H}$ NMR (400 MHz, Chloroform-d) $\delta 9.54$ (s, 1H), 8.91 (dd, J = 4.1, $\left.1.6 \mathrm{~Hz}, 1 \mathrm{H}\right)$, $8.44(\mathrm{~d}, \mathrm{~J}=1.9 \mathrm{~Hz}, 1 \mathrm{H}), 8.03(\mathrm{ddd}, \mathrm{J}=10.6,8.7,1.8 \mathrm{~Hz}, 2 \mathrm{H}), 7.68(\mathrm{~d}, \mathrm{~J}=8.8 \mathrm{~Hz}, 1 \mathrm{H})$, $7.36(\mathrm{dd}, \mathrm{J}=8.5,4.1 \mathrm{~Hz}, 1 \mathrm{H}), 7.18(\mathrm{~d}, \mathrm{~J}=3.1 \mathrm{~Hz}, 1 \mathrm{H}), 7.07(\mathrm{~s}, 1 \mathrm{H}), 6.57(\mathrm{dd}, \mathrm{J}=3.2,0.9$ $\mathrm{Hz}, 1 \mathrm{H}), 5.68$ (s, 2H), 3.97 (s, 2H), $2.80-2.58$ (m, 4H), 1.88 (p, J = 3.3 Hz, 4H).

5-((6-methoxy-1H-indol-1-yl)methyl)-7-(pyrrolidin-1-ylmethyl)quinolin-8-ol (10o). ${ }^{1} \mathrm{H}$ NMR (400 MHz, Chloroform-d) $\delta 8.84$ (dd, J = 4.1, 1.6 Hz, 1H), 8.27 (dd, J = 8.5, 1.6 Hz, 1H), $7.90(\mathrm{~s}, 1 \mathrm{H}), 7.46(\mathrm{~d}, \mathrm{~J}=8.7 \mathrm{~Hz}, 1 \mathrm{H}), 7.28(\mathrm{dd}, \mathrm{J}=8.6,4.1 \mathrm{~Hz}, 1 \mathrm{H})$, $7.15(\mathrm{~s}, 1 \mathrm{H}), 6.84(\mathrm{~d}, \mathrm{~J}=2.2 \mathrm{~Hz}, 1 \mathrm{H}), 6.78(\mathrm{dd}, \mathrm{J}=8.6,2.3 \mathrm{~Hz}, 1 \mathrm{H}), 6.48$ (dt, J = 2.4, 1.2 $\mathrm{Hz}, 1 \mathrm{H}), 4.37$ (s, 2H), 3.94 (s, 2H), 3.84 (s, 3H), $2.78-2.57$ (m, 4H), 1.85 (p, J = 3.2 Hz, $4 \mathrm{H})$.

5-((7-fluoro-1H-indol-1-yl)methyl)-7-(pyrrolidin-1-ylmethyl)quinolin-8-ol (10p). ${ }^{1} \mathrm{H}$ NMR $\left(400 \mathrm{MHz}, \mathrm{DMSO}_{-} \mathrm{d}_{6}\right) \delta 11.34(\mathrm{~s}, 1 \mathrm{H}), 8.81(\mathrm{dd}, \mathrm{J}=4.2,1.5 \mathrm{~Hz}, 1 \mathrm{H})$, $8.53(\mathrm{dd}, \mathrm{J}=8.6,1.6 \mathrm{~Hz}, 1 \mathrm{H}), 7.65-7.40(\mathrm{~m}, 2 \mathrm{H}), 7.40-7.24(\mathrm{~m}, 1 \mathrm{H}), 7.12(\mathrm{~s}, 1 \mathrm{H})$, $7.02-6.68(\mathrm{~m}, 2 \mathrm{H}), 4.41(\mathrm{~s}, 2 \mathrm{H}), 3.80(\mathrm{~s}, 2 \mathrm{H}), 2.50(\mathrm{~d}, \mathrm{~J}=6.3 \mathrm{~Hz}, 4 \mathrm{H}), 1.68(\mathrm{~h}, \mathrm{~J}=3.2$ $\mathrm{Hz}, 4 \mathrm{H})$.

5-((7-methyl-1H-indol-1-yl)methyl)-7-(pyrrolidin-1-ylmethyl)quinolin-8-ol (10q). ${ }^{1} \mathrm{H}$ NMR (400 MHz, Chloroform-d) $\delta 9.74$ (s, 1H), 8.84 (dd, J = 4.2, $\left.1.6 \mathrm{~Hz}, 1 \mathrm{H}\right)$, $8.28(\mathrm{dd}, \mathrm{J}=8.6,1.6 \mathrm{~Hz}, 1 \mathrm{H}), 8.18(\mathrm{~s}, 1 \mathrm{H}), 7.50(\mathrm{~d}, \mathrm{~J}=7.7 \mathrm{~Hz}, 1 \mathrm{H}), 7.30-7.24(\mathrm{~m}, 1 \mathrm{H})$, 
$7.19(\mathrm{~s}, 1 \mathrm{H}), 7.11-6.99(\mathrm{~m}, 2 \mathrm{H}), 6.57(\mathrm{~d}, \mathrm{~J}=2.0 \mathrm{~Hz}, 1 \mathrm{H}), 4.41(\mathrm{~s}, 2 \mathrm{H}), 3.95(\mathrm{~s}, 2 \mathrm{H})$, $2.82-2.62(\mathrm{~m}, 4 \mathrm{H}), 2.47(\mathrm{~s}, 3 \mathrm{H}), 1.97-1.78(\mathrm{~m}, 4 \mathrm{H})$.

5-((2,3-dimethyl-1H-indol-1-yl)methyl)-7-(pyrrolidin-1-ylmethyl)quinolin-8ol (10r). ${ }^{1} \mathrm{H}$ NMR (400 MHz, Chloroform-d) $\delta 10.57$ (s, 1H), 8.94 (dd, J = 4.2, $1.6 \mathrm{~Hz}$, $1 \mathrm{H}), 8.28(\mathrm{dd}, \mathrm{J}=8.6,1.6 \mathrm{~Hz}, 1 \mathrm{H}), 7.57(\mathrm{dd}, \mathrm{J}=8.2,1.7 \mathrm{~Hz}, 1 \mathrm{H}), 7.45$ (dd, J = 8.5, 4.2 $\mathrm{Hz}, 1 \mathrm{H}), 7.20-6.97(\mathrm{~m}, 3 \mathrm{H}), 6.27(\mathrm{~s}, 1 \mathrm{H}), 5.54(\mathrm{~d}, \mathrm{~J}=1.2 \mathrm{~Hz}, 2 \mathrm{H}), 3.75(\mathrm{~s}, 2 \mathrm{H}), 2.72-$ $2.46(\mathrm{~m}, 4 \mathrm{H}), 2.33$ (s, 3H), 2.24 (s, 3H), 1.79 (p, J = 3.2 Hz, 4H).

5-((5-methoxy-2-methyl-1H-indol-1-yl)methyl)-7-(pyrrolidin-1ylmethyl)quinolin-8-ol (10s). ${ }^{1} \mathrm{H}$ NMR (400 MHz, Chloroform-d) $\delta 10.18$ (s, 1H), 8.87 $(\mathrm{dd}, \mathrm{J}=4.2,1.5 \mathrm{~Hz}, 1 \mathrm{H}), 8.41$ (dd, J = 8.5, $1.6 \mathrm{~Hz}, 1 \mathrm{H}), 8.20$ (s, 1H), 7.36 (dd, J = 8.5, $4.1 \mathrm{~Hz}, 1 \mathrm{H}), 7.23-7.07(\mathrm{~m}, 1 \mathrm{H}), 6.93(\mathrm{~s}, 1 \mathrm{H}), 6.74(\mathrm{dt}, \mathrm{J}=3.9,1.9 \mathrm{~Hz}, 2 \mathrm{H}), 4.32(\mathrm{~s}, 2 \mathrm{H})$, $3.85(\mathrm{~s}, 2 \mathrm{H}), 3.69(\mathrm{~s}, 3 \mathrm{H}), 2.84-2.41(\mathrm{~m}, 4 \mathrm{H}), 2.22(\mathrm{~s}, 3 \mathrm{H}), 1.93-1.70(\mathrm{~m}, 4 \mathrm{H})$.

5-((2-ethyl-5-fluoro-1H-indol-1-yl)methyl)-7-(pyrrolidin-1-ylmethyl)quinolin8-ol (10t). ${ }^{1} \mathrm{H}$ NMR (400 MHz, Chloroform-d) $\delta 9.11$ (s, 1H), 8.89 (dd, J = 4.1, 1.6 Hz, $1 \mathrm{H}), 8.50(\mathrm{dd}, \mathrm{J}=8.6,1.7 \mathrm{~Hz}, 1 \mathrm{H}), 7.50-7.40(\mathrm{~m}, 1 \mathrm{H}), 7.39-7.31(\mathrm{~m}, 1 \mathrm{H}), 7.10-6.92$ $(\mathrm{m}, 3 \mathrm{H}), 4.83(\mathrm{~s}, 2 \mathrm{H}), 4.39(\mathrm{q}, \mathrm{J}=7.1 \mathrm{~Hz}, 2 \mathrm{H}), 3.92(\mathrm{~s}, 2 \mathrm{H}), 2.81-2.57$ (m, 4H), 1.85 (p, $\mathrm{J}=3.2 \mathrm{~Hz}, 4 \mathrm{H}), 1.28(\mathrm{t}, \mathrm{J}=7.1 \mathrm{~Hz}, 3 \mathrm{H})$.

1-((8-hydroxy-7-(pyrrolidin-1-ylmethyl)quinolin-5-yl)methyl)-6-methoxy-1Hindole-3-carbonitrile (10u). ${ }^{1} \mathrm{H}$ NMR $\left(400 \mathrm{MHz}, \mathrm{DMSO}_{6}\right) \delta 10.73(\mathrm{~s}, 1 \mathrm{H}), 8.83$ (dd, J $=4.1,1.5 \mathrm{~Hz}, 1 \mathrm{H}), 8.46(\mathrm{dd}, \mathrm{J}=8.5,1.6 \mathrm{~Hz}, 1 \mathrm{H}), 7.51(\mathrm{dd}, \mathrm{J}=8.5,4.1 \mathrm{~Hz}, 1 \mathrm{H}), 7.45(\mathrm{~d}$, $\mathrm{J}=8.5 \mathrm{~Hz}, 1 \mathrm{H}), 7.27(\mathrm{~s}, 1 \mathrm{H}), 6.82(\mathrm{~d}, \mathrm{~J}=2.3 \mathrm{~Hz}, 1 \mathrm{H}), 6.71(\mathrm{dd}, \mathrm{J}=8.6,2.3 \mathrm{~Hz}, 1 \mathrm{H}), 4.48$ $(\mathrm{s}, 2 \mathrm{H}), 4.01(\mathrm{~s}, 2 \mathrm{H}), 3.79(\mathrm{~s}, 2 \mathrm{H}), 3.73(\mathrm{~s}, 3 \mathrm{H}), 2.65-2.36(\mathrm{~m}, 4 \mathrm{H}), 1.66(\mathrm{~h}, \mathrm{~J}=3.1 \mathrm{~Hz}$, $4 \mathrm{H})$.

5-((4,5-difluoro-1H-indol-1-yl)methyl)-7-(pyrrolidin-1-ylmethyl)quinolin-8-ol (10v). ${ }^{1} \mathrm{H}$ NMR $(400 \mathrm{MHz}$, Chloroform-d) $\delta 8.86(\mathrm{dd}, \mathrm{J}=4.1,1.5 \mathrm{~Hz}, 1 \mathrm{H}), 8.50(\mathrm{~s}, 1 \mathrm{H})$, 8.27 (dd, J = 8.6, 1.6 Hz, 1H), $7.37-7.31(\mathrm{~m}, 1 \mathrm{H}), 7.29$ (d, J = 2.2 Hz, 1H), 7.19 (s, 1H), $7.15(\mathrm{dd}, \mathrm{J}=10.6,6.5 \mathrm{~Hz}, 1 \mathrm{H}), 6.69$ (s, 1H), 4.35 (s, 2H), 4.01 (s, 2H), 2.75 (q, J = 5.3, $4.6 \mathrm{~Hz}, 4 \mathrm{H}), 2.13-1.81(\mathrm{~m}, 4 \mathrm{H})$.

5-((5,6-difluoro-1H-indol-1-yl)methyl)-7-(pyrrolidin-1-ylmethyl)quinolin-8-ol (10w). ${ }^{1} \mathrm{H}$ NMR (400 MHz, Chloroform-d) $\delta 8.91-8.63(\mathrm{~m}, 1 \mathrm{H}), 8.42-8.15(\mathrm{~m}, 1 \mathrm{H})$, $7.46-6.98(\mathrm{~m}, 4 \mathrm{H}), 6.66(\mathrm{~d}, \mathrm{~J}=21.3 \mathrm{~Hz}, 1 \mathrm{H}), 4.45-4.21(\mathrm{~m}, 2 \mathrm{H}), 3.98-3.78(\mathrm{~m}, 2 \mathrm{H})$, $2.81-2.51(\mathrm{~m}, 4 \mathrm{H}), 1.99-1.69(\mathrm{~m}, 4 \mathrm{H})$.

5-((6-chloro-5-fluoro-1H-indol-1-yl)methyl)-7-(pyrrolidin-1ylmethyl)quinolin-8-ol (10x). ${ }^{1} \mathrm{H}$ NMR (400 MHz, DMSO-d $\left.{ }_{6}\right) \delta 11.04(\mathrm{~s}, 1 \mathrm{H}), 8.80(\mathrm{dd}$, $\mathrm{J}=4.2,1.5 \mathrm{~Hz}, 1 \mathrm{H}), 8.50(\mathrm{dd}, \mathrm{J}=8.6,1.6 \mathrm{~Hz}, 1 \mathrm{H}), 7.64-7.44(\mathrm{~m}, 3 \mathrm{H}), 7.40(\mathrm{~d}, \mathrm{~J}=10.3$ $\mathrm{Hz}, 1 \mathrm{H}), 7.18(\mathrm{~d}, \mathrm{~J}=1.7 \mathrm{~Hz}, 1 \mathrm{H}), 4.38(\mathrm{~s}, 2 \mathrm{H}), 3.80(\mathrm{~s}, 2 \mathrm{H}), 2.60-2.40$ (m, 4H), 1.69 (q, $\mathrm{J}=3.7,3.3 \mathrm{~Hz}, 4 \mathrm{H})$. 
5-((5,6-dichloro-1H-indol-1-yl)methyl)-7-(pyrrolidin-1-ylmethyl)quinolin-8-ol (10y). ${ }^{1} \mathrm{H}$ NMR $\left(400 \mathrm{MHz}, \mathrm{DMSO}_{-} \mathrm{d}_{6}\right) \delta 11.15(\mathrm{~s}, 1 \mathrm{H}), 8.82(\mathrm{~d}, \mathrm{~J}=4.2 \mathrm{~Hz}, 1 \mathrm{H}), 8.52$ (d, $\mathrm{J}=8.5 \mathrm{~Hz}, 1 \mathrm{H}), 7.67(\mathrm{~s}, 1 \mathrm{H}), 7.59(\mathrm{~s}, 1 \mathrm{H}), 7.55-7.38(\mathrm{~m}, 2 \mathrm{H}), 7.22(\mathrm{~s}, 1 \mathrm{H}), 4.41(\mathrm{~s}, 2 \mathrm{H})$, $3.82(\mathrm{~s}, 2 \mathrm{H}), 2.51(\mathrm{~d}, \mathrm{~J}=6.7 \mathrm{~Hz}, 4 \mathrm{H}), 1.76-1.45(\mathrm{~m}, 4 \mathrm{H})$.

General procedure for synthesis of 5a-5f. To a stirred solution of compound 4 (1.0 mmol, $140 \mathrm{mg}$ ) or 5-amino-8-hydroxyquinoline dihydrochloride and carboxylic acid $(1.2 \mathrm{mmol})$ in DMF- $\mathrm{H}_{2} \mathrm{O}(1: 5)$ were added oxyma $(2.0 \mathrm{mmol}, 284 \mathrm{mg})$, EDCI (2.0 mmol, $310 \mathrm{mg})$, and $\mathrm{NaHCO}_{3}(6.0 \mathrm{mmol}, 636 \mathrm{mg})$. After stirring at room temperature for $12 \mathrm{hr}$, the solution was extracted with EtOAc. The combined organic layers were washed with brine $(3 \mathrm{ml})$, and then dried over $\mathrm{Na}_{2} \mathrm{SO}_{4}$. Concentration of organic phase gave crude product which was purified with flash chromatography on silica. Elution with dichloromethane/methanol (10:0-10:1) gave desired compounds 5a-5f (yield: 27-59\%).

N-((8-hydroxyquinolin-5-yl)methyl)-2-(3,4,5-trimethoxyphenyl)acetamide (5a). ${ }^{1} \mathrm{H}$ NMR (400 MHz, Chloroform-d) $\delta 8.79$ (dd, J = 4.2, $\left.1.5 \mathrm{~Hz}, 1 \mathrm{H}\right), 8.34$ (dd, J = 8.5, 1.5 Hz, 1H), $7.46(\mathrm{dd}, \mathrm{J}=8.6,4.2 \mathrm{~Hz}, 1 \mathrm{H}), 7.32(\mathrm{~d}, \mathrm{~J}=7.8 \mathrm{~Hz}, 1 \mathrm{H}), 7.06$ (d, J = 7.8 $\mathrm{Hz}, 1 \mathrm{H}), 6.37(\mathrm{~s}, 2 \mathrm{H}), 5.71(\mathrm{~s}, 1 \mathrm{H}), 4.78(\mathrm{~d}, \mathrm{~J}=5.6 \mathrm{~Hz}, 2 \mathrm{H}), 3.80(\mathrm{~s}, 3 \mathrm{H}), 3.72(\mathrm{~s}, 6 \mathrm{H})$, $3.52(\mathrm{~s}, 2 \mathrm{H})$.

N-((8-hydroxyquinolin-5-yl)methyl)-2-(4-nitrophenyl)acetamide (5b). ${ }^{1} \mathrm{H}$ NMR (400 MHz, DMSO-d $\left.{ }_{6}\right) \delta 9.78(\mathrm{~s}, 1 \mathrm{H}), 8.87(\mathrm{dd}, \mathrm{J}=4.1,1.6 \mathrm{~Hz}, 1 \mathrm{H}), 8.64(\mathrm{t}, \mathrm{J}=5.5$ $\mathrm{Hz}, 1 \mathrm{H}), 8.39(\mathrm{dd}, \mathrm{J}=8.6,1.6 \mathrm{~Hz}, 1 \mathrm{H}), 8.23-8.12(\mathrm{~m}, 2 \mathrm{H}), 7.60-7.49$ (m, 3H), 7.41 (d, $\mathrm{J}=7.8 \mathrm{~Hz}, 1 \mathrm{H}), 7.04(\mathrm{~d}, \mathrm{~J}=7.8 \mathrm{~Hz}, 1 \mathrm{H}), 4.64(\mathrm{~d}, \mathrm{~J}=5.5 \mathrm{~Hz}, 2 \mathrm{H}), 3.64(\mathrm{~s}, 2 \mathrm{H})$.

2-(4-fluorophenyl)-N-((8-hydroxyquinolin-5-yl)methyl)acetamide (5c). ${ }^{1} \mathrm{H}$ NMR (400 MHz, DMSO-d $\left.{ }_{6}\right) \delta 9.76(\mathrm{~s}, 1 \mathrm{H}), 8.87(\mathrm{dd}, \mathrm{J}=4.1,1.6 \mathrm{~Hz}, 1 \mathrm{H}), 8.52(\mathrm{t}, \mathrm{J}=5.6$ $\mathrm{Hz}, 1 \mathrm{H}), 8.40(\mathrm{dd}, \mathrm{J}=8.6,1.6 \mathrm{~Hz}, 1 \mathrm{H}), 7.55(\mathrm{dd}, \mathrm{J}=8.6,4.1 \mathrm{~Hz}, 1 \mathrm{H}), 7.39$ (d, J = 7.8 Hz, $1 \mathrm{H}), 7.32-7.23(\mathrm{~m}, 2 \mathrm{H}), 7.16-7.06(\mathrm{~m}, 2 \mathrm{H}), 7.03(\mathrm{~d}, \mathrm{~J}=7.8 \mathrm{~Hz}, 1 \mathrm{H}), 4.62(\mathrm{~d}, \mathrm{~J}=5.5$ $\mathrm{Hz}, 2 \mathrm{H}), 3.44$ (s, 2H).

N-((8-hydroxyquinolin-5-yl)methyl)-2-(4-(trifluoromethyl)phenyl)acetamide (5d). ${ }^{1} \mathrm{H}$ NMR $\left(400 \mathrm{MHz}, \mathrm{DMSO}_{-} \mathrm{d}_{6}\right) \delta 9.79$ (s, 1H), 8.87 (dd, J = 4.1, $\left.1.5 \mathrm{~Hz}, 1 \mathrm{H}\right), 8.61$ $(\mathrm{t}, \mathrm{J}=5.6 \mathrm{~Hz}, 1 \mathrm{H}), 8.39(\mathrm{dd}, \mathrm{J}=8.6,1.6 \mathrm{~Hz}, 1 \mathrm{H}), 7.66(\mathrm{~d}, \mathrm{~J}=8.0 \mathrm{~Hz}, 2 \mathrm{H}), 7.55$ (dd, J = 8.6, 4.1 Hz, 1H), 7.48 (d, J = 8.0 Hz, 2H), $7.40(\mathrm{~d}, \mathrm{~J}=7.8 \mathrm{~Hz}, 1 \mathrm{H}), 7.03$ (d, J = 7.8 Hz, $1 \mathrm{H}), 4.64(\mathrm{~d}, \mathrm{~J}=5.5 \mathrm{~Hz}, 2 \mathrm{H}), 3.57(\mathrm{~s}, 2 \mathrm{H})$.

N-(8-hydroxyquinolin-5-yl)-2-(4-nitrophenyl)acetamide (5e). ${ }^{1} \mathrm{H}$ NMR (400 MHz, DMSO-d 6 ) $\delta 10.12(\mathrm{~s}, 1 \mathrm{H}), 9.83(\mathrm{~s}, 1 \mathrm{H}), 8.88(\mathrm{dd}, \mathrm{J}=4.1,1.6 \mathrm{~Hz}, 1 \mathrm{H}), 8.32(\mathrm{~d}, \mathrm{~J}=$ $1.6 \mathrm{~Hz}, 1 \mathrm{H}), 8.30-8.16(\mathrm{~m}, 2 \mathrm{H}), 7.87-7.67(\mathrm{~m}, 2 \mathrm{H}), 7.60(\mathrm{dd}, \mathrm{J}=8.6,4.1 \mathrm{~Hz}, 1 \mathrm{H})$, $7.46(\mathrm{~d}, \mathrm{~J}=8.2 \mathrm{~Hz}, 1 \mathrm{H}), 7.06(\mathrm{~d}, \mathrm{~J}=8.2 \mathrm{~Hz}, 1 \mathrm{H}), 3.97(\mathrm{~s}, 2 \mathrm{H})$.

N-(8-hydroxyquinolin-5-yl)-2-(4-(trifluoromethyl)phenyl)acetamide (5f). ${ }^{1} \mathrm{H}$ NMR (400 MHz, DMSO-d $) \delta 10.10(\mathrm{~s}, 1 \mathrm{H}), 9.83(\mathrm{~s}, 1 \mathrm{H}), 8.88(\mathrm{dd}, \mathrm{J}=4.1,1.6 \mathrm{~Hz}, 1 \mathrm{H})$, $8.30(\mathrm{dd}, \mathrm{J}=8.5,1.6 \mathrm{~Hz}, 1 \mathrm{H}), 7.74(\mathrm{~d}, \mathrm{~J}=8.2 \mathrm{~Hz}, 2 \mathrm{H}), 7.64$ (d, J = 8.0 Hz, 2H), 7.60 (dd, 
$\mathrm{J}=8.6,4.1 \mathrm{~Hz}, 1 \mathrm{H}), 7.46(\mathrm{~d}, \mathrm{~J}=8.2 \mathrm{~Hz}, 1 \mathrm{H}), 7.56-7.40(\mathrm{~m}, 1 \mathrm{H}), 7.06(\mathrm{~d}, \mathrm{~J}=8.2 \mathrm{~Hz}, 1 \mathrm{H})$, $3.90(\mathrm{~s}, 2 \mathrm{H})$.

Synthesis of 5-(azidomethyl)quinolin-8-ol (3). To a stirred solution of 5chloromethyl-8-quinolinol hydrochloride $(10 \mathrm{mmol}, 2.3 \mathrm{~g})$ in acetone $(20 \mathrm{ml})$ were added sodium azide ( $30 \mathrm{mmol}, 1.95 \mathrm{~g}$ ) at room temperature. After refluxed for $20 \mathrm{hr}$, the mixture was filtered and the residue was washed with acetone. Combined organic solvent was removed under reduced pressure to give crude product which was purified with flash chromatography on silica. Elution with hexanes/ethylacetate (10:1-1:1) gave desired compound 3 (1.54 g, 77\%). ${ }^{1} \mathrm{H}$ NMR $\left(400 \mathrm{MHz}, \mathrm{DMSO}-d_{6}\right) \delta 10.04(\mathrm{~s}, 1 \mathrm{H}), 8.92(\mathrm{dd}, J=$ 4.1, $1.6 \mathrm{~Hz}, 1 \mathrm{H}), 8.50(\mathrm{dd}, J=8.6,1.6 \mathrm{~Hz}, 1 \mathrm{H}), 7.67(\mathrm{dd}, J=8.6,4.1 \mathrm{~Hz}, 1 \mathrm{H}), 7.55(\mathrm{~d}, J$ $=7.8 \mathrm{~Hz}, 1 \mathrm{H}), 7.08(\mathrm{~d}, J=7.8 \mathrm{~Hz}, 1 \mathrm{H}), 4.83(\mathrm{~s}, 2 \mathrm{H})$.

Synthesis of 5-(aminomethyl)quinolin-8-ol (4). A suspension of azide 3 (2.00 g, $10 \mathrm{~mol})$ and $10 \% \mathrm{Pd} / \mathrm{C}(0.15 \mathrm{~g})$ in ethylacetate $(15 \mathrm{ml})$ was hydrogenated overnight, the reaction mixture was filtered off and washed with dichloromethane-methanol (1:1). The combined filtration was evaporated under vacuum to give the oily crude which was purified with flash chromatography on silica. Compound 4 was eluted out with dichloromethane/methanol (15:0-10:1) (1.18 g, 68\%). ${ }^{1} \mathrm{H}$ NMR (400 MHz, DMSO- $\left.d_{6}\right) \delta$ $8.86(\mathrm{dd}, J=4.1,1.6 \mathrm{~Hz}, 1 \mathrm{H}), 8.57(\mathrm{dd}, J=8.6,1.6 \mathrm{~Hz}, 1 \mathrm{H}), 7.58(\mathrm{dd}, J=8.5,4.1 \mathrm{~Hz}$, 1H), 7.44 (dd, $J=7.8,0.9 \mathrm{~Hz}, 1 \mathrm{H}), 7.02$ (d, $J=7.8 \mathrm{~Hz}, 1 \mathrm{H}), 4.10$ (d, $J=0.8 \mathrm{~Hz}, 2 \mathrm{H})$,.

Synthesis of 1-(4-bromobenzyl)-3-((8-hydroxyquinolin-5-yl)methyl)urea (7). To a stirred solution of compound $4(1.0 \mathrm{mmol}, 140 \mathrm{mg})$ and 4-bromobenzyl isocyanate $(1.0 \mathrm{mmol}, 212 \mathrm{mg})$ in anhydrous dichloromethane $(5 \mathrm{ml})$ were added catalytic amount of trimethylamine $(0.1 \mathrm{mmol}, 10.1 \mathrm{mg})$. After stirring at room temperature for $5 \mathrm{hr}$, solvent was removed under reduced pressure to give crude product which was purified with flash chromatography on silica. Elution with hexanes/ethylacetate (10:1-1:1) gave desired compounds 7 (220 mg, 57\%). ${ }^{1} \mathrm{H}$ NMR (400 MHz, DMSO- $\left.d_{6}\right) \delta 9.71(\mathrm{~s}, 1 \mathrm{H}), 8.88(\mathrm{dd}, J$ $=4.1,1.5 \mathrm{~Hz}, 1 \mathrm{H}), 8.52(\mathrm{dd}, J=8.6,1.6 \mathrm{~Hz}, 1 \mathrm{H}), 7.60(\mathrm{dd}, J=8.6,4.2 \mathrm{~Hz}, 1 \mathrm{H}), 7.56-$ $7.46(\mathrm{~m}, 2 \mathrm{H}), 7.38$ (d, $J=7.8 \mathrm{~Hz}, 1 \mathrm{H}), 7.30-7.14(\mathrm{~m}, 2 \mathrm{H}), 7.03(\mathrm{~d}, J=7.8 \mathrm{~Hz}, 1 \mathrm{H}), 6.44$ $(\mathrm{t}, J=5.8 \mathrm{~Hz}, 1 \mathrm{H}), 6.39(\mathrm{t}, J=6.1 \mathrm{~Hz}, 1 \mathrm{H}), 4.60(\mathrm{~d}, J=5.7 \mathrm{~Hz}, 2 \mathrm{H}), 4.21(\mathrm{~d}, J=6.1 \mathrm{~Hz}$, $2 \mathrm{H}), 3.18(\mathrm{~d}, J=5.1 \mathrm{~Hz}, 1 \mathrm{H})$.

\section{Cell culture and reagents}

Human melanoma A375, M14, WM164, RPMI7951, M14/MDR1 and B16F101 cell lines were purchased from ATCC (American Type Culture Collection, Manassas, VA, USA), and cultured in DMEM media (Mediatech, Inc., Manassas, VA) at $37^{\circ} \mathrm{C}$ in a humidified atmosphere containing 5\% $\mathrm{CO}_{2}$. The culture media were supplemented with 10\% fetal bovine serum (Atlanta Biologicals, Lawrenceville, GA) and 1\% antibioticantimycotic mixture (Sigma-Aldrich, St. Louis, MO). Compounds were dissolved in dimethylsulfoxide (DMSO; Sigma-Aldrich) to make a stock solution of $10 \mathrm{mM}$.

Compound solutions were freshly prepared by diluting stocks with cell culture medium

before use (final solution contained less than 0.5\% DMSO). 5000 cells in logarithm 
growing phase were seeded overnight into each well of a 96-well plate. Then the cells were continuously incubated for $48 \mathrm{~h}$ with sequential diluted compound solution $(100 \mu \mathrm{M}$ to $3 \mathrm{nM}, 100 \mu \mathrm{l}$ per well) in cell culture medium. The cell viability was determined in MTS assay and $\mathrm{IC}_{50}$ was calculated $(\mathrm{n}=4)$, following similar procedures as described previously [215-218]. Dulbecco's modified Eagle's Medium (DMEM), fetal bovine serum (FBS), penicillin/streptomycin and trypsin $0.25 \%$ were purchased from Hyclone (GE Healthcare Life Science, Pittsburgh, PA). Phosphate buffered saline (PBS) was purchased from Invitrogen GIBCO (Grand Island, NY). Dimethyl sulfoxide (DMSO) and 3-(4,5-dimethylthiazole-2-yl)-2,5-biphenyl tetrazolium bromide (MTT) were purchased from Sigma Chemical Co (St. Louis, MO). The P-glycoprotein (P-gp) overexpressing KB-C2 cell line was established from a parental human epidermoid carcinoma cell line KB-3-1, by a step-wise selection of KB-3-1 in increasing concentrations of colchicine up to $2 \mu \mathrm{g} / \mathrm{ml}[219]$. SW620/Ad300, which is also a P-gp overexpressing drug resistant cell line, was established by stepwise exposure of the parental human colon cancer cell line SW620 to increasing concentrations of doxorubicin up to $300 \mathrm{ng} / \mathrm{ml}[220]$. The SW620 and SW620/Ad300 cell lines were kindly provided by Dr. Susan E. Bates and Dr. Robert W. Robey (NCI, NIH, Bethesda, MD, USA). All the cell lines were grown in DMEM supplemented with $10 \% \mathrm{FBS}$ and $100 \mathrm{unit} / \mathrm{ml}$ penicillin/streptomycin in a humidified incubator containing $5 \% \mathrm{CO}_{2}$ at $37{ }^{\circ} \mathrm{C}$.

\section{Cytotoxicity assay}

A375, M14, WM164, RPMI7951, M14/MDR1 and B16F101were seeded in 96well plates at a concentration of 1,000-5,000 cells per well, depending on growth rate of the cell line. After overnight incubation, the media was replaced and cells were treated with the test compounds at 10 concentrations ranging from $0.03 \mathrm{nM}$ to $1 \mu \mathrm{M}$ plus a vehicle control for $72 \mathrm{~h}$ in four replicates. Following treatment, the MTS reagent (Promega, Madison, WI) was added to the cells and incubated in dark at $37^{\circ} \mathrm{C}$ for at least 1 hour. Absorbance at $490 \mathrm{~nm}$ was measured using a plate reader (DYNEX Technologies, Chantilly VA). Percentages of cell survival versus drug concentrations were plotted, and the $\mathrm{IC}_{50}$ (concentration that inhibited cell growth by $50 \%$ of untreated control) values were obtained by nonlinear regression analysis using GraphPad Prism (GraphPad Software, San Diego, CA).

\section{Cytotoxicity against P-gp overexpressed cell lines by MTT assay}

The MTT colorimetric assay was used to measure the sensitivity of the cells against the synthesized compounds. The assay detects the formazan product formed from the reduction of MTT in active cells thus assesses the cell viability[221]. Cells were seeded in 96-well plates at 5000 cells/well (KB-3-1 or KB-C2 cells) or at 7000 cells/well (SW620 or SW620/Ad300 cells) in $180 \mu 1$ completed medium and cultured overnight. Then various concentrations of the compounds $(20 \mu \mathrm{l})$ were added to the designated wells. After $72 \mathrm{~h}$ continuous drug incubation, $20 \mu \mathrm{l}$ of MTT reagent $(5 \mathrm{mg} / \mathrm{ml})$ was added to each well and the plates were incubated at $37^{\circ} \mathrm{C}$ for $4 \mathrm{~h}$. Subsequently, the medium 
was removed and $100 \mu 1$ of DMSO were added to dissolve the formazan crystals in each well. The absorbance was determined at $570 \mathrm{~nm}$ by the accuSkan ${ }^{\mathrm{TM}} \mathrm{GO} \mathrm{UV} / \mathrm{V}$ is Microplate Spectrophotometer (Fisher Sci., Fair Lawn, NJ). The $\mathrm{IC}_{50}$ values of each compound on each cell line were calculated from the survival curves to represent the cytotoxicity of the compounds. The fold of drug resistance was calculated by dividing the $\mathrm{IC}_{50}$ of the P-gp overexpressing cells by that of the parental cells. Two known P-gp substrates, YM155 and paclitaxel, were used as positive controls for P-gp overexpressing cell lines. On the other hand, cisplatin, which is not a substrate of P-gp, was used as negative control.

\section{Liver microsomes stability assay}

Liver microsomes stability assay was conducted following literature reports [222, 223]. The NADPH regenerating agent solutions A (catalog\#: 451220) and B (catalog\#: 451200) and mouse liver microsomes (CD-1, mixture of male, catalog\#:452701, and female, catalog\#: 452702) were obtained from BD Gentest (Woburn, MA). For each test compound, the mouse liver microsomal solution was prepared by adding $0.058 \mathrm{~mL}$ of concentrated mouse liver microsomes $(20 \mathrm{mg} / \mathrm{mL}$ protein concentration) to $1.756 \mathrm{~mL}$ of $0.1 \mathrm{M}$ potassium phosphate buffer $(\mathrm{pH} 7.4)$ containing $5 \mu \mathrm{L}$ of $0.5 \mathrm{M}$ EDTA to make a $0.6381 \mathrm{mg} / \mathrm{mL}$ (protein) microsomal solution. Each test compound $(2.2 \mu \mathrm{L}$ of $10 \mathrm{mM}$ DMSO solution) was added directly to $1.79 \mathrm{~mL}$ of mouse liver microsomal solution and $90 \mu \mathrm{L}$ was transferred to wells in 96 -well plates $(0,0.25,0.5,1,2$, and $4 \mathrm{~h}$ time points each in triplicate). The NADPH regenerating agent was prepared by mixing $0.113 \mathrm{~mL}$ of NADPH regenerating agent Solutions A, $0.023 \mathrm{~mL}$ of solution B and $0.315 \mathrm{~mL}$ of $0.1 \mathrm{M}$ potassium phosphate buffer ( $\mathrm{pH}$ 7.4) for each tested compound. To each well of the 96well plate, $22.5 \mu \mathrm{L}$ of the NADPH regenerating agent was added to initiate the reaction, and the plate was incubated at $37^{\circ} \mathrm{C}$ for each time point $(0,0.25,0.5,1,2$, and $4 \mathrm{~h}$ time points each in triplicate). The reaction was quenched by adding $225 \mu \mathrm{L}$ of cold acetonitrile containing warfarin $(4 \mathrm{mg} / \mathrm{ml})$ as internal control to each well. All of the plates were centrifuged at $4000 \mathrm{rpm}$ for $20 \mathrm{~min}$ and the supernatants $(100 \mu \mathrm{L})$ were transferred to another 96-well plates for analysis on UPLC-MS (Waters Acquity UPLC linked to Waters Acquity Photodiode Array Detector and Waters Acquity Single Quadrupole Mass Detector) on Acquity UPLC BEH C18 $1.7 \mathrm{~mm}(2.1 \times 50 \mathrm{~mm})$ column by running $90-5 \%$ gradient for water $(+0.1 \%$ formic acid $)$ and acetonitrile $(+0.1 \%$ formic acid) in 2 minutes. The area under the single ion recording (SIR) channel for the test compound divided by the area under the SIR for internal control at 0 time concentration was considered as $100 \%$ to calculate remaining concentration at each time point. The terminal phase rate constant (ke) was estimated by linear regression of logarithmic transformed concentration versus the data, where $\mathrm{ke}=$ slope $\mathrm{x}(-\ln 10)$. The half life $\mathrm{t} 1 / 2$ was calculated as $\ln 2 / \mathrm{ke}$. The intrinsic clearance $(\mathrm{CLint}, \mathrm{app})=(0.693 /$ in vitro $\mathrm{t} 1 / 2) \mathrm{x}$ ( $1 \mathrm{ml}$ incubation volume $/ 0.5 \mathrm{mg}$ of microsomal protein) x (45 mg microsomal protein/gram of liver) x (55 g of liver/kg body weight) [224, 225]. 


\section{Chemistry}

Scheme 5-1 showed the synthetic method to access UC-112 analogues 2a-2f. Starting material 5-chloromethyl-8-quinolinol hydrochloride was synthesized by following a reported procedure [214]. 5-chloromethyl-8-quinolinol hydrochloride was treated with commercially available amines in the presence of sodium hydride or sodium carbonate and potassium iodide to give 1a-1f. 1a-1f refluxed with paraformaldehyde and pyrrolidine in ethanol to provide analogues $\mathbf{2 a - 2 f}$.

Scheme 5-2 depicted the synthesis to obtain analogues 6a-6f and $\mathbf{8}$. To synthesize amide and urea analogues 6a-6d and 8, 5-chloromethyl-8-quinolinol hydrochloride was refluxed with sodium azide in acetone to yield azide compound $\mathbf{3}$. 3 was subsequently hydrogenated in the presence of a catalytic equivalent of $10 \% \mathrm{Pd} / \mathrm{C}$ to provide amine 4 . With 4 in hand, treatment of it with carboxylic acids, EDCI and oxyma was able to form amide 5a-5d. Refluxing the mixture of 5a-5d, paraformaldehyde and pyrrolidine in ethanol gave the amide analogues 6a-6d. Syntheses of another two amide analogues $\mathbf{6 e}$ and 6 f were carried out using commercially available 5-amino-8-hydroxyquinoline dihydrochloride by following the same method. Treatment of amine 4 using a catalytic equivalent of triethylamine generated the urea intermediate $\mathbf{8}$, which was subjected to Mannich reaction to give urea analogue 9.

Indole analogues 10a-10y with either mono-substitution or di-substitution were prepared by following Scheme 5-3. In brief, 5-chloromethyl-8-quinolinol hydrochloride was refluxed together with indoles in the presence of sodium carbonate and a catalytic amount of potassium iodide in acetonitrile to generate intermediate 9a-9y. Treatment of 9a-9y with paraformaldehyde and pyrrolidine under reflux condition subsequently furnished analogues 10a-10y.

\section{Results}

All analogues of UC-112 were evaluated for their cytotoxicity in human melanoma cell lines including A375, WM1641, M14, RPMI, M14/MDR1 and B16F10. The antiproliferative effects of the compounds were evaluated by MTT assay. $\mathrm{IC}_{50} \mathrm{~S}$ were reported in $\mu \mathrm{M}$ and calculated from at least three independent experiments, each performed in duplicates.

\section{In vitro growth inhibitory effects of $\mathrm{UC}-112$ analogues with modification of benzyloxy moiety}

As a continuation of our effort to develop selective survivin inhibitor based on UC-112, we initiated the SAR investigation by replacing the benzyloxy with a variety of different moieties. The structures and in vitro assay result for analogues $\mathbf{2 a - 2 f}, \mathbf{6 a - 6 f}, \mathbf{8}$ and 10a were shown in Figure 5-2 and Table 5-1. Compared to the reference compound MX-106, analogues $\mathbf{2 a}$ with a 5-fluoroindazole moiety, $\mathbf{2 b}$ with a benzotriazole moiety 


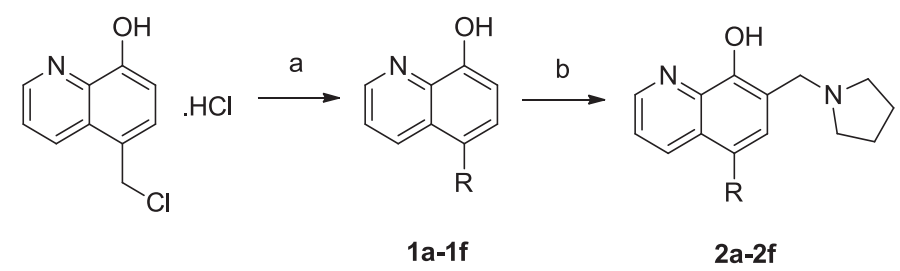

Scheme 5-1. Synthesis of 2a-2f

Reagents and conditions: (a) $\mathrm{NaH}, \mathrm{DMF}$ or $\mathrm{KI}, \mathrm{Na}_{2} \mathrm{CO}_{3}, \mathrm{MeCN}$, reflux; (b) parafomaldehyde, pyrrolidine, ethanol, reflux;

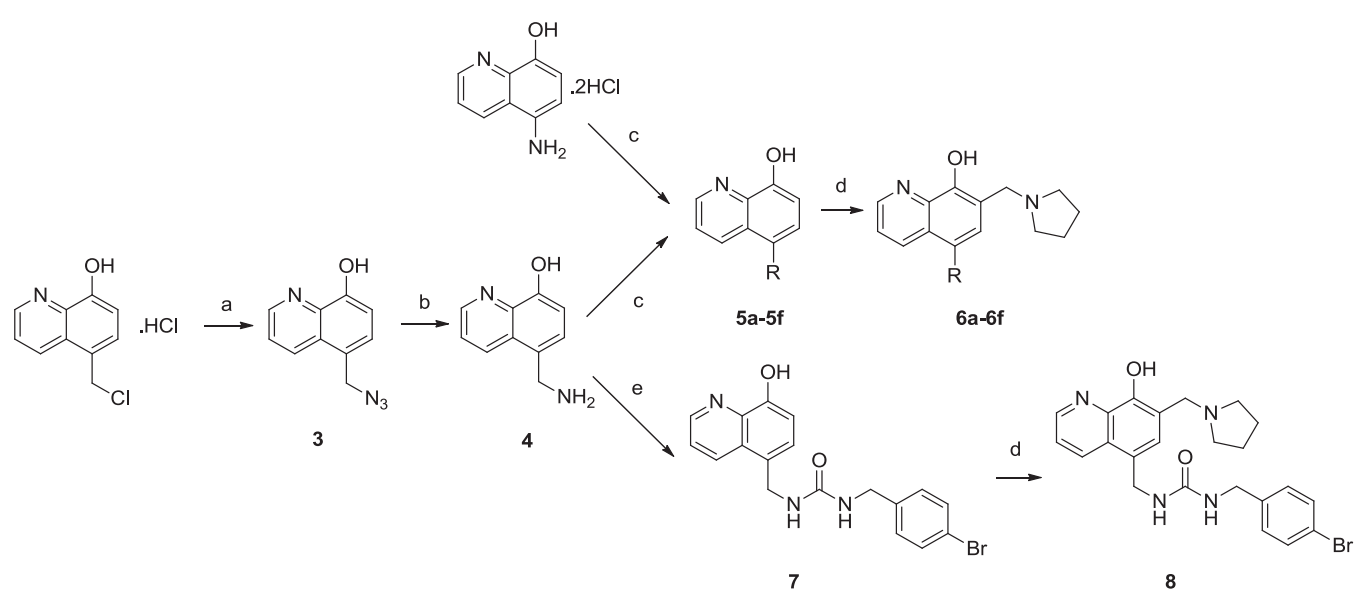

\section{Scheme 5-2. Synthesis of 6a-6f and 8}

Reagents and conditions:(a) $\mathrm{NaN}_{3}$, acetone, reflux; (b) $\mathrm{H}_{2}, \mathrm{Pd} / \mathrm{C}(10 \%)$, ethyl acetate, $\mathrm{rt}$; (c) $\mathrm{Et}_{3} \mathrm{~N}, \mathrm{DCM}, 0^{\circ} \mathrm{C}$ to rt; (d): parafomaldehyde, pyrrolidine, ethanol, reflux; (e) Oxyma, EDCI, $\mathrm{NaHCO}_{3}$, DMF- $\mathrm{H}_{2} \mathrm{O}$, rt. 


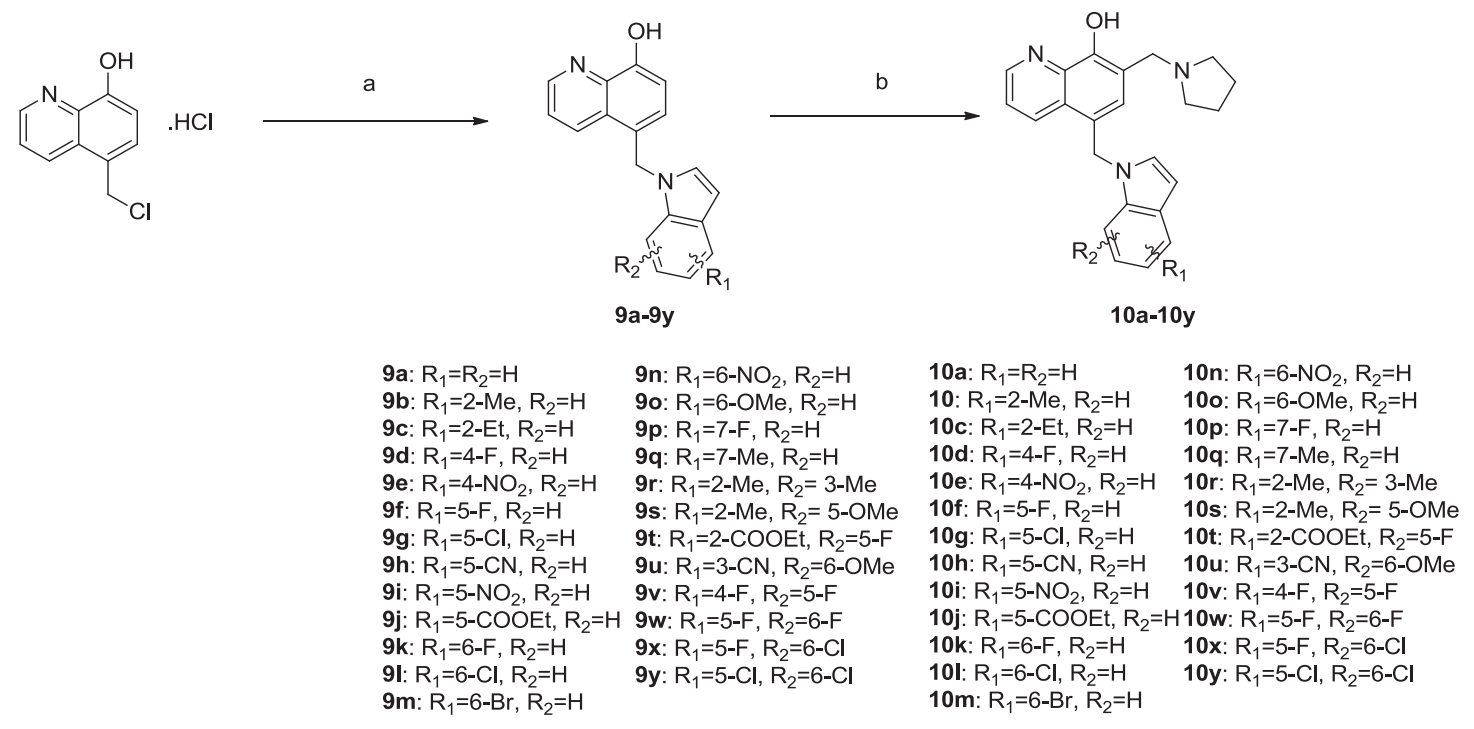

\section{Scheme 5-3. Synthesis of 10a-10y}

Reagents and conditions: (a) $\mathrm{NaH}, \mathrm{DMF}$ or $\mathrm{KI}, \mathrm{Na}_{2} \mathrm{CO}_{3}, \mathrm{MeCN}$, reflux; (b) parafomaldehyde, pyrrolidine, ethanol, reflux. 


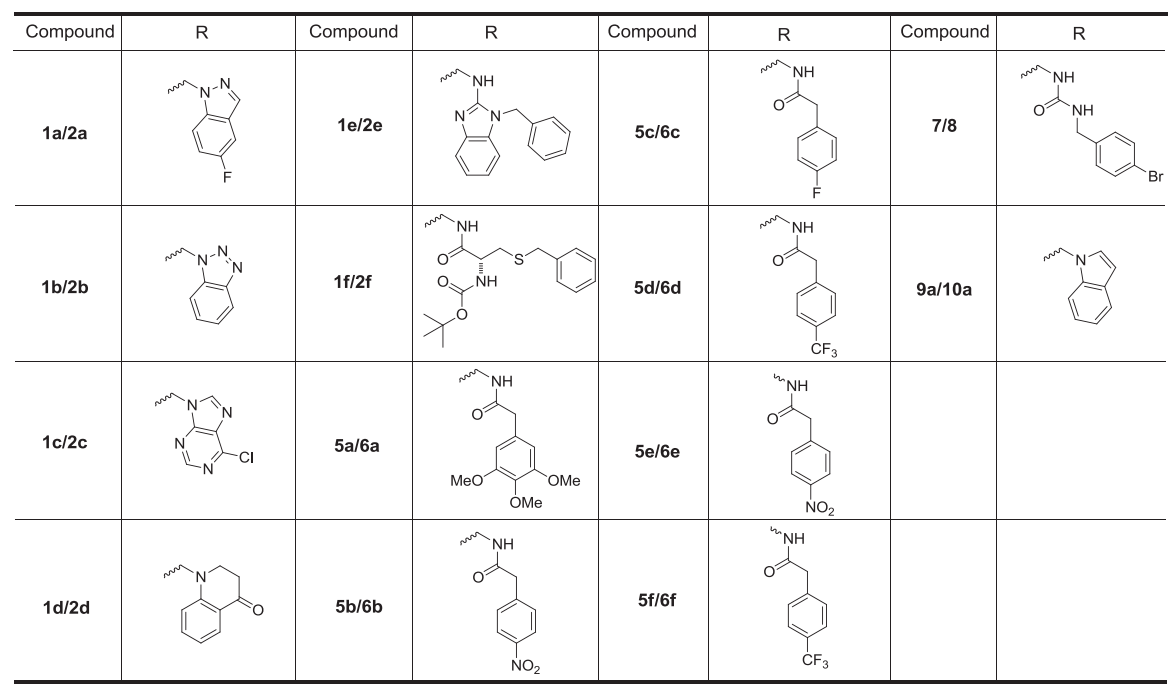

Figure 5-2. Structures of UC-112 analogues with modification of benzyloxy moiety

Table 5-1. In vitro growth inhibitory effects $(\mu \mathrm{M})$ of $\mathrm{UC}-112$ analogues with modification of benzyloxy moiety $(n=3)$

\begin{tabular}{ccccccc}
\hline Compound & A375 & WM164 & M14 & RPMI & M14/MDR1 & B16F10 \\
\hline 2a & $3.6 \pm 0.2$ & $8.6 \pm 1.1$ & $5.4 \pm 0.3$ & $11.1 \pm 0.7$ & $7.0 \pm 0.1$ & $>30.0$ \\
$\mathbf{2 b}$ & $1.9 \pm 0.1$ & $>30.0$ & $2.3 \pm 0.1$ & $6.5 \pm 0.2$ & $3.1 \pm 0.1$ & $22.5 \pm 1.2$ \\
\hline 2c & $3.9 \pm 0.1$ & $56.4 \pm 1.1$ & $4.1 \pm 0.2$ & $17.4 \pm 1.2$ & $7.9 \pm 0.1$ & $34.9 \pm 1.1$ \\
\hline 2d & $14.1 \pm 0.7$ & $33.9 \pm 1.1$ & $11.5 \pm 0.4$ & $21.0 \pm 0.4$ & $14.3 \pm 0.2$ & $22.6 \pm 0.3$ \\
\hline 2e & $3.1 \pm 0.2$ & $>30.0$ & $15.9 \pm 0.6$ & $1.3 \pm 0.2$ & $0.9 \pm 0.1$ & $4.7 \pm 0.1$ \\
\hline $\mathbf{2 f}$ & $7.6 \pm 0.1$ & $24.5 \pm 0.4$ & $16.7 \pm 0.1$ & $23.8 \pm 0.6$ & $22.0 \pm 0.3$ & $>30.0$ \\
\hline $\mathbf{6 a}$ & $>30.0$ & $13.0 \pm 0.5$ & $>30.0$ & $>30.0$ & $>30.0$ & $>30.0$ \\
\hline $\mathbf{6 b}$ & $4.7 \pm 0.2$ & $3.7 \pm 0.3$ & $5.1 \pm 0.1$ & $26.2 \pm 6.2$ & $10.7 \pm 1.2$ & $8.5 \pm 3.6$ \\
$\mathbf{6 c}$ & $3.5 \pm 0.3$ & $2.8 \pm 0.2$ & $8.6 \pm 0.2$ & $18.4 \pm 0.3$ & $7.4 \pm 1.2$ & $2.7 \pm 0.1$ \\
\hline $\mathbf{6 d}$ & $1.5 \pm 0.1$ & $1.6 \pm 0.1$ & $>30.0$ & $12.9 \pm 0.2$ & $12.2 \pm 0.2$ & $>30.0$ \\
\hline $\mathbf{6 e}$ & $6.0 \pm 1.3$ & $24.9 \pm 1.0$ & $6.7 \pm 0.3$ & $25.3 \pm 2.4$ & $12.2 \pm 0.5$ & $11.6 \pm 11.6$ \\
\hline $\mathbf{6 f}$ & $2.9 \pm 0.15$ & $\mathrm{ND}$ & $2.4 \pm 0.1$ & $6.8 \pm 0.6$ & $3.3 \pm 0.2$ & $\mathrm{ND}$ \\
\hline $\mathbf{8}$ & $>30.0$ & $20.18 \pm 0.49$ & $>30.0$ & $17.3 \pm 0.3$ & $8.7 \pm 0.2$ & $6.7 \pm 0.2$ \\
\hline $\mathbf{1 0 a}$ & $0.8 \pm 0.1$ & $0.9 \pm 0.1$ & $0.8 \pm 0.1$ & $4.4 \pm 0.3$ & $2.1 \pm 0.1$ & $8.2 \pm 0.7$ \\
\hline
\end{tabular}

ND: not determined 
and 2c with a 4-chloropurine moiety exhibited 3 5-fold reduced activities. Replacement of the benzyloxy with other moieties as shown in compounds $\mathbf{2 d}, \mathbf{2 e}$ and $\mathbf{2} \mathbf{f}$ resulted in significant reduction of inhibitory effects ( $>3$-fold). Replacing the benzyloxy with phenyl acetamides (analogues $\mathbf{6 a - 6 d}$ ) was detrimental to the antiproliferative activities. Shortening the linkage by one methylene in $\mathbf{6 b}$ and $\mathbf{6 d}$ resulted in analogues $\mathbf{6 e - 6 f}$, which showed similar activities to that of $\mathbf{6 b}$ and $\mathbf{6 d}$. The introduction of a benzylurea was revealed to be significantly detrimental for antiproliferative activity. Among all the analogues in this series, analogue 10a had an indole moiety; it exhibited the most potent activity and had an average $\mathrm{IC}_{50}$ of $0.9 \mu \mathrm{M}$, which was comparable to that of MX-106.

After discovered an equipotent scaffold to MX-106, we turned our effort to investigate the substitutional effect on the indole ring. Analogues with mono-substituent 10b-10q and analogues with di-substituents 10r-10y were then synthesized.

\section{In vitro growth inhibitory effects of $\mathrm{UC}-112$ analogues with mono-substitution on the indole moiety}

The in vitro assay result for analogues having mono-substituent (10a-10q) was shown in Table 5-2. For the 2-position substitutued analogues, $\mathbf{1 0 b}$ with a methyl group and 10c with an ethyl group showed slightly reduced activities compared to 10a. Introducing substituents to the 4-position on the indole diminished the antiproliferative activity, which was demonstrated by analogues $10 d$ and 10e. For analogues that had substituents on the 5-position of indole, they generally displayed comparable activities to that of 10a; for example, compounds $10 \mathbf{f}, 10 \mathrm{~h}$ and $10 \mathrm{i}$ had $\mathrm{IC}_{50} \mathrm{~s}$ ranging from 0.7 to $1.1 \mu \mathrm{M}$; analogues $\mathbf{1 0 g}$ and $\mathbf{1 0 j}$, which had chloro and bulky ester functional group, showed $\sim 2$-fold reduced activity in comparison with MX-106. In the series of analogues with substituents on the 6-position of the indole (10k-10o), they were generally equipotent to MX-106 and 10a; 10k-10o had $\mathrm{IC}_{50} \mathrm{~S}$ as low as $0.7 \mu \mathrm{M}$. Analogues having substituents on the 7-position of indole were slightly less potent than corresponding 5- or 6-position substituted counterparts.

\section{In vitro growth inhibitory effects of UC-112 analogues with di-substituents on the indole moiety}

Eight di-substituted indole analogues were synthesized in this series and their in vitro assay result was shown in Table 5-3. All the eight analogues did not show any improvement of activity compared to their mono-subsituted counterparts. 10t-10y were designed based on the most potent mono-substituted analogues 10f, 101 and $\mathbf{1 0 0}$. Incorporation of a secondary substituent to 5-fluoroindole or 6-methoxyindole generally was not beneficial to activity; for example, 5-fluoroindole analogues $10 \mathrm{t}, 10 \mathrm{v}, 10 \mathrm{w}$ and 10x had 2-ethylester, 4-fluro, 6-fluro and 6-chloro as the secondary functional group, respectively; they showed reduced cytotoxicities compared to $\mathbf{1 0 f}$ and had $\mathrm{IC}_{50} \mathrm{~S}$ of $>1.5$ $\mu \mathrm{M}$; the 3-cyano-6-methoxy indole analogue $10 \mathrm{u}$ was less potent than the mono- 
Table 5-2. In vitro growth inhibitory effects $(\mu \mathrm{M})$ of $\mathrm{UC}-112$ analogues with mono-substituent on the indole moiety $(n=3)$

\begin{tabular}{ccccccc}
\hline Compound & A375 & WM164 & M14 & RPMI7951 & M14/MDR1 & B16F10 \\
\hline $\mathbf{1 0 a}$ & $0.8 \pm 0.1$ & $0.9 \pm 0.1$ & $0.8 \pm 0.1$ & $4.4 \pm 0.3$ & $2.1 \pm 0.1$ & $8.2 \pm 0.7$ \\
$\mathbf{1 0 b}$ & $2.2 \pm 0.2$ & $7.5 \pm 1.2$ & $1.4 \pm 0.2$ & $2.2 \pm 0.2$ & $0.7 \pm 0.1$ & $5.7 \pm 0.8$ \\
$\mathbf{1 0 c}$ & $2.0 \pm 0.1$ & $8.9 \pm 1.4$ & $1.5 \pm 0.2$ & $3.2 \pm 0.4$ & $1.1 \pm 0.1$ & $11.5 \pm 0.9$ \\
$\mathbf{1 0 d}$ & $1.6 \pm 0.3$ & $6.5 \pm 0.6$ & $1.2 \pm 0.2$ & $2.2 \pm 0.2$ & $0.8 \pm 0.1$ & $8.9 \pm 1.7$ \\
$\mathbf{1 0 e}$ & $1.8 \pm 0.1$ & $7.0 \pm 0.3$ & $2.1 \pm 0.1$ & $0.6 \pm 0.1$ & $0.6 \pm 0.1$ & $6.8 \pm 0.2$ \\
$\mathbf{1 0 f}$ & $0.7 \pm 0.2$ & $0.7 \pm 0.2$ & $1.9 \pm 0.4$ & $\mathrm{ND}$ & $\mathrm{ND}$ & $\mathrm{ND}$ \\
$\mathbf{1 0 g}$ & $1.8 \pm 0.2$ & $1.6 \pm 0.2$ & $4.0 \pm 0.4$ & $6.4 \pm 0.6$ & $0.8 \pm 0.1$ & $1.7 \pm 0.2$ \\
\hline $\mathbf{1 0 h}$ & $1.0 \pm 0.1$ & $1.1 \pm 0.1$ & $5.1 \pm 0.3$ & $\mathrm{ND}$ & $\mathrm{ND}$ & $\mathrm{ND}$ \\
$\mathbf{1 0 i}$ & $0.7 \pm 0.1$ & $0.8 \pm 0.1$ & $5.6 \pm 0.4$ & $3.7 \pm 0.3$ & $2.2 \pm 0.1$ & $1.3 \pm 0.1$ \\
$\mathbf{1 0 j}$ & $1.9 \pm 0.2$ & $4.7 \pm 0.6$ & $2.4 \pm 0.2$ & $1.5 \pm 0.1$ & $0.8 \pm 0.1$ & $6.0 \pm 0.1$ \\
$\mathbf{1 0 k}$ & $0.9 \pm 0.1$ & $0.7 \pm 0.1$ & $1.3 \pm 0.1$ & $2.7 \pm 0.5$ & $1.3 \pm 0.1$ & $0.6 \pm 0.1$ \\
\hline $\mathbf{1 0 1}$ & $0.9 \pm 0.4$ & $0.9 \pm 0.4$ & $0.8 \pm 0.4$ & $7.7 \pm 0.5$ & $3.8 \pm 0.1$ & $25.5 \pm 2.4$ \\
\hline $\mathbf{1 0 m}$ & $0.9 \pm 0.1$ & $1.4 \pm 0.2$ & $3.5 \pm 0.3$ & $5.3 \pm 0.6$ & $0.7 \pm 0.1$ & $1.4 \pm 0.2$ \\
\hline $\mathbf{1 0 n}$ & $0.9 \pm 0.1$ & $0.7 \pm 0.1$ & $2.8 \pm 0.2$ & $4.3 \pm 0.7$ & $2.8 \pm 0.2$ & $1.1 \pm 0.2$ \\
\hline $\mathbf{1 0 0}$ & $0.8 \pm 0.2$ & $0.7 \pm 0.1$ & $0.9 \pm 0.4$ & $6.2 \pm 0.4$ & $2.8 \pm 0.1$ & $>30.0$ \\
\hline $\mathbf{1 0 p}$ & $1.7 \pm 0.2$ & $1.9 \pm 0.2$ & $2.6 \pm 0.4$ & $\mathrm{ND}$ & $\mathrm{ND}$ & $\mathrm{ND}$ \\
$\mathbf{1 0 q}$ & $2.0 \pm 0.2$ & $11.5 \pm 0.8$ & $1.4 \pm 0.1$ & $2.6 \pm 0.2$ & $0.9 \pm 0.1$ & $9.7 \pm 0.8$ \\
\hline & & & & & &
\end{tabular}

ND: not determined 
Table 5-3. In vitro growth inhibitory effects $(\mu \mathrm{M})$ of $\mathrm{UC}-112$ analogues with disubstituents on the indole moiety $(n=3)$

\begin{tabular}{ccccccc}
\hline Compound & A375 & WM164 & M14 & RPMI7951 & M14/MDR1 & B16F10 \\
\hline $\mathbf{1 0 r}$ & $1.9 \pm 0.2$ & $7.1 \pm 0.8$ & $1.5 \pm 0.2$ & $8.2 \pm 0.6$ & $1.0 \pm 0.1$ & $2.3 \pm 0.3$ \\
$\mathbf{1 0 s}$ & $1.9 \pm 0.2$ & $4.6 \pm 0.1$ & $2.0 \pm 0.1$ & $2.1 \pm 0.1$ & $1.0 \pm 0.1$ & $4.3 \pm 0.1$ \\
$\mathbf{1 0 t}$ & $2.0 \pm 0.2$ & $8.5 \pm 0.8$ & $1.3 \pm 0.1$ & $3.6 \pm 0.4$ & $1.0 \pm 0.1$ & $8.5 \pm 1.4$ \\
$\mathbf{1 0 u}$ & $1.7 \pm 0.1$ & $16.7 \pm 0.5$ & $1.6 \pm 0.1$ & $3.7 \pm 0.1$ & $1.9 \pm 0.1$ & $\mathrm{ND}$ \\
$\mathbf{1 0 v}$ & $1.2 \pm 0.1$ & $2.8 \pm 0.1$ & $2.1 \pm 0.1$ & $0.8 \pm 0.1$ & $0.6 \pm 0.1$ & $2.4 \pm 0.1$ \\
$\mathbf{1 0 w}$ & $1.5 \pm 0.1$ & $3.2 \pm 0.1$ & $2.6 \pm 0.1$ & $1.3 \pm 0.0$ & $0.7 \pm 0.1$ & $3.1 \pm 0.1$ \\
$\mathbf{1 0 x}$ & $2.0 \pm 0.2$ & $4.5 \pm 0.2$ & $2.0 \pm 0.2$ & $1.7 \pm 0.1$ & $1.0 \pm 0.1$ & $2.1 \pm 0.1$ \\
$\mathbf{1 0 y}$ & $0.7 \pm 0.1$ & $0.9 \pm 0.1$ & $8.5 \pm 0.2$ & $9.3 \pm 1.1$ & $2.2 \pm 0.1$ & $\mathrm{ND}$ \\
\hline
\end{tabular}

ND: not determined 
substituted counterpart $100 ; 5,6$-dichloroindole analogue $10 \mathrm{y}$ showed cytotoxicity comparable to that of 5-chloroindole analogue $\mathbf{1 0 1 .}$

\section{Inhibitory effect against P-gp overexpressed cell lines}

Multidrug resistance protein 1(MAP1) or P-gp belongs to the family of ATPbinding cassette $(\mathrm{ABC})$ transporters and is encoded by $\mathrm{ABCB} 1$ gene. $\mathrm{P}$-gp is responsible for the decline of concentrations of extensive anticancer drugs in multidrug resistant cells. Therefore, the ability to overcome P-gp mediated drug-resistance is a favorable property for drug candidates.

Other than M14 melanoma cell line, drug-resistant cell line M14/MDR1 was also tested to evaluate the ability of new analogue to overcome P-gp mediated drug-resistance. The result was shown in Table 5-4. 71\% of the new indole analogues had RIs less than 1, indicating that most of the new indole analogues exhibited more potent inhibitory effects against P-gp overexpressed M14/MDR1 cell line than non-resistant M14 cell line. It is worthy noting that all the di-substituted indole analogues have RIs less than 1, implying that a secondary substituent on the indole is beneficial for the ability to overcome P-gp overexpression.

Besides melanoma cell lines, cervical and colorectal carcinoma cell lines were also tested to evaluate abilities of the new analogues to surmount P-gp overexpression. The result was summarized in Table 5-5. The small-molecular survivin inhibitor YM-155 showed remarkable cytotoxicity against KB-3-1 and SW620 cell lines with $\mathrm{IC}_{50} \mathrm{~S}$ of $5 \mathrm{nM}$ and $4 \mathrm{nM}$, respectively. YM155 however displayed significantly reduced activities against the P-gp overexpressed cell lines KB-C2 and SW620/Ad300, having $\mathrm{IC}_{50}$ S of more than $20 \mu \mathrm{M}$. Similarly, paclitaxel, a notable substrate of P-gp, was not effective to P-gp overexpressed cell lines. In contrast, our indole analogues 10f, 10i, 101, 10o and the previously reported MX-106 showed remarkably stronger inhibitory effects against P-gp overexpressed cell lines than non-resistant parent cell lines. In the non-resistant KB-3-1 cell line, four compounds $\mathbf{1 0 f}, \mathbf{1 0} \mathbf{i}, \mathbf{1 0 l}$ and $\mathbf{1 0 0}$ exhibited micromolar range activities (from 1.3 to $1.7 \mu \mathrm{M}$ ); their $\mathrm{IC}_{50} \mathrm{~S}$ were in sub- $\mu \mathrm{M}$ range (from 0.2 to $0.4 \mathrm{nM}$ ) aginst P-gp overexpressed $\mathrm{KB}-\mathrm{C} 2$ cell line. 10f, 10i, 101 and $\mathbf{1 0 0}$ had $\mathrm{IC}_{50} \mathrm{~s}$ ranging from 0.2 to 0.3 $\mu \mathrm{M}$ against non-resistant SW620 cell line while their activities in P-gp overexpressed $\mathrm{KB}-\mathrm{C} 2$ cell line were 3-6.7 folds more potent with $\mathrm{IC}_{50}$ s ranging from 0.03 to $0.01 \mu \mathrm{M}$. Collectively, our new indole analogues of UC-112 can overcome drug-resistance mediated by P-gp overexpression.

\section{In vitro metabolic stability study}

Prior to in vivo study, the in vitro metabolic stabilities of analogues $10 \mathbf{f}, 10 \mathbf{i}, 10 \mathbf{1}$ and 100 were examined by measuring their half-life upon incubation with mouse, rat, and human liver microsomes in the presence of an NADPH regeneration system. The results 
Table 5-4. In vitro growth inhibitory effects of indole analogues in P-gp overexpressed cell line M14/MDR1 (n=3)

\begin{tabular}{cccc}
\hline Compound & M14 & M14/MDR1 & RI \\
\hline $\mathbf{1 0 a}$ & $0.8 \pm 0.1$ & $2.1 \pm 0.1$ & 2.6 \\
$\mathbf{1 0 b}$ & $1.4 \pm 0.2$ & $0.7 \pm 0.1$ & 0.5 \\
$\mathbf{1 0 c}$ & $1.5 \pm 0.2$ & $1.1 \pm 0.1$ & 0.7 \\
$\mathbf{1 0 d}$ & $1.2 \pm 0.2$ & $0.8 \pm 0.1$ & 0.7 \\
$\mathbf{1 0 e}$ & $2.1 \pm 0.1$ & $0.6 \pm 0.1$ & 0.3 \\
$\mathbf{1 0 f}$ & $1.9 \pm 0.4$ & ND & ND \\
$\mathbf{1 0 g}$ & $4.0 \pm 0.4$ & $0.8 \pm 0.1$ & 0.2 \\
$\mathbf{1 0 h}$ & $5.1 \pm 0.3$ & ND & ND \\
\hline $\mathbf{1 0} \mathbf{1 0}$ & $5.6 \pm 0.4$ & $2.2 \pm 0.1$ & $\mathrm{ND}$ \\
$\mathbf{1 0}$ & $2.4 \pm 0.2$ & $0.8 \pm 0.1$ & 0.3 \\
$\mathbf{1 0 k}$ & $1.3 \pm 0.1$ & $1.3 \pm 0.1$ & 1.0 \\
$\mathbf{1 0 1}$ & $0.8 \pm 0.4$ & $3.8 \pm 0.1$ & 4.8 \\
$\mathbf{1 0 m}$ & $3.5 \pm 0.3$ & $0.7 \pm 0.1$ & 0.2 \\
$\mathbf{1 0 n}$ & $2.8 \pm 0.2$ & $2.8 \pm 0.2$ & 1.0 \\
$\mathbf{1 0 0}$ & $0.9 \pm 0.4$ & $2.8 \pm 0.1$ & 3.1 \\
$\mathbf{1 0 p}$ & $2.6 \pm 0.4$ & $\mathrm{ND}$ & $\mathrm{ND}$ \\
$\mathbf{1 0 q}$ & $1.4 \pm 0.1$ & $0.9 \pm 0.1$ & 0.6 \\
$\mathbf{1 0 r}$ & $1.5 \pm 0.2$ & $1.0 \pm 0.1$ & 0.7 \\
$\mathbf{1 0 s}$ & $2.0 \pm 0.1$ & $1.0 \pm 0.1$ & 0.5 \\
$\mathbf{1 0 t}$ & $1.3 \pm 0.1$ & $1.0 \pm 0.1$ & 0.7 \\
$\mathbf{1 0 u}$ & $1.6 \pm 0.1$ & $1.9 \pm 0.1$ & 1.2 \\
$\mathbf{1 0 v}$ & $2.1 \pm 0.1$ & $0.6 \pm 0.1$ & 0.3 \\
\hline $\mathbf{1 0 w}$ & $2.6 \pm 0.1$ & $0.7 \pm 0.1$ & 0.3 \\
$\mathbf{1 0 x}$ & $2.0 \pm 0.2$ & $1.0 \pm 0.1$ & 0.5 \\
$\mathbf{1 0 y}$ & $8.5 \pm 0.2$ & $2.2 \pm 0.1$ & 0.3 \\
\hline
\end{tabular}

ND: not determined; RI: resistance index, calculated by $\mathrm{IC}_{50}(\mathrm{M} 14 / \mathrm{MDR} 1) / \mathrm{IC}_{50}(\mathrm{M} 14)$. 
Table 5-5. In vitro growth inhibitory effects of $10 \mathrm{f}, 10 \mathrm{i}, 101$ and 100 in P-gp overexpressed cell lines $(n=3)$

\begin{tabular}{|c|c|c|c|c|c|c|}
\hline \multirow{2}{*}{ Compound } & \multicolumn{2}{|c|}{$\mathrm{IC}_{50} \pm \mathrm{SD}(\mu \mathrm{M})$} & \multirow{2}{*}{ RI } & \multicolumn{2}{|c|}{$\mathrm{IC}_{50} \pm \mathrm{SD}(\mu \mathrm{M})$} & \multirow{2}{*}{ RI } \\
\hline & KB-3-1 & KB-C2 & & SW620 & SW620/Ad300 & \\
\hline $10 \mathrm{f}$ & $1.4 \pm 0.2$ & $0.2 \pm 0.0$ & 0.14 & $0.2 \pm 0.0$ & $0.03 \pm 0.00$ & 0.15 \\
\hline $10 \mathrm{i}$ & $1.4 \pm 0.4$ & $0.2 \pm 0.0$ & 0.14 & $0.2 \pm 0.0$ & $0.06 \pm 0.02$ & 0.30 \\
\hline 101 & $1.7 \pm 0.2$ & $0.3 \pm 0.0$ & 0.18 & $0.23 \pm 0.1$ & $0.05 \pm 0.03$ & 0.22 \\
\hline 100 & $1.3 \pm 0.2$ & $0.4 \pm 0.1$ & 0.31 & $0.3 \pm 0.0$ & $0.10 \pm 0.04$ & 0.33 \\
\hline MX-106 & $1.3 \pm 0.1$ & $0.3 \pm 0.1$ & 0.23 & $0.2 \pm 0.0$ & $0.03 \pm 0.01$ & 0.15 \\
\hline YM-155 & $\begin{array}{l}0.005 \pm \\
0.000\end{array}$ & $37.3 \pm 4.0$ & 7460.00 & $0.004 \pm 0.001$ & $23.4 \pm 2.4$ & $\begin{array}{l}585 \\
0\end{array}$ \\
\hline Paclitaxel & $\begin{array}{l}0.0005 \pm \\
0.0001\end{array}$ & $0.3 \pm 0.0$ & 600.00 & $0.03 \pm 0.00$ & $2.0 \pm 0.4$ & 66.7 \\
\hline Doxorubicin & $0.4 \pm 0.1$ & $1.7 \pm 0.4$ & 4.25 & $0.21 \pm 0.03$ & $15.2 \pm 2.9$ & 72.4 \\
\hline Cisplatin & $1.1 \pm 0.1$ & $1.7 \pm 0.1$ & 1.55 & $1.8 \pm 0.1$ & $5.1 \pm 0.6$ & 2.83 \\
\hline
\end{tabular}

$\mathrm{RI}$ : resistance index, which is calculated by $\mathrm{IC}_{50}(\mathrm{~KB}-\mathrm{C} 2) / \mathrm{IC}_{50}(\mathrm{~KB}-3-1)$ or

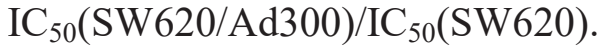


were summarized in Table 5-6. All compounds possessed acceptable stability profile in three microsome species. Four compounds were more stable in human microsome than in mouse and rat microsomes. Among the four analogues, $\mathbf{1 0 f}$ with a 5-fluoro was the most stable against mouse and rat microsomes. Therefore, $\mathbf{1 0 f}$ will be chosen for future in vivo animal study.

\section{Discussion}

UC-112 was previously discovered through a virtual screening program from a library of drug-like compounds [126]. UC-112 selectively lowered the protein level of survivin without affecting other members of the IAP family. In a subsequent SAR study of UC-112, a series of analogues were synthesized and evaluated for their antiproliferative activities in a panel of melanoma cell lines [214]. The result demonstrated that: (1) 8-hydroxyl group and the nitrogen in 8-hydroxyquinoline were essential for exerting maximum inhibitory effect; (2) modifications of the pyrrolidine ring to other heterocylcles were unsuccessful to improve activities; (3) modification of the benzyloxy was feasible to increase the activity. Based on this SAR result, we hypothesize that the benzyloxy moiety in UC-112 is too flexible; replacing the benzyloxy moiety with rigid moieties can improve the inhibitory activity.

In this chapter, we replaced the benzyloxy in UC-112 with other substructures to decrease the flexibility. Within the series of analogues modifying the benzyloxy moiety (Figure 5-2 and Table 5-1), analogue 10a which had an indole moiety was found to exert the most potent antiproliferative activity against a panel of melanoma cell lines. Further structural optimization of 10a was focused on introducing mono-substituent and disubstituents. The result showed that many substituted indole analogues exhibited comparable potencies to that of MX-106 and UC-112. Importantly, while YM155 was significantly less cytotoxic in resistant cell lines than in non-resistant cell lines, the new UC-112 analogues were more potent against several types of P-gp overexpressed cancer cell lines than non-resistant cell lines. $71 \%$ of the indole analogues had RIs less than 1 in melanoma cell lines (M14 vs M14/MDR1). 10f, 10i, 101 and 10o were $>3$-fold more cytotoxic against $\mathrm{P}$-gp overexpressed cervical and colorectal carcinoma cell lines (KB-C2 and SW620/Ad300) than non-resistant cervical and colorectal carcinoma cell lines (KB3-1 and SW620). 10f, 10i, $\mathbf{1 0 I}$ and $\mathbf{1 0 0}$ exhibit significant cytotoxicity against $\mathrm{SW} 620 / \mathrm{Ad} 300$ cell line with $\mathrm{IC}_{50}$ as low as $30 \mathrm{nM}$. The new analogues showed favorable microsomal stability profile. Currently, the in vivo efficacy evaluation of the 5-F indole analogue (10f) in a subcutaneous mouse xenograft model with human A375 melanoma is undergoing.

In conclusion, we herein have synthesized thirty-six new UC-112 analogues modifying the benzyloxy moiety. Several new analogues showed equipotency to that of MX-106 in melanoma cell lines. New analogues showed significant cytotoxicity against colorectal carcinoma cell line with $\mathrm{IC}_{50}$ as low as $0.2 \mu \mathrm{M}$. New UC-112 analogues also exhibited the ability to surmount P-gp mediated drug-resistance. 
Table 5-6. In vitro microsomal stabilities of compounds 10f, 10i, 101 and 100

\begin{tabular}{|c|c|c|c|c|c|c|}
\hline \multirow[b]{2}{*}{ Compound } & \multicolumn{2}{|r|}{ Mouse } & \multicolumn{2}{|r|}{ Rat } & \multicolumn{2}{|c|}{ Human } \\
\hline & $\begin{array}{l}\mathbf{t}_{1 / 2} \\
(\mathbf{h r})\end{array}$ & $\begin{array}{c}\text { Clint } \\
(\mathrm{mL} / \mathrm{Min} / \mathrm{Kg})\end{array}$ & $\begin{array}{l}\mathbf{t}_{1 / 2} \\
(\mathbf{h r})\end{array}$ & $\begin{array}{c}\text { Clint } \\
(\mathrm{mL} / \mathrm{Min} / \mathrm{Kg})\end{array}$ & $\begin{array}{c}\mathbf{t}_{1 / 2} \\
(\mathbf{h r})\end{array}$ & $\begin{array}{c}\text { Clint } \\
(\mathrm{mL} / \mathrm{Min} / \mathrm{Kg})\end{array}$ \\
\hline Verapermil & $1.44 \pm 0.12$ & 39.7 & $3.81 \pm 0.48$ & 12.3 & $1.57 \pm 0.17$ & 13.3 \\
\hline $10 \mathrm{f}$ & $1.36 \pm 0.06$ & 42.1 & $1.29 \pm 0.03$ & 36.1 & $4.59 \pm 0.39$ & 4.5 \\
\hline $10 \mathrm{i}$ & $1.17 \pm 0.06$ & 48.7 & $1.20 \pm 0.05$ & 39.0 & $2.16 \pm 0.19$ & 9.6 \\
\hline 101 & $1.20 \pm 0.07$ & 47.8 & $1.62 \pm 0.10$ & 29.0 & $3.50 \pm 0.36$ & 5.9 \\
\hline 100 & $0.88 \pm 0.06$ & 65.1 & $1.26 \pm 0.06$ & 37.0 & $2.80 \pm 0.18$ & 7.4 \\
\hline
\end{tabular}




\section{CHAPTER 6. TOTAL SYNTHESIS OF BIOLOGICAL ACTIVE 20S- HYDROXYVITAMIN D3*}

\section{Introduction}

25-hydroxylase (CYP2R1 or CYP27A1) in the liver and $1 \alpha$-hydroxylase (CYP27B1) in the kidney are the enzymes responsible for sequential metabolism of vitamin D3 to produce bioactive $1 \alpha, 25$-dihydroxyvitamin $\mathrm{D} 3\left[1,25(\mathrm{OH})_{2} \mathrm{D} 3\right.$, calcitriol] [226, 227]. $1,25(\mathrm{OH})_{2} \mathrm{D} 3$ activates nuclear vitamin $\mathrm{D}$ receptor (VDR). VDR is found in almost all tissues of the body and triggers numerous cellular effects including but not limited to stimulation of cell differentiation and/or apoptosis, inhibition of cell proliferation, regulation of secretory and immune factors of many cells, and cell protective functions, in a context dependent fashion [228-232]. Therefore, active forms of vitamin D can be used in therapy of cancer, hyperproliferative, autoimmune and metabolic disorders [233-235]. The applications are however limited by hypercalcemic (toxic) effect of calcitriol at pharmacological concentrations [144]. This side effect has led to the development of more than 3,000 synthetic vitamin D3 analogs showing low calcemic activity [236]. Some of these analogs such as paricalcitol, oxacalcitriol, falecalcitriol, tacalcitol and doxercalciferol were used to treat secondary hyperparathyroidism and psoriasis [233, 237]. Calcipotriol is also a promising agent for the treatment of pancreatic cancer and is currently undergoing human clinical trial [238] (Figure 6-1).

Mammalian cytochrome P450 side-chain cleavage enzyme (P450scc or CYP11A1) not only cleaves the side chain of cholesterol to produce pregnenolone (precursor of all steroids) $[145,146]$ but also hydroxylates vitamin D3 in a sequential fashion [146-150] starting from C20 to form 20S-hydroxyvitamin D3 [20S-(OH)D3] (1, Figure 6-1). This intermediate is subsequently converted to di- and trihydroxy metabolites [147, 149-152]. Functional studies showed that 20S-(OH)D3 not only stimulated keratinocyte differentiation program but also inhibited NF- $\kappa$ B activity in human keratinocytes [153]. In addition, it has shown anti-inflammatory activities, strong anti-proliferative effects, anti-leukemia and tumorostatic effects [153-157], protective effects against ultra-violet B (UVB) induced damage [158], as well as antifibrotic activity in vivo [159]. These activities are mediated either through activation of the VDR [153, 160] or inhibition of ROR $\alpha$ and ROR $\gamma$ transcriptional activities [161]. More importantly, while having comparable anti-proliferative potency with $1,25(\mathrm{OH})_{2} \mathrm{D} 3$ which has strong hypercalcemic toxicity at a concentration of $1 \mu \mathrm{g} / \mathrm{kg}, 20 S-(\mathrm{OH}) \mathrm{D} 3$ is not hypercalcemic at concentrations as high as $60 \mu \mathrm{g} / \mathrm{kg}[154,156,158,162]$.

*Modified with permission. Qinghui Wang, Zongtao Lin, Tae-Kang Kim, Andrzej T. Slominski, Duane D. Miller, Wei Li. Total synthesis of biologically active 20Shydroxyvitamin D3. Steroids, 2015, 104: 153-162 

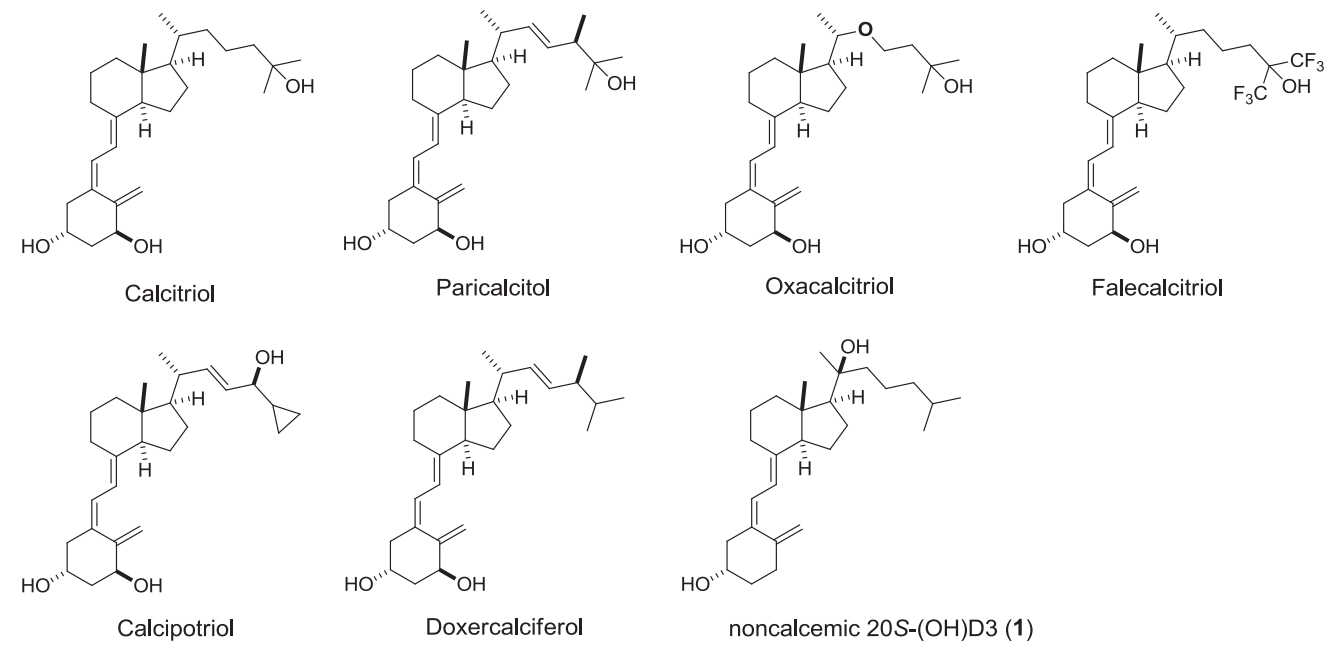

Figure 6-1. Marketed vitamin D analogs and noncalcemic 20S-(OH)D3 
In-depth evaluation of the biological activity for $20 S-(\mathrm{OH}) \mathrm{D} 3$ or its analogs was hampered by lack of an efficient synthetic method of its production [239] without using costly enzymatic approaches $[150,151,240] .20 S-(\mathrm{OH}) \mathrm{D} 3$ was first chemically synthesized from pregnenolone acetate via Grignard reaction and low yielding UVB irradiation to afford low milligram scale of $20 S-(\mathrm{OH}) \mathrm{D} 3$ stereo-specifically. However, this method also generated structurally similar and physicochemically active by-products including previtamin D3, lumisterol and tachysterol which presented a significant challenge in the purification of 20S-(OH)D3 even through preparative HPLC [239]. Due to these disadvantages, scope of synthesis through UVB irradiation of 5,7-dienal precursor, 20S-(OH)-7-dehydrocholesterol was confined to very few derivatives, if not to almost exclusive production of $20 S-(\mathrm{OH}) \mathrm{D} 3$. Therefore, an approach that could easily generate large quantity of $20 S-(\mathrm{OH}) \mathrm{D} 3$ with high quality ( $>98 \%$ purity) would facilitate further modifications on the side chain to determine the structure-activity relationships of this promising 20S-hydroxyl scaffold. Herein, we report an efficient total synthetic route for stereospecific $20 S-(\mathrm{OH}) \mathrm{D} 3$.

\section{Experimental Section}

\section{General chemistry}

Tetrahydrofuran was distilled from sodium-benzophenone. All other solvents and chemical reagents were obtained from commercial sources and directly used without further purification. Ergocalciferol was purchased from Chem Impex International Inc. Glassware was oven-dried before use. All reactions were performed under an argon atmosphere. TLC was performed on silica gel 60 GF254 and monitored under UV light or visualized using phosphomolybdic acid reagent. Flash chromatography was performed on 230-400 mesh silica gel (Fisher Scientific). Preparative TLC was performed on Analtech TLC Uniplates $(250 \mu \mathrm{m})$. Melting points were recorded on a MPA100 Automated Melting Point Apparatus. NMR spectra were obtained on a Bruker Ascend 400 (Billerica, MA) spectrometer or a Varian Inova-500 spectrometer (Agilent Technologies, Santa Clara, CA). HR-MS were obtained on Waters Acquity UPLC linked to Waters Acquity Photodiode Array Detector and Waters Acquity Single Quadrupole Mass Detector. Chemical shifts are given in ppm with tetramethylsilane (TMS) as an internal reference. All coupling constants $(J)$ are given in Hertz $(\mathrm{Hz})$.

\section{Chemical synthesis}

(4R,7aR)-1-((2R,5R,E)-5,6-dimethylhept-3-en-2-yl)-4-((R,Z)-1-hydroxy-2((S)-5-hydroxy-2-methylenecyclohexylidene)ethyl)-7a-methyloctahydro-1H-inden-4ol (2). Following a reported procedure [241], to a solution of ergocalciferol (20 g, 50.5 $\mathrm{mmol})$ in ethanol (2 L) at $-45^{\circ} \mathrm{C}$ was added dropwise solution of potassium permanganate $(9.0 \mathrm{~g}, 58.7 \mathrm{mmol})$ in water $(300 \mathrm{~mL})$, the mixture was stirred for half an hour and further 1 hour at $-15^{\circ} \mathrm{C}$ and then warmed to room temperature. After 3 hours, 
the precipitate was filtered off and the solution was evaporated to give yellowish crude oil. The crude oil was purified on silica gel column chromatography eluting with hexane/ethyl acetate (3:1) to give pure triol compound 2 as white solid $(10.5 \mathrm{~g}, 65 \%)$ and unreacted starting material (5.1 g). Mp: $170-172{ }^{\circ} \mathrm{C}(\mathrm{MeOH}) .{ }^{1} \mathrm{H}$ NMR (400 MHz, $\left.\mathrm{CD}_{3} \mathrm{OD}\right): \delta 5.52(\mathrm{dd}, J=9.9,1.7 \mathrm{~Hz}, 1 \mathrm{H}, 6-\mathrm{H}), 5.30-5.09(\mathrm{~m}, 2 \mathrm{H}, 22 / 23-\mathrm{H}), 5.02-4.98$ (m, 2H, 7/19-H), 4.90 (d, $J=9.9 \mathrm{~Hz}, 1 \mathrm{H}, 19-\mathrm{H}), 3.65$ (m, 1H, 3-H), 2.55 (ddd, $J=12.4$, 4.5, $1.9 \mathrm{~Hz}, 1 \mathrm{H}), 2.49-2.38(\mathrm{~m}, 1 \mathrm{H}), 2.17-1.90(\mathrm{~m}, 5 \mathrm{H}), 1.90-1.68(\mathrm{~m}, 4 \mathrm{H}), 1.62(\mathrm{~m}$, $1 \mathrm{H}), 1.56-1.39(\mathrm{~m}, 4 \mathrm{H}), 1.39-1.03(\mathrm{~m}, 5 \mathrm{H}), 1.00(\mathrm{~d}, J=6.6 \mathrm{~Hz}, 3 \mathrm{H}, 21-\mathrm{H}), 0.94(\mathrm{~d}, J$ $=6.8 \mathrm{~Hz}, 3 \mathrm{H}, 28-\mathrm{H}), 0.89-0.81(\mathrm{t}, J=6.4 \mathrm{~Hz}, 9 \mathrm{H}, 18 / 26 / 27-\mathrm{H}) .{ }^{13} \mathrm{C}$ NMR $(101 \mathrm{MHz}$, $\left.\mathrm{CD}_{3} \mathrm{OD}\right): \delta 147.35,140.78,137.06,133.12,126.72,111.72,76.25$ (C7), 71.42 (C8 or C3), 71.39 (C3 or C8), 61.04, 58.79, 47.60, 45.14, 44.36, 41.70, 41.53, 39.23, 37.21, 34.50, 34.38, 29.13, 22.87, 21.76, 21.29, 20.52, 20.12, 18.27, 13.59. ESI-HRMS: calculated for $\mathrm{C}_{28} \mathrm{H}_{46} \mathrm{O}_{3} \mathrm{Na}[\mathrm{M}+\mathrm{Na}]^{+} 453.3345$, found 453.3352 .

(S,Z)-3-(2-hydroxyethylidene)-4-methylenecyclohexanol(3) and (4S,7aR)-1((2R,5R,E)-5,6 -dimethylhept-3-en-2-yl)-7a-methyloctahydro-1H-inden-4-ol (4). To a suspension of $2(6.0 \mathrm{~g}, 13.9 \mathrm{mmol})$ and sodium carbonate $(14.6 \mathrm{~g}, 138 \mathrm{mmol})$ in dichloromethane $(50 \mathrm{~mL})$ was added lead tetraacetate $(6.7 \mathrm{~g}, 15.3 \mathrm{mmol})$ in portions at 0 ${ }^{\circ} \mathrm{C}$. After 2 hours, the reaction was quenched with ethylene glycol and the mixture was vigorously stirred at $0{ }^{\circ} \mathrm{C}$ for 10 minutes. Water was then added and the mixture was extracted with dichloromethane for five times, washed with brine and dried with $\mathrm{Na}_{2} \mathrm{SO}_{4}$. The combined extracts were evaporated to give crude oil mixture, which was used for next step without further purification. To a solution of the above crude oily mixture in benzene $(100 \mathrm{~mL})$ at $0{ }^{\circ} \mathrm{C}$ under argon with stirring, Red-Al $(28.7 \mathrm{mmol}, 8.6 \mathrm{~mL})$ was added dropwise and the mixture was stirred for 2 hours. On completion reaction was quenched with water. The mixture was filtered off and extracted with ethyl acetate, washed with brine and dried with anhydrous $\mathrm{Na}_{2} \mathrm{SO}_{4}$. Organic phase was evaporated to generate crude oil mixture which was purified by flash chromatography on silica. Elution with hexane/ethyl acetate (10:1) gave pure alcohol compound 4 as transparent oil (3.3 g, $86 \%$ for two steps), further elution with hexane/ethyl acetate (1:2) gave pure allylic alcohol 3 as colorless oil ( $0.91 \mathrm{~g}, 43 \%$ for two steps). compound 3: ${ }^{1} \mathrm{H}$ NMR (400 MHz, $\left.\mathrm{CDCl}_{3}\right): \delta 5.45(\mathrm{t}, J=6.6 \mathrm{~Hz}, 1 \mathrm{H}, 6-\mathrm{H}), 4.97(\mathrm{dd}, J=2.4,1.3 \mathrm{~Hz}, 1 \mathrm{H}, 19-\mathrm{H}), 4.59(\mathrm{~d}, J=$ $2.3 \mathrm{~Hz}, 1 \mathrm{H}, 19-\mathrm{H}), 4.25$ (ddd, $J=12.7,7.0,1.2 \mathrm{~Hz}, 1 \mathrm{H}, 7-\mathrm{H}), 4.14$ (ddd, $J=12.6,6.2,1.3$ $\mathrm{Hz}, 1 \mathrm{H}, 7-\mathrm{H}), 3.94(\mathrm{~m}, 1 \mathrm{H}, 3-\mathrm{H}), 2.56-2.33$ (m, 2H), 2.24 (dd, $J=13.2,7.1 \mathrm{~Hz}, 1 \mathrm{H})$, $2.19-2.06(\mathrm{~m}, 1 \mathrm{H}), 1.87(\mathrm{~m}, 1 \mathrm{H}), 1.75-1.60(\mathrm{~m}, 1 \mathrm{H}) .{ }^{13} \mathrm{C} \mathrm{NMR}\left(101 \mathrm{MHz}, \mathrm{CDCl}_{3}\right): \delta$ 144.51 (C10), 139.11 (C5), 125.95 (C6), 112.23 (C19), 68.64 (C3), 59.34 (C7), 44.82, 34.62, 31.45. ESI-HRMS: calculated for $\mathrm{C}_{9} \mathrm{H}_{11},\left[\mathrm{M}-2 \mathrm{H}_{2} \mathrm{O}+\mathrm{H}\right]^{+} 119.0861$, found 119.0861. compound 4: ${ }^{1} \mathrm{H}$ NMR (400 MHz, $\left.\mathrm{CDCl}_{3}\right): \delta 5.25-5.02(\mathrm{~m}, 2 \mathrm{H}, \mathrm{C} 22 / 23-\mathrm{H})$, $4.02(\mathrm{~d}, J=2.8 \mathrm{~Hz}, 1 \mathrm{H}, \mathrm{C} 8-\mathrm{H}), 2.04-1.88(\mathrm{~m}, 2 \mathrm{H}), 1.86-1.73(\mathrm{~m}, 3 \mathrm{H}), 1.73-1.60(\mathrm{~m}$, $1 \mathrm{H}), 1.56-1.33(\mathrm{~m}, 5 \mathrm{H}), 1.33-1.02(\mathrm{~m}, 5 \mathrm{H}), 0.96(\mathrm{~d}, J=6.6 \mathrm{~Hz}, 3 \mathrm{H}, 22-\mathrm{H}), 0.92(\mathrm{~s}$, $3 \mathrm{H}, \mathrm{C} 18-\mathrm{H}), 0.89$ (d, $J=11.2 \mathrm{~Hz}, 3 \mathrm{H}, 23-\mathrm{H}), 0.80$ (t, $J=6.6 \mathrm{~Hz}, 6 \mathrm{H}, \mathrm{C} 26 / 27-\mathrm{H}) .{ }^{13} \mathrm{C}$ NMR (101 MHz, $\left.\mathrm{CDCl}_{3}\right): \delta 135.59,131.70,69.14$ (C8), 56.48, 52.72, 42.78, 41.65, $40.32,39.75,33.53,33.00,27.57,22.46,20.71,19.88,19.55,17.57,17.40,13.61$. ESIHRMS: calculated for $\mathrm{C}_{19} \mathrm{H}_{33}\left[\mathrm{M}-\mathrm{H}_{2} \mathrm{O}+\mathrm{H}\right]^{+}$261.2582, found 261.2582. 
(S,Z)-tert-butyl(2-(5-((tert-butyldimethylsilyl)oxy)-2-

methylenecyclohexylidene)ethoxy)dimethylsilane (5). Imidazole (1.4 g, $21.2 \mathrm{mmol})$ and tert-butyldimethylsilyl chloride $(4.8 \mathrm{~g}, 31.6 \mathrm{mmol})$ was sequentially added to a solution of compound $3(0.82 \mathrm{~g}, 5.3 \mathrm{mmol})$ in dichloromethane $(50 \mathrm{~mL})$ in a round bottom flask with stirring. The resulting suspension was stirred for 2 hours. Water was then added and the mixture was extracted with dichloromethane, washed with brine and dried with anhydrous $\mathrm{Na}_{2} \mathrm{SO}_{4}$. Evaporation under vacuum gave the oily residue which was subjected to flash chromatography on silica. Elution with hexane/ethyl acetate $(80: 1)$ gave pure compound 5 as colorless oil $(1.8 \mathrm{~g}, 88 \%)$. ${ }^{1} \mathrm{H}$ NMR $\left(400 \mathrm{MHz}, \mathrm{CDCl}_{3}\right): \delta 5.38$ (ddt, $J=6.8,5.3,1.3 \mathrm{~Hz}, 1 \mathrm{H}, 6-\mathrm{H}), 4.95$ (p, $J=1.1 \mathrm{~Hz}, 1 \mathrm{H}, 19-\mathrm{H}), 4.57$ (dd, $J=2.4,1.3$ $\mathrm{Hz}, 1 \mathrm{H}, 19-\mathrm{H}$ ), 4.31 (ddt, $J=13.0,7.2,0.9 \mathrm{~Hz}, 1 \mathrm{H}, 7-\mathrm{H}), 4.21$ (ddd, $J=12.9,5.3,2.1 \mathrm{~Hz}$, $1 \mathrm{H}, 7-\mathrm{H}), 3.82(\mathrm{tt}, J=8.9,3.9 \mathrm{~Hz}, 1 \mathrm{H}, 3-\mathrm{H}), 2.47-2.31(\mathrm{~m}, 2 \mathrm{H}), 2.22-2.13(\mathrm{~m}, 1 \mathrm{H})$, $2.06(\mathrm{~m}, 1 \mathrm{H}), 1.93-1.80(\mathrm{~m}, 1 \mathrm{H}), 1.56(\mathrm{~m}, 1 \mathrm{H}), 0.89(\mathrm{~d}, J=4.7 \mathrm{~Hz}, 18 \mathrm{H}, \mathrm{TBS}), 0.08-$ 0.03 (s, 12H, TBS). ${ }^{13} \mathrm{C}$ NMR (101 MHz, $\mathrm{CDCl}_{3}$ ): $\delta 144.89$ (C10), 138.24 (C5), 126.29 (C6), 111.95 (C19), 70.11 (C3), 60.59 (C7), 45.93, 36.03, 32.15, 26.01 (TBS), 25.86 (TBS), 18.43, 18.18, -4.65 (TBS), -4.69 (TBS), -4.99 (TBS), -5.05 (TBS). ESI-HRMS: calculated for $\mathrm{C}_{21} \mathrm{H}_{42} \mathrm{O}_{2} \mathrm{Si}_{2} \mathrm{Na}[\mathrm{M}+\mathrm{Na}]^{+}$405.2621, found 405.2629.

(S,Z)-2-(5-((tert-butyldimethylsilyl)oxy)-2-methylenecyclohexylidene)ethanol (6). To a solution of compound $5(1.7 \mathrm{~g}, 4.4 \mathrm{mmol})$ in anhydrous THF $(20 \mathrm{~mL})$ in a round bottom flask at $-5{ }^{\circ} \mathrm{C}$ under nitrogen, tetra- $n$-butylammonium fluoride $(1.0 \mathrm{M}$ in THF, $4.8 \mathrm{mmol}$ ) was added dropwise with stirring. The resulting mixture was stirred for 3 hours, water was then added and the brown mixture was extracted with dichloromethane, washed with brine and dried with anhydrous $\mathrm{Na}_{2} \mathrm{SO}_{4}$. The combined extracts were evaporated under vacuum to give the oily residue which was purified with flash chromatography on silica. Pure allylic alcohol 6 was eluted out with hexane/ethyl acetate (50:1) as colorless oil $(0.93 \mathrm{~g}, 78 \%) .{ }^{1} \mathrm{H}$ NMR $\left(400 \mathrm{MHz}, \mathrm{CDCl}_{3}\right): \delta 5.44$ (ddt, $J=7.3$, $5.9,1.3 \mathrm{~Hz}, 1 \mathrm{H}, 6-\mathrm{H}), 4.96(\mathrm{~d}, J=1.2 \mathrm{~Hz}, 1 \mathrm{H}, 19-\mathrm{H}), 4.62(\mathrm{t}, J=2.4 \mathrm{~Hz}, 1 \mathrm{H}, 19-\mathrm{H}), 4.43$ $-4.01(\mathrm{~m}, 2 \mathrm{H}, 7-\mathrm{H}), 3.84(\mathrm{~m}, 1 \mathrm{H}, 3-\mathrm{H}), 2.48-2.33(\mathrm{~m}, 2 \mathrm{H}), 2.26-2.14(\mathrm{~m}, 1 \mathrm{H}), 2.13-$ $2.01(\mathrm{~m}, 1 \mathrm{H}), 1.87(\mathrm{~m}, 1 \mathrm{H}), 1.58(\mathrm{~m}, 1 \mathrm{H}), 0.88(\mathrm{~s}, 9 \mathrm{H}, \mathrm{TBS}), 0.06(\mathrm{~d}, J=2.9 \mathrm{~Hz}, 6 \mathrm{H}$, TBS). ${ }^{13} \mathrm{C}$ NMR $\left(101 \mathrm{MHz}, \mathrm{CDCl}_{3}\right): \delta 144.83,140.52,124.88,111.91,70.11$ (C3), 59.82 (C7), 46.02, 35.98, 32.26, 25.82 (TBS), 18.15, -4.67 (TBS), -4.71 (TBS). ESI-HRMS: calculated for $\mathrm{C}_{15} \mathrm{H}_{28} \mathrm{O}_{2} \mathrm{SiNa}[\mathrm{M}+\mathrm{Na}]^{+}$291.1756, found 291.1755.

\section{(S,Z)-(2-(5-((tert-butyldimethylsilyl)oxy)-2-}

methylenecyclohexylidene)ethyl)diphenylphosphine oxide (7). To a solution of the allylic alcohol $6(0.81 \mathrm{~g}, 3.0 \mathrm{mmol})$ in anhydrous THF $(20 \mathrm{~mL})$ was added $n$-BuLi $(2.5 \mathrm{M}$ in hexanes, $30.0 \mathrm{mmol}$ ) under argon at $0{ }^{\circ} \mathrm{C}$ with stirring. After 5 minutes, a solution of $p$-tosyl chloride (598 mg, $3.15 \mathrm{mmol})$ dissolved in anhydrous THF $(10 \mathrm{~mL})$ was added to the allylic alcohol-BuLi solution. On the other side, to a solution of diphenylphosphine $(1.02 \mathrm{~mL}, 6.0 \mathrm{mmol})$ in anhydrous THF $(5 \mathrm{~mL})$ under argon at $0{ }^{\circ} \mathrm{C}$ with stirring $n$-BuLi (2.5 $\mathrm{M}$ in hexanes, $2.2 \mathrm{~mL}, 5.7 \mathrm{mmol}$ ) was added dropwise to provide a red solution. After 10 minutes $4.1 \mathrm{~mL}$ of the red solution was then drawn to add to the solution of tosylate. The mixture was stirred for 30 minutes at $0{ }^{\circ} \mathrm{C}$ and quenched with $\mathrm{H}_{2} \mathrm{O}(1 \mathrm{~mL})$. Evaporation of the solution under vacuum gave a phosphine residue. To the phosphine residue in dichloromethane $(15 \mathrm{~mL})$ at $0{ }^{\circ} \mathrm{C}$ with stirring was added $10 \% \mathrm{H}_{2} \mathrm{O}_{2}(1.1 \mathrm{~mL})$. 
Reaction was quenched with water, extracted with dichloromethane, washed with cold saturated sodium sulfite solution and brine and dried with $\mathrm{Na}_{2} \mathrm{SO}_{4}$. Organic solvent was removed under vacuum to give crude residue which was subjected to flash chromatography on silica for purification. Elution with hexane/ethyl acetate (3:1) gave pure phosphine oxide compound 7 as white solid (800 mg, 59\%). Mp: 94-96 ${ }^{\circ} \mathrm{C}$ (EtOAc). ${ }^{1} \mathrm{H}$ NMR (400 MHz, $\left.\mathrm{CDCl}_{3}\right): \delta 7.71(\mathrm{~m}, 4 \mathrm{H}, \mathrm{Ph}), 7.56-7.36(\mathrm{~m}, 6 \mathrm{H}, \mathrm{Ph}), 5.35$ (q, $J=$ $7.2 \mathrm{~Hz}, 1 \mathrm{H}, 6-\mathrm{H}), 4.92(\mathrm{t}, J=1.9 \mathrm{~Hz}, 1 \mathrm{H}, 19-\mathrm{H}), 4.68$ (dd, $J=2.4,1.3 \mathrm{~Hz}, 1 \mathrm{H}, 19-\mathrm{H})$, $3.52(\mathrm{~m}, 1 \mathrm{H}, 3-\mathrm{H}), 3.36(\mathrm{~m}, 1 \mathrm{H}, 7-\mathrm{H}), 3.20(\mathrm{~m}, 1 \mathrm{H}, 7-\mathrm{H}), 2.44-2.31$ (m, 1H), 2.22 (dt, $J$ $=13.3,4.7 \mathrm{~Hz}, 1 \mathrm{H}), 2.15-2.05(\mathrm{~m}, 1 \mathrm{H}), 1.81-1.71(\mathrm{~m}, 1 \mathrm{H}), 1.66(\mathrm{~m}, 1 \mathrm{H}), 1.47(\mathrm{~m}$, $1 \mathrm{H}), 0.83(\mathrm{~s}, 9 \mathrm{H}, \mathrm{TBS}),-0.00(\mathrm{~d}, J=2.0 \mathrm{~Hz}, 6 \mathrm{H}, \mathrm{TBS}) ;{ }^{13} \mathrm{C} \mathrm{NMR}\left(101 \mathrm{MHz}, \mathrm{CDCl}_{3}\right): \delta$ 145.03 , 145.01, 142.62, 142.50, 133.49, 132.99, 132.52, 132.00, 131.75, 131.73, 131.61, $131.58,131.20,131.11,130.95,130.86,128.59,128.48,128.44,128.32,113.19,113.11$, 111.60, 111.59, 70.46 (C3), 70.43, 46.68, 46.66, 36.21, 32.48, 32.46, 31.44, 30.74, 25.82 (TBS), 18.12, -4.69 (TBS), -4.75 (TBS). ESI-HRMS: calculated for $\mathrm{C}_{27} \mathrm{H}_{37} \mathrm{O}_{2} \mathrm{PSiNa}$ $[\mathrm{M}+\mathrm{Na}]^{+}$475.2198, found 475.2203.

(4S,7aR)-1-((2R,5R,E)-5,6-dimethylhept-3-en-2-yl)-7a-methyloctahydro-1Hinden-4-yl acetate (8). Pyridine (1.3 mL, $16.1 \mathrm{mmol})$, 4-dimethylaminopyridine (352 $\mathrm{mg}, 2.88 \mathrm{mmol})$ and acetyl anhydride $(0.98 \mathrm{~mL}, 104 \mathrm{mmol})$ was sequentially added to a solution of compound 4 (3.2 g, $11.5 \mathrm{mmol})$ in anhydrous dichloromethane $(30 \mathrm{~mL})$ in a round bottom flask under argon. The resulting mixture was stirred for 3 hours. Water was then added and the mixture was extracted with dichloromethane, washed with saturated $\mathrm{NaHCO}_{3}, 0.1 \mathrm{M} \mathrm{HCl}$ and brine and then dried with $\mathrm{Na}_{2} \mathrm{SO}_{4}$. Evaporation under vacuum gave the oily residue which was purified with flash chromatography on silica. Elution with hexane/ethyl acetate (30:1) gave pure compound 8 as colorless oil $(3.4 \mathrm{~g}, 92 \%) .{ }^{1} \mathrm{H}$ NMR $\left(400 \mathrm{MHz}, \mathrm{CDCl}_{3}\right): \delta 5.31-5.00(\mathrm{~m}, 3 \mathrm{H}, 8 / 22 / 23-\mathrm{H}), 2.12-1.92(\mathrm{~m}, 5 \mathrm{H}), 1.92-$ $1.53(\mathrm{~m}, 4 \mathrm{H}), 1.53-1.03(\mathrm{~m}, 10 \mathrm{H}), 0.99(\mathrm{~d}, J=2.4 \mathrm{~Hz}, 3 \mathrm{H}, 22-\mathrm{H}), 0.94-0.85(\mathrm{~m}, 6 \mathrm{H})$, $0.82(\mathrm{t}, J=6.8 \mathrm{~Hz}, 6 \mathrm{H}, 26 / 27-\mathrm{H}) .{ }^{13} \mathrm{C} \mathrm{NMR}\left(101 \mathrm{MHz}, \mathrm{CDCl}_{3}\right): \delta 170.73$ (acetyl), 135.47, 131.90, 71.35 (C8), 56.31, 51.41, 42.79, 41.82, 39.90, 39.84, 33.05, 30.50, 27.47, 22.61, 21.31, 20.77, 19.93, 19.60, 17.90, 17.60, 13.17. ESI-HRMS: calculated for $\mathrm{C}_{21} \mathrm{H}_{36} \mathrm{O}_{2} \mathrm{Na}[\mathrm{M}+\mathrm{Na}]^{+}$343.2613, found 343.2614.

(4S,7aR)-1-((2S,3R,4R,5R)-3,4-dihydroxy-5,6-dimethylheptan-2-yl)-7amethyloctahydro-1H-inden-4-yl acetate (9). To a solution of the compound 8 (3.3 g, $10.3 \mathrm{mmol})$ in acetone $(40 \mathrm{~mL})$ was added $N$-methylmorpholine $N$-oxide $(6.0 \mathrm{~g}, 51.5$ $\mathrm{mmol})$ and $2.5 \%$ osmium tetroxide in tert-butanol $(6.5 \mathrm{~mL}, 0.52 \mathrm{mmol})$ at room temperature with stirring. After 48 hours, water and ethyl acetate was added and the organic phase was separated, washed with brine and dried with $\mathrm{Na}_{2} \mathrm{SO}_{4}$. Evaporation under vacuum gave the oily residue which was purified with flash chromatography on silica. Elution with hexane/ethyl acetate (10:1) gave pure compound 9 as colorless oil (2.44 g, 67\%). ${ }^{1} \mathrm{H}$ NMR (400 MHz, $\left.\mathrm{CDCl}_{3}\right): \delta 5.14(\mathrm{~d}, J=2.6 \mathrm{~Hz}, 1 \mathrm{H}, 8-\mathrm{H}), 3.71(\mathrm{dd}, J=$ 2.4, 4.4 Hz, 1H, 22-H), 3.59 (t, $J=2.8 \mathrm{~Hz}, 1 \mathrm{H}, 23-\mathrm{H}), 2.39$ (s, 1H), 2.04 (s, 4H), $1.94-$ $1.79(\mathrm{~m}, 2 \mathrm{H}), 1.70(\mathrm{~m}, 5 \mathrm{H}), 1.55-1.09(\mathrm{~m}, 9 \mathrm{H}), 1.00(\mathrm{~d}, J=6.9 \mathrm{~Hz}, 3 \mathrm{H}, 21-\mathrm{H}), 0.96(\mathrm{~d}$, $J=6.7 \mathrm{~Hz}, 3 \mathrm{H}, 28-\mathrm{H}), 0.92-0.84$ (m, 9H, 18/26/27-H). ${ }^{13} \mathrm{C} \mathrm{NMR}\left(101 \mathrm{MHz}, \mathrm{CDCl}_{3}\right): \delta$ 170.80 (acetyl), 73.26 (C23), 71.19 (C8), 70.26 (C22), 53.02, 51.04, 44.11, 43.93, 42.45, 
$41.65,40.00,30.49,29.89,29.75,26.91,22.82,21.44,21.34,18.94,17.88,13.91,13.52$, 12.83, 9.91. ESI-HRMS: calculated for $\mathrm{C}_{21} \mathrm{H}_{38} \mathrm{O}_{4} \mathrm{Na}[\mathrm{M}+\mathrm{Na}]^{+} 377.2668$, found 377.2668.

(4S,7aR)-7a-methyl-1-((S)-1-oxopropan-2-yl)octahydro-1H-inden-4-yl acetate (10). To a suspension of compound 9 (2.2 g, $6.2 \mathrm{mmol})$ in $\mathrm{THF}_{-} \mathrm{H}_{2} \mathrm{O}(4: 1,10 \mathrm{~mL})$, sodium periodate $(1.45 \mathrm{~g}, 6.82 \mathrm{mmol})$ was added at $0{ }^{\circ} \mathrm{C}$ in portions with stirring. After 1 hour, the reaction was quenched with ethylene glycol and the mixture was stirred at $0{ }^{\circ} \mathrm{C}$ for 10 minutes. Water was then added and the mixture was extracted with ethyl acetate for three times, washed with brine and dried with $\mathrm{Na}_{2} \mathrm{SO}_{4}$. The combined extracts were evaporated to give crude oil, which was purified with flash chromatography on silica. Elution with hexane/ethyl acetate (5:1) gave pure compound $\mathbf{1 0}$ as transparent oil $(1.03 \mathrm{~g}$, $66 \%$ ). ${ }^{1} \mathrm{H}$ NMR (400 MHz, $\left.\mathrm{CDCl}_{3}\right): \delta 9.57(\mathrm{~d}, J=3.2 \mathrm{~Hz}, 1 \mathrm{H}, \mathrm{CHO}), 5.17(\mathrm{~d}, J=2.0$ $\mathrm{Hz}, 1 \mathrm{H}, 8-\mathrm{H}), 2.36$ (m, 1H, 20-H), 2.05 (s, 3H), 1.97 (dt, J=12.3, $3.3 \mathrm{~Hz}, 1 \mathrm{H}), 1.89-$ $1.71(\mathrm{~m}, 3 \mathrm{H}), 1.59-1.24(\mathrm{~m}, 8 \mathrm{H}), 1.11(\mathrm{~d}, J=6.8 \mathrm{~Hz}, 3 \mathrm{H}, 21-\mathrm{H}), 0.93(\mathrm{~s}, 3 \mathrm{H}, 18-\mathrm{H}) .{ }^{13} \mathrm{C}$ NMR (101 MHz, CDCl $): \delta 204.78$ (CHO), 170.70 (acetyl), 70.89 (C8), 51.37, 50.74, 49.17, 42.47, 39.75, 30.47, 26.00, 22.95, 21.32, 17.83, 13.42, 13.35. ESI-HRMS: calculated for $\mathrm{C}_{15} \mathrm{H}_{23} \mathrm{O}_{2}\left[\mathrm{M}-\mathrm{H}_{2} \mathrm{O}+\mathrm{H}\right]^{+} 235.1698$, found 235.1696 .

(1S,4S,7aS)-1-acetyl-7a-methyloctahydro-1H-inden-4-yl acetate (12). To a stirred solution of compound $\mathbf{1 0}(1.0 \mathrm{~g}, 3.9 \mathrm{mmol})$ in benzene $(8 \mathrm{~mL})$ was added morpholine $(0.524 \mathrm{~mL}, 4.8 \mathrm{mmol})$ and $p$-toluenesulfonic acid $(34 \mathrm{mg}, 0.195 \mathrm{mmol})$. The mixture was refluxed over a Dean-Stark water separator overnight. During the course of the reaction the theoretical amount of water $(\sim 70 \mathrm{mg})$ was separated. Upon completion as indicated by mass spectrum, the reaction mixture was cooled to room temperature and solvent was removed under vacuum to afford yellowish oil which was immediately used for next step. To a stirred solution of the above crude mixture in acetone $(20 \mathrm{~mL})$ was added alumina (481 mg, $4.72 \mathrm{mmol}$ ) supported potassium permanganate $(616 \mathrm{mg}, 3.9$ $\mathrm{mmol}$ ) in portions. The reaction mixture was filtered after 2 hours and washed with ethyl acetate. Solvents were removed under vacuum to afford crude oily product which was purified with flash chromatography on silica. Elution with hexane/ethyl acetate (6:1) gave pure compound 12 as colorless oil $\left(659 \mathrm{mg}, 70 \%\right.$ for two steps). ${ }^{1} \mathrm{H}$ NMR (400 MHz, $\left.\mathrm{CDCl}_{3}\right): \delta 5.16(\mathrm{~d}, J=2.8 \mathrm{~Hz}, 1 \mathrm{H}, 8-\mathrm{H}), 2.48(\mathrm{dd}, J=10.0,8.0 \mathrm{~Hz}, 1 \mathrm{H}, 17-\mathrm{H}), 2.20-$ $1.99(\mathrm{~m}, 8 \mathrm{H}), 1.92-1.82(\mathrm{~m}, 1 \mathrm{H}), 1.70-1.39(\mathrm{~m}, 8 \mathrm{H}), 0.81(\mathrm{~s}, 3 \mathrm{H}, 18-\mathrm{H}) .{ }^{13} \mathrm{C} \mathrm{NMR}$ (101 MHz, $\left.\mathrm{CDCl}_{3}\right): \delta 208.52$ (C20), 170.26 (acetyl), 70.27 (C8), 63.54, 51.15, 43.06, 38.85, 31.26, 30.08, 22.54, 21.46, 20.98, 17.64, 14.51 (C18). ESI-HRMS: calculated for $\mathrm{C}_{14} \mathrm{H}_{22} \mathrm{O}_{3} \mathrm{Na}[\mathrm{M}+\mathrm{Na}]^{+}$261.1467, found 261.1467.

(1S,4S,7aS)-1-((S)-2-hydroxy-6-methylheptan-2-yl)-7a-methyloctahydro-1Hinden-4-ol (14). To a stirred suspension of magnesium (181 $\mathrm{mg}, 7.5 \mathrm{mmol})$ in anhydrous THF (10 mL) was added 1-bromo-4-methyl-pentane ( $0.733 \mathrm{~mL}, 5.0 \mathrm{mmol})$ under argon at room temperature. The mixture was then refluxed for 2 hours and cooled down in ice bath to give Grignard reagent $\mathbf{1 3}$ which was used without further purification. Compound 12 (100 mg, $0.42 \mathrm{mmol}$ ) in $2 \mathrm{~mL}$ THF was subsequently added to the reaction mixture which was warmed to room temperature after 30 minutes and stirred overnight. Cooled saturated $\mathrm{NH}_{4} \mathrm{Cl}$ solution was added to quench the reaction and the mixture was extracted with ethyl acetate for three times, washed with brine and dried with $\mathrm{Na}_{2} \mathrm{SO}_{4}$. The 
combined extracts were evaporated to give crude oil, which was purified with flash chromatography on silica. Elution with hexane/ethyl acetate (3:1) afforded pure compound 14 as colorless oil (94 mg, 80\%). ${ }^{1} \mathrm{H}$ NMR (400 MHz, $\left.\mathrm{CDCl}_{3}\right): \delta 4.09$ (d, $J=$ $2.8 \mathrm{~Hz}, 1 \mathrm{H}, 8-\mathrm{H}), 2.14-2.02(\mathrm{~m}, 1 \mathrm{H}), 1.91-1.74(\mathrm{~m}, 3 \mathrm{H}), 1.74-1.37(\mathrm{~m}, 9 \mathrm{H}), 1.37-$ $1.08(\mathrm{~m}, 14 \mathrm{H}), 0.87(\mathrm{dd}, J=6.7,0.8 \mathrm{~Hz}, 6 \mathrm{H}, 26 / 27-\mathrm{H}) .{ }^{13} \mathrm{C} \mathrm{NMR}\left(101 \mathrm{MHz}, \mathrm{CDCl}_{3}\right): \delta$ 75.14 (C20), 69.41 (C8), 57.82, 52.55, 44.10, 42.52, 40.77, 39.56, 33.42, 27.92, 26.29, $22.71,22.55,22.21,21.94,21.30,17.39,15.44$. ESI-HRMS: calculated for $\mathrm{C}_{18} \mathrm{H}_{31}$ [M$\left.2 \mathrm{H}_{2} \mathrm{O}+\mathrm{H}\right]^{+} 247.2426$, found 247.2430 .

(1S,7aR)-1-((S)-2-hydroxy-6-methylheptan-2-yl)-7a-methylhexahydro-1Hinden-4(2H)-one (15). To a stirred solution of compound $14(84 \mathrm{mg}, 0.3 \mathrm{mmol})$ in dichloromethane $(10 \mathrm{~mL})$ was added pyridinium dichromate $(225 \mathrm{mg}, 0.6 \mathrm{mmol})$ at room temperature. The reaction mixture was stirred for 1 hour and filtered through celite. The celite was washed with dichloromethane and the combined solvent was removed under vacuum to give crude oily product which was purified with flash chromatography on silica. Elution with hexane/ethyl acetate (8:1) gave pure compound $\mathbf{1 5}$ as colorless oil (74 mg, 89\%). ${ }^{1} \mathrm{H}$ NMR (400 MHz, $\mathrm{CDCl}_{3}$ ): $\delta 2.43$ (dd, $\left.J=10.5,6.9 \mathrm{~Hz}, 1 \mathrm{H}, 9-\mathrm{H}\right), 2.33$ $-2.13(\mathrm{~m}, 3 \mathrm{H}, 9 / 12 / 14-\mathrm{H}), 2.07-1.83(\mathrm{~m}, 2 \mathrm{H}), 1.82-1.66(\mathrm{~m}, 4 \mathrm{H}), 1.66-1.40(\mathrm{~m}$, $4 \mathrm{H}), 1.35-1.10(\mathrm{~m}, 9 \mathrm{H}), 0.87(\mathrm{~d}, J=6.6 \mathrm{~Hz}, 6 \mathrm{H}, 26 / 27-\mathrm{H}), 0.80(\mathrm{~s}, 3 \mathrm{H}, 18-\mathrm{H})) .{ }^{13} \mathrm{C}$ NMR (101 MHz, $\mathrm{CDCl}_{3}$ ): $\delta 211.99$ (C8), 74.63 (C20), 62.10, 58.04, 49.84, 44.07, 40.80, 39.47, 39.26, 27.89, 26.53, 23.90, 22.67, 22.52, 21.95, 21.77, 18.73, 14.37. ESI-HRMS: calculated for $\mathrm{C}_{18} \mathrm{H}_{31} \mathrm{O}\left[\mathrm{M}-\mathrm{H}_{2} \mathrm{O}+\mathrm{H}\right]^{+}$263.2375, found 263.2377.

(1S,7aR)-1-((S)-2-(ethoxymethoxy)-6-methylheptan-2-yl)-7amethylhexahydro-1H-inden-4(2H)-one (16). To a stirred solution of compound 15 (67 $\mathrm{mg}, 0.24 \mathrm{mmol}), N, N$-diisopropylethylamine $(83 \mu \mathrm{L}, 0.48 \mathrm{mmol})$ and $4-$ dimethylaminopyridine $(12 \mathrm{mg}, 0.096 \mathrm{mmol})$ in anhydrous dichloromethane $(3 \mathrm{~mL})$ was added chloromethyl ethyl ether $(45 \mu \mathrm{L}, 0.48 \mathrm{mmol})$ dropwise at ice temperature. The resulting mixture was stirred for overnight at room temperature. Water was then added and the reaction mixture was extracted with dichloromethane, washed with brine and dried with $\mathrm{Na}_{2} \mathrm{SO}_{4}$. The combined extracts were evaporated under vacuum to give the oily residue which was separated with flash chromatography on silica. Elution with hexane/ethyl acetate (30:1) gave pure compound $\mathbf{1 6}$ as colorless oil $(73 \mathrm{mg}, 90 \%) .{ }^{1} \mathrm{H}$ NMR (400 MHz, $\left.\mathrm{CDCl}_{3}\right): \delta 4.81-4.64$ (m, 2H, EOM), $3.69-3.45$ (m, 2H, EOM), 2.41 (dd, $J=11.5,7.0 \mathrm{~Hz}, 1 \mathrm{H}), 2.32-2.06(\mathrm{~m}, 3 \mathrm{H}), 2.03-1.43(\mathrm{~m}, 11 \mathrm{H}), 1.31(\mathrm{~s}, 3 \mathrm{H}, 21-\mathrm{H})$, $1.26-1.09(\mathrm{~m}, 7 \mathrm{H}), 0.86(\mathrm{dd}, J=6.6,0.9 \mathrm{~Hz}, 6 \mathrm{H}, 26 / 27-\mathrm{H}), 0.76(\mathrm{~s}, 3 \mathrm{H}, 18-\mathrm{H}) .{ }^{13} \mathrm{C}$ NMR (101 MHz, $\mathrm{CDCl}_{3}$ ): $\delta 212.17$ (C8), 88.76 (EOM), 79.75 (C20), 63.20 (EOM), $62.19,57.31,49.72,40.83,40.26,39.70,39.40,27.87,23.92,23.21,22.70,22.57,22.50$, 21.70, 18.74, 15.14, 14.66. ESI-HRMS: calculated for $\mathrm{C}_{21} \mathrm{H}_{38} \mathrm{O}_{3} \mathrm{Na}[\mathrm{M}+\mathrm{Na}]^{+}$361.2719, found 361.2719 .

Tert-butyl(((1S,Z)-3-((E)-2-((1S,7aS)-1-((S)-2-(ethoxymethoxy)-6methylheptan-2-yl)-7a-methylhexahydro-1H-inden-4(2H)-ylidene)ethylidene)-4methylenecyclohexyl)oxy)dimethylsilane (17). To a stirred solution of compound 7 (51 $\mathrm{mg}, 0.15 \mathrm{mmol})$ in anhydrous THF $(3 \mathrm{~mL})$ was added phenyllithium $(1.8 \mathrm{M}$ in hexanes, $0.37 \mathrm{mmol}$ ) under argon at $-78^{\circ} \mathrm{C}$. The mixture was stirred for another 30 minutes at this 
temperature and was added precooled compound $16(167 \mathrm{mg}, 0.37 \mathrm{mmol})$ in $100 \mu \mathrm{L}$ anhydrous THF. Reaction was kept stirring at this temperature for 3 hours and further 12 hours at room temperature. Water was then added and the reaction mixture was extracted with ethyl acetate, washed with brine and dried with $\mathrm{Na}_{2} \mathrm{SO}_{4}$. The combined extracts were evaporated under vacuum to give the oily residue which was purified with flash chromatography on silica. Elution with hexane/ethyl acetate (30:1) gave pure compound 17 as colorless oil $(45 \mathrm{mg}, 52 \%) .{ }^{1} \mathrm{H}$ NMR $\left(400 \mathrm{MHz}, \mathrm{CDCl}_{3}\right): \delta 6.16(\mathrm{~d}, J=11.2 \mathrm{~Hz}$, $1 \mathrm{H}, 6-\mathrm{H}), 6.01$ (d, $J=11.2 \mathrm{~Hz}, 1 \mathrm{H}, 7-\mathrm{H}), 5.02$ (s, 1H, 19-H), $4.85-4.64$ (m, 3H, 19-H and EOM), 3.81 (m, 1H, H-3), $3.71-3.50$ (m, 2H, EOM), 2.82 (d, $J=12.4 \mathrm{~Hz}, 1 \mathrm{H}, 9-\mathrm{H})$, $2.44(\mathrm{dd}, J=13.0,4.2 \mathrm{~Hz}, 1 \mathrm{H}), 2.36(\mathrm{dt}, J=13.5,4.8 \mathrm{~Hz}, 1 \mathrm{H}), 2.28-2.17(\mathrm{~m}, 1 \mathrm{H}), 2.16$ - $1.93(\mathrm{~m}, 3 \mathrm{H}), 1.93-1.79(\mathrm{~m}, 2 \mathrm{H}), 1.77-1.44(\mathrm{~m}, 13 \mathrm{H}), 1.39-1.08(\mathrm{~m}, 12 \mathrm{H}), 0.87(\mathrm{~d}$, $J=7.7 \mathrm{~Hz}, 15 \mathrm{H}, 26 / 27-\mathrm{H}$ and TBS), $0.67(\mathrm{~s}, 3 \mathrm{H}, 18-\mathrm{H}), 0.06(\mathrm{~d}, J=2.2 \mathrm{~Hz}, 6 \mathrm{H}, \mathrm{TBS})$;

${ }^{13} \mathrm{C} \mathrm{NMR}\left(101 \mathrm{MHz}, \mathrm{CDCl}_{3}\right): \delta 145.34$ (C10), 141.18 (C8), 136.36 (C5), 121.32 (C6), 118.21 (C7), 112.13 (C19), 88.80 (EOM), 80.42 (C20), 70.54 (C3), 63.14 (EOM), 57.38, $56.63,46.84,45.73,40.98,40.30,39.79,36.34,32.73,28.80,27.94,25.99,25.96,25.91$, 25.88, 23.32, 22.97, 22.77, 22.55, 21.98, 21.91, 18.18, 15.19, 14.15, -4.59 (TBS), -4.63 (TBS). ESI-HRMS: calculated for $\mathrm{C}_{36} \mathrm{H}_{64} \mathrm{O}_{3} \mathrm{SiNa}[\mathrm{M}+\mathrm{Na}]^{+}$595.4522, found 595.4509.

\section{(1S,Z)-3-((E)-2-((1S,7aS)-1-((S)-2-hydroxy-6-methylheptan-2-yl)-7a-} methylhexahydro-1H-inden-4(2H)-ylidene)ethylidene)-4-methylenecyclohexanol (1). To a stirred solution of compound 17 (10 mg, $0.017 \mathrm{mmol})$ in $\mathrm{MeOH}-\mathrm{DCM}$ (5:1, $3 \mathrm{~mL})$ was added camphorsulfonic acid $(4.3 \mathrm{mg}, 0.020 \mathrm{mmol})$ at room temperature. The mixture was stirred for 3 hours and saturated $\mathrm{NaHCO}_{3}$ was added. The mixture was extracted with dichloromethane, washed with brine and dried with $\mathrm{Na}_{2} \mathrm{SO}_{4}$. The combined extracts were evaporated under vacuo to give the oily residue which was purified with preparative TLC (hexane/ethyl acetate $=5: 1$ ) to afford pure compound 1 as colorless solid $(2.6 \mathrm{mg}$, 37\%). Mp: 91-93 ${ }^{\circ} \mathrm{C}(\mathrm{MeOH}) .{ }^{1} \mathrm{H}$ NMR (400 MHz, $\left.\mathrm{CD}_{3} \mathrm{OD}\right): \delta 6.22(\mathrm{~d}, J=11.2 \mathrm{~Hz}, 1 \mathrm{H}$, 6-H), $6.02(\mathrm{~d}, J=11.2 \mathrm{~Hz}, 1 \mathrm{H}, 7-\mathrm{H}), 5.08-5.00(\mathrm{~s}, 1 \mathrm{H}, 19-\mathrm{H}), 4.74$ (d, $J=1.6 \mathrm{~Hz}, 1 \mathrm{H}$, 19-H), 3.76 (m, 1H, 3-H), 2.85 (dd, $J=11.9,4.0 \mathrm{~Hz}, 1 \mathrm{H}, 9-\mathrm{H}), 2.58-2.48$ (dd, 13.0, 4.2, $1 \mathrm{H}, 4-\mathrm{H}), 2.40(\mathrm{dt}, J=13.6,4.9 \mathrm{~Hz}, 1 \mathrm{H}, 1-\mathrm{H}), 2.25-1.91(\mathrm{~m}, 5 \mathrm{H}), 1.81-1.62(\mathrm{~m}, 5 \mathrm{H})$, $1.61-1.43(\mathrm{~m}, 6 \mathrm{H}), 1.43-1.09(\mathrm{~m}, 11 \mathrm{H}), 0.89$ (d, $J=6.6 \mathrm{~Hz}, 6 \mathrm{H}, 26 / 27-\mathrm{H}), 0.69$ (s, 3H, 18-H). ${ }^{13} \mathrm{C}$ NMR (101 MHz, CD 3 OD): $\delta 147.00$ (C10), 142.30 (C8), 137.34 (C5), 122.61 (C6), 119.37 (C7), 112.65 (C19), 75.99 (C20), 70.55 (C3), 59.89, 57.80, 47.02, 45.11, 42.25, 40.95, 36.60, 33.59, 29.84, 29.17, 26.15, 24.44, 23.16, 23.06, 23.02, 22.97, 14.14. ESI-HRMS: calculated for $\mathrm{C}_{27} \mathrm{H}_{44} \mathrm{O}_{2} \mathrm{Na}[\mathrm{M}+\mathrm{Na}]^{+}$423.3239, found 423.3235.

\section{Chemistry}

A retrosynthetic strategy was proposed as Scheme 6-1. The vitamin D3 scaffold could be established by Wittig-Horner coupling reaction between phosphine oxide 7 and C/D-ring fragment 16. Due to steric effect of 18-methyl, stereoselective generation of $20 S$-hydroxy of 16 could be achieved using Grignard reagent 13 to attack $\mathbf{1 2}$. In addition, introducing a relatively bulky protecting group on $8 S$-hydroxy was envisioned to assist the stereoselectivity of Grignard reaction. Conversion of VD2 to 7 and 12 could be 


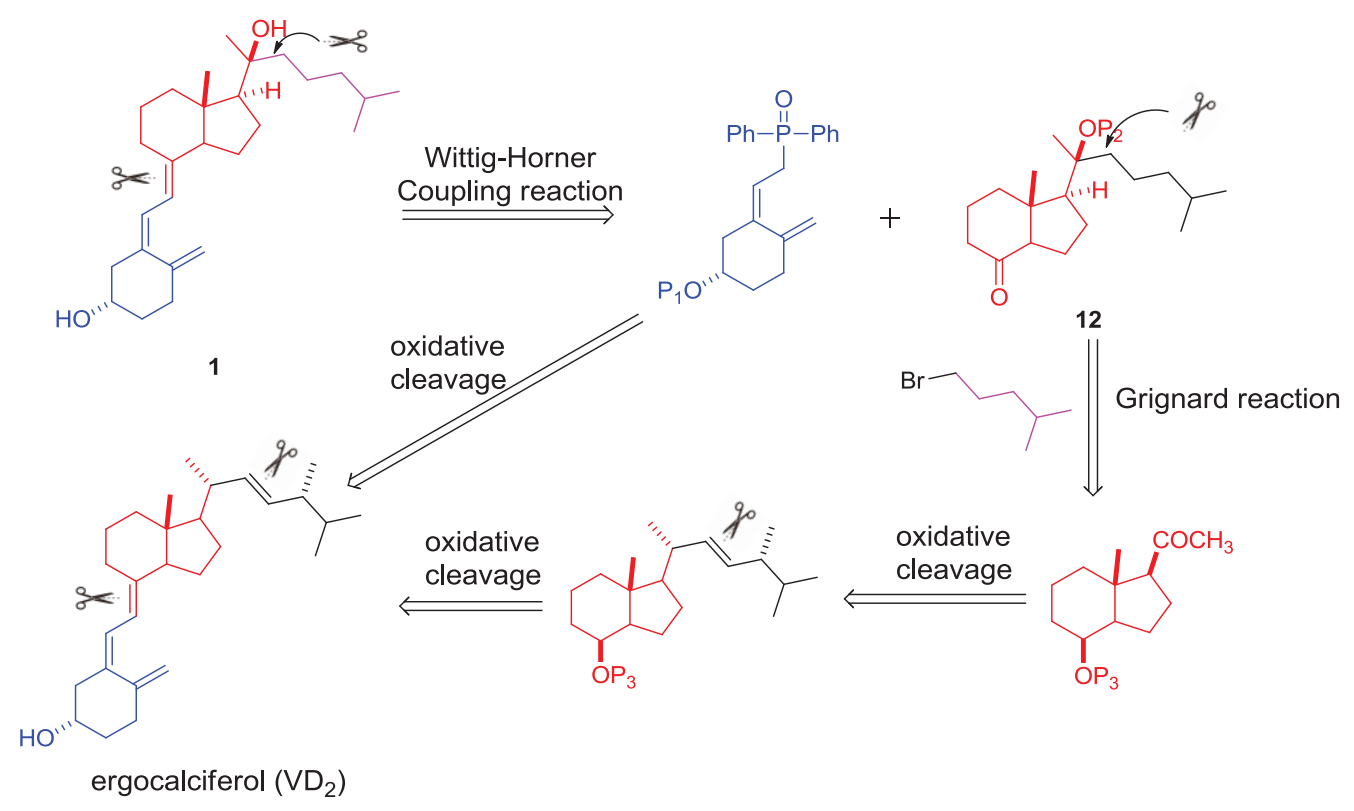

Scheme 6-1. Retrosynthetic analysis of 20S-(OH)D3 
carried out through oxidative cleavages.

The synthesis of phosphine oxide 7 and protected C/D-ring ketone 12 were performed following literature reports [241, 242]. To prepare 7 and $\mathbf{1 2}$ in large scale so as to facilitate future structure-activity relationship studies, we modified the synthesis which were outlined as Scheme 6-2 and Scheme 6-3. Initially, commercially available ergocalciferol was regioselectively dihydroxylated on the triene linkage to provide triol 2 with a yield of $65 \%$ when treating with potassium permanganate in ethanol at low temperature. Due to steric effect of 18-methyl, single $7 R, 8 R$-diostereoisomer was exclusively isolated over chromatography [241]. It is worth mentioning that when 3-OH was protected with TBS, dihydroxylation of the triene did not proceed. Subsequent treatment of vicinol 2 with lead tetraacetate in dichloromethane in the presence of sodium carbonate led to formation of corresponding C/D-ring ketone and A-ring allylic aldehyde. Although complete consumption of $\mathbf{2}$ was indicated on TLC, after workup procedures and purification using flash chromatography, A-ring allylic aldehyde ended up with poor yield $(<20 \%)$ while C/D-ring ketone was obtained in $94 \%$ yield. We found that A-ring allylic aldehyde was unstable when exposed to air and moisture as clearly indicated by its spot on TLC and it should be used immediately. Thus, after quenching the oxidation reaction with ethylene glycol followed by simple workup procedure the crude mixture was directly used without purification to the following reduction step using excess equivalent of sodium bisaluminumhydride (65\% in toluene) in benzene at $0{ }^{\circ} \mathrm{C}$.

Gratifyingly, these modified procedures afforded pure A-ring allylic alcohol 3 and C/Dring alcohol 4 with yield of $43 \%$ and $86 \%$ for two steps after chromatography, respectively. It is worth noting that after TLC indicated completion of the oxidation reaction, quenching the reaction by adding ethylene glycol was crucial to prevent further oxidation of the aldehyde to carboxylic acid. In addition, compared with lithium aluminum hydride (LAH) and diisobutylaluminium hydride (DIBAL-H in toluene or tetrahydrofuran), Red-Al ( $>65 \%$ in toluene) was more efficient and regioselective toreduce only aldehyde rather than conjugated diene to form $\mathbf{3}$. Compound $\mathbf{3}$ was subsequently protected with TBS to generate 5, which underwent selective removal of TBS on the allylic moiety to produce alcohol 6 in $71 \%$ yield for two steps when stirring with tetra-n-butylammonium fluoride (TBAF) in THF under low temperature $\left(-5^{\circ} \mathrm{C}\right.$ to ice temperature). The final A-ring intermediate phosphine oxide 7 was prepared following literature procedures in three steps with 59\% overall yield [242].

Acetate $\mathbf{8}$ was produced when secondary alcohol $\mathbf{4}$ was treated with acetic anhydride and pyridine. Compound $\mathbf{8}$ was subjected to Upjohn reaction stirring with osmium tetroxide $(0.5 \% \mathrm{wt}$ in $t$-butanol) and $N$-methylmorpholine $N$-oxide in acetone at ambient temperature for $48 \mathrm{hr}$ to form the major diastereoisomer 9 due to strong steric effect of 21- and 24-methyl groups. While TLC indicated existence of the other diastereomer as minor product, 9 was isolated in $67 \%$ yield. Cleavage of vicinol 9 in the presence of sodium periodate in $\mathrm{H}_{2} \mathrm{O}$-THF (1:4) provided aldehyde $\mathbf{1 0}$ in $66 \%$ yield. Aldehyde 10 was then refluxed in a Dean-Stark apparatus stirring with morpholine and catalytic amount of $p$-toluenesulfonic acid in benzene to form crude enamine $\mathbf{1 1}$ as, after dried on vacuum, slightly yellowish oil. Due to its instability and sensitivity to moisture, 


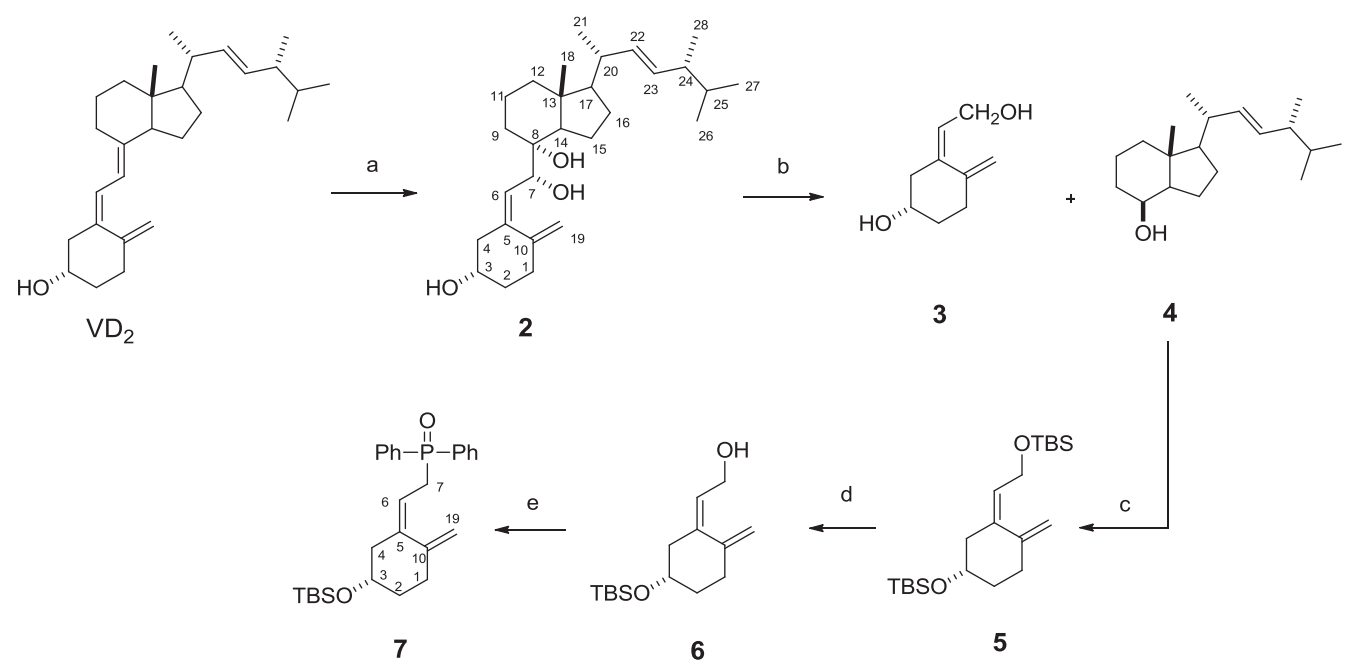

Scheme 6-2. Synthesis of intermediate 7

Reagents and conditions: (a): $\mathrm{KMnO}_{4}, \mathrm{EtOH}-\mathrm{H}_{2} \mathrm{O}$, rt; 65\%; (b): i. $\mathrm{Pb}(\mathrm{OAc})_{4}, \mathrm{Na}_{2} \mathrm{CO}_{3}$, $\mathrm{DCM}, 0^{\circ} \mathrm{C}$;ii. Red-Al, benzene, $0^{\circ} \mathrm{C}$ to $\mathrm{rt} ; 43 \%$ for 3 and $86 \%$ for 4 in two steps; (c):

TBSCl, Imidazole, DCM, rt; 88\%; (d): TBAF, THF, rt;78\%; (e): i. $n$-BuLi, $p$-TsCl, THF, $-78^{\circ} \mathrm{C}$; ii. $n$-BuLi, $\mathrm{Ph}_{2} \mathrm{PH}, \mathrm{THF},-78^{\circ} \mathrm{C}$; iii. $\mathrm{H}_{2} \mathrm{O}_{2}, \mathrm{H}_{2} \mathrm{O}, \mathrm{DCM}, \mathrm{rt} ; 59 \%$ in three steps. 

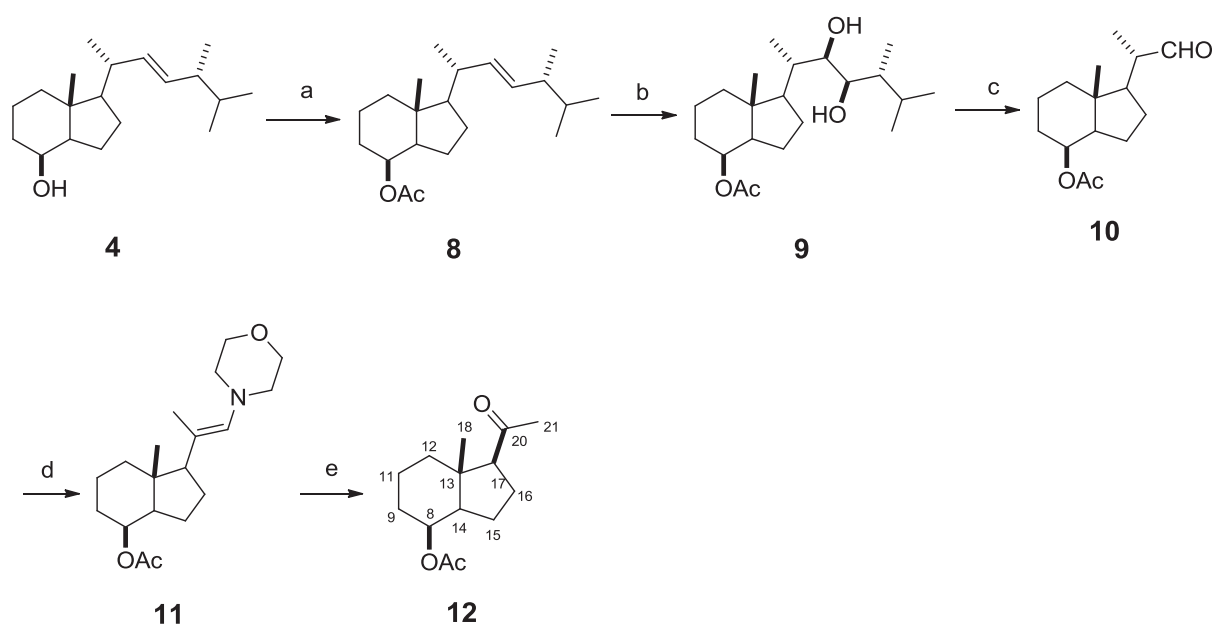

\section{Scheme 6-3. Synthesis of intermediate 12}

Reagents and conditions: (a): $\mathrm{Ac}_{2} \mathrm{O}, \mathrm{Pyr}, \mathrm{DMAP}, \mathrm{DCM}, \mathrm{rt} ; 92 \%$; (b): $\mathrm{OsO}_{4}, \mathrm{NMO}$, Acetone $/ t-\mathrm{BuOH}$, rt; 67\%; (c): $\mathrm{NaIO}_{4}, \mathrm{H}_{2} \mathrm{O}-\mathrm{THF}, 0^{\circ} \mathrm{C}$; 66\%; (d): Morpholine, $p$-TsOH, $\mathrm{PhH}$, reflux; (e): $\mathrm{KMnO}_{4} / \mathrm{Al}_{2} \mathrm{O}_{3}$, Acetone, rt; $70 \%$ in two steps. 
the crude enamine mixture was used for next step immediately without further purification. While the removal of C-22 on the chiron could be accomplished when treating 11 with singlet oxygen [242], this photo-oxygenation procedure was rather tedious. By referring to an alternative strategy [243], the yellowish oil was dissolved in acetone and treated with alumina supported potassium permanganate that was made prior to use, to provide the other key intermediate $\mathbf{1 2}$ in $70 \%$ for two steps after chromatography.

As shown in Scheme 6-4, Grignard reagent 13 was readily accessible by refluxing commercially available 1-bromo-4-methyl-pentane with magnesium in anhydrous THF. After 2 hours, 13 was immediately subjected to Grignard reaction to form the diol 14 with $80 \%$ yield. Similar to our previous studies [239], only the $20 S$-epimer was isolated over chromatography due to the steric effect of both 18-methyl and 8-acetyl. This stereospecificity is further supported by quantum mechanical calculations employing density functional theory (DFT) using Schrodinger Molecular Modeling Suite 2015. Figure 6-2 shows the thermodynamically most stable and the preferred orientation of the acetyl group for the intermediate 12. This conformational preference dictated the strongly favored back-side attack by the Grignard reagent 13 to form 14 with $20 \mathrm{~S}-\mathrm{OH}$ configuration. The attack from the front side to form $20 \mathrm{R}-\mathrm{OH}$ configuration is sterically prohibited, consistent with what we found previously [239, 244]. Oxidation of diol 14 using Cornforth reagent pyridinium dichloromate (PDC) gave 20S-hydroxy Grundmann `s ketone 15 in 89\% yield. Compound 15 was subsequently introduced protecting group EOM on its tertiary alcohol to form ketone 16, the other key intermediate for the final coupling step. With both $\mathrm{C} / \mathrm{D}$-ring fragment 16 and phosphine oxide $\mathbf{7}$ in hand, construction of the 20S-(OH)D3 framework was successfully accomplished by employing Wittig-Horner reaction in the presence of phenyllithium $(0.18 \mathrm{M}$, diluted from commercial source) in THF to form 17 in 52\% yield. Simultaneously removal of EOM and TBS was achieved using camphorsulfonic acid (CSA) to produce the target compound $20 S-(\mathrm{OH}) \mathrm{D} 3$ in $37 \%$ yield.

\section{Results}

Figure 6-3 showed the comparison of ${ }^{1} \mathrm{H}-\mathrm{NMR}$ of $20 \mathrm{~S}-(\mathrm{OH}) \mathrm{D} 3 \mathrm{~s}$ obtained from UVB irradiation and total synthesis. Clearly, smilar to the one that was generated via UVB irradiation, $20 S-(\mathrm{OH}) \mathrm{D} 3$ obtained from total synthesis showed a desirable purity.

\section{Discussion}

20S- $(\mathrm{OH}) \mathrm{D} 3$, a noncalcemic vitamin D3 analog, was enzymatically converted from vitamin D3 by P450scc and was first chemically synthesized via UVB irradiation [239]. However, this photochemical method also produces structurally similar and physicochemically active by-products that present a significant challenge for purification and further SAR studies for the promising 20S-hydroxyl scaffold. To overcome the 

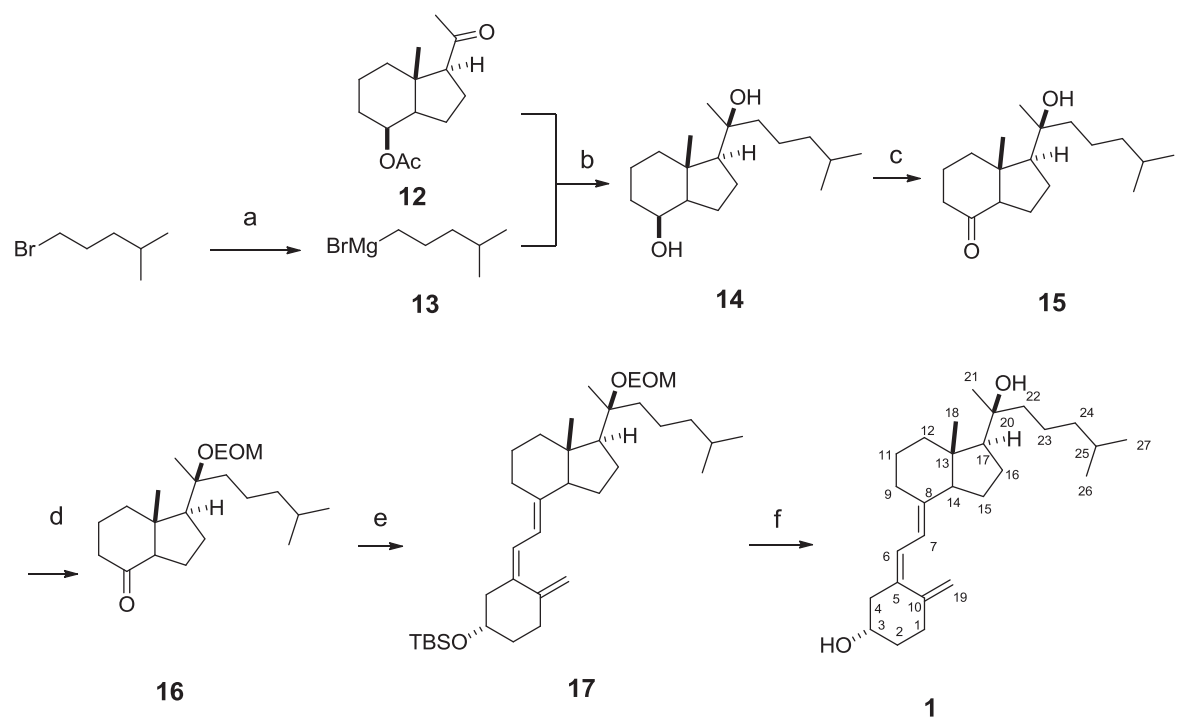

Scheme 6-4. Synthesis of 20S-(OH)D3

Reagents and conditions: (a): Mg. THF, reflux; (b): THF, reflux; 80\% (c): PDC, DCM, rt; 89\%; (d): EOMCl, DMAP, TEA, DCM, rt; 90\%; (e): 7, PhLi, THF, $-78^{\circ} \mathrm{C}$ to rt; $52 \%$; (f): CSA, DCM-MeOH, rt; 37\%.

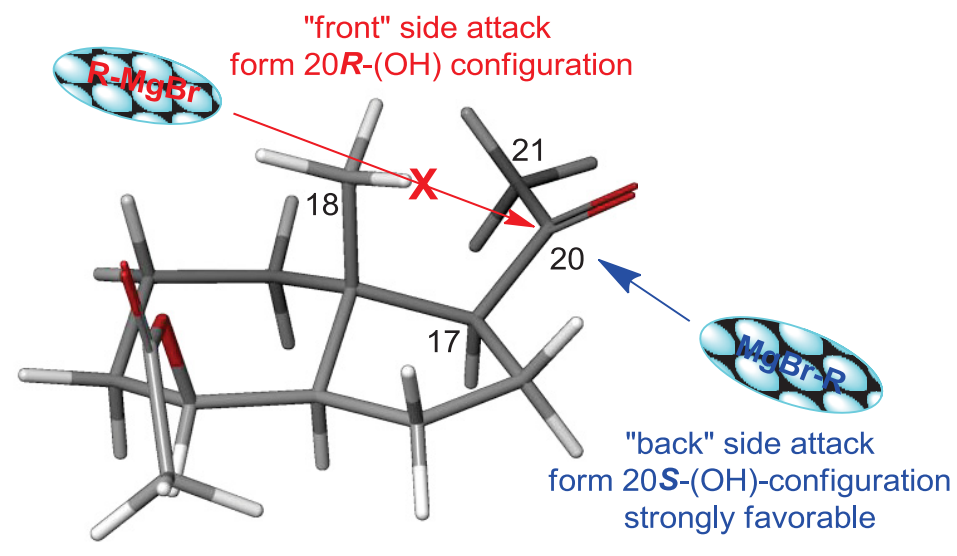

Intermediate 12

Figure 6-2. Preferred conformation of the intermediate (compound 12) calculated with density function theory with $6-31 G * *$ baseset

"Front" side attack by the bulky Grignard agent $\mathbf{1 3}$ to form $20 R$ isomer of $\mathbf{1 4}$ is prohibited due to the steric hindrance from the 18-methyl and other moieties in compound 12, while the "back" side attack to form $20 S$ isomer is strongly favored. 


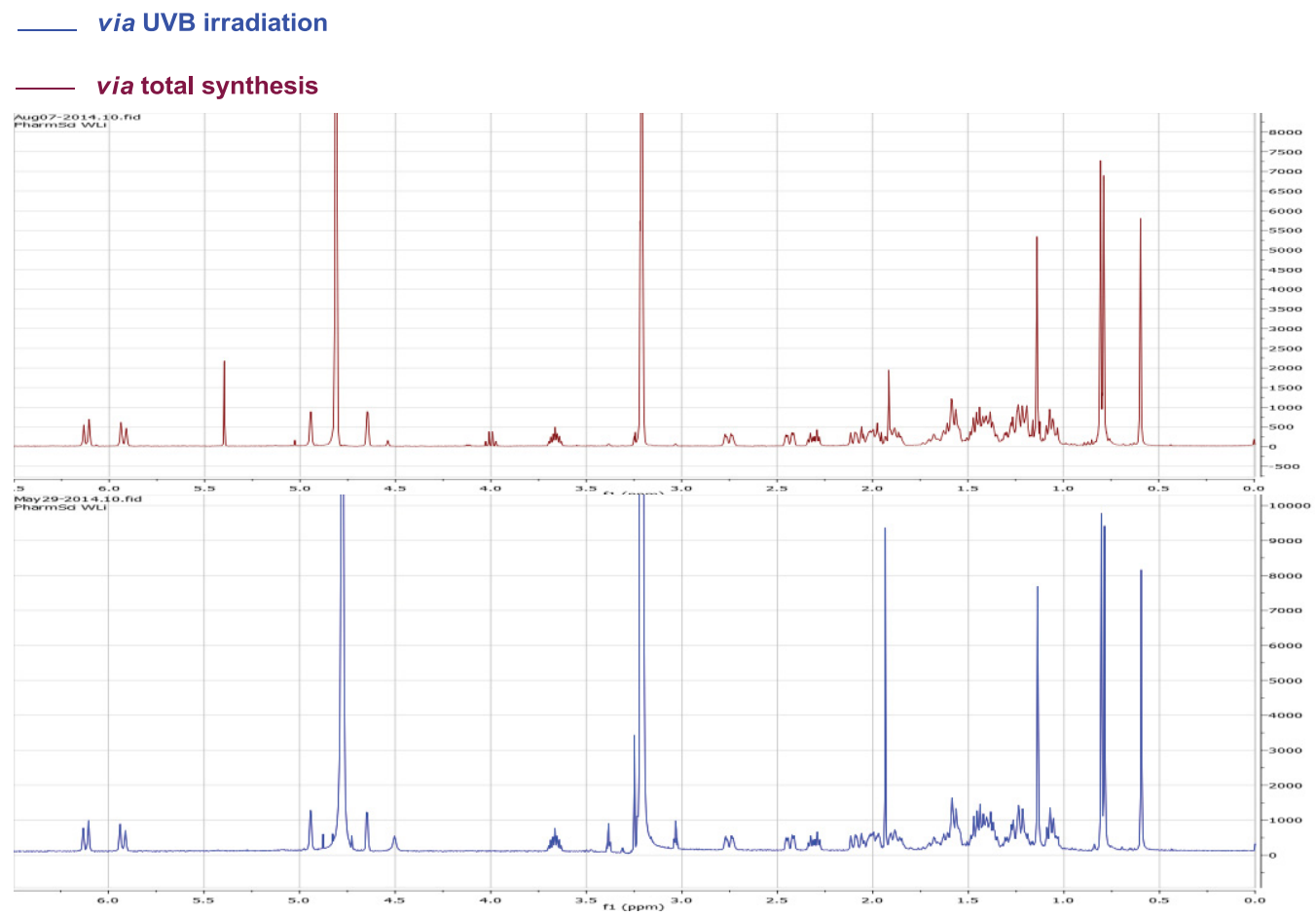

Figure 6-3. $\quad{ }^{1} \mathrm{H}-\mathrm{NMR}$ comparison of $20 \mathrm{~S}-(\mathrm{OH}) \mathrm{D3}$ obtained via UVB irradiation and total synthesis 
deficiencies in current synthesis an alternative synthetic method was developed. The total synthetic strategy described in this report involves Wittig-Horner coupling and Grignard reaction and is successful in generating $20 S-(\mathrm{OH}) \mathrm{D} 3$ in $0.4 \%$ overall yield in 16 steps. A distinct advantage of this method over our previously reported method is that after we generate the two key intermediates phosphine oxide 7 and C/D-ring ketone $\mathbf{1 2}$ on gram scale from a common starting material vitamin D2, we can efficiently make side chain derivatives for in-depth SAR studies of this 20S-hydroxyl scaffold. 


\section{CHAPTER 7. SUMMARY AND FUTURE DIRECTION}

Cancer poses a tremendous challenge for public health in the $21^{\text {st }}$ century. According to the statistics from the American Cancer Society, 1,688,780 new cases and 600,920 deaths are estimated to result from cancers in 2017. Melanoma is the least common but is the most lethal form of all skin cancers. About $80 \%$ deaths of patients with skin cancers are attributed to melanoma. Melanoma can spread to nearby lymph nodes and distant organ to eventually form advanced or metastatic melanoma. The overall 5-year survival rate for patients with advanced melanoma is as low as $5 \%$. Encouragingly, targeted therapy and immunotherapy have achieved sensational success in the 2000s. Many BRAF inhibitors, MEK1/2 inhibitors, and immune checkpoint inhibitors have been approved by the FDA, vemurafenib, dabrafenib, trametinib, cobimetinib, nivolumab, pembrolizumab, lpilimumab, for instance. These drugs are more effective to treat advanced melanoma than traditional chemotherapy (e.g., dacarbazine and temozolomide).

There are however problems within both targeted therapy and immune checkpoint inhibitors. For targeted therapy, patients are found to acquire drug-resistance after 6month treatment with BRAF inhibitors vemurafenib or dabrafenib; the acquired resistance can markedly result in the resumption of tumor progression. Melanoma cancer cells develop drug-resistance to targeted therapy through many mechanisms; these mechanisms include but are not limited to: reactivation of the MAPK pathway by activating mutation of the downstream or upstream of BRAF; elevation of other RAF subtypes; BRAF amplification; ERK1/2 mutation; RTK upregulation; and PI3K pathway gene mutation. For immunotherapy, irAEs are significant problems. IrAEs if not treated in time, can be fatal.

Anticancer agents can be obtained from a natural source or through a medicinal chemistry program. Many of these agents are demonstrated to exhibit significant antitumor effects in preclinical and clinical trials, however, only a small portion of these agents are ultimately approved by the FDA for clinical cancer treatment. This is because that a large portion of antitumor agents are non-specific to tumor cells and can result in systemic toxicities to healthy cells. In the last decade, ADC is one of the most dynamic fields in drug discovery. ADC resorts to its antibody to selectively deliver cytotoxin to the target disease tissues or tumor cells. This can not only minimize the exposure of cytotoxins to healthy tissues but also maximize the concentration of cytotoxins to reach the tumors. Compared to cytotoxin alone, ADC generally has a broader therapeutic window.

ADC is composed of a potent cytotoxic chemical, a linker and an antibody. The roles of each portion of ADC are summarized well in excellent reviews published recently [166-168]. In general, all the three portions in ADC and the antigen localizing on the surface of tumor cell are vital for a successful ADC. The antigen should be highly expressed in the tumor instead of in the healthy tissue. This is because, on one hand, expression of antigen in the normal tissue can induce the ADC to move toward normal 
cells and thereafter result in off-target toxicity; on the other hand, expression of antigen in the healthy tissue will reduce the availability of ADC to the tumor and lead to reduced antitumor effect [245]. In addition to the specificity in tumor, the antigen should have the ability to internalize the ADC upon its binding to the antibody; an inability of the antigen to recycle ADC to extracellular environment is also desirable in order to maintain the concentration of the free cytotoxic chemical in the cytoplasm of tumor cell. In ADC, the antibody is also critical. A favorable antibody should show not only high specificity and affinity to the antigen on the surface of tumor cell but also pharmacokinetic stability in circulating blood [246]. A stable antibody can increase the level of ADC to reach the antigen. Similarly, a stable linker in circulating blood also increases the opportunity for the ADC to bind to the antigen. Currently, linkers in ADCs can be divided into two groups: cleavable linkers (e.g., acid-labile linkers, protease cleavable linkers, and disulfide linkers) and non-cleavable linkers. The cleavable linkers are not only required to be stable in circulating blood but also should allow rapid release of cytotoxic chemical upon internalization to the cytoplasm of tumor cells [247, 248]. Cytotoxic chemical in ADC is named payload or warhead. A successful ADC highly depends on the payload. An ideal payload should have functional group(s) to conjugate to the linker; the new bond formed after conjugation should be stable in circulating blood. In addition to the conjugable site(s), the payload is strictly required to have significant potency $\left(\mathrm{IC}_{50}\right.$ in sub-nanomolar range) [249].

The FDA has approved two ADCs for clinical uses. Brentuximab vedotinin is approved in 2011 for the treatment of Hodgkin lymphoma and systemic anaplastic large cell lymphoma; trastuzumab emtansine is approved in 2013 for the treatment of HER2 positive breast cancer. There are approximately sixty ADCs in different stages of clinical trials currently. The payloads applied to the construction of ADCs are limited to mainly two categories: DNA-damaging agents and microtubule inhibitors. The challenges to broaden the pool of amenable payloads for ADCs development lie in: (1) the payload should be linkable; (2) the payload should be hydrophilic enough to prevent the antibody from aggregating; (3) the payload should overcome major drug-resistance mechanisms to prolong the therapeutic effect of ADC. Therefore, identification of payload with properties mentioned above is of importance.

$\mathrm{ABI}-231$ is an anti-tubulin having potent antiproliferative activity (average $\mathrm{IC}_{50}=$ $5.2 \mathrm{nM}$ ) against a panel of cancer cell lines. ABI-231 binds to the colchicine binding site in tubulin and inhibits the tubulin polymerization. Importantly, ABI-231 can effectively overcome P-gp mediated drug-resistance and inhibit expression of tubulin $\beta$-III isotype. Its in-depth SAR study was however obstructed for many years due to an inefficient synthesis $(0.28 \%$ over five steps $)$.

In Chapter 2, we have established a novel synthetic method, which is amenable to SAR investigation and gram-scale synthesis of ABI-231. The synthetic strategy involves the synthesis of a diamine intermediate and imidazoline cyclization. Among the thirty new ABI-231 analogues, 4-methyl-3-indole and 4-indole analogues are the most potent and have average $\mathrm{IC}_{50} \mathrm{~S}$ of 2.2 and $3.0 \mathrm{nM}$, respectively. The co-crystal structure of 4methyl-3-indole analogue in complex with tubulin reveals the existence of three H-bond 
interactions between the ligand and receptor. In vivo efficacy evaluations of the most potent analogues in a subcutaneous mouse xenograft model with human A375 melanoma and an experimental lung metastasis model with B16F10 mouse melanoma are currently undergoing.

In a consecutive SAR study of ABI-231 as reported in Chapter 3, we modify the 3,4,5-TMP moiety in ABI-231. 3,4,5-TMP is one of the most common moieties in current tubulin inhibitors targeting the colchicine binding site. To the best of our knowledge, most structural modifications of CA-4 and its derivatives focus on either the double bond linkage or the 3-hydroxy-4-methoxy benzene moiety; rare modifications on the 3,4,5TMP moiety is reported. In Chapter 3 , we have established a concise synthetic method to overcome the limitation of a potentially explosive diazide intermediate. This novel method involves a Suzuki coupling and Grignard reaction strategy. Eight new ABI-231 analogues modifying the 3,4,5-TMP moiety are synthesized. Among these analogues, 3methoxy-benzo[4,5]-dioxene analogue exhibits the most potent activity (average $\mathrm{IC}_{50}=$ $1.9 \mathrm{nM}$ ); 3-methoxy-benzo[4,5]-dioxole analogue shows equipotent activity (average $\mathrm{IC}_{50}=4.9 \mathrm{nM}$ ) to ABI-231. To our best knowledge, 3-methoxy-benzo[4,5]-dioxene analogue represents the most successful instance modifying the 3,4,5-TMP moiety in CA-4 and its derivatives isosterically. Currently, mechanistic study and in vivo efficacy evaluation of these novel ABI-231 analogues are under investigation.

During our exploration of gram-scale synthesis of ABI-231 analogues, a reaction that can generate a substructure of RABI scaffold in $24 \%$ yield is observed. Based on this observation, a concise synthetic method involving a strategy of Grignard reaction/Suzuki coupling reaction is established to access twelve novel RABI analogues in Chapter 4. Among the twelve analogues, 4-indole RABI analogue (average $\mathrm{IC}_{50}=3.5 \mathrm{nM}$ ) exhibits significantly more potent activity than that of MX-RABI; the strongest antiproliferative activity is observed in the 4-indazole RABI analogue, which has an average $\mathrm{IC}_{50}$ of 0.8 $\mathrm{nM}$. The 4-indazole RABI analogue is the first CBSI showing sub-nanomolar range activity in the related scaffolds. Effort on investigating the mechanism of action and cocrystal structures in complex with tubulin protein for the potent 4-indazole RABI analogues is currently undergoing.

In Chapter 5, the SAR study of UC-112 is conducted by modifying the benzyloxy moiety. Thirty-six UC-112 analogues are synthesized. Several of the substituted indole analogues exhibit equipotency to that of UC-112 and MX-106. The novel indole analogues display significant abilities to overcome multidrug-resistance mediated by $\mathrm{P}$ gp overexpression. In the future study, obtaining a co-crystal structure of one the indole analogues in complex with survivin protein is warranted to confirm the therapeutic target.

In Chapter 6, we have established an efficient total synthesis of biologically active $20 S-(\mathrm{OH}) \mathrm{D} 3$. This method involves divergent generation of key intermediates from a common starting material VD2, stereoselective formation of the $20 S$-hydroxyl scaffold through Grignard reaction, as well as Wittig-Horner coupling to construct VD3 core structure. This synthetic strategy provides an alternative for the synthesis of $20 S-(\mathrm{OH}) \mathrm{D} 3$ analogs rather than through UVB irradiations [250-253]. 
In Chapter 2-4, we have modified the indole and 3,4,5-TMP in ABI-231. We have discovered several novel ABI-231 analogues showing more potent activities than the prototype ABI-231. For future structural modification of the ABI-231 scaffold, it can commence with the imidazole moiety in ABI-231. The co-crystal structure of 4-methyl-3indole analogue in complex with tubulin suggests the existence of a $\alpha$-ASN101 residue nearby the imidazole moiety. By introducing functional groups such as amine, amide or heterocycles to the imidazole in ABI-231, it is potential to observe new H-bond interactions between these functional groups with $\alpha$-Asn 101 residue. Based on this hypothesis, two ABI-231 analogues with modifications of the imidazole moiety are proposed in Figure 7-1. A molecular modeling study of the proposed analogues has been performed on the platform Schrodinger 2015 molecular modeling suite (Schrodinger, Inc., New York, NY) using the co-crystal structure of 4-methyl-3-indole analogue in tubulin. The docking result is shown in Figure 7-1. 4-methyl-3-indole analogue shows a perfect conformational overlap with the original crystal structure and has a docking score of 12.0. The proposed analogues fit the pocket in a similar manner to that of 4-methyl-3indole analogue. Except the H-bond interactions between the imidazole $\mathrm{NH}$ and carbonyl with nearby residues $\alpha$-Thr 179 and $\beta$-Asp 249 , the modeling result also reveals the existence of extra $\mathrm{H}$-bond interactions between the newly introdueced amino functional group on imidazole with nearby $\alpha$-Asn 101 and $\alpha$-Thr 179 residues. Both proposed analogues have similar docking scores to that of 4-methyl-3-indole analogue.

One of the proposed analogues has been synthesized by following Scheme 7-1 and its in vitro antiproliferative activity is tested. As shown in Table 7-1, the amino analogue $\mathbf{5}$ is equipotent to colchicine while two intermediates $\mathbf{3}$ and $\mathbf{4}$ exhibit slightly decreased activities. This suggests that the 4-position on the imidazole is tolerable for modification. Future structural optimization can commence with relatively larger functional groups such as amide or imidazole ring because the molecular modeling result indicates the pocket in the vicinity of imidazole is broad enough to accommodate bulkier groups.

Besides modification of the ABI-231 scaffold, RABI scaffold is also worthy investigating. An in-depth structural optimization of the most potent RABI analogue (15i, in Chapter 4) may provide a good chance to generate analogues having $\mathrm{IC}_{50} \mathrm{~s}$ within picomolar range. Obtaining the co-crystal structure of $\mathbf{1 5 i}$ in complex with tubulin is therefore important and helpful for designing new generations of tubulin inhibitors. 

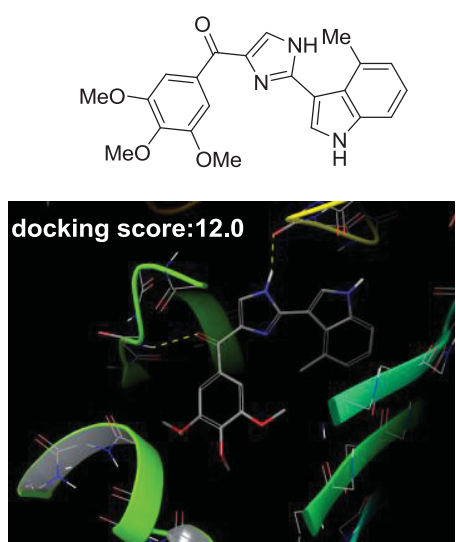

A
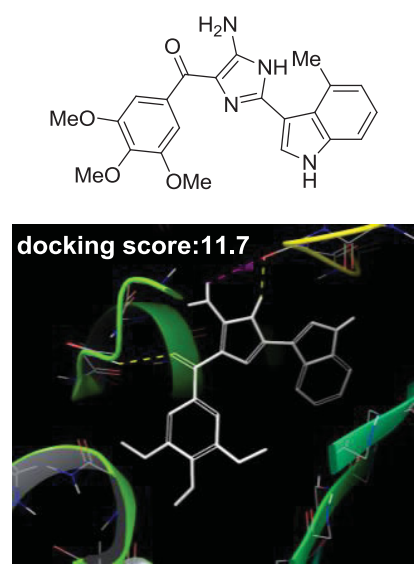

B
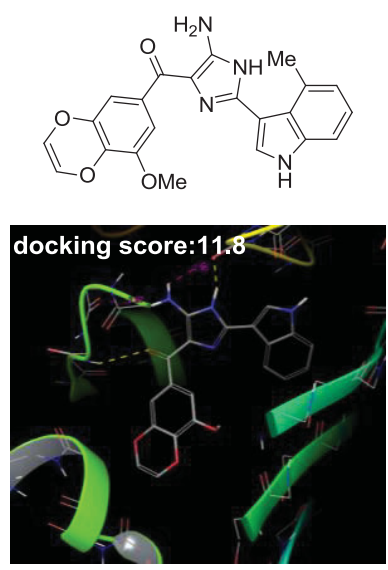

C

Figure 7-1. Docking study of proposed ABI-231 analogues in co-crystal structure of 4-methyl-3-indole analogue in complex with tubulin
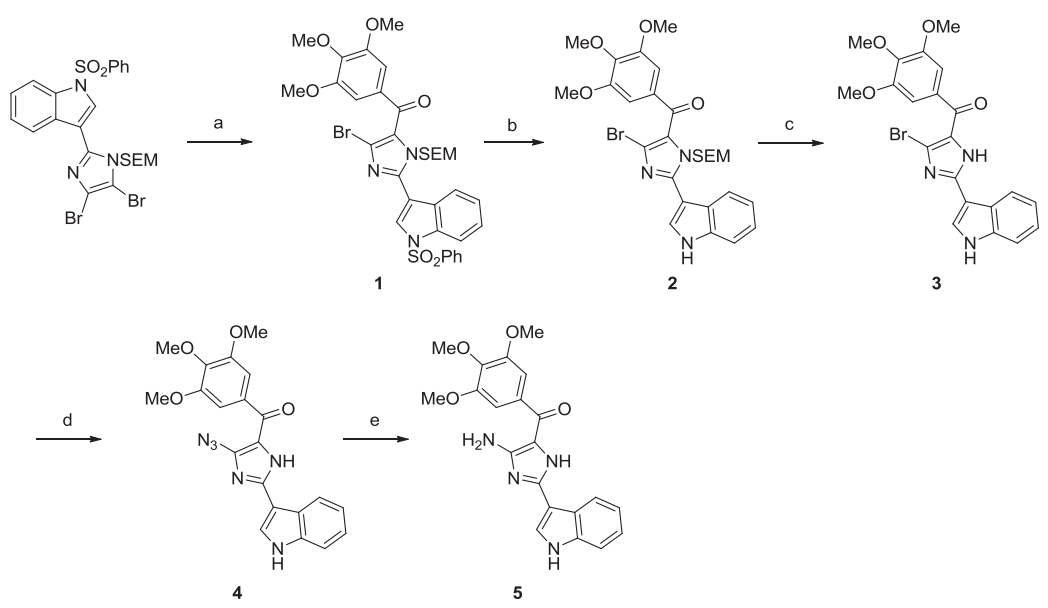

Scheme 7-1. Synthesis of proposed ABI-231 analogue 5

Reagents and conditions: (a): 3,4,5-trimethoxybenzoyl chloride, $i$ - $\mathrm{PrMgCl}(\mathrm{LiCl}), \mathrm{THF}, \mathrm{rt}$; (b): $\mathrm{NaOH}\left(40 \%\right.$ in $\left.\mathrm{H}_{2} \mathrm{O}\right), \mathrm{MeOH}$, reflux; (c): TFA, DCM; (d): $\mathrm{NaN}_{3}, \mathrm{DMSO}$, reflux; (e): $\mathrm{H}_{2}, \mathrm{Pd} / \mathrm{C}, \mathrm{EtOAc}-\mathrm{MeOH}, \mathrm{rt}(1: 1)$. 
Table 7-1. In vitro growth inhibitory effect of proposed analogue and its intermediates

\begin{tabular}{cccc}
\hline Compound & A375 & M14 & RPMI7951 \\
\hline $\mathbf{3}$ & $18.9 \pm 1.1$ & $16.4 \pm 0.9$ & $21.5 \pm 1.3$ \\
$\mathbf{4}$ & $17.1 \pm 1.4$ & $18.6 \pm 1.0$ & $27.0 \pm 1.1$ \\
$\mathbf{5}$ & $12.7 \pm 0.9$ & $11.9 \pm 1.4$ & $17.2 \pm 2.0$ \\
Colchicine & $14.5 \pm 0.7$ & $14.2 \pm 1.0$ & $10.5 \pm 0.8$ \\
\hline
\end{tabular}




\section{LIST OF REFERENCES}

1. Siegel RL, Miller KD, Jemal A: Cancer Statistics, 2017. Ca-Cancer J Clin 2017, 67(1):7-30.

2. Schachter J, Laish A, Mekhmandarov S, Feinmesser M, Fenig E, Tamir G, Gutman H: Standard and nonstandard applications of sentinel node-guided melanoma surgery. World J Surg 2000, 24(4):491-495.

3. Sandru A, Voinea S, Panaitescu E, Blidaru A: Survival rates of patients with metastatic malignant melanoma. Journal of medicine and life 2014, 7(4):572576.

4. Nikolaou VA, Stratigos AJ, Flaherty KT, Tsao H: Melanoma: New Insights and New Therapies. J Invest Dermatol 2012, 132(3):854-863.

5. McCubrey JA, Steelman LS, Chappell WH, Abrams SL, Wong EWT, Chang F, Lehmann B, Terrian DM, Milella M, Tafuri A et al: Roles of the Raf/MEK/ERK pathway in cell growth, malignant transformation and drug resistance. $B b a$ Mol Cell Res 2007, 1773(8):1263-1284.

6. $\quad$ Liang H, Liu T, Chen FJ, Liu ZQ, Liu SJ: A full-length 3D structure for MAPK/ERK kinase 2 (MEK2). Sci China Life Sci 2011, 54(4):336-341.

7. Sacks DB: The role of scaffold proteins in MEK/ERK signalling. Biochem Soc T 2006, 34:833-836.

8. Akinleye A, Furqan M, Mukhi N, Ravella P, Liu DL: MEK and the inhibitors: from bench to bedside. J Hematol Oncol 2013, 6.

9. Strickland LR, Pal HC, Elmets CA, Afaq F: Targeting drivers of melanoma with synthetic small molecules and phytochemicals. Cancer Lett 2015, 359(1):20-35.

10. Davies MA: The Role of the PI3K-AKT Pathway in Melanoma. Cancer $J$ 2012, 18(2):142-147.

11. Manning BD, Cantley LC: AKT/PKB signaling: Navigating downstream. Cell 2007, 129(7):1261-1274.

12. Slipicevic A, Holm R, Nguyen MTP, Bohler PJ, Davidson B, Florenes VA: Expression of activated Akt and PTEN in malignant melanomas Relationship with clinical outcome. Am J Clin Pathol 2005, 124(4):528-536.

13. Karbowniczek M, Spittle CS, Morrison T, Wu H, Henske EP: MTOR is activated in the majority of malignant melanomas. J Invest Dermatol 2008, 128(4):980-987.

14. Roskoski R: RAF protein-serine/threonine kinases: Structure and regulation. Biochem Bioph Res Co 2010, 399(3):313-317.

15. Davies H, Bignell GR, Cox C, Stephens P, Edkins S, Clegg S, Teague J, Woffendin H, Garnett MJ, Bottomley W et al: Mutations of the BRAF gene in human cancer. Nature 2002, 417(6892):949-954.

16. Karasarides M, Chiloeches A, Hayward R, Niculescu-Duvaz D, Scanlon I, Friedlos F, Ogilvie L, Hedley D, Martin J, Marshall CJ et al: B-RAF is a therapeutic target in melanoma. Oncogene 2004, 23(37):6292-6298. 
17. Hoeflich MP, Gray DC, Eby MT, Tien JY, Wong L, Bower J, Gogineni A, Zha $\mathrm{ZP}$, Cole MJ, Stern HM et al: Oncogenic BRAF is required for tumor growth and maintenance in melanoma models. Cancer research 2006, 66(2):999-1006.

18. Eggermont AMM, Spatz A, Robert C: Cutaneous melanoma. Lancet 2014, 383(9919):816-827.

19. Tsai J, Lee JT, Wang W, Zhang J, Cho H, Mamo S, Bremer R, Gillette S, Kong J, Haass NK et al: Discovery of a selective inhibitor of oncogenic B-Raf kinase with potent antimelanoma activity. P Natl Acad Sci USA 2008, 105(8):30413046.

20. Beck D, Niessner H, Smalley KSM, Flaherty K, Paraiso KHT, Busch C, Sinnberg T, Vasseur S, Iovanna JL, Driessen S et al: Vemurafenib Potently Induces Endoplasmic Reticulum Stress-Mediated Apoptosis in BRAFV600E Melanoma Cells. Sci Signal 2013, 6(260).

21. Trunzer K, Pavlick AC, Schuchter L, Gonzalez R, McArthur GA, Hutson TE, Moschos SJ, Flaherty KT, Kim KB, Weber JS et al: Pharmacodynamic Effects and Mechanisms of Resistance to Vemurafenib in Patients With Metastatic Melanoma. J Clin Oncol 2013, 31(14):1767-+.

22. Hallmeyer S, Hamid O, Sorof TA, Mun Y, Liu SY, Abhyankar S, Gibney GT, Puzanov I: Phase II study of vemurafenib in patients with locally advanced, unresectable stage IIIc or metastatic melanoma and activating exon 15 BRAF mutations other than V600E. J Clin Oncol 2014, 32(15).

23. Schilling B, Sondermann W, Zhao F, Griewank KG, Livingstone E, Sucker A, Zelba H, Weide B, Trefzer U, Wilhelm T et al: Differential influence of vemurafenib and dabrafenib on patients' lymphocytes despite similar clinical efficacy in melanoma. Ann Oncol 2014, 25(3):747-753.

24. Roskoski R, Jr.: MEK1/2 dual-specificity protein kinases: structure and regulation. Biochem Biophys Res Commun 2012, 417(1):5-10.

25. Wu XY, Noh SJ, Zhou GC, Dixon JE, Guan KL: Selective activation of MEK1 but not MEK2 by A-Raf from epidermal growth factor-stimulated Hela cells. The Journal of biological chemistry 1996, 271(6):3265-3271.

26. Marais R, Light Y, Paterson HF, Mason CS, Marshall CJ: Differential regulation of Raf-1, A-Raf, and B-Raf by oncogenic ras and tyrosine kinases. The Journal of biological chemistry 1997, 272(7):4378-4383.

27. Neuzillet C, Tijeras-Raballand A, de Mestier L, Cros J, Faivre S, Raymond E: MEK in cancer and cancer therapy. Pharmacol Therapeut 2014, 141(2):160171.

28. Falchook GS, Lewis KD, Infante JR, Gordon MS, Vogelzang NJ, DeMarini DJ, Sun P, Moy C, Szabo SA, Roadcap LT et al: Activity of the oral MEK inhibitor trametinib in patients with advanced melanoma: a phase 1 dose-escalation trial. Lancet Oncol 2012, 13(8):782-789.

29. Kim KB, Kefford R, Pavlick AC, Infante JR, Ribas A, Sosman JA, Fecher LA, Millward M, McArthur GA, Hwu P et al: Phase II Study of the MEK1/MEK2 Inhibitor Trametinib in Patients With Metastatic BRAF-Mutant Cutaneous Melanoma Previously Treated With or Without a BRAF Inhibitor. J Clin Oncol 2013, 31(4):482-489. 
30. Azijli K, Stelloo E, Peters GJ, Van den Eertwegh AJM: New Developments in the Treatment of Metastatic Melanoma: Immune Checkpoint Inhibitors and Targeted Therapies. Anticancer research 2014, 34(4):1493-1505.

31. Flaherty KT, Robert C, Hersey P, Nathan P, Garbe C, Milhem M, Demidov LV, Hassel JC, Rutkowski P, Mohr P et al: Improved Survival with MEK Inhibition in BRAF-Mutated Melanoma. New Engl J Med 2012, 367(2):107114.

32. Signorelli J, Gandhi AS: Cobimetinib: A Novel MEK Inhibitor for Metastatic Melanoma. Ann Pharmacother 2017, 51(2):146-153.

33. Adjei AA, Cohen RB, Franklin W, Morris C, Wilson D, Molina JR, Hanson LJ, Gore L, Chow L, Leong S et al: Phase I pharmacokinetic and pharmacodynamic study of the oral, small-molecule mitogen-activated protein kinase kinase 1/2 inhibitor AZD6244 (ARRY-142886) in patients with advanced cancers. $J$ Clin Oncol 2008, 26(13):2139-2146.

34. Yeh TC, Marsh V, Bernat BA, Ballard J, Colwell H, Evans RJ, Parry J, Smith D, Brandhuber BJ, Gross S et al: Biological characterization of ARRY-142886 (AZD6244), a potent, highly selective mitogen-activated protein kinase kinase 1/2 inhibitor. Clin Cancer Res 2007, 13(5):1576-1583.

35. Friday BB, Yu CR, Dy GK, Smith PD, Wang L, Thibodeau SN, Adjei AA: BRAF V600E disrupts AZD6244-Induced abrogation of negative feedback pathways between extracellular signal-regulated kinase and Raf proteins. Cancer research 2008, 68(15):6145-6153.

36. Kirkwood JM, Bastholt L, Robert C, Sosman J, Larkin J, Hersey P, Middleton M, Cantarini M, Zazulina V, Kemsley K et al: Phase II, Open-Label, Randomized Trial of the MEK1/2 Inhibitor Selumetinib as Monotherapy versus Temozolomide in Patients with Advanced Melanoma. Clin Cancer Res 2012, 18(2):555-567.

37. Beadling C, Jacobson-Dunlop E, Hodi FS, Le C, Warrick A, Patterson J, Town A, Harlow A, Cruz F, Azar S et al: KIT Gene Mutations and Copy Number in Melanoma Subtypes. Clin Cancer Res 2008, 14(21):6821-6828.

38. Todd JR, Scurr LL, Becker TM, Kefford RF, Rizos H: The MAPK pathway functions as a redundant survival signal that reinforces the PI3K cascade in c-Kit mutant melanoma. Oncogene 2014, 33(2):236-245.

39. Guo J, Si L, Kong Y, Flaherty KT, Xu XW, Zhu YY, Corless CL, Li L, Li HF, Sheng XN et al: Phase II, Open-Label, Single-Arm Trial of Imatinib Mesylate in Patients With Metastatic Melanoma Harboring c-Kit Mutation or Amplification. J Clin Oncol 2011, 29(21):2904-2909.

40. Hodi FS, Corless CL, Giobbie-Hurder A, Fletcher JA, Zhu MJ, Marino-Enriquez A, Friedlander P, Gonzalez R, Weber JS, Gajewski TF et al: Imatinib for Melanomas Harboring Mutationally Activated or Amplified KIT Arising on Mucosal, Acral, and Chronically Sun-Damaged Skin. J Clin Oncol 2013, 31(26):3182-+.

41. Cho JH, Kim KM, Kwon M, Kim JH, Lee J: Nilotinib in patients with metastatic melanoma harboring KIT gene aberration. Invest New Drug 2012, 30(5):2008-2014. 
42. Lebbe C, Chevret S, Jouary T, Dalac S, Dalle S, Guillot B, Arnault JP, Avril MF, Bedane $\mathrm{C}$, Bens $\mathrm{G}$ et al: Phase II multicentric uncontrolled national trial assessing the efficacy of nilotinib in the treatment of advanced melanomas with c-KIT mutation or amplification. J Clin Oncol 2014, 32(15).

43. Drake CG, Jaffee E, Pardoll DM: Mechanisms of immune evasion by tumors. Adv Immunol 2006, 90:51-81.

44. Eggermont AM, Chiarion-Sileni V, Grob JJ, Dummer R, Wolchok JD, Schmidt $\mathrm{H}$, Hamid O, Robert C, Ascierto PA, Richards JM et al: Ipilimumab versus placebo after complete resection of stage III melanoma: Initial efficacy and safety results from the EORTC 18071 phase III trial. J Clin Oncol 2014, 32(18).

45. Hodi FS: Improved Survival with Ipilimumab in Patients with Metastatic Melanoma (vol 363, pg 711, 2010). New Engl J Med 2010, 363(13):1290-1290.

46. De Sousa SMC, Long GV, Tonks KT: Ipilimumab-induced hypophysitis: early Australian experience. Med J Australia 2014, 201(4):198-199.

47. Camacho LH, Antonia S, Sosman J, Kirkwood JM, Gajewski TF, Redman B, Pavlov D, Bulanhagui C, Bozon VA, Gomez-Navarro J et al: Phase I/II Trial of Tremelimumab in Patients With Metastatic Melanoma. J Clin Oncol 2009, 27(7):1075-1081.

48. Ribas A, Kefford R, Marshall MA, Punt CJA, Haanen JB, Marmol M, Garbe C, Gogas H, Schachter J, Linette G et al: Phase III Randomized Clinical Trial Comparing Tremelimumab With Standard-of-Care Chemotherapy in Patients With Advanced Melanoma. J Clin Oncol 2013, 31(5):616-622.

49. Weber JS, D'Angelo SP, Minor D, Hodi FS, Gutzmer R, Neyns B, Hoeller C, Khushalani NI, Miller WH, Lao CD et al: Nivolumab versus chemotherapy in patients with advanced melanoma who progressed after anti-CTLA-4 treatment (CheckMate 037): a randomised, controlled, open-label, phase 3 trial. Lancet Oncol 2015, 16(4):375-384.

50. Hamid O, Robert C, Daud A, Hodi FS, Hwu WJ, Kefford R, Wolchok JD, Hersey P, Joseph RW, Weber JS et al: Safety and Tumor Responses with Lambrolizumab (Anti-PD-1) in Melanoma. New Engl J Med 2013, 369(2):134144.

51. Ribas A, Wolchok JD, Robert C, Kefford R, Hamid O, Daud A, Hwu WJ, Weber JS, Joshua AM, Gangadhar TC et al: Updated Clinical Efficacy of the Anti-Pd1 Monoclonal Antibody Pembrolizumab (Mk-3475) in 411 Patients with Melanoma. Eur J Cancer 2015, 51:E24-E24.

52. Chapman PB, Hauschild A, Robert C, Haanen JB, Ascierto P, Larkin J, Dummer $\mathrm{R}$, Garbe C, Testori A, Maio M et al: Improved Survival with Vemurafenib in Melanoma with BRAF V600E Mutation. New Engl J Med 2011, 364(26):25072516.

53. Hauschild A, Grob JJ, Demidov LV, Jouary T, Gutzmer R, Millward M, Rutkowski P, Blank CU, Miller WH, Kaempgen E et al: Dabrafenib in BRAFmutated metastatic melanoma: a multicentre, open-label, phase 3 randomised controlled trial. Lancet 2012, 380(9839):358-365. 
54. Shi HB, Hong AY, Kong XJ, Koya RC, Song CY, Moriceau G, Hugo W, Yu CC, $\mathrm{Ng} \mathrm{C}$, Chodon T et al: A Novel AKT1 Mutant Amplifies an Adaptive

Melanoma Response to BRAF Inhibition. Cancer Discov 2014, 4(1):69-79.

55. Rizos H, Menzies AM, Pupo GM, Carlino MS, Fung C, Hyman J, Haydu LE, Mijatov B, Becker TM, Boyd SC et al: BRAF Inhibitor Resistance Mechanisms in Metastatic Melanoma: Spectrum and Clinical Impact. Clin Cancer Res 2014, 20(7):1965-1977.

56. Shi HB, Hugo W, Kong XJ, Hong A, Koya RC, Moriceau G, Chodon T, Guo RQ, Johnson DB, Dahlman KB et al: Acquired Resistance and Clonal Evolution in Melanoma during BRAF Inhibitor Therapy. Cancer Discov 2014, 4(1):80-93.

57. Poulikakos PI, Persaud Y, Janakiraman M, Kong XJ, Ng C, Moriceau G, Shi HB, Atefi M, Titz B, Gabay MT et al: RAF inhibitor resistance is mediated by dimerization of aberrantly spliced BRAF(V600E). Nature 2011, 480(7377):387-U144.

58. Shi HB, Moriceau G, Kong XJ, Lee MK, Lee H, Koya RC, Ng C, Chodon T, Scolyer RA, Dahlman KB et al: Melanoma whole-exome sequencing identifies B-V600E-RAF amplification-mediated acquired B-RAF inhibitor resistance. Nat Commun 2012, 3.

59. Carlino MS, Fung C, Shahheydari H, Todd JR, Boyd SC, Irvine M, Nagrial AM, Scolyer RA, Kefford RF, Long GV et al: Preexisting MEK1(P124) Mutations Diminish Response to BRAF Inhibitors in Metastatic Melanoma Patients. Clin Cancer Res 2015, 21(1):98-105.

60. Wagle N, Van Allen EM, Treacy DJ, Frederick DT, Cooper ZA, Taylor-Weiner A, Rosenberg M, Goetz EM, Sullivan RJ, Farlow DN et al: MAP Kinase Pathway Alterations in BRAF-Mutant Melanoma Patients with Acquired Resistance to Combined RAF/MEK Inhibition. Cancer Discov 2014, 4(1):6168.

61. Johannessen CM, Boehm JS, Kim SY, Thomas SR, Wardwell L, Johnson LA, Emery CM, Stransky N, Cogdill AP, Barretina J et al: COT drives resistance to RAF inhibition through MAP kinase pathway reactivation. Nature 2010, 468(7326):968-U370.

62. Welsh SJ, Rizos H, Scolyer RA, Long GV: Resistance to combination BRAF and MEK inhibition in metastatic melanoma: Where to next? Eur J Cancer 2016, 62:76-85.

63. Amaral T, Sinnberg T, Meier F, Krepler C, Levesque M, Niessner H, Garbe C: The mitogen-activated protein kinase pathway in melanoma part $I$ Activation and primary resistance mechanisms to BRAF inhibition. Eur $J$ Cancer 2017, 73:85-92.

64. Sullivan RJ, Flaherty KT: Resistance to BRAF-targeted therapy in melanoma. Eur J Cancer 2013, 49(6):1297-1304.

65. Wellbrock C: MAPK pathway inhibition in melanoma: resistance three ways. Biochem Soc T 2014, 42:727-732.

66. Flaherty KT, Infante JR, Daud A, Gonzalez R, Kefford RF, Sosman J, Hamid O, Schuchter L, Cebon J, Ibrahim N et al: Combined BRAF and MEK Inhibition in Melanoma with BRAF V600 Mutations. New Engl J Med 2012, 367(18):1694-1703. 
67. Long GV, Weber JS, Infante JR, Kim KB, Daud A, Gonzalez R, Sosman JA, Hamid O, Schuchter L, Cebon J et al: Overall Survival and Durable Responses in Patients With BRAF V600-Mutant Metastatic Melanoma Receiving Dabrafenib Combined With Trametinib. J Clin Oncol 2016, 34(8):871-+.

68. Nijenhuis CM, Haanen JBAG, Schellens JHM, Beijnen JH: Is combination therapy the next step to overcome resistance and reduce toxicities in melanoma? Cancer Treat Rev 2013, 39(4):305-312.

69. Villadolid J, Amin A: Immune checkpoint inhibitors in clinical practice: update on management of immune-related toxicities. Translational lung cancer research 2015, 4(5):560-575.

70. Sorger PK, Dobles M, Tournebize R, Hyman AA: Coupling cell division and cell death to microtubule dynamics. Curr Opin Cell Biol 1997, 9(6):807-814.

71. Horio $\mathrm{T}$, Murata $\mathrm{T}$ : The role of dynamic instability in microtubule organization. Front Plant Sci 2014, 5.

72. Kavallaris M: Microtubules and resistance to tubulin-binding agents. Nat Rev Cancer 2010, 10(4).

73. Kaur R, Kaur G, Gill RK, Soni R, Bariwal J: Recent developments in tubulin polymerization inhibitors: An overview. European journal of medicinal chemistry 2014, 87:89-124.

74. Islam MN, Iskander MN: Microtubulin binding sites as target for developing anticancer agents. Mini-Rev Med Chem 2004, 4(10):1077-1104.

75. Jordan A, Hadfield JA, Lawrence NJ, McGown AT: Tubulin as a target for anticancer drugs: Agents which interact with the mitotic spindle. Med Res Rev 1998, 18(4):259-296.

76. Kumar S, Mahdi H, Bryant C, Shah JP, Garg G, Munkarah A: Clinical trials and progress with paclitaxel in ovarian cancer. International journal of women's health 2010, 2:411-427.

77. Ornstein DL, Rigas JR: Taxotere: Clinical Trials in Non-Small Cell Lung Cancer. The oncologist 1998, 3(2):86-93.

78. Vahdat LT: Clinical studies with epothilones for the treatment of metastatic breast cancer. Seminars in oncology 2008, 35(2 Suppl 2):S22-30; quiz S40.

79. Krick EL, Cohen RB, Gregor TP, Salah PC, Sorenmo KU: Prospective clinical trial to compare vincristine and vinblastine in a COP-based protocol for lymphoma in cats. Journal of veterinary internal medicine / American College of Veterinary Internal Medicine 2013, 27(1):134-140.

80. Ling V: Multidrug resistance: molecular mechanisms and clinical relevance. Cancer chemotherapy and pharmacology 1997, 40 Suppl:S3-8.

81. Kerb R, Hoffmeyer S, Brinkmann U: ABC drug transporters: hereditary polymorphisms and pharmacological impact in MDR1, MRP1 and MRP2. Pharmacogenomics 2001, 2(1):51-64.

82. Doyle L, Ross DD: Multidrug resistance mediated by the breast cancer resistance protein BCRP (ABCG2). Oncogene 2003, 22(47):7340-7358.

83. Sparreboom A, van Tellingen O, Nooijen WJ, Beijnen JH: Nonlinear pharmacokinetics of paclitaxel in mice results from the pharmaceutical vehicle Cremophor EL. Cancer research 1996, 56(9):2112-2115. 
84. Mozzetti S, Ferlini C, Concolino P, Filippetti F, Raspaglio G, Prislei S, Gallo D, Martinelli E, Ranelletti FO, Ferrandina G et al: Class III beta-tubulin overexpression is a prominent mechanism of paclitaxel resistance in ovarian cancer patients. Clin Cancer Res 2005, 11(1):298-305.

85. Seve $\mathrm{P}$, Dumontet $\mathrm{C}$ : Is class III beta-tubulin a predictive factor in patients receiving tubulin-binding agents? Lancet Oncol 2008, 9(2):168-175.

86. Aoki D, Oda Y, Hattori S, Taguchi K, Ohishi Y, Basaki Y, Oie S, Suzuki N, Kono S, Tsuneyoshi $\mathrm{M}$ et al: Overexpression of Class III beta-Tubulin Predicts Good Response to Taxane-Based Chemotherapy in Ovarian Clear Cell Adenocarcinoma. Clin Cancer Res 2009, 15(4):1473-1480.

87. Robinson MW, Trudgett A, Hoey EM, Fairweather I: Triclabendazole-resistant Fasciola hepatica: beta-tubulin and response to in vitro treatment with triclabendazole. Parasitology 2002, 124:325-338.

88. Kavallaris M, Verrills NM, Hill BT: Anticancer therapy with novel tubulininteracting drugs. Drug Resist Update 2001, 4(6):392-401.

89. Seve $\mathrm{P}$, Dumontet $\mathrm{C}$ : Is class III beta-tubulin a predictive factor in patients receiving tubulin-binding agents? Lancet Oncol 2008, 9(2):168-175.

90. Wilson L, Panda D, Jordan MA: Modulation of microtubule dynamics by drugs: A paradigm for the actions of cellular regulators. Cell Struct Funct 1999, 24(5):329-335.

91. Jordan MA, Wilson L: Microtubules as a target for anticancer drugs. Nat Rev Cancer 2004, 4(4):253-265.

92. Verrills NM, Walsh BJ, Cobon GS, Hains PG, Kavallaris M: Proteome analysis of Vinca alkaloid response and resistance in acute lymphoblastic leukemia reveals novel cytoskeletal alterations. The Journal of biological chemistry 2003, 278(46):45082-45093.

93. Verrills NM, Po'uha ST, Liu MLM, Liaw TYE, Larsen MR, Ivery MT, Marshall GM, Gunning PW, Kavallaris M: Alterations in gamma-actin and tubulintargeted drug resistance in childhood leukemia. J Natl Cancer I 2006, 98(19):1363-1374.

94. Stengel C, Newman SP, Leese MP, Potter BV, Reed MJ, Purohit A: Class III beta-tubulin expression and in vitro resistance to microtubule targeting agents. British journal of cancer 2010, 102(2):316-324.

95. Mukhtar E, Adhami VM, Mukhtar H: Targeting Microtubules by Natural Agents for Cancer Therapy. Molecular cancer therapeutics 2014, 13(2):275284.

96. Ravelli RBG, Gigant B, Curmi PA, Jourdain I, Lachkar S, Sobel A, Knossow M: Insight into tubulin regulation from a complex with colchicine and a stathmin-like domain. Nature 2004, 428(6979):198-202.

97. Finkelstein Y, Aks SE, Hutson JR, Juurlink DN, Nguyen P, Dubnov-Raz G, Pollak U, Koren G, Bentur Y: Colchicine poisoning: the dark side of an ancient drug. Clin Toxicol 2010, 48(5):407-414.

98. Borisy GG, Taylor EW: The mechanism of action of colchicine. Binding of colchincine-3H to cellular protein. The Journal of cell biology 1967, 34(2):525533. 
99. Kanthou C, Tozer GM: Microtubule depolymerizing vascular disrupting agents: novel therapeutic agents for oncology and other pathologies. Int $J$ Exp Pathol 2009, 90(3):284-294.

100. Stengel C, Newman SP, Leese MP, Potter BVL, Reed MJ, Purohit A: Class III beta-tubulin expression and in vitro resistance to microtubule targeting agents. Brit $J$ Cancer 2010, 102(2):316-324.

101. Wu XX, Wang QH, Li W: Recent Advances in Heterocyclic Tubulin Inhibitors Targeting the Colchicine Binding Site. Anti-cancer agents in medicinal chemistry 2016, 16(10):1325-1338.

102. Lu Y, Chen JJ, Xiao M, Li W, Miller DD: An Overview of Tubulin Inhibitors That Interact with the Colchicine Binding Site. Pharm Res-Dordr 2012, 29(11):2943-2971.

103. Ji YT, Liu YN, Liu ZP: Tubulin Colchicine Binding Site Inhibitors as Vascular Disrupting Agents in Clinical Developments. Current medicinal chemistry 2015, 22(11):1348-1360.

104. Ryan BM, O'Donovan N, Duffy MJ: Survivin: A new target for anti-cancer therapy. Cancer Treat Rev 2009, 35(7):553-562.

105. Altieri DC: Opinion - Survivin, cancer networks and pathway-directed drug discovery. Nat Rev Cancer 2008, 8(1):61-70.

106. Duffy MJ, O'Donovan N, Brennan DJ, Gallagher WM, Ryan BM: Survivin: A promising tumor biomarker. Cancer Lett 2007, 249(1):49-60.

107. Shin S, Sung BJ, Cho YS, Kim HJ, Ha NC, Hwang JI, Chung CW, Jung YK, Oh $\mathrm{BH}$ : An anti-apoptotic protein human survivin is a direct inhibitor of caspase-3 and-7. Biochemistry-Us 2001, 40(4):1117-1123.

108. Tamm I, Wang Y, Sausville E, Scudiero DA, Vigna N, Oltersdorf T, Reed JC:

IAP-family protein Survivin inhibits caspase activity and apoptosis induced by Fas (CD95), Bax, caspases, and anticancer drugs. Cancer research 1998, 58(23):5315-5320.

109. Hu DQ, Liu SW, Shi L, Li C, Wu LF, Fan ZS: Cleavage of Survivin by Granzyme M Triggers Degradation of the Survivin-X-linked Inhibitor of Apoptosis Protein (XIAP) Complex to Free Caspase Activity Leading to Cytolysis of Target Tumor Cells. The Journal of biological chemistry 2010, 285(24):18326-18335.

110. Altieri DC: Survivin in apoptosis control and cell cycle regulation in cancer. Progress in cell cycle research 2003, 5:447-452.

111. Chakravarti A, Zhai GG, Zhang M, Malhotra R, Latham DE, Delaney MA, Robe $\mathrm{P}$, Nestler U, Song QH, Loeffler J: Survivin enhances radiation resistance in primary human glioblastoma cells via caspase-independent mechanisms. Oncogene 2004, 23(45):7494-7506.

112. Cheung CHA, Chen HH, Kuo CC, Chang CY, Coumar MS, Hsieh HP, Chang JY: Survivin counteracts the therapeutic effect of microtubule de-stabilizers by stabilizing tubulin polymers. Mol Cancer 2009, 8.

113. Pennati M, Folini M, Zaffaroni N: Targeting survivin in cancer therapy: fulfilled promises and open questions. Carcinogenesis 2007, 28(6):1133-1139. 
114. O'Connor DS, Grossman D, Plescia J, Li FZ, Zhang H, Villa A, Tognin S, Marchisio PC, Altieri DC: Regulation of apoptosis at cell division by p34(cdc2) phosphorylation of survivin. P Natl Acad Sci USA 2000, 97(24):13103-13107.

115. Yan H, Thomas J, Liu T, Raj D, London N, Tandeski T, Leachman SA, Lee RM, Grossman D: Induction of melanoma cell apoptosis and inhibition of tumor growth using a cell-permeable Survivin antagonist. Oncogene 2006, 25(52):6968-6974.

116. Talbot DC, Davies J, Callies S, Andre V, Lahn M, Ang J, De Bono JS, Ranson M: First human dose study evaluating safety and pharmacokinetics of LY2181308, an antisense oligonucleotide designed to inhibit survivin. J Clin Oncol 2008, 26(15).

117. Xiao M, Li W: Recent Advances on Small-Molecule Survivin Inhibitors. Current medicinal chemistry 2015, 22(9):1136-1146.

118. Roy K, Singh N, Kanwar RK, Kanwar JR: Survivin Modulators: An Updated Patent Review (2011-2015). Recent Pat Anti-Canc 2016, 11(2):152-169.

119. Meli M, Pennati M, Curto M, Daidone MG, Plescia J, Toba S, Altieri DC, Zaffaroni N, Colombo G: Small-molecule targeting of heat shock protein 90 chaperone function: Rational identification of a new anticancer lead. Journal of medicinal chemistry 2006, 49(26):7721-7730.

120. Huang K, Li LA, Meng YG, You YQ, Fu XY, Song L: Arctigenin Promotes Apoptosis in Ovarian Cancer Cells via the iNOS/NO/STAT3/Survivin Signalling. Basic Clin Pharmacol 2014, 115(6):507-511.

121. Ling X, Cao SS, Cheng QY, Keefe JT, Rustum YM, Li FZ: A Novel Small Molecule FL118 That Selectively Inhibits Survivin, Mcl-1, XIAP and cIAP2 in a p53-Independent Manner, Shows Superior Antitumor Activity. Plos One 2012, 7(9).

122. Xia WL, Bisi J, Strum J, Liu LH, Carrick K, Graham KM, Treece AL, Hardwicke MA, Dush M, Liao QY et al: Regulation of survivin by ErbB2 signaling: Therapeutic implications for ErbB2-overexpressing breast cancers. Cancer research 2006, 66(3):1640-1647.

123. Agarwal E, Chaudhuri A, Leiphrakpam PD, Haferbier KL, Brattain MG, Chowdhury S: Akt inhibitor MK-2206 promotes anti-tumor activity and cell death by modulation of AIF and Ezrin in colorectal cancer. Bmc Cancer 2014, 14.

124. Iizuka D, Ogura A, Kuwabara M, Inanami O: Purvalanol A induces apoptosis and downregulation of antiapoptotic proteins through abrogation of phosphorylation of JAK2/STAT3 and RNA polymerase II. Anti-Cancer Drug 2008, 19(6):565-572.

125. Nakahara T, Kita A, Yamanaka K, Mori M, Amino N, Takeuchi M, Tominaga F, Hatakeyama S, Kinoyama I, Matsuhisa A et al: YM155, a Novel Small-Molecule Survivin Suppressant, Induces Regression of Established Human HormoneRefractory Prostate Tumor Xenografts (vol 67, pg 8014, 2007). Cancer research 2012, 72(15):3886-3886.

126. Wang J, Li W: Discovery of Novel Second Mitochondria-Derived Activator of Caspase Mimetics as Selective Inhibitor of Apoptosis Protein Inhibitors. The Journal of pharmacology and experimental therapeutics 2014, 349(2):319-329. 
127. Wall NR, O'Connor DS, Plescia J, Pommier Y, Altieri DC: Suppression of survivin phosphorylation on $\operatorname{Thr}(34)$ by flavopiridol enhances tumor cell apoptosis. Cancer research 2003, 63(1):230-235.

128. Chang CC, Heller JD, Kuo J, Huang RCC: Tetra-O-methyl nordihydroguaiaretic acid induces growth arrest and cellular apoptosis by inhibiting Cdc2 and survivin expression. P Natl Acad Sci USA 2004, 101(36):13239-13244.

129. Arora R, Yates C, Gary BD, McClellan S, Tan M, Xi YG, Reed E, Piazza GA, Owen LB, Dean-Colomb W: Panepoxydone Targets NF-kB and FOXM1 to Inhibit Proliferation, Induce Apoptosis and Reverse Epithelial to Mesenchymal Transition in Breast Cancer. Plos One 2014, 9(6).

130. Chantalat L, Skoufias DA, Kleman JP, Jung B, Dideberg O, Margolis RL: Crystal structure of human survivin reveals a bow tie-shaped dimer with two unusual alpha-helical extensions. Mol Cell 2000, 6(1):183-189.

131. Cheng JB, Motola DL, Mangelsdorf DJ, Russell DW: De-orphanization of cytochrome P450 2R1 - A microsomal vitamin D 25-hydroxylase. The Journal of biological chemistry 2003, 278(39):38084-38093.

132. Deeb KK, Trump DL, Johnson CS: Vitamin D signalling pathways in cancer: potential for anticancer therapeutics. Nat Rev Cancer 2007, 7(9):684-700.

133. Washington MN, Kim JS, Weigel NL: 1alpha,25-dihydroxyvitamin D3 inhibits C4-2 prostate cancer cell growth via a retinoblastoma protein (Rb)independent G1 arrest. The Prostate 2011, 71(1):98-110.

134. Akutsu N, Lin R, Bastien Y, Bestawros A, Enepekides DJ, Black MJ, White JH: Regulation of gene Expression by 1alpha,25-dihydroxyvitamin D3 and Its analog EB1089 under growth-inhibitory conditions in squamous carcinoma Cells. Mol Endocrinol 2001, 15(7):1127-1139.

135. Bao BY, Hu YC, Ting HJ, Lee YF: Androgen signaling is required for the vitamin D-mediated growth inhibition in human prostate cancer cells. Oncogene 2004, 23(19):3350-3360.

136. Diaz GD, Paraskeva C, Thomas MG, Binderup L, Hague A: Apoptosis is induced by the active metabolite of vitamin D-3 and its analogue EB1089 in colorectal adenoma and carcinoma cells: Possible implications for prevention and therapy. Cancer research 2000, 60(8):2304-2312.

137. Motomura S, Kanamori H, Maruta A, Kodama F, Ohkubo T: The Effect of 1Hydroxyvitamin D3 for Prolongation of Leukemic Transformation-Free Survival in Myelodysplastic Syndromes. Am J Hematol 1991, 38(1):67-68.

138. Villaggio B, Soldano S, Cutolo M: 1,25-dihydroxyvitamin D3 downregulates aromatase expression and inflammatory cytokines in human macrophages. Clin Exp Rheumatol 2012, 30(6):934-938.

139. Kaler P, Augenlicht L, Klampfer L: Macrophage-derived IL-1 beta stimulates Wnt signaling and growth of colon cancer cells: a crosstalk interrupted by vitamin D-3. Oncogene 2009, 28(44):3892-3902.

140. Ben-Shoshan M, Amir S, Dang DT, Dang LH, Weisman Y, Mabjeesh NJ: 1 alpha,25-dihydroxyvitamin D-3 (Calcitriol) inhibits hypoxia-inducible factor1/vascular endothelial growth factor pathway in human cancer cells. Molecular cancer therapeutics 2007, 6(4):1433-1439. 
141. Chung I, Hang GZ, Seshadri M, Gillard BM, Yu WD, Foster BA, Trump DL, Johnson CS: Role of Vitamin D Receptor in the Antiproliferative Effects of Calcitriol in Tumor-Derived Endothelial Cells and Tumor Angiogenesis In vivo. Cancer research 2009, 69(3):967-975.

142. Kovalenko PL, Zhang ZT, Cui M, Clinton SK, Fleet JC: 1,25 dihydroxyvitamin D-mediated orchestration of anticancer, transcript-level effects in the immortalized, non-transformed prostate epithelial cell line, RWPE1. Bmc Genomics 2010, 11.

143. Figueroa JA, De Raad S, Tadlock L, Speights VO, Rinehart JJ: Differential expression of insulin-like growth factor binding proteins in high versus low Gleason score prostate cancer. J Urology 1998, 159(4):1379-1383.

144. Jones G: Pharmacokinetics of vitamin D toxicity. The American journal of clinical nutrition 2008, 88(2):582S-586S.

145. Miller WL, Auchus RJ: The molecular biology, biochemistry, and physiology of human steroidogenesis and its disorders. Endocrine reviews 2011, 32(1):81151.

146. Tuckey RC: Progesterone synthesis by the human placenta. Placenta 2005, 26(4):273-281.

147. Slominski AT, Li W, Kim TK, Semak I, Wang J, Zjawiony JK, Tuckey RC: Novel activities of CYP11A1 and their potential physiological significance. The Journal of steroid biochemistry and molecular biology 2014.

148. Slominski A, Zjawiony J, Wortsman J, Semak I, Stewart J, Pisarchik A, Sweatman T, Marcos J, Dunbar C, R CT: A novel pathway for sequential transformation of 7-dehydrocholesterol and expression of the P450scc system in mammalian skin. European journal of biochemistry / FEBS 2004, 271(21):4178-4188.

149. Slominski A, Semak I, Wortsman J, Zjawiony J, Li W, Zbytek B, Tuckey RC: An alternative pathway of vitamin D metabolism. Cytochrome P450sce (CYP11A1)-mediated conversion to 20-hydroxyvitamin D2 and 17,20dihydroxyvitamin D2. The FEBS journal 2006, 273(13):2891-2901.

150. Slominski A, Semak I, Zjawiony J, Wortsman J, Li W, Szczesniewski A, Tuckey $\mathrm{RC}$ : The cytochrome P450sce system opens an alternate pathway of vitamin D3 metabolism. The FEBS journal 2005, 272(16):4080-4090.

151. Tuckey RC, Li W, Zjawiony JK, Zmijewski MA, Nguyen MN, Sweatman T, Miller D, Slominski A: Pathways and products for the metabolism of vitamin D3 by cytochrome P450sce. The FEBS journal 2008, 275(10):2585-2596.

152. Guryev O, Carvalho RA, Usanov S, Gilep A, Estabrook RW: A pathway for the metabolism of vitamin D3: unique hydroxylated metabolites formed during catalysis with cytochrome P450sce (CYP11A1). Proceedings of the National Academy of Sciences of the United States of America 2003, 100(25):14754-14759.

153. Slominski AT, Kim TK, Li W, Yi AK, Postlethwaite A, Tuckey RC: The role of CYP11A1 in the production of vitamin D metabolites and their role in the regulation of epidermal functions. The Journal of steroid biochemistry and molecular biology 2014, 144 Pt A:28-39.

154. Janjetovic Z, Zmijewski MA, Tuckey RC, DeLeon DA, Nguyen MN, Pfeffer LM, Slominski AT: 20-Hydroxycholecalciferol, product of vitamin D3 
hydroxylation by P450sce, decreases NF-kappaB activity by increasing IkappaB alpha levels in human keratinocytes. PloS one 2009, 4(6):e5988.

155. Zbytek B, Janjetovic Z, Tuckey RC, Zmijewski MA, Sweatman TW, Jones E, Nguyen MN, Slominski AT: 20-Hydroxyvitamin D3, a product of vitamin D3 hydroxylation by cytochrome P450sce, stimulates keratinocyte differentiation. The Journal of investigative dermatology 2008, 128(9):22712280.

156. Slominski AT, Janjetovic Z, Fuller BE, Zmijewski MA, Tuckey RC, Nguyen MN, Sweatman T, Li W, Zjawiony J, Miller D et al: Products of vitamin D3 or 7dehydrocholesterol metabolism by cytochrome P450sce show anti-leukemia effects, having low or absent calcemic activity. PloS one 2010, 5(3):e9907.

157. Slominski AT, Janjetovic Z, Kim TK, Wright AC, Grese LN, Riney SJ, Nguyen MN, Tuckey RC: Novel vitamin D hydroxyderivatives inhibit melanoma growth and show differential effects on normal melanocytes. Anticancer research 2012, 32(9):3733-3742.

158. Chen J, Wang J, Kim TK, Tieu EW, Tang EK, Lin Z, Kovacic D, Miller DD, Postlethwaite A, Tuckey RC et al: Novel vitamin D analogs as potential therapeutics: metabolism, toxicity profiling, and antiproliferative activity. Anticancer research 2014, 34(5):2153-2163.

159. Slominski A, Janjetovic Z, Tuckey RC, Nguyen MN, Bhattacharya KG, Wang J, Li W, Jiao Y, Gu W, Brown M et al: 20S-hydroxyvitamin D3, noncalcemic product of CYP11A1 action on vitamin D3, exhibits potent antifibrogenic activity in vivo. The Journal of clinical endocrinology and metabolism 2013, 98(2):E298-303.

160. Slominski AT, Kim TK, Janjetovic Z, Tuckey RC, Bieniek R, Yue J, Li W, Chen $\mathrm{J}$, Nguyen MN, Tang EK et al: 20-Hydroxyvitamin D2 is a noncalcemic analog of vitamin $D$ with potent antiproliferative and prodifferentiation activities in normal and malignant cells. American journal of physiology Cell physiology 2011, 300(3):C526-541.

161. Slominski AT, Kim TK, Takeda Y, Janjetovic Z, Brozyna AA, Skobowiat C, Wang J, Postlethwaite A, Li W, Tuckey RC et al: RORalpha and ROR gamma are expressed in human skin and serve as receptors for endogenously produced noncalcemic 20-hydroxy- and 20,23-dihydroxyvitamin D. FASEB journal : official publication of the Federation of American Societies for Experimental Biology 2014, 28(7):2775-2789.

162. Kim TK, Wang J, Janjetovic Z, Chen JJ, Tuckey RC, Nguyen MN, Tang EKY, Miller D, Li W, Slominski AT: Correlation between secosteroid-induced vitamin D receptor activity in melanoma cells and computer-modeled receptor binding strength. Mol Cell Endocrinol 2012, 361(1-2):143-152.

163. Fedorenko IV, Gibney GT, Sondak VK, Smalley KSM: Beyond BRAF: where next for melanoma therapy? Brit J Cancer 2015, 112(2):217-226.

164. Wolchok JD, Kluger H, Callahan MK, Postow MA, Rizvi NA, Lesokhin AM, Segal NH, Ariyan CE, Gordon RA, Reed K et al: Nivolumab plus Ipilimumab in Advanced Melanoma. New Engl J Med 2013, 369(2):122-133.

165. Sznol M, Kluger HM, Callahan MK, Postow MA, Gordon RA, Segal NH, Rizvi NA, Lesokhin AM, Atkins MB, Kirkwood JM et al: Survival, response 
duration, and activity by BRAF mutation (MT) status of nivolumab (NIVO, anti-PD-1, BMS-936558, ONO-4538) and ipilimumab (IPI) concurrent therapy in advanced melanoma (MEL). J Clin Oncol 2014, 32(18).

166. Beck A, Wurch T, Bailly C, Corvaia N: Strategies and challenges for the next generation of therapeutic antibodies. Nat Rev Immunol 2010, 10(5):345-352.

167. Panowski S, Bhakta S, Raab H, Polakis P, Junutula JR: Site-specific antibody drug conjugates for cancer therapy. Mabs-Austin 2014, 6(1):34-45.

168. Peters $\mathrm{C}$, Brown $\mathrm{S}$ : Antibody-drug conjugates as novel anti-cancer chemotherapeutics. Bioscience Rep 2015, 35.

169. Chen JJ, Ahn S, Wang J, Lu Y, Dalton JT, Miller DD, Li W: Discovery of Novel 2-Aryl-4-benzoyl-imidazole (ABI-III) Analogues Targeting Tubulin Polymerization As Antiproliferative Agents. Journal of medicinal chemistry 2012, 55(16):7285-7289.

170. Mukhtar E, Adhami VM, Mukhtar H: Targeting microtubules by natural agents for cancer therapy. Mol Cancer Ther 2014, 13(2):275-284.

171. Heald R, Nogales E: Microtubule dynamics. J Cell Sci 2002, 115(1):3-4.

172. Kuppens IE: Current state of the art of new tubulin inhibitors in the clinic. Current clinical pharmacology 2006, 1(1):57-70.

173. Loong $\mathrm{HH}$, Yeo $\mathrm{W}$ : Microtubule-targeting agents in oncology and therapeutic potential in hepatocellular carcinoma. OncoTargets and therapy 2014, 7:575585.

174. McGuire S: World Cancer Report 2014. Geneva, Switzerland: World Health Organization, International Agency for Research on Cancer, WHO Press, 2015. Adv Nutr 2016, 7(2):418-419.

175. Orr GA, Verdier-Pinard P, McDaid H, Horwitz SB: Mechanisms of Taxol resistance related to microtubules. Oncogene 2003, 22(47):7280-7295.

176. Kavallaris M, Tait AS, Walsh BJ, He LF, Horwitz SB, Norris MD, Haber M: Multiple microtubule alterations are associated with Vinca alkaloid resistance in human leukemia cells. Cancer research 2001, 61(15):5803-5809.

177. Zagouri F, Sergentanis TN, Chrysikos D, Dimopoulos MA, Bamias A: Epothilones in epithelial ovarian, fallopian tube, or primary peritoneal cancer: a systematic review. OncoTargets and therapy 2015, 8:2187-2198.

178. Trendowski M: Recent Advances in the Development of Antineoplastic Agents Derived from Natural Products. Drugs 2015, 75(17):1993-2016.

179. Aseyev O, Ribeiro JM, Cardoso F: Review on the clinical use of eribulin mesylate for the treatment of breast cancer. Expert Opin Pharmaco 2016, 17(4):589-600.

180. Li CM, Wang Z, Lu Y, Ahn S, Narayanan R, Kearbey JD, Parke DN, Li W, Miller DD, Dalton JT: Biological Activity of 4-Substituted MethoxybenzoylAryl-Thiazole: An Active Microtubule Inhibitor. Cancer research 2011, 71(1):216-224.

181. Lu Y, Li CM, Wang Z, Ross CR, Chen J, Dalton JT, Li W, Miller DD: Discovery of 4-Substituted Methoxybenzoyl-aryl-thiazole as Novel Anticancer Agents: Synthesis, Biological Evaluation, and Structure-Activity Relationships. Journal of medicinal chemistry 2009, 52(6):1701-1711. 
182. Chen JJ, Wang Z, Li CM, Lu Y, Vaddady PK, Meibohm B, Dalton JT, Miller DD, Li W: Discovery of Novel 2-Aryl-4-benzoyl-imidazoles Targeting the Colchicines Binding Site in Tubulin As Potential Anticancer Agents. Journal of medicinal chemistry 2010, 53(20):7414-7427.

183. Chen JJ, Li CM, Wang J, Ahn S, Wang Z, Lu Y, Dalton JT, Miller DD, Li W: Synthesis and antiproliferative activity of novel 2-aryl-4-benzoyl-imidazole derivatives targeting tubulin polymerization. Bioorganic \& medicinal chemistry 2011, 19(16):4782-4795.

184. Alves FRD, Barreiro EJ, Fraga CAM: From Nature to Drug Discovery: The Indole Scaffold as a 'Privileged Structure'. Mini-Rev Med Chem 2009, 9(7):782-793.

185. Xiao M, Ahn SJ, Wang J, Chen JJ, Miller DD, Dalton JT, Li W: Discovery of 4Aryl-2-benzoyl-imidazoles as Tubulin Polymerization Inhibitor with Potent Antiproliferative Properties. Journal of medicinal chemistry 2013, 56(8):33183329.

186. Lu Y, Chen JJ, Wang J, Li CM, Ahn S, Barrett CM, Dalton JT, Li W, Miller DD: Design, Synthesis, and Biological Evaluation of Stable Colchicine Binding Site Tubulin Inhibitors as Potential Anticancer Agents. Journal of medicinal chemistry 2014, 57(17):7355-7366.

187. Fujioka H, Murai K, Kubo O, Ohba Y, Kita Y: One-pot synthesis of imidazolines from aldehydes: detailed study about solvents and substrates. Tetrahedron 2007, 63(3):638-643.

188. Lee SH, Kohn H: Cyclic disulfide C(8) iminoporfiromycin: Nucleophilic activation of a porfiromycin. J Am Chem Soc 2004, 126(13):4281-4292.

189. Guinchard X, Vallee Y, Denis JN: Total synthesis of marine sponge bis(indole) alkaloids of the topsentin class. J Org Chem 2007, 72(10):3972-3975.

190. Hwang DJ, Wang J, Li W, Miller DD: Structural Optimization of Indole Derivatives Acting at Colchicine Binding Site as Potential Anticancer Agents. Acs Med Chem Lett 2015, 6(9):993-997.

191. Etienne-Manneville S: From signaling pathways to microtubule dynamics: the key players. Curr Opin Cell Biol 2010, 22(1):104-111.

192. Yue QX, Liu XA, Guo DA: Microtubule-Binding Natural Products for Cancer Therapy. Planta Med 2010, 76(11):1037-1043.

193. Dong M, Liu F, Zhou H, Zhai S, Yan B: Novel Natural Product- and Privileged Scaffold-Based Tubulin Inhibitors Targeting the Colchicine Binding Site. Molecules 2016, 21(10).

194. Chen J, Liu T, Dong XW, Hu YZ: Recent Development and SAR Analysis of Colchicine Binding Site Inhibitors. Mini-Rev Med Chem 2009, 9(10):11741190.

195. van Otterlo WAL, Ngidi EL, de Koning CB: Sequential isomerization and ringclosing metathesis: masked styryl and vinyloxyaryl groups for the synthesis of benzo-fused heterocycles. Tetrahedron Lett 2003, 44(34):6483-6486.

196. Robert C, Long GV, Brady B, Dutriaux C, Maio M, Mortier L, Hassel JC, Rutkowski P, McNeil C, Kalinka-Warzocha E et al: Nivolumab in Previously Untreated Melanoma without BRAF Mutation. New Engl J Med 2015, 372(4):320-330. 
197. Vinay DS, Ryan EP, Pawelec G, Talib WH, Stagg J, Elkord E, Lichtor T, Decker WK, Whelan RL, Kumara HMCS et al: Immune evasion in cancer:

Mechanistic basis and therapeutic strategies. Semin Cancer Biol 2015, 35:S185-S198.

198. Farkona S, Diamandis EP, Blasutig IM: Cancer immunotherapy: the beginning of the end of cancer? Bmc Med 2016, 14.

199. Pellegrini F, Budman DR: Review: Tubulin function, action of antitubulin drugs, and new drug development. Cancer Invest 2005, 23(3):264-273.

200. Stanton RA, Gernert KM, Nettles JH, Aneja R: Drugs That Target Dynamic Microtubules: A New Molecular Perspective. Med Res Rev 2011, 31(3):443481.

201. Liu YM, Chen HL, Lee HY, Liou JP: Tubulin inhibitors: a patent review. Expert Opin Ther Pat 2014, 24(1):69-88.

202. Dong MQ, Liu F, Zhou HY, Zhai SM, Yan B: Novel Natural Product- and Privileged Scaffold-Based Tubulin Inhibitors Targeting the Colchicine Binding Site. Molecules 2016, 21(10).

203. Klute K, Nackos E, Tasaki S, Nguyen DP, Bander NH, Tagawa ST: Microtubule inhibitor-based antibody-drug conjugates for cancer therapy. OncoTargets and therapy 2014, 7.

204. Teicher BA, Chari RVJ: Antibody Conjugate Therapeutics: Challenges and Potential. Clin Cancer Res 2011, 17(20):6389-6397.

205. Edfeldt F, Evenas J, Lepisto M, Ward A, Petersen J, Wissler L, Rohman M, Sivars U, Svensson K, Perry M et al: Identification of indole inhibitors of human hematopoietic prostaglandin D-2 synthase (hH-PGDS). Bioorganic \& medicinal chemistry letters 2015, 25(12):2496-2500.

206. Richardson TI, Clarke CA, Yu KL, Yee YK, Bleisch TJ, Lopez JE, Jones SA, Hughes NE, Muehl BS, Lugar CW et al: Novel 3-Aryl Indoles as Progesterone Receptor Antagonists for Uterine Fibroids. Acs Med Chem Lett 2011, 2(2):148153.

207. Zeng R, Dong GB: Rh-Catalyzed Decarbonylative Coupling with Alkynes via C-C Activation of Isatins. J Am Chem Soc 2015, 137(4):1408-1411.

208. Hoffman WH, Biade S, Zilfou JT, Chen JD, Murphy M: Transcriptional repression of the anti-apoptotic survivin gene by wild type p53. The Journal of biological chemistry 2002, 277(5):3247-3257.

209. Chandele A, Prasad V, Jagtap JC, Shukla R, Shastry PR: Upregulation of survivin in G2/M cells and inhibition of caspase 9 activity enhances resistance in staurosporine-induced apoptosis. Neoplasia 2004, 6(1):29-40.

210. Wang HJ, Gambosova K, Cooper ZA, Holloway MP, Kassai A, Izquierdo D, Cleveland K, Boney CM, Altura RA: EGF regulates survivin stability through the Raf-1/ERK pathway in insulin-secreting pancreatic beta-cells. Bmc Mol Biol 2010, 11.

211. Chen YQ, Li DM, Liu HL, Xu HB, Zheng HH, Qian F, Li W, Zhao CL, Wang $\mathrm{ZH}$, Wang XJ: Notch-1 signaling facilitates survivin expression in human nonsmall cell lung cancer cells. Cancer Biol Ther 2011, 11(1):14-21. 
212. Coumar MS, Tsai FY, Kanwar JR, Sarvagalla S, Cheung CHA: Treat cancers by targeting survivin: Just a dream or future reality? Cancer Treat Rev 2013, 39(7):802-811.

213. Rauch A, Hennig D, Schafer C, Wirth M, Marx C, Heinzel T, Schneider G, Kramer OH: Survivin and YM155: How faithful is the liaison? Bba-Rev Cancer 2014, 1845(2):202-220.

214. Xiao M, Wang J, Lin ZT, Lu Y, Li ZM, White SW, Miller DD, Li W: Design, Synthesis and Structure-Activity Relationship Studies of Novel Survivin Inhibitors with Potent Anti-Proliferative Properties. Plos One 2015, 10(6).

215. Wang J, Li W: Discovery of novel second mitochondria-derived activator of caspase mimetics as selective inhibitor of apoptosis protein inhibitors. $J$ Pharmacol Exp Ther 2014, 349(2):319-329.

216. Xiao M, Wang J, Lin Z, Lu Y, Li Z, White SW, Miller DD, Li W: Design, Synthesis and Structure-Activity Relationship Studies of Novel Survivin Inhibitors with Potent Anti-Proliferative Properties. PLoS One 2015, 10(6): e0129807.

217. Wang J, Chen J, Miller DD, Li W: Synergistic combination of novel tubulin inhibitor ABI-274 and vemurafenib overcome vemurafenib acquired resistance in BRAFV600E melanoma. Mol Cancer Ther 2014, 13(1):16-26.

218. Hwang DJ, Wang J, Li W, Miller DD: Structural Optimization of Indole Derivatives Acting at Colchicine Binding Site as Potential Anticancer Agents. ACS Med Chem Lett 2015, 6(9):993-997.

219. Akiyama S, Fojo A, Hanover JA, Pastan I, Gottesman MM: Isolation and genetic characterization of human KB cell lines resistant to multiple drugs. Somat Cell Mol Genet 1985, 11(2):117-126.

220. Robey RW, Shukla S, Finley EM, Oldham RK, Barnett D, Ambudkar SV, Fojo T, Bates SE: Inhibition of P-glycoprotein (ABCB1)- and multidrug resistanceassociated protein 1 (ABCC1)-mediated transport by the orally administered inhibitor, CBT-1((R)). Biochem Pharmacol 2008, 75(6):1302-1312.

221. Carmichael J, DeGraff WG, Gazdar AF, Minna JD, Mitchell JB: Evaluation of a tetrazolium-based semiautomated colorimetric assay: assessment of chemosensitivity testing. Cancer Res 1987, 47(4):936-942.

222. Mahindroo N, Connelly MC, Punchihewa C, Yang L, Yan B, Fujii N: Amide conjugates of ketoprofen and indole as inhibitors of Gli1-mediated transcription in the Hedgehog pathway. Bioorganic \& medicinal chemistry 2010, 18(13):4801-4811.

223. Di L, Kerns EH, Li SQ, Petusky SL: High throughput microsomal stability assay for insoluble compounds. Int J Pharm 2006, 317(1):54-60.

224. Davies B, Morris T: Physiological-Parameters in Laboratory-Animals and Humans. Pharm Res-Dordr 1993, 10(7):1093-1095.

225. Lu C, Li P, Gallegos R, Uttamsingh V, Xia CQ, Miwa GT, Balani SK, Gan LS: Comparison of intrinsic clearance in liver microsomes and hepatocytes from rats and humans: Evaluation of free fraction and uptake in hepatocytes. Drug Metab Dispos 2006, 34(9):1600-1605. 
226. Cheng JB, Motola DL, Mangelsdorf DJ, Russell DW: De-orphanization of cytochrome P450 2R1: a microsomal vitamin D 25-hydroxilase. The Journal of biological chemistry 2003, 278(39):38084-38093.

227. DeLuca HF: Vitamin D: the vitamin and the hormone. Federation proceedings 1974, 33(11):2211-2219.

228. Pike JW: Intracellular receptors mediate the biologic action of 1,25dihydroxyvitamin D3. Nutrition reviews 1985, 43(6):161-168.

229. Korf H, Decallonne B, Mathieu C: Vitamin D for infections. Current opinion in endocrinology, diabetes, and obesity 2014, 21(6):431-436.

230. Bikle DD: Vitamin D receptor, a tumor suppressor in skin. Canadian journal of physiology and pharmacology 2015, 93(5):349-354.

231. Chiang KC, Chen TC: The anti-cancer actions of vitamin D. Anti-cancer agents in medicinal chemistry 2013, 13(1):126-139.

232. Li YC: Vitamin D receptor signaling in renal and cardiovascular protection. Seminars in nephrology 2013, 33(5):433-447.

233. Plum LA, DeLuca HF: Vitamin D, disease and therapeutic opportunities. Nat Rev Drug Discov 2010, 9(12):941-955.

234. Kulie T, Groff A, Redmer J, Hounshell J, Schrager S: Vitamin D: an evidencebased review. Journal of the American Board of Family Medicine : JABFM 2009, 22(6):698-706.

235. Cheung FS, Lovicu FJ, Reichardt JK: Current progress in using vitamin D and its analogs for cancer prevention and treatment. Expert review of anticancer therapy 2012, 12(6):811-837.

236. Stein MS, Wark JD: An update on the therapeutic potential of vitamin D analogues. Expert opinion on investigational drugs 2003, 12(5):825-840.

237. Leyssens C, Verlinden L, Verstuyf A: The future of vitamin D analogs. Frontiers in physiology 2014, 5:122.

238. Sherman MH, Yu RT, Engle DD, Ding N, Atkins AR, Tiriac H, Collisson EA, Connor F, Van Dyke T, Kozlov $\mathrm{S}$ et al: Vitamin d receptor-mediated stromal reprogramming suppresses pancreatitis and enhances pancreatic cancer therapy. Cell 2014, 159(1):80-93.

239. Li W, Chen J, Janjetovic Z, Kim TK, Sweatman T, Lu Y, Zjawiony J, Tuckey RC, Miller D, Slominski A: Chemical synthesis of 20S-hydroxyvitamin D3, which shows antiproliferative activity. Steroids 2010, 75(12):926-935.

240. Tuckey RC, Janjetovic Z, Li W, Nguyen MN, Zmijewski MA, Zjawiony J, Slominski A: Metabolism of 1 alpha-hydroxyvitamin D3 by cytochrome P450sce to biologically active 1 alpha,20-dihydroxyvitamin D3. J Steroid Biochem 2008, 112(4-5):213-219.

241. Kutner A, Zhao H, Fitak H, Wilson SR: Synthesis of Retiferol Rad(1) and $\operatorname{Rad}(2)$, the Lead Representatives of a New Class of Des-Cd Analogs of Cholecalciferol. Bioorg Chem 1995, 23(1):22-32.

242. Posner GH, Crawford K, Siu-Caldera ML, Reddy GS, Sarabia SF, Feldman D, van Etten E, Mathieu C, Gennaro L, Vouros P et al: Conceptually new 20-epi22-oxa sulfone analogues of the hormone 1alpha,25-dihydroxyvitamin $D(3)$ : synthesis and biological evaluation. Journal of medicinal chemistry 2000, 43(19):3581-3586. 
243. Harris CE, Chrisman W, Bickford SA, Lee LY, Torreblanca AE, Singaram B:

Enamine oxidations .2. Selective oxidative cleavage of beta,beta-disubstituted enamines using alumina supported permanganate. Synthesis of one-carbon dehomologated carbonyl compounds from enamines. Tetrahedron Lett 1997, 38(6):981-984.

244. Lu Y, Chen J, Janjetovic Z, Michaels P, Tang EK, Wang J, Tuckey RC, Slominski AT, Li W, Miller DD: Design, synthesis, and biological action of 20R-hydroxyvitamin D3. Journal of medicinal chemistry 2012, 55(7):35733577.

245. Teicher BA: Antibody-Drug Conjugate Targets. Curr Cancer Drug Tar 2009, 9(8):982-1004.

246. Wang W, Wang EQ, Balthasar JP: Monoclonal Antibody Pharmacokinetics and Pharmacodynamics. Clin Pharmacol Ther 2008, 84(5):548-558.

247. Carter PJ, Senter PD: Antibody-drug conjugates for cancer therapy. Cancer $J$ 2008, 14(3):154-169.

248. Feld J, Barta SK, Schinke C, Braunschweig I, Zhou YY, Verma AK: Linked-In: Design and Efficacy of Antibody Drug Conjugates in Oncology. Oncotarget 2013, 4(3):397-412.

249. Pietersz GA, Krauer K: Antibody-Targeted Drugs for the Therapy of Cancer. J Drug Target 1994, 2(3):183-215.

250. Lin ZT, Marepally SR, Ma DJ, Kim TK, Oak ASW, Myers LK, Tuckey RC, Slominski AT, Miller DD, Li W: Synthesis and Biological Evaluation of Vitamin D3 Metabolite 20S,23S-Dihydroxyvitamin D3 and Its 23R Epimer. Journal of medicinal chemistry 2016, 59(10):5102-5108.

251. Lin Z, Marepally SR, Kim TK, Janjetovic Z, Oak ASW, Postlethwaite AE, Myers LK, Tuckey RC, Slominski AT, Miller DD et al: Design, Synthesis and Biological Activities of Novel Gemini 20S-Hydroxyvitamin D-3 Analogs. Anticancer research 2016, 36(3):877-886.

252. Lin ZT, Marepally SR, Ma DJ, Myers LK, Postlethwaite AE, Tuckey RC, Cheng CYS, Kim TK, Yue JM, Slominski AT et al: Chemical Synthesis and Biological Activities of 205,24S/R-Dihydroxyvitamin D3 Epimers and Their 1 alphaHydroxyl Derivatives. Journal of medicinal chemistry 2015, 58(19):7881-7887.

253. Lu Y, Chen JJ, Janjetovic Z, Michaels P, Tang EKY, Wang J, Tuckey RC, Slominski AT, Li W, Miller DD: Design, Synthesis, and Biological Action of 20R-Hydroxyvitamin D3. Journal of medicinal chemistry 2012, 55(7):35733577. 


\section{VITA}

Qinghui Wang was born in Fuzhou, Jiangxi Province, China in 1985. He graduated from Jiang University of Traditional Chinese Medicine with a Bachelor of Engineering in 2007. He entered Peking University Health Science Center in 2008 and obtained his Master of Science (advisor: Dr. Mingying Shang) in Pharmacognosy.

Starting from August 2011, he studied at The University of Tennessee Health Science Center and joined Dr.Wei Li`s lab in Spring 2014. He is the recipient of Robert A. Magarian Outstanding Podium Presentation Award in the 43rd annual MALTO Medicinal Chemistry-Pharmacognosy Meeting-in-Miniature hold in Houston. 